\title{
Radiation Effects on Reactor Pressure Vessel Supports
}

RECEIVED

MAY 221938

OSTI

\section{U.S. Nuclear Regulatory Commission}

Office of Nuclear Regulatory Research

\author{
R. E. Johnson, R. E. Lipinski
}

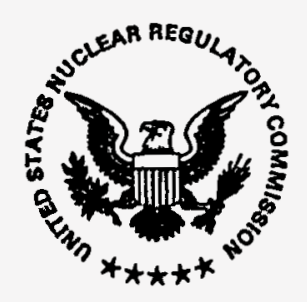




\section{AVAILABILITY NOTICE}

Availability of Reference Materials Cited in NRC Publications

Most documents cited in NRC publications will be available from one of the following sources:

1. The NRC Public Document Room, 2120 L Street. NW., Lower Level. Washington, DC 20555-0001

2. The Superintendent of Documents, U.S. Government Printing Office, P. O. Box 37082 , Washington, DC 20402-9328

3. The National Technical Information Service. Springfield, VA 22161-0002

Although the listing that follows represents the majority of documents cited in NRC publications, it is not intended to be exhaustive.

Referenced documents available for inspection and copying for a fee from the NRC Public Document Room include NRC correspondence and internal NRC memoranda: NRC bulletins, circulars, information notices, inspection and investigation notices; licensee event reports; vendor reports and correspondence; Commission papers; and applicant and licensee documents and correspondence.

The following documents in the NUREG series are available for purchase from the Government Printing Office: formal NRC staff and contractor reports, NRC-sponsored conference proceedings, international agreement reports, grantee reports, and NRC booklets and brochures. Also available are regulatory guides, NRC regulatlons in the Code of Federal Regulations, and Nuclear Regulatory Commission Issuances.

Documents avallable from the Natlonal Technical Information Service include NUREG-series reports and technical reports prepared by other Federal agencies and reports prepared by the Atomic Energy Commission, forerunner agency to the Nuclear Regulatory Commission.

Documents available from public and special technical libraries include all open literature items, such as books. Journal articles, and transactions. Federal Register notices. Federal and State legislation, and congressional reports can usually be obtained from these libraries.

Documents such as theses, dissertations. foreign reports and translations, and non-NRC conference proceedings are available for purchase from the organization sponsoring the publication cited.

Single copies of NRC draft reports are available free. to the extent of supply. upon written request to the Office of Administration, Distribution and Mail Services Section, U.S. Nuclear Regulatory Commission, Washington, DC 20555-0001.

Coples of industry codes and standards used in a substantive manner in the NRC regulatory process are maintained at the NRC Library. Two White Flint North. 11545 Rockville Pike. Rockville. MD 20852-2738, for use by the public. Codes and standard's are usually copyrighted and may be purchased from the originating organizatlon or, if they are American National Standards. from the American National Standards Institute, 1430 Broadway, New York, NY 10018-3308.

\section{DISCLAIMER NOTICE}

This report was prepared as an account of work sponsored by an agency of the United States Govemment. Neither the United States Government nor any agency thereof, nor any of their employees, makes any warranty, expressed or implied, or assumes any legal liability or responsibility for any third party's use, or the results of such use, of any information, apparatus, product, or process disclosed in this report, or represents that its use by such third party would not infringe privately owned rights. 


\section{Radiation Effects on Reactor Pressure Vessel Supports}

Manuscript Completed: April 1996

Date Published: May 1996

R. E. Jøhnson, R. E. Lipinski*

Division of Engineering Technology Office of Nuclear Regulatory Research U.S. Nuclear Regulatory Commission Washington, DC 20555-0001

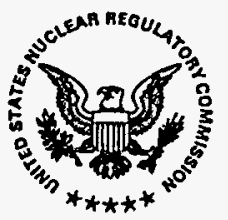

*Idaho National Engineering Laboratory 11426 Rockville Pike, Rockville, MD 20852 


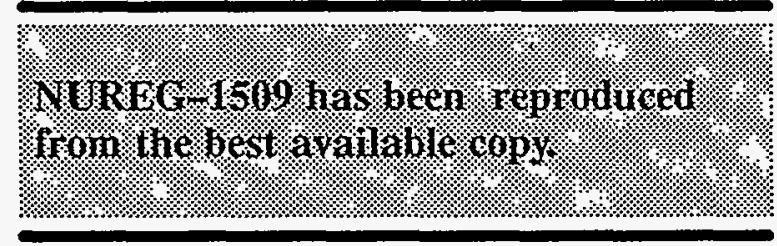




\begin{abstract}
The purpose of this report is to present the findings from the work done in accordance with the Task Action Plan developed to resolve the Nuclear Regulatory Commission (NRC) Generic Safety Issue No. 15, (GSI-15), "Radiation Effects On Reactor Pressure Vessel Supports." GSI-15 was established to evaluate the potential for low-temperature, low-fluxlevel neutron irradiation to embrittle reactor pressure vessel (RPV) supports to the point of compromising plant safety. An evaluation of surveillance samples from the high flux isotope reactor (HFIR) at the Oak Ridge National Laboratory (ORNL) had suggested that some materials used for RPV supports in pressurized-water reactors could exhibit higher than expected embrittlement rates. However, further tests designed to evaluate the applicability of the HFIR data to reactor RPV supports under operating conditions led to the conclusion that RPV supports could be evaluated using traditional methods. It was found that the unique HFIR radiation environment allowed the gamma radiation to contribute significantly to the embrittlement. The shielding provided by the thick steel RPV shell ensures that degradation of RPV supports from gamma irradiation is improbable or minimal.
\end{abstract}

The findings reported herein were used, in part, as the basis for technical resolution of the issue. 


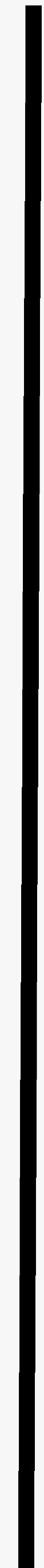




\section{CONTENTS}

Page

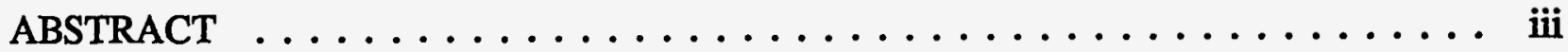

EXECUTIVE SUMMARY $\ldots \ldots \ldots \ldots \ldots \ldots \ldots \ldots \ldots \ldots \ldots$ vii

ACKNOWLEDGEMENTS $\ldots \ldots \ldots \ldots \ldots \ldots \ldots \ldots \ldots \ldots \ldots \ldots \ldots$ xi

ACRONYMS AND INITIALISMS $\ldots \ldots \ldots \ldots \ldots \ldots \ldots \ldots \ldots$ xiii

1 INTRODUCTION $\ldots \ldots \ldots \ldots \ldots \ldots \ldots \ldots \ldots \ldots \ldots \ldots \ldots$

2 BACKGROUND ....................... 3

2.1 General Discussion: Irradiation and Structural Steels . . . . . . . . 5

2.2 Stone \& Webster Notification . . . . . . . . . . . . . 5

2.3 Summary of NUREG/CR-5320 . . . . . . . . . . . 7

3 TECHNICAL FINDINGS FROM THE GSI-15 TASK ACTION PLAN . . . . . 9

3.1 Review of Initial Analyses . . . . . . . . . . . . . . 9

3.2 Shippingport Neutron Shield Tank Testing . . . . . . . . . 11

3.3 Trojan Dosimetry . . . . . . . . . . . . . . . . . . 12

3.4 Low-Energy Neutron Damage Theory . . . . . . . . . . . . . 15

3.5 HFIR Dosimetry and Gamma Radiation . . . . . . . . . 17

4 RPV SUPPORT REEVALUATION CRITERIA $\ldots \ldots \ldots \ldots \ldots \ldots \ldots 21$

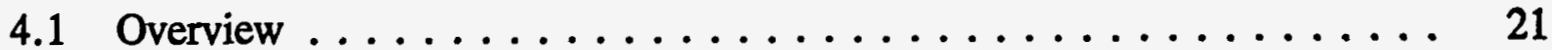

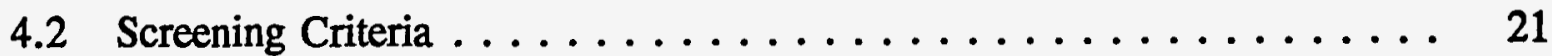

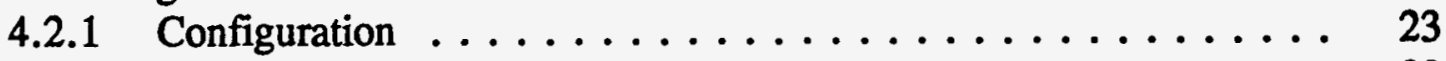

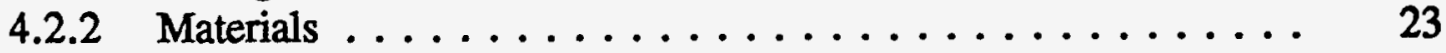

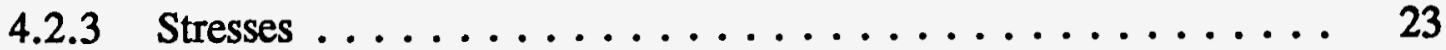

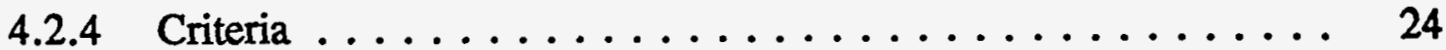

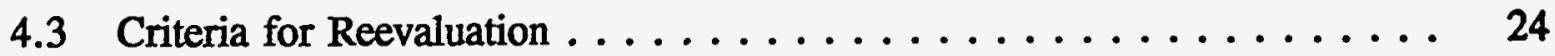

4.3.1 Evaluation of Current Conditions ............ 28

4.3.1.1 Physical Examination of Structural Components .... 28

4.3.1.2 Inspection Report . . . . . . . . . . . 29

4.3.2 Evaluation of the Original Design . . . . . . . . . . 30

4.3.3 Establishing the EOL NDT Temperature . . . . . . . 30

4.3.3.1 Strain-Rate Effects . . . . . . . . . . . . . 31

4.3.3.2 Metallurgical Condition of the RPV Supports ...... 31

4.3.3.3 Radiation-Induced NDT Shift . . . . . . . . . 31

4.3.4 Fracture Analysis of RPV Support Integrity ... . . . . . 31

4.3.4.1 Fracture Toughness Approach ............ 31

4.3.4.2 Transition Temperature Approach .......... 32 


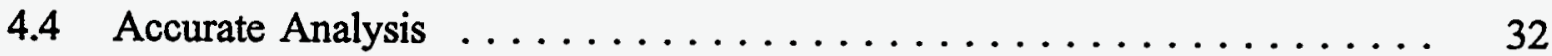

4.5 Structural Consequence Analysis $\ldots \ldots \ldots \ldots \ldots \ldots \ldots \ldots \ldots, 33$

4.6 Fracture Mechanics Analysis of Pins . . . . . . . . . . . . 36

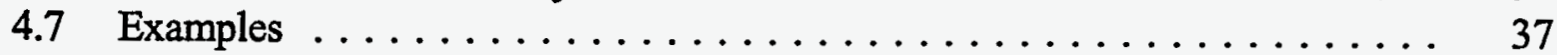

5 SUMMARY OF THE COST/BENEFIT ANALYSIS $\ldots \ldots \ldots \ldots \ldots \ldots .45$

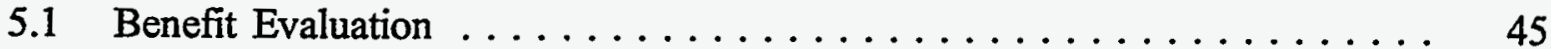

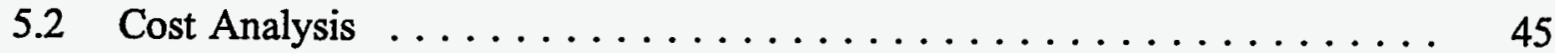

5.3 Cost/Benefit Analysis . . . . . . . . . . . . . . . 46

6 DISCUSSION OF THE GSI-15 TECHNICAL FINDINGS $\ldots \ldots \ldots \ldots \ldots .49$

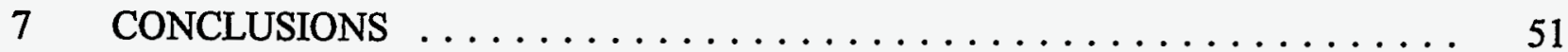

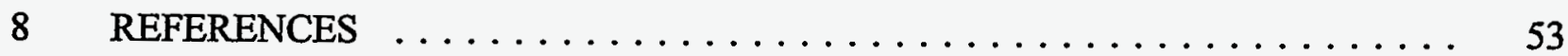

\section{APPENDICES}

A R. E. Gregg, et al., GSI-15 Cost/Benefit Analysis

B Shippingport NST Vessel/Shield-Tank Fluence Calculations

C Recommendations Regarding Evaluation of Cost Stainless Steel with Respect to Aging Embrittlement

D E. H. Ottewitte, Gamma Radiation Effects

\section{FIGURES}

2-1 Radial Section Through Trojan Reactor Vessel ................ 4

3-1 The Change in Transition Temperature as a Function of Total Radiation

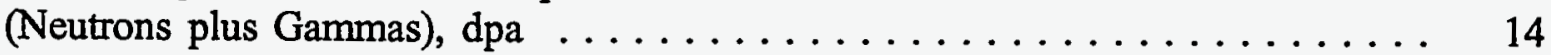

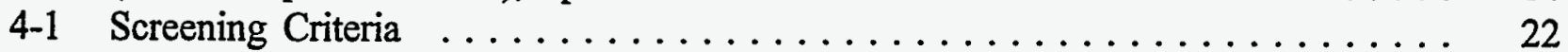

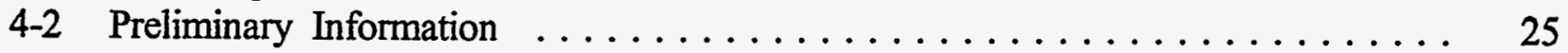

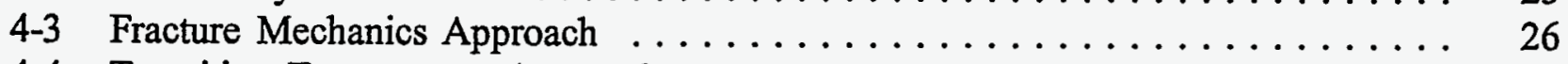

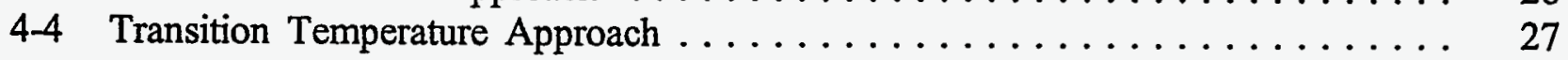

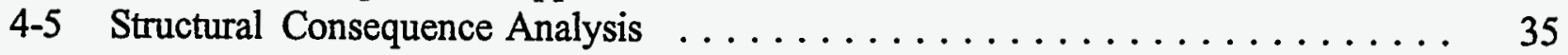

\section{TABLES}

3-1 Summary of Analyses Related to GSI-15 . . . . . . . . . . . . . . 10

4-1 Compilation of NDT Temperature Results $\ldots \ldots \ldots \ldots \ldots \ldots \ldots \ldots, 41$

4-2 Classification of Wrought Grades into Groups $\ldots \ldots \ldots \ldots \ldots \ldots . \ldots 42$

4-3 Minimum Fracture Toughness Data at $75^{\circ} \mathrm{F} \ldots \ldots \ldots \ldots \ldots \ldots . \ldots \ldots$

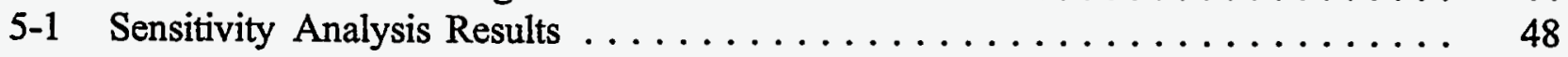




\section{EXECUTIVE SUMMARY}

Generic Safety Issue No. 15 (GSI-15), "Radiation Effects On Reactor Pressure Vessel Supports," addresses the potential for embrittlement of reactor pressure vessel (RPV) supports from exposure to low-temperature, low-flux-level neutron radiation. The initial action came in 1978 from Virginia Electric and Power Company (VEPCO) as a notification to the NRC under Title 10, Chapter I, Part 21 of the Code of Federal Regulations (10 CFR Part 21). VEPCO concluded that radiation might compromise plant safety by significantly reducing the integrity of RPV supports.

Although the NRC confirmed the potential for embrittlement, GSI-15 was assigned a low priority. The issue was revitalized after the Oak Ridge National Laboratory (ORNL) reported unexpectedly high embrittlement rates (measured as a change in nil ductility transition, or $\triangle \mathrm{NDT}$ ) in surveillance specimens from the High-Flux Isotope Reactor (HFIR). GSI-15 then was reprioritized and assigned a HIGH ranking. A Task Action Plan was prepared to evaluate the possibility that RPV supports may be degraded and subject to failure in the event of a design-basis accident. The investigation was designed to address the loss of integrity using either the fracture toughness reduction or the NDT increase (relative to the lowest operating temperature).

In the course of completing the program proposed in the GSI-15 Task Action Plan, several findings emerged that contributed to the technical resolution of the issue. At the start of the program, the RPV supports at the Trojan Nuclear Plant (TNP) were identified as the most vulnerable to degradation; a conclusion that had consensual approval. Several analyses were conducted, with the expectation that if the Trojan supports could be shown to be acceptable, the result would envelop the industry. Different engineering approaches and various degrees of sophistication were employed by the analysts. Although the analyses provided some confidence to the extent that the issue did not appear to pose a serious safety threat, the results showed that there was no single method, applicable to all reactors, by which GSI-15 could be resolved.

Concurrently, other radiation experiments were conducted to explain the post-irradiation irregularities seen in the HFIR surveillance data. Archival material (the identical steel used to construct the HFIR pressure vessel) was irradiated in test reactors along with samples of other, related steels. The observed $\triangle$ NDTs were not significantly different from the trend band for low-temperature irradiation. Thus, the steel tested in the HFIR surveillance program was not the cause of the irregularity. The availability of the neutron shield tank (NST) from the Shippingport plant afforded the opportunity to test the same grade of steel (ASTM A 212-B) as that used in the HFIR vessel after exposure to similar radiation conditions (low neutron flux and low temperature). However, when the Shippingport data fell close to the trend band, attention turned to the conditions in the HFIR for a solution.

One seemingly important aspect of the HFIR environment was the reported 50-to-1 ratio of thermal-to-fast neutron flux. That report, coupled with models advanced by theoreticians at the Argonne and Pacific Northwest national laboratories (Argonne National Laboratory and 
Pacific Northwest Laboratory), led analysts to devise a new damage parameter. By modifying the parameter displacements per atom (dpa) to include neutrons of all energies, rather than only those with $\mathrm{E}>1 \mathrm{MeV}$, the new parameter included damage from the entire neutron energy spectrum. Replotting the HFIR data as functions of "dpa mod" brought most of the relevant embrittlement data within a reasonably narrow scatter band along the line of the established trend curve.

The proof of the efficacy of the "dpa mod" exposure parameter, however, was limited by the fact that the HFIR neutron energy spectrum had been determined at a single location (from a capsule containing A 212-B steel). Therefore, the program was expanded to provide calculations at additional capsule locations but those results added more confusion than resolution. Specifically, the new spectrum calculations found the 50-to-1 energy ratio in error by (roughly) a factor of 10 . That is, the thermal-to-fast neutron ratio was revised to the order of 5-to-1, effectively eliminating thermal neutrons as the cause of the high $\Delta$ NDT. An experiment designed to settle the quandary further muddied the water, because the results from the fast neutron flux dosimeters varied by as much as a factor of 17 .

When checks of the measurements ruled out experimental error, a comprehensive program of experiments and calculations was launched. To conduct the work, a team was assembled drawing from the NRC, ORNL, and consultants from DOE laboratories, academia, and industry. The results of the effort provided enough evidence to suggest reasons for both the greater-than-expected HFIR surveillance data and the dosimetry discrepancies noted above.

The following underlying factors were key contributors to the discrepancies:

- The annulus of water in the HFIR attenuates neutrons, but does little to gamma ( $\gamma$ ) radiation.

- $\quad \gamma$ radiation can produce atomic displacements (hence embrittlement), but is more likely to result in heating than damage.

- Because the HFIR specimens were kept at a low temperature (about $50^{\circ} \mathrm{C}$ or $120^{\circ} \mathrm{F}$ ), the damage done by $\gamma$ radiation (and low-energy neutrons) was retained.

- Because the high-energy ( $\mathrm{E}>1.0 \mathrm{MeV}$ ) neutron flux was so low, it took a long time (about 20 years) to accumulate a significant level of fluence.

Therefore, the evidence suggests that the HFIR surveillance specimen embrittlement was a function of the entire neutron energy spectrum and the $\gamma$ radiation. The reported variation in fast neutron flux values among the several dosimeters occurred because those monitors sensitive to photofission or photoneutron reactions exhibited additional radioactivity induced by the significant level of $\gamma$ flux.

The radiation environment in the HFIR was judged to be unique to that reactor. The RPV supports of an operating reactor are shielded from $\gamma$ radiation by the 6 to 10 inches of steel interposed by the vessel shell. Therefore, no significant $\gamma$ radiation embrittlement is 
expected in RPV supports. However, embrittlement predictions should employ the complete dpa energy spectrum to include any contribution from low-energy neutrons.

Limited surveys of RPV supports conducted in response to the unexpectedly high HFIR embrittlement data noted that data often were too sketchy to be definitive. Some steels used in RPV support construction, such as ASTM A 36, exhibit considerable variability in (unirradiated) NDT. Because NRC licensing reviews did not include fracture resistance requirements for RPV supports, no data were uncovered by which the margin between the NDT and the lowest operating temperature could be evaluated. We note that the ASME Boiler and Pressure Vessel Code recommends a margin of not less than 60F.

The Task Action Plan for GSI-15 included development of an engineering approach for assessing the structural integrity in the event that evaluation of RPV supports would be necessary. The methods reported in this paper should provide adequate guidance for RPV support reassessment. The approach begins with screening criteria, continues (for those cases where it is necessary) with fracture resistance evaluation and provides a consequence analysis model for situations wherein there is insufficient data to complete a fracture analysis. Application of the consequence analysis to the Trojan plant configuration (believed to be the most vulnerable) showed that RPV support failure could be tolerated providing that other components were not degraded. Analyses demonstrated the importance of the components which would have to carry additional loads in the event of RPV support failure but some critical components have exhibited other, unique, degradation mechanisms.

The route to GSI-15 resolution included a detailed cost/benefit analysis. The resulting bestestimate base case supported a total calculated contribution to core damage frequency from RPV support failure of $8.8 \times 10^{-5} / \mathrm{yr}$. Five alternative corrective measures were identified and cost estimates were made; however, the estimated costs varied widely. Cost/benefit ratios were calculated for a range of remaining life-spans and three cost categories: (1) without either averted onsite costs (AOSC) or replacement power; (2) with AOSC but without replacement power; and (3) with both AOSC and replacement power. Benefit analysis associated with the above core damage frequency resulted in an offsite dose risk per plant of 2.9 person-rem/year. The influence on the cost/benefit ratio of variability in several parameters was investigated, and the resulting cost/benefit ratios ranged from a minimum of $\$ 53 /$ person-rem to a maximum of $\$ 3,300,000$ /person-rem.

The wide variability rendered the cost/benefit analysis inconclusive and could not be used to support regulatory requirements for GSI-15. However, the technical findings presented in this report will be useful in the event of a review of RPV support integrity. 



\section{ACKNOWLEDGEMENTS}

The authors gratefully acknowledge the many people who helped in the resolution of GSI-15. To name every contributor would take too much space; however, certain individuals are cited for the special reasons given.

F. B. K. Kam, the Principal Investigator of the Technical Assistance Contract at the Oak Ridge National Laboratory, led the efficient effort that provided the basis for resolution of the issue. In addition to many others at ORNL, the authors appreciate the support of Dr. R. Nanstad and Mr. W. Corwin. The invaluable nucleonics consultants were Professor John Williams, Dr. Larry Greenwood, and Mr. E. D. McGarry.

The authors also wish to thank participating NRC staff, including A. Taboada, M. Mayfield, T. Walker, J. Mitchell, and S. Weiss. Special thanks are due to C. Hrabal for his critical assistance. We appreciate the consistent support and constructive criticism given by $\mathrm{R}$. Baer, who served as Branch Chief through the early days of confounding findings. Also, $\mathbf{N}$. Anderson at Idaho National Engineering Laboratory (INEL) actively participated as a manager, advisor, and contributor.

Finally, the authors gratefully acknowledge the support and encouragement of the NRC management, including W. Minners (ret.), J. Murphy, C. Serpan, and F. Cherny. 



\section{ACRONYMS AND INITIALISMS}

$\begin{array}{ll}\text { ACRS } & \text { Advisory Committee on Reactor Safety } \\ \text { AIF } & \text { Atomic Industrial Forum } \\ \text { AISC } & \text { American Institute of Steel Construction } \\ \text { ANL } & \text { Argonne National Laboratory } \\ \text { AOSC } & \text { averted onsite cost } \\ \text { ASME } & \text { American Society of Mechanical Engineers } \\ \text { ASME Code } & \text { ASME Boiler \& Pressure Vessel Code } \\ \text { ASTM } & \text { American Society of Testing and Materials } \\ \text { BNL } & \text { Brookhaven National Laboratory } \\ \text { BOL } & \text { beginning of life } \\ \text { BTC } & \text { Bolting Technology Council } \\ \text { B\&W } & \text { Babcock and Wilcox } \\ \text { BWR } & \text { boiling water reactor } \\ \text { CMTR } & \text { Certified Material Test Report } \\ \text { CP } & \text { construction permit } \\ \text { CRGR } & \text { Committee for Review of Generic Requirements } \\ \text { CSDS } & \text { chemical shutdown system } \\ \text { CVN } & \text { Charpy V-notch } \\ \text { dpa } & \text { displacements per atom } \\ \text { DPR } & \text { dollar-to-person-rem } \\ \text { ECCS } & \text { emergency core cooling system } \\ \text { EFPY } & \text { effective-full-power-years } \\ \text { EOL } & \text { end-of-life } \\ \text { EPRI } & \text { Electric Power Research Institute } \\ \text { FSAR } & \text { Final Safety Analysis Report } \\ \text { GSI } & \text { Generic Safety Issue } \\ \text { GL } & \text { Generic Letter } \\ \text { HFIR } & \text { High-Flux Isotope Reactor } \\ \text { HSST } & \text { Heavy Section Steel Technology (Program) } \\ \text { HSLA } & \text { high-strength low-alloy (steel) } \\ \text { HSST } & \text { Heavy Section Steel Technology (Program) } \\ \text { INEL } & \text { Idaho National Engineering Laboratory } \\ \text { LBLOCA } & \text { large-break loss-of-coolant accident } \\ \text { LEFM } & \text { linear-elastic fracture mechanics } \\ \text { LLNL } & \text { Lawrence Livermore National Laboratory } \\ \text { LOCA } & \text { loss-of-coolant accident } \\ \text { LOT } & \text { lowest operating temperature } \\ \text { LST } & \text { lowest service temperature } \\ \text { LWBR } & \text { light-water breeder reactor } \\ \text { LWR } & \text { light-water reactor } \\ \text { MPC } & \text { Materials Properties Council } \\ \text { MTR } & \text { materials test reactor } \\ \text { NDT } & \text { nil ductility transition } \\ & \\ & \end{array}$


NDTT

NIST

NRC

NRL

NRR

NSSS

NST

OBE

ORNL

ORR

PG\&E

PNL

PSAR

PWR

RCL

RCP

RCS

RES/DSIR

RES

RPS

RPV

RSIC

SBLOCA

SCC

SG

SRP

SRSS

SSE

S\&W

SSTR

TT

USI

VEPCO nil ductility transition temperature

National Institute of Standards and Technology

Nuclear Regulatory Commission

Naval Research Laboratory

Office of Nuclear Reactor Regulation (NRC)

nuclear steam supply system

neutron shield tank

operating basis earthquake

Oak Ridge National Laboratory

Oak Ridge (test) Reactor

Pacific Gas \& Electric Company

Pacific Northwest Laboratory

preliminary safety analysis report

pressurized-water reactor

reactor coolant loop

reactor coolant pump

reactor coolant system

Office of Nuclear Regulatory Research/Division of Safety Issue Resolution

NRC Office of Nuclear Regulatory Research

reactor protection system

reactor pressure vessel

Radiation Shielding Information Center

small-break loss-of-coolant accident

stress-corrosion cracking

steam generator

Standard Review Plan

square-root-sum-of-squares

safe-shutdown earthquake

Stone and Webster Engineering Corp.

solid state track recorders

transition temperature

Unresolved Safety Issue

Virginia Electric Power Company 


\section{INTRODUCTION}

The U.S. Nuclear Regulatory Commission (NRC) was first advised of a potential problem associated with reactor pressure vessel (RPV) support radiation embrittlement in a letter from the Virginia Electric and Power Company (VEPCO) dated March 3, 1978, submitted in accordance with the reporting requirements of 10 CFR Part 21. In a subsequent letter to James O'Reilly (NRC), dated March 28, 1978, VEPCO stated that they were evaluating the nil-ductility transition (NDT) temperature shift of neutron shield tank steel, and would transmit the results when they became available. VEPCO explained that the issue dealt with low-temperature, low-energy irradiation of neutron shield tanks supporting the RPV. Inclusion of damage from neutrons of lower energy (less than $1.0 \mathrm{MeV}$ ) would result in a larger calculated shift of the ductile-to-brittle fracture mode transition temperature. Generic Safety Issue 15 (GSI-15), "Radiation Effects on Reactor Vessel Supports," was established to address the possibility that embrittlement of RPV supports by irradiation could impair the safety of nuclear power plants.

The issue of accelerated degradation of the fracture toughness of RPV supports was revitalized by the Advisory Committee on Reactor Safety (ACRS) as a result of the committee's review of surveillance specimen data from the High-Flux Isotope Reactor (HFIR) at the Oak Ridge National Laboratory (ORNL) (Ref. 1). The HFIR data exhibited unexpectedly high embrittlement rates in terms of the nil ductility temperature shift ( $\triangle$ NDT). Initially, ORNL attributed the shift to a rate effect. Since RPV supports could be exposed to similar conditions, an investigation was initiated under the assumption that the loss of fracture toughness was greater than originally believed, and that the NDT temperature could be as high as the minimum operating temperature.

Following review by the ACRS and the NRC staff, the issue of embrittlement of RPV supports (GSI-15) was designated as HIGH priority. The Idaho National Engineering Laboratory (INEL) was selected to provide technical assistance in resolving the issue.

The remainder of this document contains the following sections:

Section 2 provides background concerning GSI-15.

- Section 3 presents the technical findings resulting from the work done in accordance with the Task Action Plan (TAP) (Ref. 2).

- Section 4 describes criteria that could be used in RPV support structural integrity reevaluation.

- Section 5 contains a summary of the cost/benefit analysis.

- Section 6 is a general discussion of the technical findings presented in Sections 3 and 4.

- Section 7 contains the conclusions reached, along with the-related justifications.

- Section 8 lists all of the numbered references from this report.

- The Appendices contain some of the completed work that was used to support the conclusions. 



\section{BACKGROUND}

GSI-15 was established to address the concern that low-temperature, low-energy neutron irradiation may embrittle RPV supports more rapidly than expected. This issue was originally classified as a candidate Unresolved Safety Issue (USI) in NUREG-0705, "Identification of New Unresolved Safety Issues Relating to Nuclear Power Plant Stations" (Ref. 3). In that document, the staff recommended that further studies be conducted to provide a basis for disposition of the issue. In November 1983, the issue was evaluated and designated as LOW priority.

The issue was revitalized when ORNL reported the data from tests on the pressure vessel surveillance specimens exposed in the HFIR (Ref. 1). The data exhibited more rapid than expected embrittlement when compared to low-temperature radiation experiment results. ORNL suggested that the excessive embrittlement was due to low-flux irradiation $\left(10^{8}-10^{9}\right.$ $\mathrm{n} / \mathrm{cm}^{2}$-s; E > $1 \mathrm{MeV}$ ). By extrapolating the HFIR data, ORNL predicted significant amounts of radiation-induced embrittlement in steels under low-temperature, low-flux radiation (Ref. 4). In June 1987, the ACRS reviewed the HFIR data and since the environmental conditions at RPV supports and the HFIR surveillance locations were believed to be similar, a concern was raised regarding embrittlement of the supports. Based on the ORNL findings, the staff reassessed the issue and designated it as HIGH priority in December, 1988.

In 1988, under the Heavy Section Steel Technology (HSST) program, ORNL conducted a survey of all operating reactors to identify the RPV supports that might be vulnerable to embrittlement (Ref. 4). The study led to the selection of two plants, Trojan and Turkey Point Unit 3, for further study. The selections were based on the plants' common RPV support design of short steel columns, supported by steel cantilever beams embedded in the concrete shield wall at the core beltline and projecting into the cavity toward the reactor vessel (Fig. 2-1). That configuration induces tensile stresses in the upper flange of the beam, where the neutron flux is greatest, thereby creating a condition conducive to brittle fracture. The ORNL investigators concluded that the minimum critical flaw sizes corresponding to the most severe credible loading condition at 32 effective-full-power-years (EFPY) could be small enough to be of concern for both plants.

On January 11, 1989, the NRC Office of Nuclear Reactor Regulation (NRR) requested that the NRC Office of Nuclear Regulatory Research (RES) initiate a program that would (1) provide a structural consequence analysis of RPV support failure, (2) perform a probabilistic fracture mechanics risk analysis of the limiting RPV supports, and (3) gather pertinent metallurgical and mechanical information by performing tests (if necessary) to demonstrate the capability of flawed RPV supports to satisfy regulatory requirements.

On March 23, 1989, at the joint meeting of the ACRS Materials \& Metallurgy and Structural Engineering Subcommittees, and at the full ACRS meeting on April 6, 1989, presentations by the staff indicated that further work was needed to quantify the structural integrity of the 
ORNL-DWG 88-4858 ETD

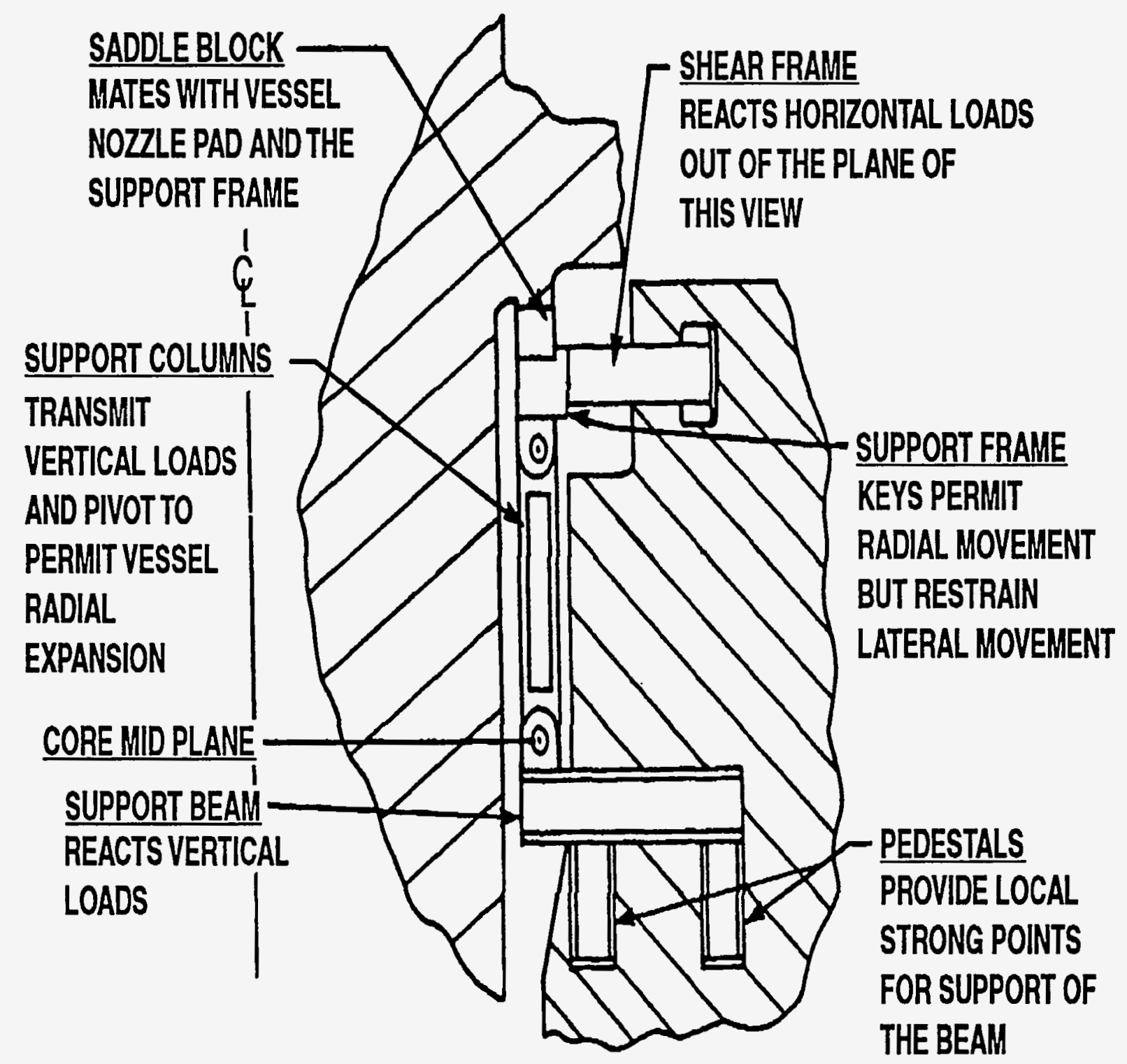

Figure 2-1 Radial section through Trojan reactor vessel supports showing principle structural and kinematic elements 
RPV supports. Analyses by the staff either evaluated the consequences of support failure or predicted the potential of fracture of the embrittled steel. The preliminary analyses failed to demonstrate an immediate safety problem. These and other analyses were described and reviewed in Ref. 5 and a brief summary is provided in Section 3. It should be noted that all analysts accepted the assertion that the two plants cited by ORNL, Trojan and Turkey Point Unit 3, had the most vulnerable RPV supports.

\subsection{General Discussion: Irradiation and Structural Steels}

The initial ORNL studies (Ref. 1) indicated that low-flux neutron irradiation may embrittle steel more rapidly than trend bands from low temperature $\left(<200^{\circ} \mathrm{F}\right)$ would predict. The studies were based on data generated in the ORNL HFIR RPV irradiation surveillance program.

Generally, an NDT temperature shift is an accepted indicator of neutron radiation damage. The NDT temperature is the temperature below which commonly observed flaws may be critical with regard to brittle fracture initiation. The traditional procedure for predicting neutron damage uses the shift (increase) in NDT temperature ( $\Delta$ NDT) expressed as a function of fast $(\mathrm{E}>1.0 \mathrm{MeV})$ neutron fluence. More recently, it has been noted that this method is not comprehensive because it does not include reactions from the entire neutron energy spectrum. For example, neutrons are absorbed in some thermal neutron-atom interactions, leading to transmutation and attendant atomic displacements, while other neutrons may not interact at all. As a result, the amount of damage (embrittlement) for a given fluence may vary with the neutron spectrum.

A more accurate method of predicting neutron damage employs $\Delta$ NDT as a function of calculated displacements per atom (dpa). The dpa parameter is an estimate of the number of atomic displacements (vacancy-interstitial pairs) per atom produced by neutron irradiation. Shortcomings in neutron damage predictions based on the dpa parameter arise because this method only counts the number of radiation-induced displacements. In fact, some displaced atoms and vacancies recombine, annihilating (annealing) the damage related to the point defects. The modified dpa parameter (Ref. 6), discussed in detail in section 3.4, accounts for a broader base of atomic-level damage.

Experimental determinations of $\triangle \mathrm{NDT}$ can serve as measures of radiation damage whether reported as functions of fluence or dpa, but whichever radiation parameter is chosen, it must be accompanied in practice by dosimetry calculations or measurements.

\subsection{Stone \& Webster Notification}

In late 1977, the Stone and Webster Engineering Corporation (S\&W) alerted VEPCO to a potential irradiation embrittlement problem related to the neutron shield tanks (NSTs) at North Anna Units 3 and 4. Those plants and others of similar design employ NSTs as RPV supports. The NST designer, S\&W, had concluded that the $\triangle$ NDT shift could be higher than previously calculated. On February 27,1978 , VEPCO submitted a report to the NRC under the provisions of 10 CFR 50.55(a), citing the concern for the effect of radiation on the NDT 
of the NSTs. Subsequently, in accordance with the provisions of 10 CFR 21, VEPCO submitted a letter dated March 3, 1978 (designated: Serial No. 117), to the NRC Region II Director, providing information regarding the deficiency. VEPCO submitted another letter dated March 28, 1978 (designated: Serial No. 117A), as a 30-day follow-up report on the potential embrittlement problem.

The possibility of a larger than expected $\triangle$ NDT of the NST steel was based on state-of-theart methods for predicting neutron embrittlement. Those methods employed damage crosssections derived for materials with irradiation damage behavior similar to the tank material. The neutron embrittlement calculational method had been developed by C. Z. Serpan, Jr. (of the NRC) while at the U.S. Naval Research Laboratory. Neutron energy groups with less than $1.0 \mathrm{MeV}$ were considered in addition to fast neutron groups. Inelastic scattering in the RPV steel resulted in an abundance of neutrons in the range $0.1<\mathrm{E}<1.0 \mathrm{MeV}$ at the NST. Individually, low energy neutrons do not create much damage but collectively they make an appreciable contribution, additive to that from fast neutrons ( $\mathrm{E}>1 \mathrm{MeV})$. By virtue of supporting the RPV, the NST is QA Category I equipment thus VEPCO reckoned that it must be capable of maintaining the intended functional integrity. On those grounds, VEPCO concluded that the $\triangle$ NDT of the NST steel must be determined over the life of the plant, in order to permit proper evaluation of tank integrity.

Apropos of the licensee's notification, VEPCO advised that the shield tank $\triangle$ NDT analysis would continue with the help of outside consultants. On June 23, 1978, members of the NRC staff met with S\&W representatives; Naval Research Laboratory (NRL) personnel attended the meeting by NRC invitation. It was agreed that no immediate action was necessary on the part of any licensee, largely because actions were planned or underway that were expected to shed more light on the problem. For example, a program aimed at resolving the shield tank material problem was underway with RPV support materials being irradiated as the "Void Box Experiment" in the HFIR facility at ORNL to simulate the environment in the cavity of an operating reactor. (The experiment did not meet its goals, however, as noted below). Also, the NRC staff planned to review the S\&W neutron flux determinations and evaluate the applicability of the damage analysis to other supports. Initially, the RPV support problem was added as a new and separate task to the Unresolved Safety Issue (USI) A-12, which at the time covered all structural support problems. Within that task, the staff selected Brookhaven National Laboratory (BNL) to provide technical assistance by independently verifying the reactor flux spectrum at the NST. Meanwhile, VEPCO noticed that the neutron flux data had been based on the wrong core geometry, contracted with Babcock and Wilcox (B\&W) to perform an updated study, and notified the NRC of the revised results. BNL submitted a letter report dated April 23, 1979, with the results from the calculations of energy-dependent neutron fluxes at the North Anna Unit 3 and 4 NSTs. The report substantially agreed with the B\&W results, with the minor differences largely explained by the choices in the energy-group structures employed. If anything, the BNL results suggested that B\&W's analysis underestimated the damage.

Since more precise calculations enlarged on the problem rather than making it go away, the staff turned to the NRL for assistance on the effect of irradiation on A 537-B steel, the material used to fabricate the North Anna NSTs. Fortunately, NRL had recently concluded low-temperature irradiation of A 537-B steel, so the relatively easy task of accounting for 
flux and spectrum differences could be handled through dpa correlations. In a letter report dated October 22, 1979, NRL concluded that irradiation might raise the NDT of the VEPCO NSTs at end-of-life (EOL) to more than $105^{\circ} \mathrm{F}$ and might reduce the Charpy V-notch upper shelf energy to as low as $30 \mathrm{ft}-\mathrm{lb}$.

From the evidence at hand, the NRC concluded that radiation embrittlement of RPV supports posed a clear and significant threat to the overall integrity of domestic nuclear power plants. The staff recommended that the problem be addressed as a separate generic issue; GSI-15 was instituted.

\subsection{Summary of NUREG/CR-5320}

The results of the ORNL investigation suggested that radiation damage to RPV supports could pose a significant threat to the structural integrity of light-water reactors (LWRs). The HFIR irradiation surveillance program data were interpreted as an indication that at low temperature and low flux, the embrittlement rates for vessel and support steels were substantially higher than previously observed low temperature radiation data. (The surveillance materials were ASTM A 212-B, A 350-LF3, and A 105-II.)

The ORNL researchers established two correlation trend lines of NDT temperature shift as a function of dpa, one on log-log and one on semi-logarithmic coordinates, using data from other published reports. In both cases, a curve parallel to the trend line was drawn through selected HFIR data and extrapolated to higher exposures. To the extent that the curves drawn through the HFIR data were physically meaningful, extrapolations suggested that typical EOL exposures would result in rather large NDT increases.

The more rapid rate of embrittlement of the RPV support material was attributed to a socalled "fluence-rate effect," theorizing that a low flux would cause more irradiation damage per neutron than a high flux. ORNL cited another study (Ref. 7) in which data had been reported that showed no rate effect from a variation in fast $(E>1.0 \mathrm{MeV})$ flux over the range from $1 \times 10^{10}$ to $3 \times 10^{13} \mathrm{n} / \mathrm{cm}^{2} \cdot \mathrm{s}$ at approximately $200^{\circ} \mathrm{F}$; however, those fluxes were too high to be applicable to the HFIR experiments. The ORNL researchers suggested that the excess embrittlement might only occur below some critical value of flux.

ORNL concluded that there is a credible possibility of a brittle fracture in RPV supports and that the estimated critical flaw could be as small as 0.42 inch with small-break loss-ofcoolant accident (SBLOCA) loads. Also, ORNL noted that residual stresses from flamecutting during construction (a feature of the Trojan supports) could further reduce the critical flaw size.

The ORNL project was terminated without providing satisfactory answers to some critical questions. First, the HFIR surveillance data fell outside of the trend band established by other sources, such as data from materials test reactor (MTR) radiation experiments. The ORNL investigators suggested that the large increase in NDT temperature was related to a fluence-rate effect, although there are data that show no rate effect for a similar fast flux range (see Section 3.2, following). Second, the investigators did not exploit the suggestion 
that the excess embrittlement of the HFIR samples was the result of thermal-neutron radiation rather than a fluence rate effect. Finally, although the mechanical property test results were thoroughly audited, insufficient attention was given to the dosimetry and verification of the radiation exposure, as later work under GSI-15 has shown. 


\section{TECHNICAL FINDINGS FROM THE GSI-15 TASK ACTION PLAN}

This section presents the technical findings from the work performed to resolve Generic Safety Issue 15.

\subsection{Review of Initial Analyses}

As noted in Section 2, the ORNL report of unexpected embrittlement motivated several analysts to examine the case for RPV supports. Some of that work was discussed at ACRS meetings. One of the first tasks undertaken in the GSI-15 resolution was to review those analyses for commonalities and differences. That review was described in detail in NUREG/CR-5556 (Ref. 5.) A brief overview is provided in this section.

Of eleven reported structural analyses of RPV support integrity, each evaluated the RPV supports of the Trojan Nuclear Plant; NUREG/CR-5320 (Ref. 4) also evaluated Turkey Point Unit 3. Only two of the Trojan structural analyses considered radiation embrittlement. [Both of those reports used fast neutron ( $\mathrm{E}>1.0 \mathrm{MeV}$ ) fluence as the measure of neutron exposure. However, as shown in Sections 3.4 and 3.5, the high-energy neutron fluence may be insufficient to predict radiation damage sustained at relatively low temperatures, depending on the nature of the radiation.] The other analyses focused on failure consequences; that is, how the failure of one or more supports would impact the RPV and the reactor coolant system (RCS). The salient features of the analyses are described below and summarized in Table 3-1.

Two distinctly different approaches were used by those analyzing the RPV supports. One involved postulated catastrophic failure of one or more supports and the prediction of the consequences of such an occurrence. The second involved examination of stresses and radiation embrittlement as the basis for predicting the possibility of a brittle fracture. On the basis of the information presented in the reports, it is difficult to decide which analysis is more accurate. The complexity of the problem requires considerable engineering judgement regarding the efficacy of the liner, the possibility of the concrete support being crushed, and the possibility of shear failure of the concrete above the remaining portion of the beam.

The consequence analyses (the first group) were based on generally accepted methods using recognized principles of structural mechanics, such as beams on elastic foundations or finite element analysis. However, despite similar assumptions, the results differed considerably. The discrepancies illustrate the sensitivity of the analyses to assumptions and methodologies used. The analysis reported by BNL used information drawn from the sophisticated finite element results in the ORNL report (Ref. 4). The BNL report concluded that the capacity of the fractured beam is lower than the applied load allowing the beam to deform until it reaches equilibrium through load redistribution to other supports.

The structural consequence analysis (Ref. 8) performed by the Lawrence Livermore National Laboratory (LLNL) is deficient in the following ways: 

Table 3-1 Summary of Analyses Related to GSI-15

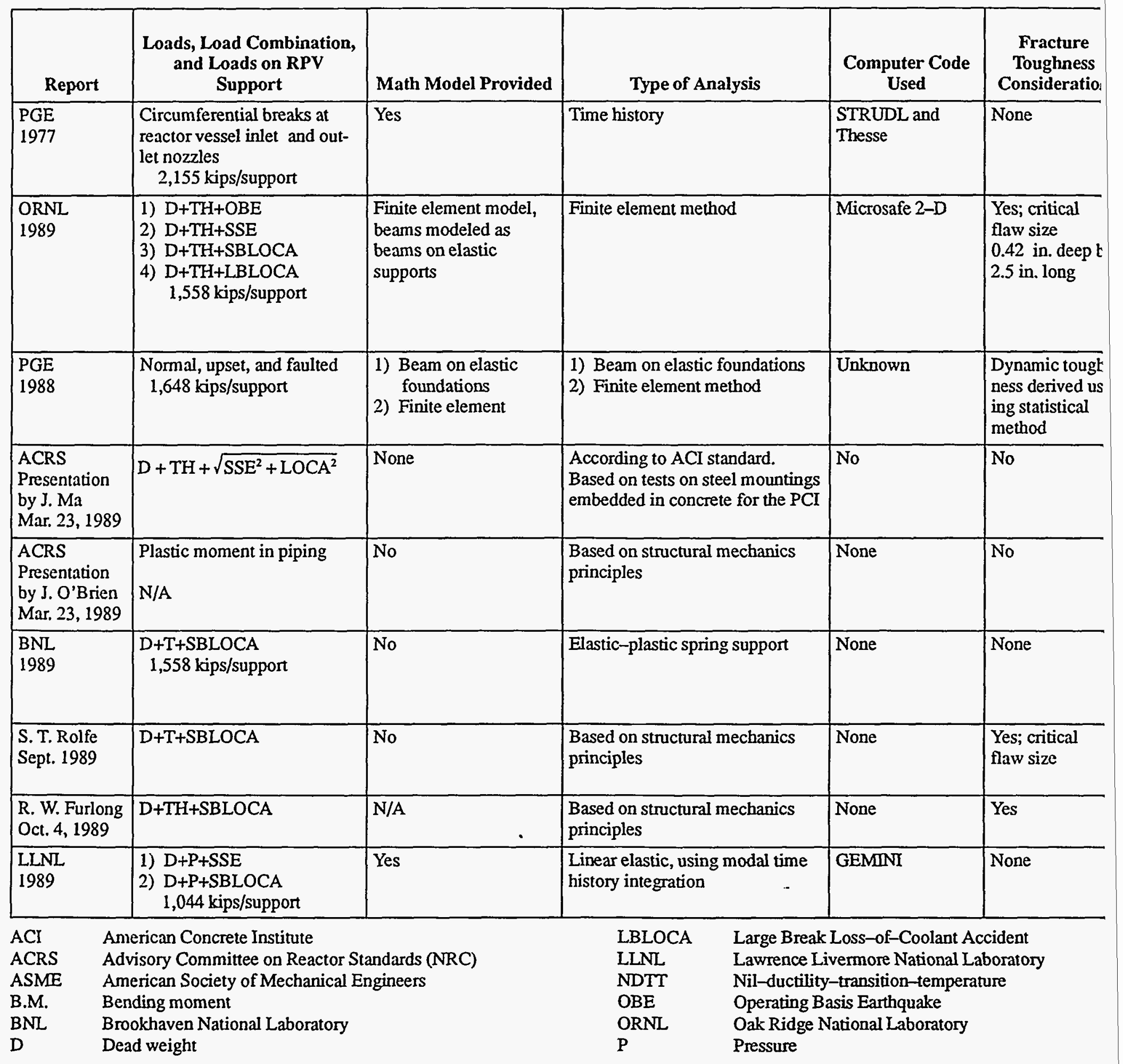




\begin{tabular}{|c|c|c|c|}
\hline $\begin{array}{l}\text { Components } \\
\text { Evaluated }\end{array}$ & Assumptions Made & Results & Conclusions and Comments \\
\hline $\begin{array}{l}\text { RCL piping, com- } \\
\text { ponents, and sup- } \\
\text { ports for LOCA }\end{array}$ & $\begin{array}{l}\text { Circumferential breaks at reactor } \\
\text { vessel inlet and outlet nozzles, and } \\
\text { RCP discharge nozzle }\end{array}$ & $\begin{array}{l}\text { Plant can be safely shut } \\
\text { down if pipe rupture occurs }\end{array}$ & - \\
\hline RPV supports & $\begin{array}{l}\text { Fluence-rate effect causes increase } \\
\text { in NDTT and embrittlement }\end{array}$ & $\begin{array}{l}\text { Size of critical flaw is small } \\
\text { enough to possibly have } \\
\text { been overlooked during } \\
\text { fabrication }\end{array}$ & $\begin{array}{l}\text { Fluence-rate effect at low temperatures } \\
\text { accelerates radiation embrittlement in } \\
\text { RPV steels. Since RPV supports are fabri- } \\
\text { cated of similar materials, may apply to } \\
\text { supports also. Application to Trojan and } \\
\text { Turkey Point indicates concern during } 32 \\
\text { EFPY lifetime. }\end{array}$ \\
\hline $\begin{array}{l}\text { Support column } \\
\text { pins and radial } \\
\text { beams }\end{array}$ & $\begin{array}{l}\text { Flaw size in beam }=0.5 \text { in. } \\
\text { Flaw size in pin }=0.05 \text { in. }\end{array}$ & $\begin{array}{l}\text { RPV supports meet safety } \\
\text { factor of } 1.41 \text { with the postu- } \\
\text { lated flaws }\end{array}$ & - \\
\hline $\begin{array}{l}\text { Load capacity for } \\
\text { a fractured beam } \\
\text { embedded in } \\
\text { concrete }\end{array}$ & $\begin{array}{l}\text { Vertical fracture of the supporting } \\
\text { beam }\end{array}$ & $\begin{array}{l}\text { The remaining portion of the } \\
\text { beam can support the design } \\
\text { load }\end{array}$ & - \\
\hline RCL piping & $\begin{array}{l}\text { RPV supports fail, and RCL piping } \\
\text { supports the RPV }\end{array}$ & $\begin{array}{l}\text { Failure of RPV supports will } \\
\text { not result in a LOCA. }\end{array}$ & $\begin{array}{l}\text { RCL piping is capable of transferring } \\
\text { RPV loads to RCL components (steam } \\
\text { generator and RCP) }\end{array}$ \\
\hline RPV supports & $\begin{array}{l}\text { One support (both beams) fracture } \\
\text { in vertical plane }\end{array}$ & $\begin{array}{l}\text { Fractured support would not } \\
\text { fail, but would redistribute } \\
\text { load to other supports }\end{array}$ & $\begin{array}{l}\text { Used analysis information (bending mo- } \\
\text { ment and spring constant) from the } \\
\text { ORNL report; capacity of embedded beam } \\
\text { from PCI test data (see J. Ma's approach) }\end{array}$ \\
\hline $\begin{array}{l}\text { RPV support } \\
\text { beams }\end{array}$ & See conclusions in report & $\begin{array}{l}\text { Size of critical flaw } \\
(2.20 \text { in.) too large to be un- } \\
\text { observed during fabrication }\end{array}$ & $\begin{array}{l}\text { Stress analysis based on calculations by } \\
\text { Furlong. Questions possibility of brittle } \\
\text { fracture. }\end{array}$ \\
\hline $\begin{array}{l}\text { RPV support } \\
\text { beams }\end{array}$ & None & $\begin{array}{l}\text { Max. B.M. }=12,700 \mathrm{k}-\mathrm{in} . \\
\text { Max. stress }=16.7 \mathrm{ksi}\end{array}$ & $\begin{array}{l}\text { For embrittlement to be significant, a } \\
1.8 \text {-in. crack would have to exist. }\end{array}$ \\
\hline RCL piping & All RPV supports fail & $\begin{array}{l}\text { RCL piping is capable of } \\
\text { transfering RPV loads to } \\
\text { RCL components }\end{array}$ & $\begin{array}{l}\text { Need to evaluate capability of steam gen- } \\
\text { erator and RCP supports to carry addition- } \\
\text { al loads from RPV }\end{array}$ \\
\hline
\end{tabular}

$\begin{array}{ll}\text { PGE } & \text { Portland General Electric } \\ \text { PCI } & \text { Prestressed Concrete Institute } \\ \text { RCL } & \text { Reactor Coolant Loop } \\ \text { RCP } & \text { Reactor Cooling Pump } \\ \text { SBLOCA } & \text { Small Break Loss-of-Coolant Accident } \\ \text { SSE } & \text { Safe Shutdown Earthquake } \\ \text { TH } & \text { Thermal }\end{array}$


- The analysis did not combine the dynamic loads associated with safe-shutdown earthquake (SSE) and loss-of-coolant-accident (LOCA); this constitutes a deviation from the Standard Review Plan (SRP), Section 3.9.3, Table 1 (Ref. 9).

- The consequence analysis did not consider degradation in related, critical components such as thermal aging of cast austenitic-ferritic (duplex) stainless steels in the primary coolant piping in some PWRs. Those that contain significant amounts of delta ferrite may exhibit low-temperature aging embrittlement.

- The consequence analysis considered one component at a time, but in reality, several components may be affected simultaneously suggesting that a cumulative interactive effect be considered.

It is possible that consideration of all the above items in a more comprehensive analysis might reveal cumulative effects and modify the consequences of RPV support failure relative to what was reported, but that was not explored.

The analytical methods used to predict the potential for brittle fracture in the second group were equally complicated. Fracture mechanics is relatively new to design, and many of its methods are not codified, leaving analysts considerable freedom of choice. Compounding that uncertainty in the solution to the problem were several factors capable of profoundly affecting the results. For example, the mechanical properties, chemical composition, and metallurgical condition of structural steels may vary widely from heat to heat, and frequently are not known with much certainty. Also, the location, size, and orientation of flaws often can only be postulated or approximated at best. For such reasons, variability is almost certain.

Both approaches have advantages and disadvantages. Although the "consequence analysis" approach rests on proven engineering theories, it depends greatly on assumptions that must reflect real conditions and on models that must predict the behavior of the structure. On the other hand, although fracture mechanics has proven to be a rather precise method for predicting brittle fracture, complicated structures may be difficult to model and mixed-mode (elastic-plastic) fractures, common in low-strength steels, demand sophisticated material property data and a measure of judgement. It follows that in today's state of the art, there is no single method, applicable to all reactors, by which GSI-15 could be resolved.

\subsection{Shippingport Neutron Shield Tank Testing}

To augment the HFIR surveillance data, the Argonne National Laboratory (ANL) undertook related activities pertinent to resolution of GSI-15 (Ref. 10). The goal of these activities was to test a steel similar to one of those in the HFIR program to determine the NDT shift after irradiation under similar conditions (i.e., low neutron flux and low temperature). The results were expected to provide a comparison with both the HFIR and test reactor data, thereby helping to resolve questions related to the affect of fluence rate or energy spectrum on radiation embrittlement. 
The ANL investigation involved testing specimens machined from samples of the NST from the decommissioned Shippingport reactor for the purpose of characterizing the radiationinduced embrittlement. The NST was made from hot-rolled A 212 Grade B steel. The reported inner wall exposure was a (maximum) fluence of approximately $6 \times 10^{17} \mathrm{n} / \mathrm{cm}^{2}(\mathrm{E}$ $>1 \mathrm{MeV})$ over a life of $9.25 \mathrm{EFPY}$, while operating at about $55^{\circ} \mathrm{C}\left(130^{\circ} \mathrm{F}\right)$. The ANL report (Ref 10) indicated that the radiation embrittlement of the Shippingport NST A 212-B steel was not as severe as that reported for the HFIR surveillance samples. Additionally, the report concluded that the results agreed with the available data for irradiation at temperatures less than $232^{\circ} \mathrm{C}\left(450^{\circ} \mathrm{F}\right)$, and with data from MTRs and Army reactors. The ANL investigators suggested that the accelerated embrittlement of the HFIR surveillance samples probably reflected the high proportion of thermal neutrons relative to test reactors.

\subsection{Trojan Dosimetry}

As previously noted, the NRC staff, contractors, consultants, and industry representatives generally agreed that the Trojan Nuclear Plant presented the best case for RPV support embrittlement. This conclusion was supported by the fact that there were structural elements at the reactor beltline under tensile loading with flame-cut holes at the maximum moment (peak tensile stress) made of steel of questionable ancestry. It was expected that if the Trojan RPV supports could be certified as safe, the rest of the industry could be deemed acceptable. One parameter in such an analysis for which there were no data was the radiation flux at the supports. Consequently, the Materials Engineering Branch, Engineering Division, RES (NRC), initiated a program in 1990 to obtain dosimetry data in the Trojan reactor cavity. The results were published in 1994 (Ref. 11).

To obtain the data, two sets of dosimeters were placed in each of two vertical access channels in the concrete biological shield at Trojan before operating cycle 13 . Cycle 13 ended after 242 days of operation on March 4, 1991. The location of the dosimeter trains is of some importance. The plant was designed with vertical channels in the concrete structure to provide access to horizontal instrumentation ports. The radial location of the vertical channels was close enough to that of the flame-cut holes in the box beam flanges to make the measurements directly applicable.

Each dosimeter set included radiometric dosimeters and solid state track recorders (SSTR). Several problems were discovered (Ref. 11):

- At one channel, a large neutron-moderating polyethylene shield surrounding an ex-core detector significantly perturbed the neutron flux and complicated the geometry used in the transport calculations.

- Because the available pinwise core power distribution was generic rather than plantspecific, an error was introduced in the dosimetry activity calculations.

- The best cross-section library with multiple thermal groups available at the time of the study introduced some uncertainty in the accuracy of the computed thermal flux. 
- An unexplained inconsistency between the calculated and measured dosimetry results was observed, some of which may have resulted from using a generic (rather than plant-specific) core power distribution.

To expand on the last point, two sets of cross-section data were used in the transport calculations. Previous studies had found that one set would underestimate the fast neutron reaction rates and the other would not; however, in this program, the set reported to underpredict gave results about $20 \%$ higher than the experimental values.

Although the ratios of calculated to experimental (c/e) values for the various fast-neutron dosimeters were fairly consistent, the c/e ratios were not close enough to unity to be deemed in agreement. Since the apparent discrepancy between calculated and measured values could only be resolved with additional information, the high value resulting from the transport calculations was selected as a measure of the RPV support exposure. At the critical point (the flame-cut grout hole in the upper flange of the box beam), the following values were given:

- $\quad$ Fast-neutron flux $(\mathrm{E}>1 \mathrm{MeV})=6.90 \times 10^{7} \mathrm{nvt}$.

- $\quad$ Thermal-to-fast neutron flux ratio $=46$.

- $\quad$ dpa rate $=2.0 \times 10^{-13}$ displacements per atom per second.

Typical EOL conditions (40 calendar years; $32 \mathrm{EFPY}=1.01 \times 10^{9} \mathrm{sec}$ ) would result in:

- Fluence $(\mathrm{E}>1 \mathrm{MeV})=7 \times 10^{16}$ neutrons $/ \mathrm{cm}^{2}$.

- $\quad \mathrm{dpa}=2.02 \times 10^{-4}$.

Plant life extension might increase the exposure to 60 years, or $1 \frac{1 / 2}{2}$ times the standard period, which would increase the exposure to dpa $=3.03 \times 10^{-4}$.

Refer to Figure 3-1; reading from the upper-bound curve, the above two dpa exposure levels yield the following transition temperature shifts $(\Delta \mathrm{TT})$ :

- $\quad \Delta \mathrm{TT}(40 \mathrm{yr})=12.5^{\circ} \mathrm{C}=22.5^{\circ} \mathrm{F}$.

- $\Delta \mathrm{TT}(60 \mathrm{yr})=17.6^{\circ} \mathrm{C}=31.7^{\circ} \mathrm{F}$.

The Trojan horizontal box beams (where the critical location is situated) were fabricated of A 36 steel. The as-built transition temperature for that grade of steel commonly ranges up to $50^{\circ} \mathrm{F}$ (but could be higher). Thus the radiation exposure could raise the TT to approach the operating temperature (reported as $90^{\circ} \mathrm{F}$ by Pacific Gas and Electric Company (PG\&E)) within the term of the plant's expected life. The NRC staff noted that the upper limit for the as-received TT of A 36 as cited by Bechtel, the Trojan Nuclear Plant architectengineer, was $90^{\circ} \mathrm{F}$, i.e., equal to the operating temperature prior to any shift from neutron radiation. 


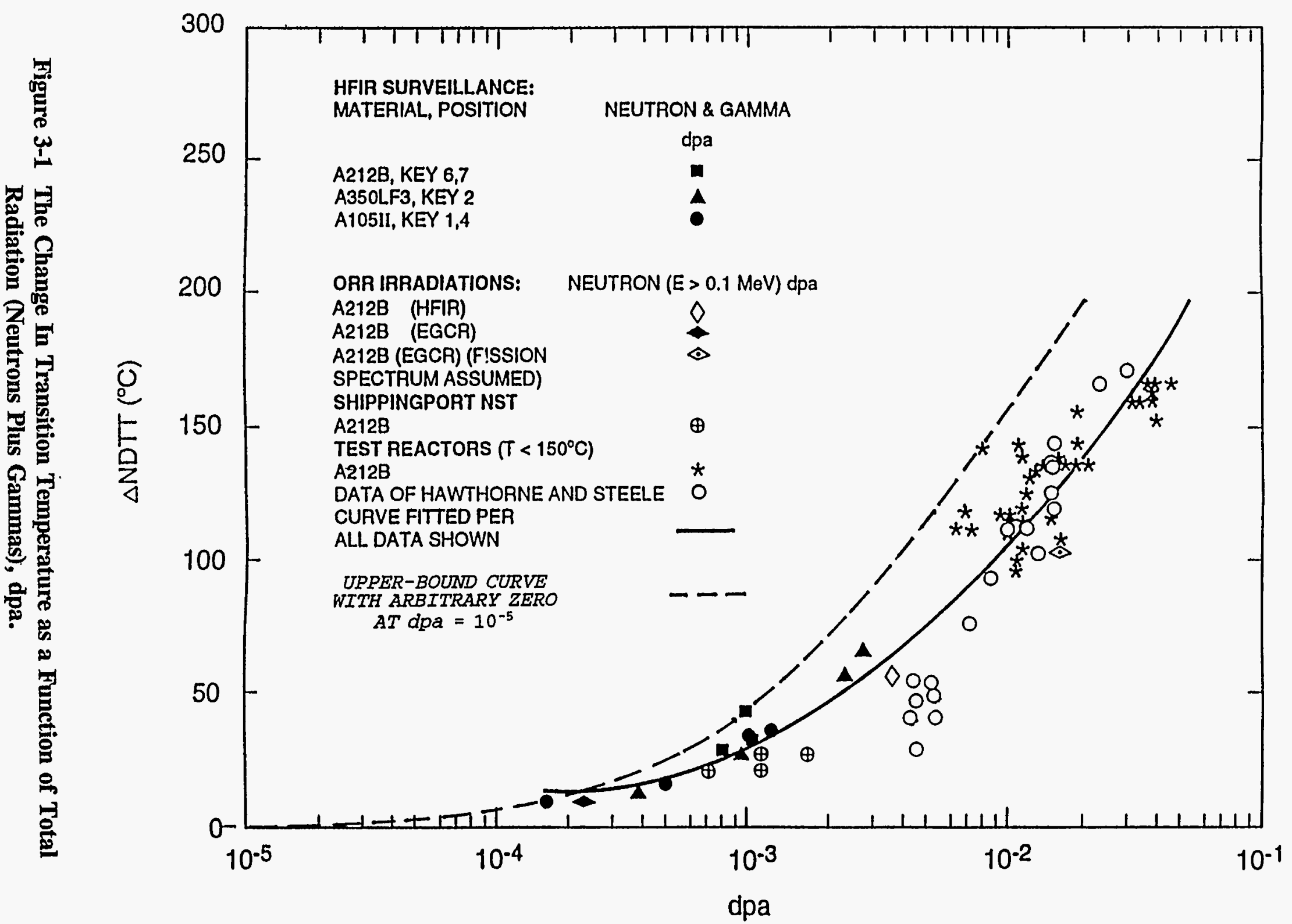


Sound technical reasons support the concern for the initial (as-built) toughness of RPV supports. The Charpy V-notch impact transition temperature of low-alloy (structural) steels is very dependent on thermal-mechanical history. At a constant austenite grain size, an increase in ferrite grain size by about 50 percent (e.g., from $\sim 22$ to -33 microns) could raise the transition temperature by 35 to $50 \mathrm{~F}$ (Ref. 12). Additionally, a loss in control of the $\gamma$-phase grain size could greatly expand the Charpy curve differential.

Capitalizing on the opportunity to expose radiation monitors to the neutron field in the Trojan shield wall, the NRC staff requested that a few Charpy specimens be attached to the dosimeter trains. Although the dosimeters were withdrawn after one fuel cycle, the Charpy specimens were exposed to a second cycle, which was cut short. Dr. R. Nanstad, ORNL, reported* that the fluence (E $>1.0 \mathrm{MeV}$ ) was $10^{16} \mathrm{nvt}$. The set of specimens included A 212 and A 36 steels; the unirradiated A 36 steel results showed a great deal of scatter. There was essentially no NDT shift, which would be expected from the established trend curve at that exposure.

\subsection{Low-Energy Neutron Damage Theory}

As previously mentioned, the ORNL report (Ref. 4) on the test results from the HFIR steel vessel surveillance specimens attributed the excessive NDT temperature shift to a neutron fluence-rate effect. Only brief mention was made of the potential for low-energy neutrons (epithermal and thermal) to make a significant contribution to the observed embrittlement. Citing the results of multigroup transport calculations, the authors reported a thermal-to-fastneutron ratio of about 50-to-1. Even granting that the average amount of damage from each low-energy neutron is a small fraction of that from a fast-neutron, the greater abundance would contribute to the embrittlement. That is, radiation by a neutron flux skewed strongly to the low-energy end would result in more total damage than a traditional trend curve would predict. Actual conditions are complicated because the low-energy neutron micromechanisms are not the same as for fast neutrons (principally elastic scattering). For example, a lowenergy neutron can be captured by an iron nucleus, which will in time transmute to a manganese atom. The resulting energetic recoil of the manganese atom will cause damage that may contribute to embrittlement.

Low-energy neutron damage considerations by Heinisch and Greenwood led to theoretical models and a reexamination of the HFIR data by Hrabal (Ref. 6). Modified damage parameters were used to develop new correlations between radiation-induced mechanical property changes and exposure. Development of the modified damage parameters involved rather sophisticated procedures that accounted for the recombination of point defects following displacement, thereby taking the parameter dpa to a more physically correct level. The best results came from Greenwood's application to damage calculations of a recombination model developed at ANL by Weidersich which Hrabal used to calculate modified values of dpa (hereinafter "dpa mod") from revised inputs into the computer code SPECTER (Ref. 13). Neutron spectra, applicable to the specific irradiated mechanical property data surveyed, were obtained from several sources associated with the experiments.

*Private communication, R. Nanstad (ORNL) to R. Johnson (NRC), April 26, 1994. 
The task resulted in the diverse data collapsing (with typical scatter) onto a single trend curve. Specifically, the data set included HFIR surveillance results, HFIR archival A 212-B steel data (irradiated in the ORR), and the initial Shippingport NST results (reported by ANL). Although the HFIR and ORR data represented the same plate of steel, the NST steel was unrelated other than having the same ASTM specification.

The analysis was expanded to include other steels with the result that, despite differences in chemistry and metallurgical condition, the data stayed reasonably close to a single trend band of property change as a function of dpa mod. Also, the A 212-B data represented a range in neutron flux of a factor of 40,000 (from $2.4 \times 10^{8}$ to $9.6 \times 10^{12} \mathrm{n} / \mathrm{cm}^{2} \cdot \mathrm{s}$ ), which failed to support the theory that the excessive embrittlement of the HFIR steel was a manifestation of a neutron fluence-rate effect.

Another set of data added some interesting, if not convincing, information to this task. Specifically,we refer to the results of the Void Box irradiation experiment (Ref. 14). The purpose of the experiment was to determine the effect of irradiation on several RPV support steels in conditions designed to simulate the reactor cavity environment. Eight different materials were encapsulated; irradiation took place in the ORNL poolside facility. Early in the 1.6-year irradiation period, the capsule filled with water, but this condition was not discovered until the irradiation was complete. Because the fluence target value of $5 \times 10^{17}$ $\mathrm{n} / \mathrm{cm}^{2}(\mathrm{E}>1 \mathrm{MeV})$ was not reached, the report cites the results as inconclusive. If close attention is paid to the data, however, the eight materials yield the following observations:

- The six wrought steels exhibited $\triangle \mathrm{NDT}$ values of zero (that is, the unirradiated and irradiated Charpy curves essentially superimposed).

- One set of Charpy specimens, representing weld heat-affected material, showed too much scatter to allow interpretation.

- One set of specimens, taken from a bulk weldment, showed both a shift in the NDT temperature and a decrease in the upper shelf energy.

- The weldment chemical analysis included $3.39 \% \mathrm{Ni}$, which was more than the nickel content of any of the other steels. This may be significant; an increase in Ni in a steel is suspected of increasing the sensitivity to neutron radiation.

Because the influx of water only attenuated the neutrons, shifting the distribution to the lowenergy region of the spectrum, it was interesting to include the data in the dpa mod analysis. Of course, six points fall on the abscissa $(\Delta \mathrm{NDT}=0.0$ ) and contribute nothing, but the high $\mathrm{Ni}$ weld metal lends itself to the review and was included with the other data.

When the disparate data were normalized by the dpa mod parameter, the HFIR problem was viewed as a matter of accounting for low-energy neutron damage. In fact, the staff had begun preparing GSI-15 resolution documents on that basis when confirmatory data, reviewed below, failed to support the 50-to-1 thermal-to-fast-neutron ratio initially reported for HFIR. Although the low energy damage theory did not resolve GSI-15, low-energy neutrons do induce radiation damage in steel. At temperatures below $200^{\circ} \mathrm{F}$, even the 
relatively, short-range lattice disruptions are retained. The tenacity of any damage sustained at low temperature can be illustrated by noting the diffusivity, D, of iron in ferrite (the lowtemperature, body-centered-cubic, phase) at, for example, $550^{\circ} \mathrm{F}$ and $100^{\circ} \mathrm{F}$, and calculating the ratio $\mathrm{D}_{550} / \mathrm{D}_{100}$. The staff did so by extrapolating the "Fe in bcc Fe" Arrhenius curve included in an article on Material Engineering Education in the January 1990 Journal of Metals (p. 8, Fig. 2). Finding $D_{550}=3 \times 10^{-22}$ and $D_{100}=1.5 \times 10^{45}$, the ratio was $2 \times$ $10^{23}$. Since the product $\mathrm{Dt}$ ( $\mathrm{t}$ being time) is constant, other things being equal, to get the same amount of recovery (thermal annealing) at $100^{\circ} \mathrm{F}$ as would occur in one minute at $550^{\circ} \mathrm{F}$ would take $2 \times 10^{23} \mathrm{~min}$ or $3.8 \times 10^{17}$ years. That is, there will be essentially no annealing of radiation damage at ambient temperatures in RPV supports. Therefore, the lowenergy neutron fluence should be included in damage predictions if accuracy is of some importance.

\subsection{HFIR Dosimetry and Gamma Radiation}

The early results from application of a low-energy neutron damage theory by re-analysis of the HFIR surveillance data using the dpa mod parameter appeared to resolve the problem of the exceptionally high NDT shift; however, the analysis was based on very limited data. In fact, neutron spectrum data were available in HFIR at only one capsule (of A 212 steel) location. To rectify that situation, the staff requested that ORNL calculate the neutron spectrum at other surveillance capsule locations, especially those that held specimens of other grades of steel. This work was done under a change of scope order to the HSST Program. After some delays related to changes in both hardware and software at ORNL, the results indicated that the thermal-to-fast flux ratios at eight surveillance capsule locations were found to vary from 3.6 to 7.1 with an average of 4.9 , i.e., one-tenth of the previously reported 50to-1 value.

The next stage of the investigation was dictated by the desire to resolve the question of the physically correct neutron energy spectrum using state-of-the-art dosimetry. At the request of the NRC, dosimeters were inserted in the HFIR. Although intended to follow generally accepted procedures for neutron spectra determination, the experiment (identified as "DOS1" by ORNL) created a temporarily unexplained outcome (Ref. 15). Specifically, fast-neutron $(\mathrm{E}>1 \mathrm{MeV}$ ). flux measurements from the activity of $\mathrm{Np}$ and Be monitors resulted in values approximately 17 times and 15 times higher, respectively, than the flux values derived from the Ni monitors. When careful checks of the measurements ruled out experimental errors, a comprehensive experimental program was initiated as a new, separate contract.

The program proceeded in two steps, identified as the DOS2 and DOS3 experiments. In the DOS2 experiment, the dosimeters were "bare" within the capsules, whereas in the DOS3 experiment they were clad with a 4-mil Gd cover to attenuate the thermal neutron flux and prevent interference with the response of the monitors. The scope of the project consisted of neutron and gamma transport calculations, dosimetry measurements, and least-squares logarithmic adjustments of the transport calculations and dosimetry measurements to obtain optimum neutron spectra estimates. Gamma dosimeters were furnished and (after irradiation in the HFIR) counted by the National Institute for Standards and Technology (NIST). The $\gamma$ measurements verified that the calculated gamma field, deduced from 1-D neutron and $\gamma$ 
transport calculations, was adequate to determine the $\gamma$ contribution to fast fission and $\mathrm{Be}$ radiometric monitors.

Those interested in precise radiometric measurements and transport calculations may note a relatively minor correction to the ORNL report (Ref. 15). Specifically, the report states that the measured value of $\gamma$ dose rate was $36.4 \mathrm{~Gy} / \mathrm{s}$, compared to a calculated value of $36.6 \mathrm{~Gy} / \mathrm{s}^{*}$. Because readers might miss the point made in Appendix A of Ref 15, the measured value should be corrected downward by 10 to 20 percent. The reason for the adjustment is that the NIST investigator converted the measured change in optical absorption in polychlorostyrene on the basis of a $20^{\circ} \mathrm{C}$ irradiation temperature, whereas the HIFR temperature was nominally $50^{\circ} \mathrm{C}$. This fact was uncovered after the program reached completion and, although the report had not been published, the calculations had been completed. The correction would require considerable work to redo all of the neutron/gamma unfolding and all of the affected tables. Moreover, the correction was within the measurement uncertainty. As a result, the figures were allowed to stand.

The project was conducted by a team of NRC reviewers, ORNL investigators, and outside consultants from national laboratories, academia, and industry. Several major findings were reached:

- Discrepancies in fast-neutron flux values from various monitors irradiated in the DOS1 experiment were shown to be related to photofission and photoneutron reactions in certain monitors.

- Because photo-induced reactions dominate in the $\mathrm{Be}$ and fast-threshold fission dosimeters, those monitors are good candidates for measuring the $\gamma$ dose in some radiation fields.

- Neutron flux gradients within the dimensions of the surveillance capsules in the HFIR were not consistent, being nearly flat at some locations and steep at others.

- The stainless steel monitors, located in the V-notch of the Charpy specimens in the HFIR surveillance program, were shown to be adequate for fast-neutron (E $>1 \mathrm{MeV}$ ) flux measurements.

- At the one location where measurements permitted the calculation to be made, the $\gamma$ dpa was about five times higher than the neutron dpa.

- The feasibility of applying simultaneous adjustment of neutron and $\gamma$ fluxes was demonstrated and, although the finding had little impact on this program, the methodology would be extremely useful in future work.

Going well beyond the scope of the program reported in NUREG/CR-6117 (Ref. 15), the experimental and calculational results obtained in the DOS1, DOS2, and DOS3 programs

*See the NOTE on $\gamma$ radiation at the end of this Chapter. 
allow the mechanical property measurements from the HFIR surveillance tests to be related to dpa based on total neutron and gamma fluxes. That relation reveals that the embrittlement measured as $\triangle \mathrm{NDT}$, previously judged excessive, falls on the same trend band as other results (See Fig. 3-1, adapted from Ref. 6). Thus, the NRC staff tentatively concludes that the deviation of the HFIR data from the correlation established from experiments done under traditional conditions (e.g., in a materials test reactor) was a manifestation of (1) the relatively large gamma radiation and (2) the fact that the steel could retain the damage from that source because of the low temperature $\left(<200^{\circ} \mathrm{F}\right)$ during irradiation. The water annulus of about 20 inches in HFIR created a favorable set of conditions: the neutrons were attenuated by the water resulting in an energy spectrum skewed toward low energy values whereas the gamma flux was changed only slightly. The conclusion is "tentative" because there are no supporting data independent of the HFIR surveillance results. It is unlikely that a verification experiment will be mounted soon since it is necessary that the $\gamma$ flux be moderate. Otherwise, so much heat would be generated that the submicroscopic damage would be simultaneously annealed. At the same time, the neutron dpa cross section is much larger than the $\gamma$ dpa cross sections; thus, if the $\gamma$ dpa is to be a significant factor, the neutron flux must be low compared to the $\gamma$ flux.

With respect to the RPV of an operating LWR, there are additional important mitigating factors. First, the irradiation temperature of an RPV is about $550^{\circ} \mathrm{F}$. At that temperature, the diffusivity of steel is high enough that most of the short-range submicroscopic damage will be annealed within a few months, if not a few weeks. Second, the vessel steel, being six to ten inches thick, provides shielding for the supports from gamma radiation. That is more than enough to reduce the $\gamma$ flux by several decades. We take note of the $\gamma$ radiation measurements made in operating reactor cavities and reported in Refs. 16 and 17. The B\&W experiment, conducted at a plant where low-leakage core management was in effect, resulted in a reported beltline $\gamma$ flux value of $45 \mathrm{~Gy} / \mathrm{hr}$, where the quantity grey (Gy) is a unit of absorbed dose. The measured $\gamma$ flux in HFIR (Ref. 15) was reported as $36.4 \mathrm{~Gy} / \mathrm{s}$, or $131,040 \mathrm{~Gy} / \mathrm{hr}$; the ratio: [131,040 Gy/hr(HFIR)/45 Gy/hr(plant)] $=2912 \simeq 3000$, shows the shielding efficacy of the RPV. The Westinghouse cavity $\gamma$ flux measurements were made at a 3-loop plant that had not instituted low-leakage fuel management procedures. The reported results (Ref. 17) were 40,000 to $150,000 \mathrm{rad} / \mathrm{hr}(100 \mathrm{rad}=1$ grey). For this case, the NRC staff calculated the ratio of the HFIR $\gamma$ flux to the peak operating reactor value (both in $\mathrm{Gy} / \mathrm{hr}$ ) as $131,040 / 1500=87.36 \simeq 100$.

The calculated ratios showed that (1) the $\gamma$ flux in cavities of operating reactors is much less than that in HFIR, and (2) low-leakage cores will reduce the cavity $\gamma$ flux, thus affording additional protection from damage to the RPV supports. Exposure to low levels of $\gamma$ radiation, as reported in References 16 and 17, should not induce a significant increase in embrittlement (i.e., $\triangle \mathrm{NDT}$ ) of the RPV supports beyond that resulting from neutron irradiation.

\section{Note on Gamma Radiation.}

Gamma flux can be reported in units of Gy/s, "Gy" being the symbol for "Greys." Note that: $1 \mathrm{~Gy}=1 \mathrm{~J} / \mathrm{kg}$., a joule being a measure of work or energy, proportional to $\mathrm{ft}-\mathrm{lb}$ in English units. Because 1 joule/s $=1$ watt (unit of power), it follows that $1 \mathrm{~Gy} / \mathrm{s}=$ 
$1 \mathrm{watt} / \mathrm{kg}$. This relationship highlights an expected result of $\gamma$ radiation: heat generated in the irradiated body. At steady state in a solid with the surfaces maintained at constant temperature, the temperature is proportional to the gamma flux.

Although the $\gamma$ dose rate bears some similarity to neutron flux, the relationship between the relative damage (in steel) from the two kinds of radiation involves more complicated considerations of the physics of the two types of radiation, including the relative damage cross-sections, the relative efficiencies of lattice displacements, and the relative radiation energy spectra. Those subjects are beyond the scope of this paper. 


\section{RPV SUPPORT REEVALUATION CRITERIA}

\subsection{Overview}

As a result of recent data obtained from tests of surveillance specimens representative of RPV support materials exposed to low-temperature, low-flux radiation (Ref. 4), the NRC became concerned that RPV supports could exhibit considerably more rapid embrittlement than was considered in the original support design. As noted earlier, subsequent analyses did not support regulatory action by the NRC. However, there may be reasons to reassess the structural integrity of RPV supports. This section provides an engineering approach, including screening criteria and technical evaluation procedures, which may be taken as guidelines acceptable to the NRC.

The objective of developing screening criteria was to identify those RPV supports that, because of their configuration, material properties, or stress level, should be free from excessive radiation embrittlement or failure under accident loading. That objective was met with criteria for reevaluation of RPV supports, augmented by flow charts and associated notes containing specific references and acceptance criteria. Also, examples were developed, one with only membrane stresses and another with both direct tension and bending, to facilitate application. The criteria also address combined shear and tension. These subjects are presented in this Section.

The criteria contain many of the provisions of the American Society of Mechanical Engineers (ASME) Boiler and Pressure Vessel Code (ASME Code), Sections III and XI (Refs. 18 and 19). This material was included despite the design differences between vessels (to which most of the Code applies) and supports because the principles of fracture mechanics apply equally well to the RPV and its supports. The criteria are offered as guidance rather than as specifications, and the ASME Code requirements should be valuable.

\subsection{Screening Criteria}

Reactor pressure vessel supports should be screened sequentially for evaluation, as illustrated in Figure 4-1. The procedure is designed to assess support vulnerability by eliminating supports that are not affected by embrittlement because of their configuration or state of stress. The most vulnerable supports are considered to be those that are exposed to a relatively high fluence (hence, have a large $\triangle \mathrm{NDT}$ ), have high initial NDT temperature, and have tensile stresses. Figure 4-1 illustrates that these elements are the essential criteria for screening the RPV supports.

To achieve a useful screening evaluation, reliable and accurate information is necessary in the indicated areas of Figure 4-1. The information may be obtained from the construction and fabrication records if such records are available. According to the ASME Code, Section III, Subsection NCA, "General Requirements," such records should be maintained and be available at each plant. Some testing may be necessary if chemical and mechanical property information is not available. 


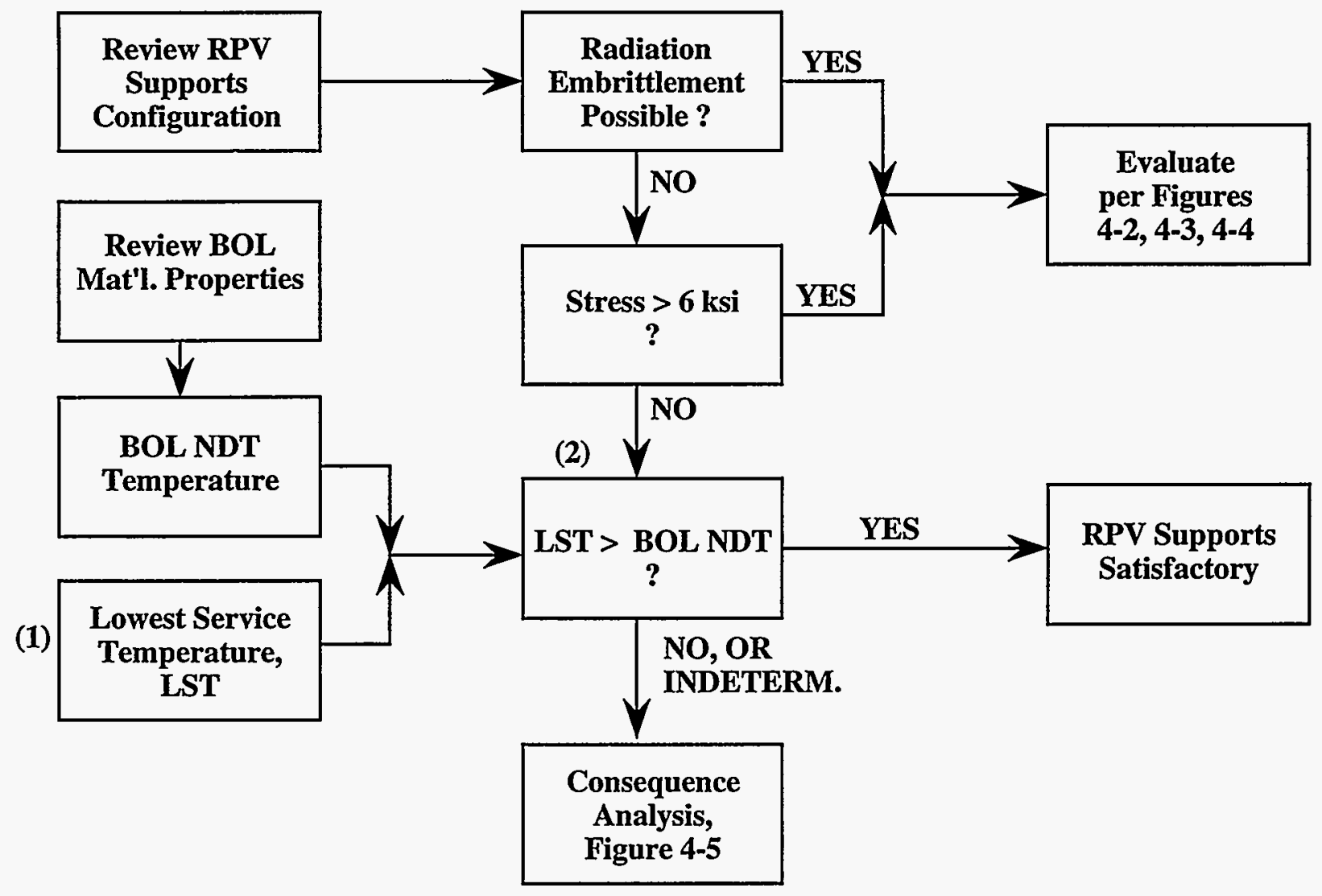

Note: The numbers next to the blocks above refer to the corresponding paragraphs of "Explanatory Notes" at the end of this section.

Figure 4-1 Screening Criteria 


\subsubsection{Configuration}

Support configuration is an important consideration, because it indicates whether supports or support members are likely to receive the amount of radiation necessary to accelerate embrittlement. Consequently, configuration is the first item in Figure 4-1 to be evaluated. If the review of "as built" design drawings indicates that the supports are located in an area where irradiation is low (e.g. skirt-supported RPVs), radiation induced embrittlement is not an issue. Supports of other configurations also may be eliminated using the same criterion, provided that low exposure to radiation is demonstrated and the initial NDT temperature is sufficiently low.

\subsubsection{Materials}

Materials of construction of RPV supports also are very important, because some compositions may be so sensitive to radiation that even a very low fluence may cause enough embrittlement to make brittle fracture a possibility. The NDT temperature shift will vary depending on the metallurgical condition and the chemistry of the steel, although available data do not cover all variations. The data relating to the materials used in construction of the RPV supports should be collected, analyzed and if reliable information is not available, some testing may be necessary.

\subsubsection{Stresses}

For brittle fracture to occur, a tensile stress must be present. Following the recommendations of the ASME Code, the threshold below which the NRC staff considers brittle fracture unlikely is $6 \mathrm{ksi}^{*}$. However, a fracture is most likely to be triggered by events such as a loss-of-coolant accident (LOCA) or an earthquake. Both of these events produce sudden, dynamic stresses. Also, the shift in NDT temperature is related to the rate of load application. Consequently, strain-rate effects should be considered, the load-rate should be specified, and an explanation should be provided as to how the load rates are used in the analysis. Furthermore, residual stresses resulting from fabrication processes should be considered additive to the operational stresses. Thus, they may have a pronounced effect on the overall state of stress. This is especially important wherever there are heavy welds. Although post-weld stress relieving should reduce the magnitude of residual stresses, there are indications that the reduction is only partial. The residual stress orientation and the manner of inclusion in the analysis should be specified and documented. Finally, the cumulative effect of the chemical composition of the material, the fluence effect, and the stresses should be considered in the screening criteria, and the decision-making rationale for the screening should be provided in accordance with the guidance outlined in Section 4.3.1.2 of this report.

\footnotetext{
*The tensile stress of $6.0 \mathrm{ksi}$ was used in the Portland General Electric Co. report, entitled "Trojan Nuclear Plant Reactor Vessel Support Design Basis and Evaluation Summary," dated October 24, 1988. Private communication between R. Lipinski (INEL) and B. Elliot (NRC) on October 10,1989, confirmed that this threshold is in accordance with current NRC policy.
} 


\subsubsection{Criteria}

By satisfying the following criteria, the supports should be free from radiation embrittlement, the integrity may be reasonably assured, and no further investigation should be required.

- The initial NDT of the RPV supports is well below the minimum operating temperature.

- The radiation exposure at the supports is low.

- The peak tensile stresses are $6 \mathrm{ksi}$, or less.

\subsection{Criteria for Reevaluation}

The RPV support reevaluation process can be divided into several distinct steps as illustrated by the flow charts (Figures 4-1, 4-2, 4-3, and 4-4). A structural integrity reevaluation should include all RPV support design-basis loading combinations, as documented in the plant's preliminary or final safety analysis report (PSAR or FSAR) for CP holders or licensees, respectively.

Using Figure 4-2, Step One of the reevaluation involves assessment of the existing condition of the supports at the time of reevaluation, comparison with the initial construction condition, and the degree of degradation predicted by the end of plant life. The assessment includes a mandatory, visual physical condition inspection of the vital parts of the supports. Rust, cracks, or permanent deformation of any part of the RPV support should be noted as evidence that some distress has been sustained. Limited accessibility may preclude some or all of the examinations; if so, the supports should be examined by remote means. There must be assurance that the supports have not been physically degraded to such an extent that the parameters important to load carrying capacity (such as cross-sectional area, section modulus, etc.) have changed substantially. If significant degradation is observed, it should be recorded, and remedial measures seriously considered.

Step One also entails a review of the original design and safety margin. This review should include the original design methodology, load combinations for which the supports were designed, allowable stresses and their margins with respect to the actual stresses in the members, and codes governing the original design. If brittle fracture avoidance was part of the original design, the review should include the criteria and methodology used, sources of information, and the bases for the conclusions reached. If the codes governing the original design differ from those currently promulgated, to the extent that they are currently accepted by the NRC, the difference, if any, between the original design margin and that which would be achieved from design in accord with the current codes and standards should be determined. This information will be useful if and when one of the subsequent options is selected. Upon completing Step One, the information obtained and the conclusions reached regarding the structural integrity of RPV supports should be documented and retained. 


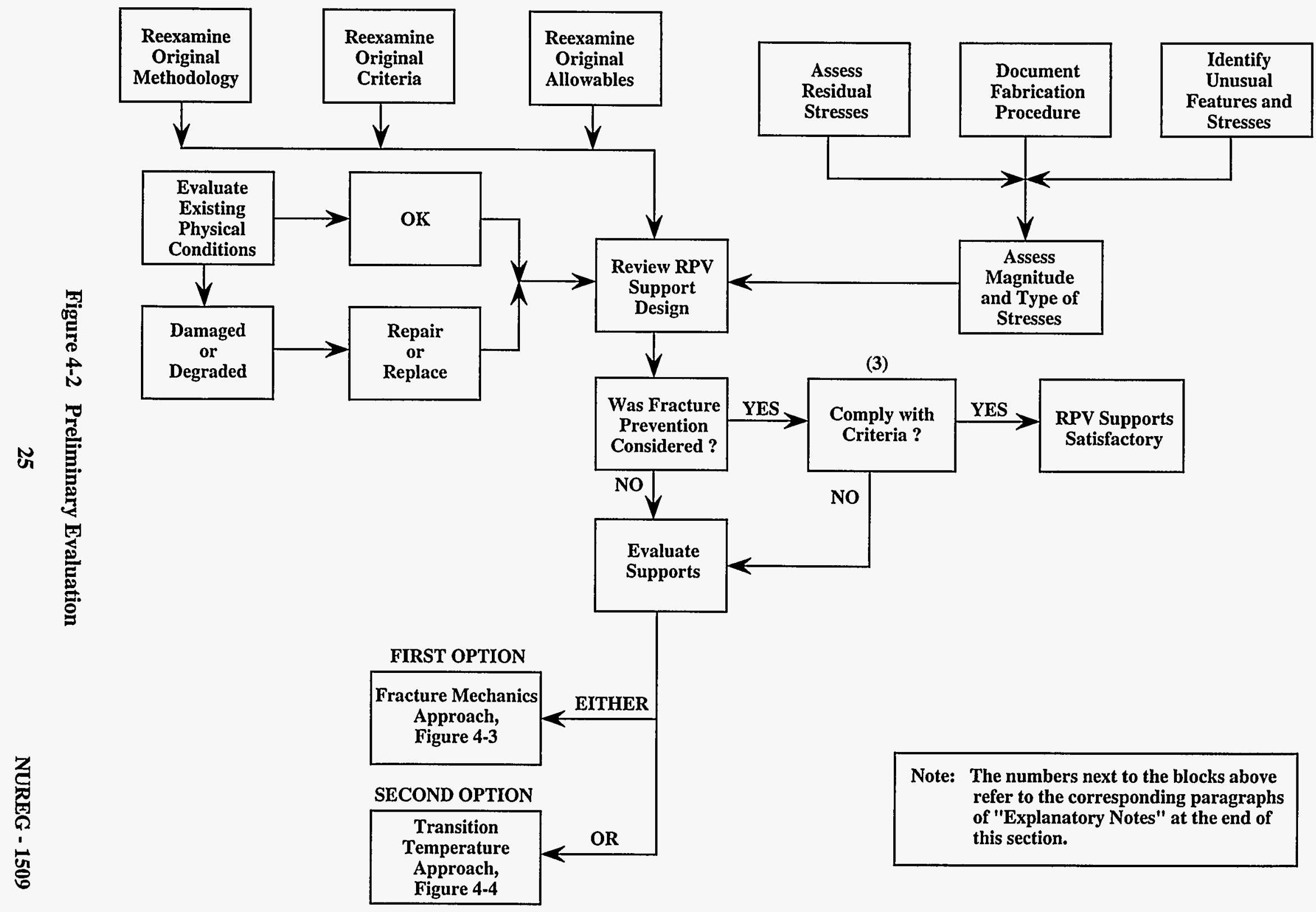




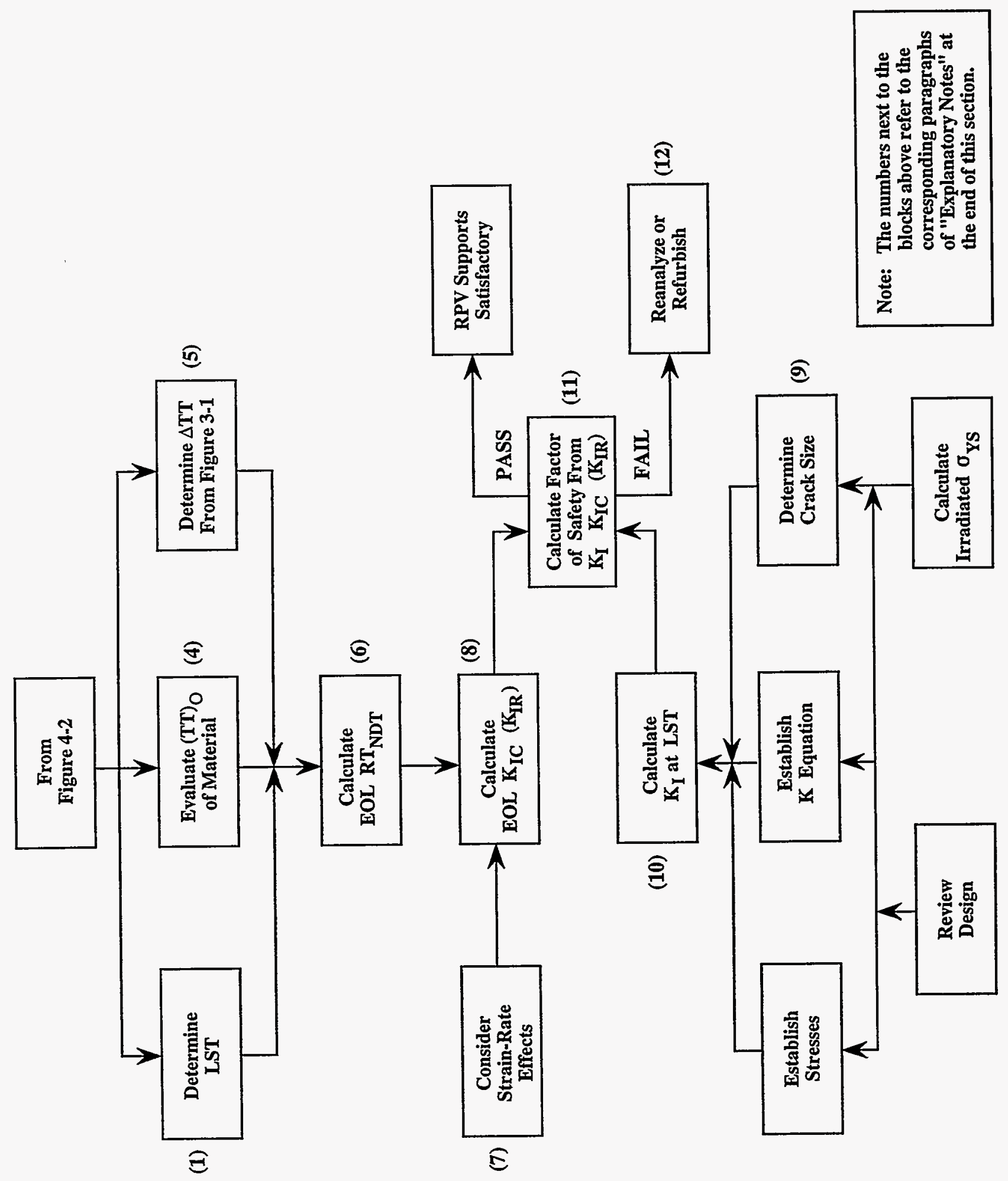

Figure 4-3 Fracture Mechanics Approach 


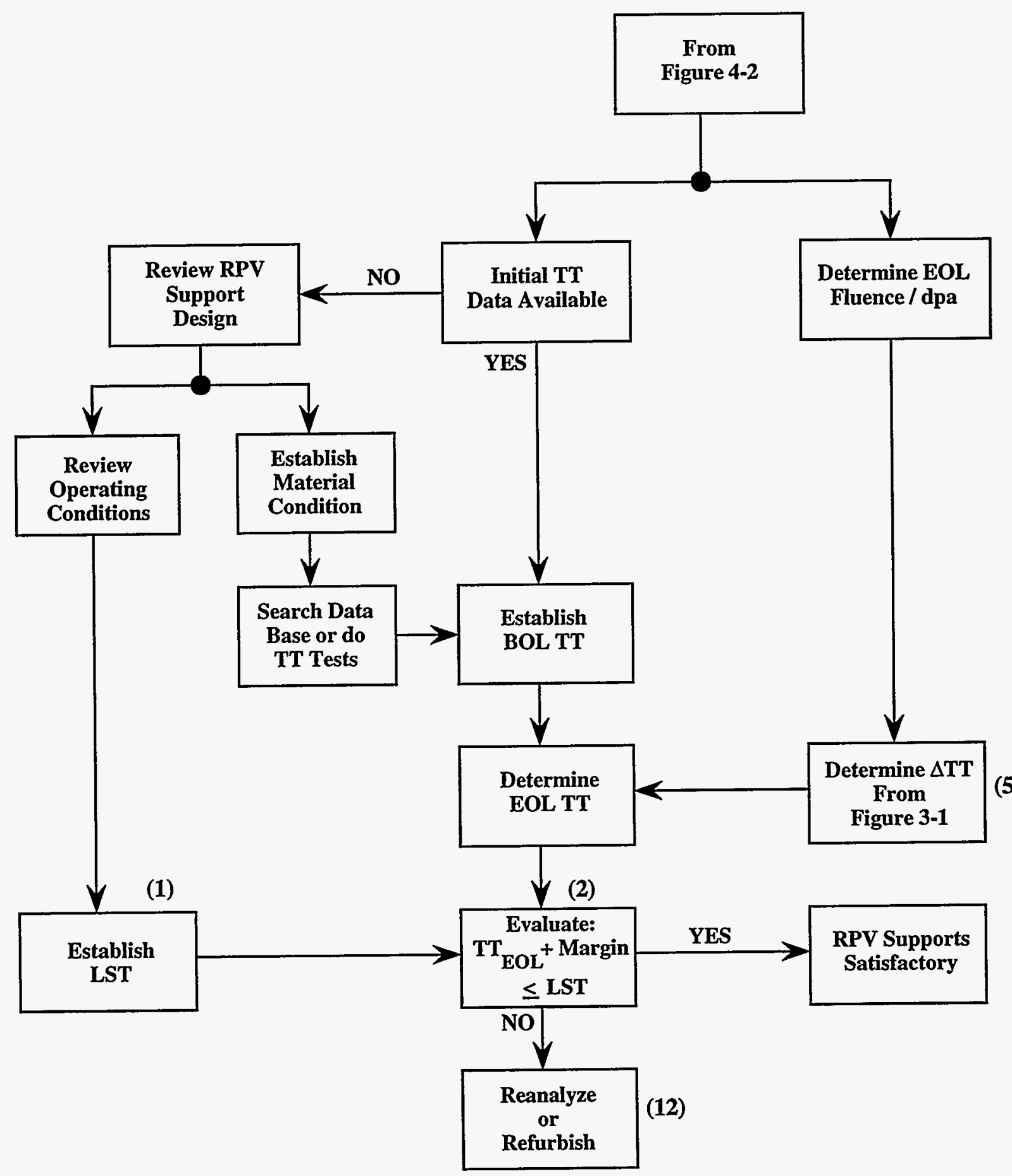

Note: The numbers next to the blocks above refer to the corresponding paragraphs of "Explanatory Notes" at the end of this section.

Figure 4-4 Transition Temperature Approach 
If the RPV support assessment according to Step One fails to confirm that there is adequate fracture resistance, Step Two can be followed. As shown in Figure 4-2, the Step One path can lead to one of two alternative approaches (See Figures 4-3 and 4-4, as follows).

- The more certain assessment would be based on a fracture mechanics analysis aimed at showing an acceptable safety margin between the calculated stress intensity factor, $\mathrm{K}_{\mathrm{l}}$, and the material toughness, $\mathrm{K}_{\mathrm{Ic}}$ (Fig. 4-3). Material properties, including a $\mathrm{K}_{\mathrm{Ic}}$ value applicable to the given material, temperature, and radiation exposure, must be known with some accuracy or must be conservative handbook values. Equivalently, the fracture mechanics evaluation can be based on a maximum credible flaw size (either estimated, known from related destructive evaluation, or determined by nondestructive examination), which must be less than the calculated critical flaw size by at least the same (relative) margin as would be acceptable in the $\mathrm{K}_{\mathrm{r}}-$ to- $_{\mathrm{Ic}}$ comparison.

- $\quad$ Alternatively, the assessment can be based on a transition temperature analysis, wherein it is sufficient to demonstrate that there is an adequate margin between the minimum operating temperature and the NDT temperature for EOL conditions (Fig. 4-4).

The details of the assessment, especially the safety margin resulting from the analysis, should be adequately documented.

Step Three, a more exact reevaluation, can be taken if the Step Two results fail to provide an acceptable margin against support failure. The more exact analysis can include an elastic-plastic approach and a more detailed model. A lower stress level may result and, other things being equal, a larger flaw may be tolerated. The goal is the same as before: to demonstrate that the RPV supports are not vulnerable to failure.

If the Step Three analysis cannot be done or if the results are inconclusive, a Structural Consequence Analysis can be performed (as described in Section 4.5). The Consequence Analysis assumes RPV support failure with the loads shed by the supports transferred to the reactor coolant loop (RCL) piping and supports.

\subsubsection{Evaluation of the Current Conditions}

\subsubsection{Physical Examination of Structural Components}

For brittle fracture to occur in the structural steels used in RPV supports, a significant tensile stress must exist. Accordingly, the structural elements that should be examined with the utmost scrutiny are the ones loaded in tension, such as cantilever beams, brackets, hangers, and bolts.

Physical examination of the RPV supports is essential to the reevaluation. As mentioned previously, the purpose of the examination is to detect visible signs of degradation of the supports, including, but not limited to, rust, corrosion, cracks or permanent deformation of the members. 
Sometimes the reactor cavity dimensions provide insufficient space for personnel to access the part being examined. If so, the examination must be done using remotely manipulated equipment. Inspections should be performed by personnel trained and experienced to be cognizant of the function of the parts, familiar with the plant, and capable of making judgements regarding the importance of any degradation. The inspection report (next Section) should include short résumés (education and experience) of inspection team members.

\subsubsection{Inspection Report}

An accurate reporting program is essential to the structural evaluation, ensuring the correct and efficient assessment of current conditions. An inspection report will be necessary; in many cases it may be the only basis for deciding on maintenance priorities, criteria for replacement, structural capacity, and/or replacement-versus-repair of supports. Consequently, the importance of the reporting system to the success of any RPV support inspection cannot be over-emphasized.

The RPV support inspection report should present a systematic evaluation of the current condition of the supports, as well as observations and predictions of their possible future weaknesses. To accomplish this the following approach is recommended:

(1) Conduct a thorough study of all available historical information on the structure, including design, "as built" drawings, and records of previous inspections.

(2) Plan, organize, and establish a system for recording information on the actual conditions of the supports, including an organized and detailed notebook, standard forms, sketches, and so on.

(3) Evaluate the findings of the inspection team. This task should be delegated to experienced engineers capable of exercising judgement regarding the degree of degradation of the RPV supports. Collectively, the engineers should have sound knowledge of key disciplines, such as structural mechanics, materials, and construction practices.

(4) Provide a narrative summary of the report, including an assessment of the overall condition of the structure, expert opinions on "as is" conditions, and recommendations regarding repair or replacement.

The inspection report should be included in the RPV support evaluation report, and should provide sufficient detail to serve as the basis for decisions regarding further actions to be taken, if any (i.e., that the support is acceptable as is, or that modifications should be considered). 


\subsubsection{Evaluation of the Original Design}

Some older nuclear plants were designed to codes and standards that differ significantly from the current ones. Many of the presently used standards were non-existent at the advent of some original designs; others have changed over time. To make best use of present day techniques, it is necessary that the original design evaluation employ current criteria and knowledge.

Typically, the analysis should be based on the loads developed for the specific type of nuclear steam supply system (NSSS), which can be obtained either from the vendor or by a thermo-hydraulic analysis. The structural components must be capable of carrying the imposed loads. The structural design criteria for the RPV supports are included in the current issue of the Standard Review Plan (SRP) (Ref. 9), augmented by the ASME Code, Sections III (Ref. 18) and XI (Ref. 19), as appropriate. The structural analysis should address the most adverse loading conditions (including seismic), in accordance with the criteria of Regulatory Guides $1.60,1.61$, and 1.122 (References 20,21 and 22, respectively). Dynamic responses should be combined in conformance with the provisions of NUREG-0484, Rev. 1 (Ref. 23).

Original design evaluations should account for known or estimated residual stresses. Because residual stress levels vary with fabrication processes, welding procedures, and other construction details, it is important that such information be included in the analysis and be recorded in the final report. Residual stress calculations should use state-of-the-art techniques, several of which are presently available. Frequently, finite element models are used with required inputs of the thermal history, thermal properties of the material, Poisson's ratio, and details regarding the welding process. A description of a computational model that can be used for weld-induced residual stress is contained in Reference 24. Stress concentrations from discontinuities, holes, and other factors should also be taken into account in establishing the state of stresses.

Having determined the stresses at the critical locations of the support system, the original design can be evaluated. Structural acceptance criteria and allowable stresses can be found in Section 3.8.3, of NUREG-0800 (Ref. 9) and in Subsection NF, Section III, Division 1, of the ASME Code (Ref. 18).

\subsubsection{Establishing the EOL NDT Temperature}

The ductile-to-brittle fracture mode transition temperature (commonly known as the NDT temperature) of steel is one of the essential parameters in brittle fracture analysis. Following the ASME Code, the NDT temperature may be defined as the highest temperature for fracture of a standard drop-weight specimen when tested to ASTM Standard Test Method E 208-87a (Ref. 25). The NDT also can be based on the temperature at which Charpy V-notch specimens absorb a specified amount of energy. To determine the EOL NDT temperature, it is necessary to know the initial, material-dependent NDT and the anticipated shift (increase) as a function of radiation exposure. 


\subsubsection{Strain-Rate Effects}

It is well known that the fracture resistance of steels such as ASTM A 36 is sensitive to the rate of load application (Ref. 26, for example). Since the most adverse RPV support loads may occur during an earthquake or a LOCA, strain rates associated with dynamic loading should be addressed. Equations acceptable for this purpose are available in the current literature (Ref. 26). If the NDT was determined in accordance with Reference 25 or an equivalent procedure, no further adjustment for dynamic effects is necessary.

\subsubsection{Metallurgical Condition of the RPV Supports}

Alloying elements, such as copper, influence the rate of radiation embrittlement. Hence, it is important to know the chemical composi-tion of the steel when in establishing radiation effects on RPV supports. Although quantitative relationships between radiation embrittlement and alloying additions or impurities are still under development, some progress has been reported. An equation to calculate the maximum embrittlement as a function of copper content can be found in Reference 27. Also, a very informative discussion on the subject can be found in Reference 28.

\subsubsection{Radiation-Induced NDT Shift}

Irradiation test results in the form of measured $\triangle \mathrm{NDT}$ as functions of dpa are shown in Figure 3-1. (The graph was taken from reported NRC work; further information on dpa is available in Reference 15). Figure 3-1 can be used in the transition temperature approach to RPV support reevaluation.

\subsubsection{Fracture Analysis of RPV Support Integrity}

If brittle fracture avoidance was not considered in the original design, two options are offered in Step Two, either of which may suffice to ensure that the RPV support system is not vulnerable to brittle fracture. Conversely, if the original design included brittle fracture avoidance considerations based on currently accepted or equivalent criteria, no further action is necessary.

\subsubsection{Fracture Toughness Approach}

As noted in Section 4.1, the reevaluation criteria include provisions from References 18 and 19 applicable to higher operating temperatures $\left(\sim 550^{\circ} \mathrm{F}\right)$ than those for the RPV supports $\left(90-120^{\circ} \mathrm{F}\right)$. However, the Code methodology as applied herein to RPV support analyses is useful, provided that conservative relationships are used.

The fracture toughness approach requires measurement of the material fracture toughness, $\mathrm{K}_{\mathrm{Ic}}$, or determination of the critical flaw size, $\mathrm{a}_{\mathrm{c}}$. The sharp crack stress intensity factor, $\mathrm{K}_{\mathrm{l}}$, must be calculated and should represent the RPV support location of highest tensile stress; the methodology can be based on Article A-3000, Appendix A, Section XI, of the ASME Code (Ref. 19). The assumed reference flaw size may be as specified in Table IWB-3510-1 of Ref. 19 if the RPV support material satisfies the limitations of Appendix G, Article G- 
2000, Ref. 18. The acceptance criteria may be based either on the allowable stress intensity factor or on the postulated flaw size using the above references. In either case, the criteria should comply with the requirements of Article IWB-3000, Ref. 19 . If the material toughness cannot be positively defined, a safety margin should be defined on the basis of $\mathrm{K}_{\mathbb{R}}$ rather than $K_{I c}$ (using $K_{\mathbb{R}}$ as defined in Appendix G, Article G-2000, Ref. 18). In the above method, the temperature ("T" in Article G-2000, Ref. 18) is taken at the location of the most adverse loading conditions. The fracture toughness approach to RPV support evaluation is illustrated by examples in Section 4.7.

\subsubsection{Transition Temperature Approach}

The transition temperature approach is based on the proposition that catastrophic failure by brittle (cleavage) fracture can be avoided by maintaining the RPV support service temperature above the NDT temperature of the steel. When using the transition temperature to evaluate the support integrity, the NDT temperature at EOL should include the irradiationinduced shift. Uncertainties related to NDT determinations demand that a margin of safety be maintained between the LST and the NDT temperature, such as provided in Appendix R, Figure R-1200-1, Ref. 18. Demonstration that the RPV supports are in conformance with this relationship is necessary and sufficient to preclude their failure by brittle fracture.

\subsection{Accurate Analysis}

If RPV support reevaluation by the above method fails to show adequate integrity (fracture resistance), a more accurate analysis, denoted Step Three, may be performed. To demonstrate that the structural integrity of RPV supports is not violated, structural and thermal-hydraulic loads may be recalculated more accurately, which may result in lower stresses. Because of the inverse-square-root relationship between stress and flaw size, a decrease in stress results in a larger critical flaw size. The analysis should comply with the current licensing criteria, design codes, and regulatory requirements.

The fluid thrust forces may be based on a model of the actual NSSS system of the plant, or on the simplified methodology presented in Ref. 29.

The initial NDT temperature of the RPV support material should be evaluated in accordance with the notes pertinent to Fig. 4-2. The radiation-induced $\triangle$ NDT should be estimated from the upper bound correlation curve from Fig. 3-1. Flux profiles used in the irradiation embrittlement estimate should include the zones above and below the active core. The parameter dpa should cover the full neutron energy spectrum, not just $E>1 \mathrm{MeV}$.

The structural analysis should satisfy the following conditions:

- Allowable stresses may be based on one of the following methods: (1) use a value specified in the codes and specifications approved by the NRC, (2) determine an average value from tests of samples taken from the supports, or (3) use the records of the material producer, if available. (Certified Material Test Reports, described in Ref. 18 , may be used in the third method.) 
The analysis should address the simultaneous application of vertical, tangential, and radial loads to supports.

The load combinations that produce the maximum tensile stresses should be included in the analysis.

The analytical model should be developed in sufficient detail to permit quantitative definition of all significant tensile stresses. Specifically, the analysis must include local stresses caused by (1) transfer of loads between support structure elements, (2) load line offsets within the structural members, and (3) structure discontinuities and stress concentrations.

Residual'stresses and thermal effects should be included in the analysis.

The assembly preload of threaded fasteners should be included in the analysis.

The support loading definition should include an estimate of loading frequency (cycles/sec.) for major dynamic loads.

- The scope of the RPV support structure analytical model should include transmission of the vessel support loads from the point of interaction with the reactor vessel to the point(s) where the load transfer to the interfacing concrete structure is complete.

Elastic-plastic properties of the support material may be factored into the analysis, but the pertinent provisions of References 9 and 19 should be satisfied.

\subsection{Structural Consequence Analysis}

If the RPV support analysis is inconclusive because of insufficient information or other reasons, integrity may be assessed by performing a structural consequence analysis. The structural consequence analysis reported by the Lawrence Livermore National Laboratory (LLNL) (Ref. 8) should be useful as guidance for such a task. However, the LLNL approach assumed RPV support failure and focused the analysis on determining the capability of the reactor coolant loop (RCL) piping to transfer the loads shed by the RPV supports to the.remaining reactor coolant system (RCS) supports. Also, LLNL examined the capacity of the RCS components and their supports to resist these loads, and examined the effects of RPV support failure on the RCL system, including the RPV, reactor coolant pump (RCP), steam generator (SG), and safety injection lines. With certain qualifications, the LLNL analysis concluded that the consequences of Trojan RPV support failure would not result in significant safety concern. Ref. 8 may be used as guidance for a similar assessment of RPV supports, provided that the critical comments noted above in Section 3.1 are addressed.

The LLNL evaluation considered two load combinations:

1. Dead load + operating pressure + SSE

2. Dead load + operating temperature + LOCA 
Both load combinations are designated as Level D Service Limits in the ASME Code, Section III, Division 1. The LLNL analysis was performed in accordance with the provisions of Subsection NB, in conjunction with Appendix F, ASME Code (Ref. 18).

The logic for a Structural Consequence Analysis was illustrated in Figure 4-5. To perform an RCL piping analysis in accordance with Fig. 4-5, the following information regarding the piping and associated loads must be obtained:

- Information on piping should include material properties, location of piping supports, and verification of piping design details (such as pipe diameter and wall thickness).

- Static loads should be determined based on dead weight, pressure, and temperature.

In many situations, thermal loads are self-limiting, have no bearing on the analysis, and may be neglected. However, there are cases in which thermal loads result in primary stresses, and those should be included. For example, in a thermal transient, an RPV support connected to another structural element by a bolted flange can induce an increase in stress in the bolts by differential thermal expansion.

Usually, the site seismic design basis, the mathematical model of the NSSS, and the floor response spectra are available for the RPV supports. If not, they must be generated. The guidance for acceptable procedure of seismic analysis is provided in the pertinent sections of NUREG-0800 (Ref. 9).

Some systems qualify for leak-before-break considerations; in such cases, small-break LOCA (SBLOCA) loads apply. Loads from pressure, dead weight of the RPV, thermal gradient (if applicable), LOCA (SBLOCA or LBLOCA), and SSE should be combined in accordance with the provisions of Reference 23.

From the loads identified above, stresses in the RCL piping and RPV displacements (vertical and horizontal) should be computed. Vessel displacement may adversely affect the insertability of control rods or the functionality of safety injection lines, flux monitoring systems (such as thimble tube guide lines) and instrument thimble tubes. Also, excessive RPV displacement may deform the reactor coolant pump (RCP) casing(s) and bind the impeller(s). Tilting of the RCP may disrupt the continuity of flow (coastdown) following a loss of RCP power. Coastdown allows the reactor power to be reduced before flow through the core is reduced, thereby ensuring that localized boiling and departure from nucleate boiling do not occur. To help maintain coastdown, the RCP receives the kinetic energy necessary for coastdown from a flywheel. Tilting of the RCP may cause excessive vibration of the RCP assembly, which could lead to loss of the flywheel. Because the flywheel is massive and rotates at a high speed $(1200 \mathrm{rpm})$ in normal operation, loss of flywheel integrity could generate high-energy missiles. The safety consequences of such scenarios may be significant because of possible damage to the reactor coolant system, the primary containment, or the engineered safety features equipment. 


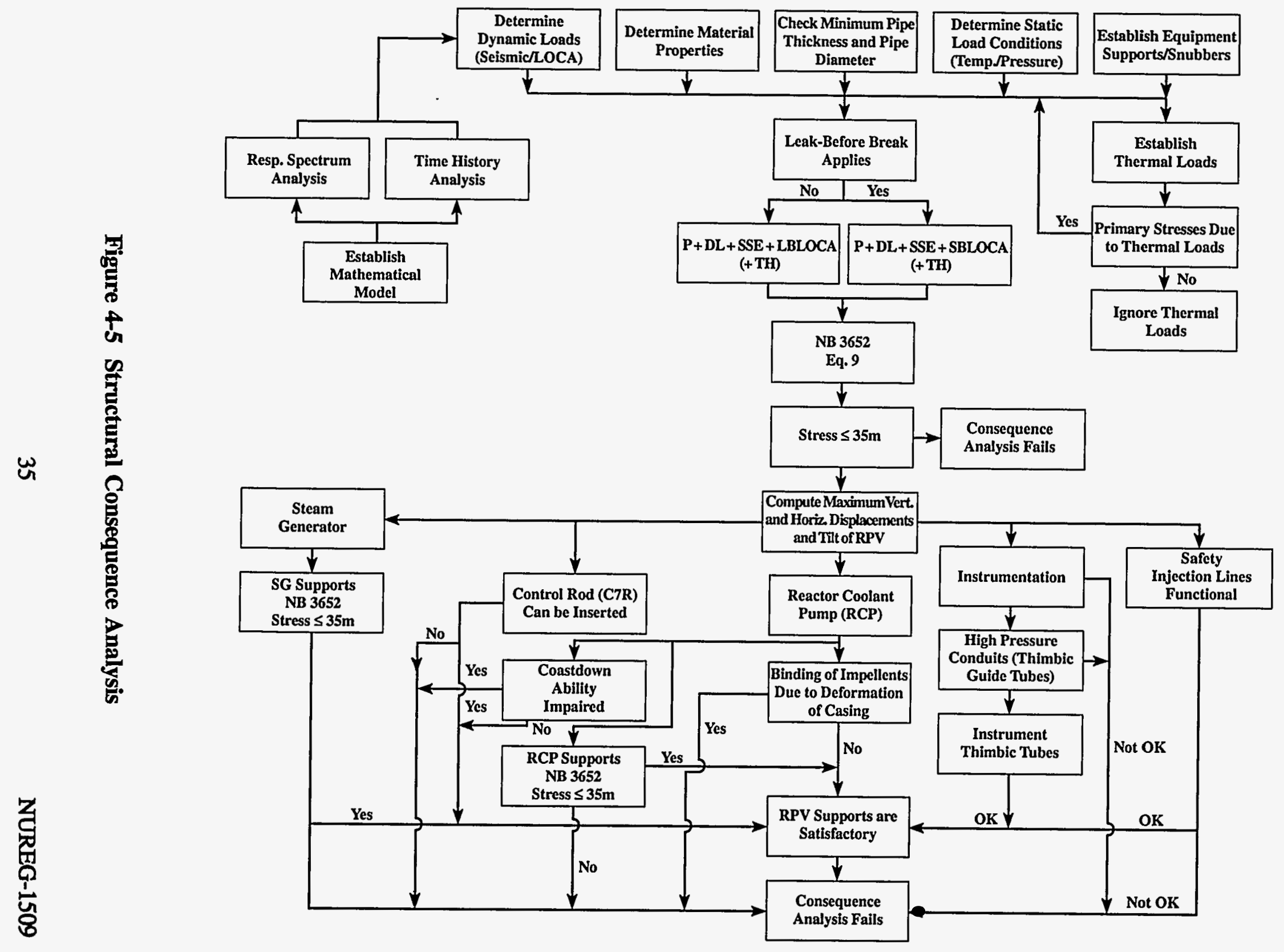


Another potential cause of loss of coastdown from RCP tilting is the fact that tilting of a pump assembly may cause stresses sufficient to induce deformation or failure of the bearings. In either case, malfunction of the bearings could impede or terminate coastdown.

The SG and RCP supports must be evaluated to ensure sufficient margin under the additional loads resulting from support failure.

The scenarios described above do not encompass the entire potential problem associated with integrity of RPV supports and safety of nuclear power plants. Consideration should be given to uncertainty regarding initial transition temperature of component support material, such as steam generator and reactor coolant pump, degradation of material over the life of the plant, aging embrittlement of stainless steel primary coolant loop piping (see Appendix C), degradation of large hydraulic snubbers, and erosion of piping walls, to name a few. The LLNL structural consequence analysis (Ref. 8) did not consider these conditions, but the cumulative effect of these problems could aggravate consequences of RPV support failure significantly.

If the RPV support integrity cannot be ensured by any of the alternatives described in Sections 4.3 through 4.5 , modifications to the supports or to the plant operation should be considered.

\subsection{Fracture Mechanics Evaluation of Pins}

Pins and clevises deserve special attention. Because of their geometry, the predominant stress may not be tension, but shear or a combination of the two. Evaluation of $\mathrm{K}_{\mathrm{Ic}}$ is controversial, and the parameter is not routinely included in design considerations. However, some progress to find a viable and practical solution to this problem has been made (Refs. 30 and 31). Tests performed on oblique cracks showed that the predominant crack extension direction was dictated by the maximum $\mathrm{K}_{\mathrm{I}}$ value, thus reducing the value of $\mathrm{K}_{\mathrm{II}}$. Some investigators, however, obtained Mode II cracks in their experiments, indicating that the that Mode II failure is probable (Ref. 30). L. Banks-Sills expressed an opinion that "The direction of crack growth is governed by properties of the material being tested and the conditions of the crack tip. If there is 'brittle' fracture as occurs with Perspex, a crack in a Mode II field propagates between 60 and $70^{\circ}$ with respect to the parent crack. In elastic materials, this coincides with the direction of maximum tangential stress" (Ref. 31). From this, one may conclude that Mode II fracture behavior is uncertain. Although more work is needed in this area, it is evident that in components loaded in shear, Mode I considerations alone may be insufficient, and the analysis should consider both Mode I and Mode II. 


\subsection{Examples}

\section{EXAMPLE 1}

GIVEN: Beginning of Life (BOL) NDTT $=+39.0^{\circ} \mathrm{F}$ [Table 4-1 for C-MN Steel (A-36)]

Lowest Operating Temp. (LOT) $=100^{\circ} \mathrm{F}$

Thickness of Member $=2.0$ in.

$\Delta \mathrm{NDTT}=80^{\circ} \mathrm{F}$ (from Fig. 3-1)

Calculated Stress $=15.0 \mathrm{ksi}$ (Tension)

Residual Stress $=10.0 \mathrm{ksi}$ (Tension)

Bending Stress $=0$

Use ASME Code

OB,JECTIVE: Find: factor of safety against brittle fracture

1. Calculate $K_{\mathbb{R}}$

From ASME Code Section III, App. G, Article G-2000

$$
\begin{aligned}
& T-R T_{N D T_{\text {BOL }}}=100-(+39)=+61.0^{\circ} \mathrm{F} \\
& T-R T_{N D T_{\text {EOL }}}=100-(+39+80)=-19^{\circ} \mathrm{F}
\end{aligned}
$$

From Fig. G-2210-1

$$
\begin{gathered}
K_{I R}=1.233 \exp \cdot\left[0.0145\left(T-R T_{N D T}+160\right)\right]+26.78 \\
\therefore K_{I R}=1.233 \exp \cdot[0.0145(-19+160)]+26.78=36.3 \mathrm{ksi} \sqrt{\text { in }} .
\end{gathered}
$$

2. Calculate $\mathrm{K}_{\mathrm{I}}$

From ASME Code Section XI, App. A, Article A-3000

$$
\begin{gathered}
K_{I}=\sigma_{m} M_{m} \sqrt{\pi(a / Q)}+\sigma_{b} M_{b} \sqrt{\pi(a / Q)} \quad \text { since } \sigma_{b}=0 \\
K_{I}=\sigma_{m} M_{m} \sqrt{\pi(a / Q)}
\end{gathered}
$$


Total Stress $=15.0+10.0=25.0 \mathrm{ksi}$ (Tension)

Flaw Size $a=t / 4=2.0 / 4=0.5$ in.

(Ref. ASME Code App. G, Article G-2000)

Flaw Size $a=t / 4=2.0 / 4=0.5 \mathrm{in}$.

$$
\begin{aligned}
& l=1.5 t=1.5 \times 2=3.0 \mathrm{in} . \\
& a / l=0.5 / 3.0=0.166 \mathrm{in} .
\end{aligned}
$$

Yield Stress $\left(\sigma_{y}\right)=36.0 \mathrm{ksi}$

Est. $\Delta\left(\sigma_{y}\right)$ Due To Radiation $=\underline{20.0 \mathrm{ksi}}$ $\left(\sigma_{y}\right) I R R$. $56.0 \mathrm{ksi}$

Use ASME Code Sect. XI, App. A, Fig. A-3300-1

$$
\begin{gathered}
\left(\sigma_{m}+\sigma_{b}\right) / \sigma_{y s}=(0+25.0) / 56.0=0.45 \\
a / b=0.166
\end{gathered}
$$

ASME Code Sect. XI, App. A, Fig. A-3300-1 Read Q $=1.19$

Use ASME Code Sect. XI, App. A, Fig. 3300-3

$$
\begin{gathered}
\begin{array}{c}
\text { For alt }=0.25) \quad \text { Read } \\
\text { all }=0.166)
\end{array} \\
M_{m}=1.18 \\
\therefore K_{I}=M_{m} \sigma_{m} \sqrt{\pi a / Q}=1.18(25.0) \sqrt{\pi(0.5 / 1.19)} \\
K_{I}=33.89 \mathrm{ksi} \sqrt{\text { in }} . \\
K_{I R} / K_{I}=36.3 / 33.89=1.07<\sqrt{2} \therefore N G .
\end{gathered}
$$




\section{EXAMPLE 2}

GIVEN: Same as Example 1, plus Bending Stress $=10.0 \mathrm{ksi}$

Membrane + Residual Stresses $=25.0 \mathrm{ksi}($ Ex. 1)

Bending Stresses $=10.0 \mathrm{ksi}$

Total

$35.0 \mathrm{ksi}$

ASME CODE

Fig. A-3300-1:

$$
\begin{aligned}
\left(\sigma_{m}+\sigma_{b}\right) / \sigma_{y}=35.0 / 56.0 & =0.625) & \text { Read } \\
\text { all } & =0.166) & Q=1.13
\end{aligned}
$$

Fig. A-3300-5:

$$
\begin{gathered}
a / t=0.5 / 2.0=0.25) \text { Read } \\
a / l=0.5 / 3.0=0.166) M_{b}=0.79 \\
K_{I}=\sigma_{m} M_{m} \sqrt{\pi(a / Q)}+\sigma_{b} M_{b} \sqrt{\pi(a / Q)} \\
=25.0(1.18) \sqrt{\pi(0.5 / 1.13)}+10(0.79) \sqrt{\pi 0.5 / 1.13)}=44.12 \mathrm{ksi} \sqrt{\text { in. }} \\
K_{I I} / K_{I}=36.3 / 44.12=0.82<\sqrt{2} \mathrm{NG} .
\end{gathered}
$$




\section{EXPLANATORY NOTES FOR FIGURES 4-1 THROUGH 4-3}

(See Figure 4-1)

(1) The safety margin between LST-BOL $\mathrm{NDT}_{\mathrm{N}}$ is established using Figure R-1200-1 of Appendix R to ASME Code, Section XI (Ref. 19).

(See Figure 4-2)

(1) $\underline{\text { LT }}$

The lowest service temperature (LST) is defined as the minimum temperature of the most vulnerable part of the fracture-critical member when design-basis accident loads occur. RPV support temperatures can be established either from measurements or theoretical calculations.

(2) Adjustments

a. Irradiation

The radiation-induced temperature shift should be based on reliable and relevant dosimetry information.

\section{b. Strain-rate}

Consideration for strain-rate effects must be appropriate to the subject material. The loading rate should be estimated and its effect documented.

\section{(3) NDT Evaluation Procedure}

List all support materials and available NDT temperature data. State the authority for material tests (e.g., Subsection NF, ASME Code Section III).

\section{a. Material having minimum specified yield strength of $180 \mathrm{ksi}$ or less}

For materials in new RPV supports, the NDT temperature should be determined in accordance with the provisions of ASTM E-208 (Reference 25). If Charpy V-notch testing is performed it should satisfy the requirements of Subsection NF, "Component Supports," Paragraphs NF 2320 and 2330 of ASME Code, Section III (Ref. 18).

\section{b. Estimated NDT}

For existing RPV supports, in case the NDT temperature cannot be determined experimentally, an estimated NDT temperature can be obtained from Table 4-1. The value of the NDT temperature, used for this purpose, should be the NDT mean plus 1.3 standard deviation. 
Table 4-1 Compilation of NDT Results

$\underline{\text { Material }}$

Cast Steels

A-27, A-216

(heat treated $>1 "$

condition)

A-352

Wrought Steels

all "mild" steels*

all "mild" steels

except A-201

C-Mn*(as-hot rolled) (normalized)

HSLA* (as-hot rolled)

(normalized)

Low Alloy, Non-O\&T

A-302

A-353

A-387

Quenched \& Tempered

A-508 C12

A-514

A-517

A-533B C11

A-537 C12

A-543
NDT

$\underline{\sigma}$

$\underline{\mathrm{NDT}}+1.3 \sigma$

$\underline{\mathrm{NDT}}+2 \sigma$

$-6^{\circ} \mathrm{F}$

35

$12^{\circ} \mathrm{F}$

17

$10^{\circ} \mathrm{F}$

57

$18^{\circ} \mathrm{F}$

69

$\max .-20$

\section{7}

31

67

89

40

28

77

96

22

$-28$

13

18

39

$-5$

48

8

$25^{* *}$

$-50 * *$

$12 * *$

$18 * *$

$41 * *$

$-27^{* *}$

$49 * *$

$-14 * *$

8

28

45

64

$\max .-320$

$65^{* *}$

$\max .40^{\circ} \mathrm{F}$

$\max .-10^{\circ} \mathrm{F}$

$\max .-20^{\circ} \mathrm{F}$

$\max .20^{\circ} \mathrm{F}$

$\max .-60^{\circ} \mathrm{F}$

$\max .-60^{\circ} \mathrm{F}$

* See Table 4-2 for ASTM specs included in this category.

** HSLA steels, "high-strength" means yield strength $>40$ ksi. For further discussion on HSLA steels, see NUREG-0705, "Identification of New Unresolved Safety Issues Relating to Nuclear Power Plant Stations" (Ref. 3).

(Source: Table 4.4 of NUREG/CR-3009 (Ref. 32) 
Table 4-2 Classification of Wrought Grades into Groups

Plain Carbon:

Carbon-Manganese:

High-strength low alloy:

Low alloy (not quenched \& tempered):

Quenched \& tempered:
A-7, A-53, A-106, A-201, A-212, A-283, A-284, A-285, A-306, A-307, A-501, A-515

A-36, A-105, A-516, A-537

A-441, A-572, A-588, A-618

A-302, A-322, A-353, A-387

A-193, A-194, A-325, A-354, A-461, A-490

A-508, A-514, A-517, A-533, A-537, A-540

A-543, A-563, A-574

(Source: Table 3.2 of NUREG/CR-3009 (Ref. 32)

\section{c. Bolting Materials}

Code bolting materials shall meet the fracture toughness requirements of Subsection NC, Paragraph NC-2332.3, and Appendix G, Article G-4000, "Bolting," ASME Code, Section III (Ref. 18). Those materials not specified in the Code must be analyzed in accordance with, and meet the criteria of notes $3 a$ or $3 b$ above.

\section{d. Steels having minimum specified yield strength greater than $180 \mathrm{ksi}$}

Resistance to fracture under tensile loads for materials with minimum yield strength greater than $180 \mathrm{ksi}$ is considered unreliable, unless it can be justified by LEFM analysis. If such a justification cannot be provided, high-strength materials should be assumed to have inadequate fracture toughness, and the fracture mechanics or transition temperature options (Figures 4-3 and 4-4) should be deemed inapplicable. Structural adequacy of RPV supports should be demonstrated by means of the structural consequence analysis (Figure 4-5).

(4) The "Criteria" are those contained in Article IWB-3000 of ASME Code, Section XI (Ref. 19).

(See Figure 4-3)

(1) a. Estimated fracture toughness by conversion of an hyperbolic tangent function fitted to Charpy data is not acceptable.

b. Confirmation of correlations between CVN and $\mathrm{K}_{\mathrm{Ic}}$ data is required.

c. The proper determination of fracture toughness curves is based on multiple $\mathrm{K}_{\mathrm{Ic}}$ tests at each of several temperatures for each class of material. 
d. Minimum fracture toughness values contained in Table 4-3 may be used if sufficient evidence is available to demonstrate that the material used in the RPV supports is the same as that listed in Group III in Table 4.6 of NUREG/CR-3009 (Ref. 32).

e. Where applicable, fracture toughness $\left(\mathrm{K}_{\mathrm{Ic}}\right.$ and/or $\left.\mathrm{K}_{\mathrm{L}}\right)$ can be obtained from the information contained in Appendix A, Figure A-4200-1, of ASME Code, Section XI (Ref. 19).

(2) a. Acceptance criteria for the flaw size can be based on Subarticle IWB-3611, of ASME Code, Section XI (Ref. 19).

b. The analysis of flaw indications should be in accordance with the provisions of Appendix A of ASME Code, Section XI (Ref. 19).

(3) a. The maximum stress intensity factor, $K_{\mathrm{l}}$, must be related to the flaw size $a_{\mathrm{f}}$, as defined in Subarticle IWB-3600 of ASME Code, Section XI (Ref. 19).

b. If the supports are subjected to combined loading, which necessitates consideration of Mode II, an appropriate fracture toughness shall be established based on the present state of the art.

c. If applicable, the reference temperature for the nil ductility transition $\left(\mathbf{R T}_{\mathrm{NDT}}\right)$ may be used in conjunction with the provisions of Appendix G, Article G-2000, of ASME Code, Section III, Division 1 (Ref. 18).

d. Calculate $\mathrm{K}_{\mathrm{I}}$ using Eq. 1 in Appendix A, Article A-3000, of ASME Code, Section XI (Ref. 19).

(4) Safety factors shall satisfy the criteria of Article IWB-3600 of ASME Code, Section XI (Ref. 19).

(5) a. The analysis may be performed using elastic-plastic properties of the material. The load combinations, allowable stresses, and design criteria for linear supports (consisting of shapes, beams, and columns) should conform with the provisions of Section 3.8.3, "Concrete and Steel Internal Structures of Steel and or Concrete Containments," and for non-linear supports with Section 3.9.3, "ASME Code Class 1, 2, and 3 Components, Component Supports, and Core Support Structures" of NUREG-0800 (Ref. 9), respectively.

b. The thermo-hydraulic loads may be based on ANSI/ANS 58.2, Appendix B (Ref. 29). 
Table 4-3 Minimum Fracture Toughness Data at $75^{\circ} \mathrm{F}$

\begin{tabular}{lr} 
& ksi i \\
\cline { 2 - 2 } Plain Carbon & 32 \\
C/Mn & 36 \\
HSLA & 36 \\
& \\
Low Alloy (non Quenched and Tempered) & 30 \\
A-302 & 150 \\
A-353 & 65 \\
A-387 & \\
& \\
Quenched and Tempered & 35 \\
A-508 & 65 \\
A-514/A-517 & 35 \\
A-533 & 55 \\
A-537 & 95 \\
A-543 &
\end{tabular}

Other

A-461, Gr. $630 \quad 100$

(Source: Table 4.5 of NUREG/CR-3009 (Ref. 32) 


\section{SUMMARY OF THE COST/BENEFIT ANALYSIS}

The cost/benefit analysis conducted in support of GSI-15 consisted of three steps. First, the core damage frequency and risk associated with RPV support failures were estimated; second, detailed cost estimates of potential corrective measures for damaged RPV supports were derived; and third, cost/benefit ratios for implementation of any of the five identified corrective measures were calculated. Details and results of the analysis presented in Appendix A to this report.

\subsection{Benefit Evaluation}

The benefit is defined as the reduction in risk obtained by fixing the neutron-embrittled RPV supports. To estimate the risk, standard methodologies were used to generate event trees based on two different scenarios that could potentially cause the supports to fail. The first scenario is a safe shutdown earthquake (SSE) as an initiating event with the subsequent failure of the RPV supports. The second scenario involves a small-break loss-of-coolant accident (SBLOCA). Event trees were generated by commonly-used methods. Initiating event frequencies were adjusted to fit the scenario of brittle failure of the supports. In the case of the SSE event tree, the probability of the earthquake was reduced to correspond to the peak ground acceleration and RPV support stress level at which brittle fracture could be expected to occur. In the case of the SBLOCA, the frequency used was taken from the Sequoyah 1 PRA and reduced by a factor of 2 because it was assumed that not all break locations would produce significant loads on the RPV supports. It was also assumed that, given the initiating event, the probability of support failure would be 0.5 . The event trees were quantified, and event sequences that resulted in core damage were grouped into one of seven categories. Each sequence was assigned to the offsite release category that best modeled its outcome. The offsite release categories were taken from the WASH 1400 reactor safety report (Ref. 33), in which various degrees of release from the reactor containment are classified. For the best estimate base case considered in the analysis, the total contribution to core damage frequency resulting from RPV support failure was calculated to be $8.8 \times 10^{-5}$.

\subsection{Cost Analysis}

The following five alternatives were considered as corrective measures to preclude RPV support failure in the event of an SSE or SBLOCA:

(1) shielding the RPV supports from neutron radiation

(2) increasing the RPV support operating temperature above the NDT temperature

(3) replacing the RPV supports

(4) heating the RPV supports sufficiently to anneal out any embrittlement 
(5) strengthening or adding additional RPV supports.

The cost estimates for each of the five options were developed using the guidelines of NUREG/CR-3568 (Ref. 34), NUREG/CR-4627, Rev. 1 (Ref. 35) and the FORECAST 2.1 computer code (Ref. 36), which incorporates cost evaluation information. Cost estimation involved evaluating each proposed modification, identifying equipment and materials necessary to make the proposed modifications, and assessing the work area in which the proposed modifications would be made.

The variation in estimated costs among the alternatives was so large as to render them useless. The maximum cost per plant was $\$ 89,000,000$ (alternative 3 , replacing existing supports), and the minimum cost per plant was $\$ 920,000$ (alternative 2 , increasing the operating temperature of the supports).

\subsection{Cost/Benefit Analysis}

Results of the cost/benefit analysis were calculated using the dollar-to-person-rem averted (DPR) ratio. The DPR ratio was calculated as the cost of the modification divided by the offsite person-rem averted had the modification been made. In calculating the cost, the averted onsite cost (AOSC) is subtracted from the modification cost. For the case where the occupational exposure was considered, such exposure is subtracted from the averted offsite dose. In some cases, the occupational exposure from making the modification exceeded the averted offsite dose, resulting in no net benefit. Cost/benefit calculations were made for 10-, 20-, 40-, and 60-year remaining life spans, the remaining life span is the time left to operate the plant after the supports are assumed to be embrittled. Results of the cost/benefit analysis (presented in Appendix A) were calculated for three cost categories: (1) without either AOSC or replacement power, (2) with AOSC but without replacement power, and (3) with both AOSC and replacement power.

The results of the benefit analysis indicated a per-plant offsite dose risk of 2.9 personrem/year, with a calculated core damage frequency of $8.8 \times 10^{-5} / \mathrm{yr}$. The risk value includes all the risk associated with support failure after embrittlement occurs. It was assumed that any of the proposed options would remove 100 percent of the risk associated with failure of an embrittled support. This means that after the modification, the risk associated with support failure was assumed to be zero.

A number of cost/benefit calculations were made using combinations of assumptions that produced a range of values to fit the various scenarios. The calculated cost/benefit ratios ranged from \$54 per person-rem (increasing the operating temperature of the supports, without replacement power, and considering a 60 year life span after embrittlement) to $\$ 3,300,000$ per person-rem (replacing supports, with averted onsite costs, with replacement power, without occupational exposure, and considering a 10-year life span after embrittlement).

Sensitivity studies were conducted considering $10,20,40$, and 60 years of operation after embrittlement of the supports. Cost/benefit ratios were calculated both with and without 
consideration of occupational doses. Several supplemental cases were evaluated with more conservative estimates of failure probability to judge the sensitivity of the risk calculation results to the event probabilities in the event trees. Seven cases were evaluated:

(1) Increase the frequency of an SSE by a factor of 10. For most plants, this is equivalent to assuming peak ground acceleration of $0.5 \mathrm{~g}$ earthquake and may result in RPV support failure.

(2) Increase offsite dose rates by a factor of 100 to simulate a plant located in an area of high population density.

(3) Increase the probabilities of RPV support failure and LBLOCA to 1 to show the maximum uncertainty in the RPV support failure mechanisms.

(4) Increase the failure probabilities of the RPV supports and the RPS to 1 and decrease the probability of a LBLOCA to 0 .

(5) Increase the failure probabilities of ECCS and chemical shutdown system (CSDS) to 1 to simulate failure of these safety systems.

(6) Increase the probabilities of LBLOCA and ECCS failure to 1 to simulate the pressure vessel displacing sufficiently (following RPV support failure) to cause the ECCS injection lines to break or become inoperable.

(7) Set the failure probabilities of the RPV supports, RPS, CSDS, and ECCS and the incidence of LBLOCA to 1, which is a worst-case model of complete failure of the entire reactor protection system with the exception of the containment. This scenario involves prior embrittlement of the RPV supports and loss of primary piping support to the RPV. Following the initiating event, the subsequent shifting of the RPV results in failure of all core protection systems.

Table 5-1 shows the results for each case considered for 1, 10, 20, 40 and 60 years. From the sensitivity analysis, the extreme values of the cost/benefit ratio were obtained. Specifically, the core melt frequencies per year were obtained by modifying the appropriate events in the sequence event trees (not shown) for the two initiating events, SSE and SBLOCA. The Base Case shows the results of the original analysis without modifications of the sensitivity analysis parameters. To obtain risk per year for other cases, the probabilities for each sequence (PWR 7, PWR 3, and PWR 1) were multiplied by the corresponding consequence factors taken from NUREG/CR-2800 (Ref. 37). The result was the risk per year in person-rem. The risks for 10,20, 40 , and 60 years simply represent the products of the risk for one year times the number of years in question. 
Table 5-1 Sensitivity Analysis Results

\begin{tabular}{|c|c|c|c|c|c|c|}
\hline CASE & $\begin{array}{l}\text { CORE MEIT } \\
\text { FREQUENCY } \\
\text { (per Year) }\end{array}$ & $\begin{array}{c}\text { RISK } \\
\text { (per year) } \\
\text { [person-rem] }\end{array}$ & $\begin{array}{l}\text { RISK } \\
\text { (10 years) } \\
\text { [person-rem] }\end{array}$ & $\begin{array}{c}\text { RISK } \\
(20 \text { years }) \\
\text { [person-rem] }\end{array}$ & $\begin{array}{c}\text { RISK } \\
(40 \text { years) } \\
{[\text { person-rem] }}\end{array}$ & $\begin{array}{l}\text { RISK } \\
(60 \text { years) } \\
\text { [person-rem] }\end{array}$ \\
\hline 1 & $6.5 \times 10^{-4}$ & 21 & 210 & 420 & 840 & 1,300 \\
\hline 2 & $8.8 \times 10^{-5}$ & 290 & 2,900 & 5,800 & 12,000 & 17,000 \\
\hline 3 & $1.8 \times 10^{-4}$ & 10 & 100 & 200 & 400 & 600 \\
\hline 4 & $3.5 \times 10^{-4}$ & 2.7 & 27 & 54 & 110 & 160 \\
\hline 5 & $6.6 \times 10^{-4}$ & 26 & 260 & 520 & 1,000 & 1,600 \\
\hline 6 & $8.8 \times 10^{-4}$ & 49 & 490 & 980 & 2,000 & 2,900 \\
\hline 7 & $1.8 \times 10^{-3}$ & 98 & 980 & 2,000 & 3,900 & 5,900 \\
\hline Base & $8.8 \times 10^{-5}$ & 2.9 & 29 & 58 & 120 & 170 \\
\hline
\end{tabular}

From Table 5-1, the minimum benefit was Case 4, and the risk reduction was 27 person-rem for a period of 10 years. The maximum benefit occurred in Case 2, with 17,400 person-rem for a period of 60 years. From the results of the sensitivity analyses and the corresponding costs, four extreme cases of cost/benefit were calculated:

(1) Maximum cost/minimum benefit $=\$ 3,300,000 /$ person-rem

(2) Minimum cost/maximum benefit $=\$ 5,120 /$ person-rem

(3) Minimum cost/minimum benefit $=\$ 34,000 /$ person-rem

(4) Minimum cost $/$ maximum benefit $=\$ 54 /$ person-rem

The above results illustrate the large variability of the results. They also indicate that all except Case 4 exceeded $\$ 1,000$ /person-rem, the accepted threshold for taking regulatory action. The minimum cost/maximum benefit of $\$ 54 /$ person-rem (Case 4) resulted from option 2 (increasing the operating temperature of the RPV supports above the new, embrittled NDT temperature), and the cost, without replacement power, was $\$ 920,000$. The corresponding benefit (the risk reduction) was 17,000 person-rem. Because the majority of the calculated cost/benefit ratios were well above the $\$ 1,000$ /person-rem criterion, there was little justification for taking regulatory actions. Moreover, the range of cost/benefit ratios stems from uncertainty in the values used in the analysis and, being uncertain, were of little use to the staff in reaching a regulatory position.

In the process of reviewing the proposed GSI-15 resolution, NRC management questioned the probabalistic risk assessment supporting the cost/benefit analysis. Assurance that RPV support failure would pose no risk to the public was requested. INEL responded by providing (1) a bounding risk analysis that demonstrated that evaluation of the supports is not cost effective, and (2) review of structural analyses that showed how loads would be carried in the event of support failure (Ref. 38). The NRC staff concluded that the supplemental analyses strengthened the position that it would not be cost beneficial to take action to mitigate the effects of radiation on RPV supports. 


\section{DISCUSSION OF THE GSI-15 TECHNICAL FINDINGS}

The ORNL report (Ref. 4), citing a thermal-to-fast-neutron flux ratio of about 50-to-1, was sufficient motivation for some theoreticians to propose mechanisms for submicroscopic damage by low-energy neutron radiation at low temperature in steel. Using those models, the NRC staff developed a method for evaluating the effects of low energy neutron damage in steel by a modified dpa parameter (Ref. 6). To expand the available database, the NRC staff requested that ORNL calculate the neutron energy spectra at additional surveillance locations in the HFIR. The resulting thermal-to-fast-neutron flux ratios were on the order of 3-to-1 to 7-to-1. That finding (1) cast doubt on the roughly 10 times greater ratio reported in Ref. 4, (2) suggested that the low-energy neutron damage theory was not the answer to the HFIR embrittlement, and (3) set in motion a dosimetry program with the goal of determining the radiation conditions in HFIR by the best experimental and calculational means available.

The results of the dosimetry program were the basis for the conclusion that the accelerated embrittlement of the HFIR surveillance samples could be attributed to long-term, lowtemperature gamma radiation (Ref. 15). Also, the NRC staff found that the HFIR $\gamma$ flux was about 100 to 3000 times higher than the measured $\gamma$ flux in the cavity of an operating reactor. The interpretation of these findings provided the following analysis. The HFIR vessel had an annulus between the Be reflector and the vessel inside surface (where the surveillance capsules were located) of almost two feet. The annulus was filled with water that attenuated the neutrons reducing the flux of those with $\mathrm{E}>1 \mathrm{MeV}$ by orders of magnitude. However, the $\gamma$ flux reduction was much less. Although the $\gamma$ flux was not unusually high, it was sufficient to create submicroscopic damage in the steel. In fact, had the $\gamma$ flux been very high, it would have heated the steel annihilating some of the damage. Likewise, the relatively low neutron flux may have kept that type of radiation from annealing some of the $\gamma$-radiation damage. The temperature of the steel was kept relatively low, well below $200^{\circ} \mathrm{F}$, ensuring that much of the damage from $\gamma$ and low-energy neutrons would be retained. Because nuclear reactor pressure vessels operate at about $550^{\circ} \mathrm{F}$, the diffusivity in the steel is so much greater than at the low temperatures of the HFIR or the RPV supports that the relatively short-range crystal lattice damage from $\gamma$ radiation is annealed in months, if not in weeks, even with a flux of the same order of magnitude as in the HFIR.

From these arguments, we see that the radiation environment in the HFIR is unique to that reactor, and the embrittlement observed in the surveillance specimens can be explained on the basis of the radiation details. In addition, when plotted against a dpa parameter for all radiation (neutrons of all energies and the $\gamma$ ), the HFIR data fell on the trend band established with other data. Thus the uniqueness of the HFIR surveillance data was refuted. Moreover, those data are not relevant to RPV support embrittlement in operating LWRs. In an operating LWR, the vessel supports are shielded from $\gamma$ radiation by the vessel itself. The steel thickness of 6 to 10 inches is sufficient to reduce the $\gamma$ flux by two, three, or four powers of ten. For this reason, no significant $\gamma$ radiation embrittlement is expected in RPV supports; however, embrittlement should be predicted on the basis of the complete dpa 
parameter, because there may be a significant additional contribution from low-energy neutrons.

In this regard, the ASTM Standard Guide for RPV supports, E 1035 (in the ASTM Book of Standards), addresses radiation considerations in the following manner. The designer and owner/operator are cautioned to consider the potential for radiation embrittlement. However, the Guide suggests that if the fluence of neutrons of energy greater than $1 \mathrm{MeV}$ is no more than $10^{17} \mathrm{nvt}$, there is no need for further consideration. From the findings in the work aimed at resolution of GSI-15, it is clear that fast-neutron (E $>1 \mathrm{MeV}$ ) fluence may not be sufficient for accurate predictions. Although neglecting all radiation but fast neutrons is probably acceptable for a fission spectrum or something close to it, other particles can do damage and, if present in sufficient numbers, they should be counted, especially at low temperature.

The work that led to NUREG/CR-5320 (Ref. 4) included a survey of LWR vessel supports using the FSAR library located at the Nuclear Operations Analysis Center at ORNL. The information from the ORNL survey was supplemented by two other studies (Refs. 32 and 39). In many instances, the data from all sources were too sketchy to be definitive. Based on the above surveys, at least in some of the older reactors, (1) neither the exact chemical composition nor the mechanical properties of the RPV supports is known, (2) neither their initial nor shifted NDT temperatures could be found in documents available to the NRC. RPV supports have been constructed of steels such as ASTM A 36, exhibiting considerable variability in (unirradiated) NDT. Absent factual determinations, margins between lowest operating temperatures and specific NDT temperatures are not known and may be less than is recommended in the ASME Code, Section III, Appendix R, allowing little, if any, room for radiation-induced increase. Should such uncertainties be sufficient motivation to perform an engineering reassessment of the RPV support integrity, the methods reported in this paper should provide adequate guidance. 


\section{CONCLUSIONS}

On the basis of the findings summarized in Section 6, the NRC staff reached the following conclusions:

(1) The specimens that were incorporated in the surveillance program at the HFIR exhibited more radiation-induced embrittlement than would be predicted from preexisting trend curves.

(2) At the start of the program, a limited review of RPV supports in operating plants was performed by ORNL but the available information was insufficient for the determination of the initial NDT, the radiation-induced $\triangle \mathrm{NDT}$ or the operating margin (the lowest operating temperature minus NDT).

(3) Specimens cut from the decommissioned Shippingport neutron shield tank exhibited embrittlement $(\triangle N D T)$ commensurate with pre-existing trend curves even though the steel and the irradiation conditions (in terms of the neutron spectrum) were similar to those at HFIR.

(4) Specimens of the same steel used in the construction of the HFIR reactor vessel (archival material), when tested in other facilities, did not confirm the excess embrittlement found in the surveillance specimens.

(5) In response to the initial report that the HFIR neutron energy spectrum had about 50 times more low energy (thermal) than high-energy (fast) neutron flux, a model was developed to account for the complete neutron energy spectrum by modifying the dpa parameter.

(6) A comprehensive dosimetry program, designed to provide data necessary to confirm the low-energy neutron damage model (above), suggested that the excess embrittlement of the HFIR specimens could be attributed to long-term, low-temperature gamma radiation.

(7) Conclusions derived from the comprehensive dosimetry program included the following:

a. At the location in HFIR where $\gamma$ flux calculations were confirmed by measurements, the $\gamma$ dpa was five times higher than the neutron dpa.

b. Discrepancies in neutron flux values from dosimeters irradiated in the HFIR were the result of photofission and photoneutron reactions triggered by the $\gamma$ radiation. 
c. Fast-threshold fission dosimeters and $\mathrm{Be}$ (with its high scattering cross-section) exhibit photo-induced reactions, making them good $\gamma$ dose monitors in some radiation fields.

d. Neutron flux gradients across the surveillance capsules in HFIR were not consistent from one to another.

e. Locating stainless steel fast-neutron dosimeters in Charpy specimen V-notches resulted in adequate flux measurements.

f. Simultaneous adjustment of the neutron and $\gamma$ fluxes was feasible.

(8) Experimental results showed that embrittlement of the HFIR specimens was not excessive when exposure was based on dpa values that included gamma radiation.

(9) The above finding led to the tentative conclusion that the deviation reported in the HFIR surveillance data probably resulted from the combination of a long-time exposure at relatively low temperatures to a radiation field with a very low density of fast neutrons and a much larger density of gammas.

(10) Because the HFIR $\gamma$ flux is much greater than that in an operating power LWR cavity, the HFIR surveillance data do not apply to RPV support steel embrittlement.

(11) A detailed engineering approach for assessing the structural integrity of RPV supports was developed.

(12) A consequence analysis, based on the Trojan plant configuration (believed to be the most vulnerable) showed that RPV support failure could be tolerated but the influence of degradation in other, related, components was not addressed.

(13) Based on a detailed cost/benefit analysis, although the resulting range of ratios was extremely variable, a bounding risk analysis demonstrated that neither support evaluation nor regulatory action would be cost beneficial. 


\section{REFERENCES}

1. ORNL/TM-10444, "Evaluation of HFIR Pressure Vessel Integrity Considering Radiation Embrittlement," Oak Ridge National Laboratory, 1988.

2. Memorandum from Warren Minners (NRC) to Eric S. Beckjord (NRC), dated January $16,1990$.

3. NUREG-0705, "Identification of New Unresolved Safety Issues Relating to Nuclear Power Plant Stations," U.S. Nuclear Regulatory Commission, June 1981.

4. NUREG/CR-5320, "Impact of Irradiation Embrittlement on Integrity of Pressure Vessel Supports for Two PWR Plants," Oak Ridge National Laboratory, January 1989.

5. NUREG/CR-5556, "Review of Current Literature Related to Generic Safety Issue 15," Idaho National Engineering Laboratory, EG\&G Idaho, Inc., July 1990.

6. Craig A. Hrabal, "Modified Damage Parameters Applied to a Typical Light-Water Reactor's Pressure Vessel Supports," Presented at the 7th ASTM-Euratom Symposium on Reactor Dosimetry, Strasbourg, France, August 27-29, 1990.

7. M. L. Hamilton and A. L. Heinesch, "Tensile Properties of Neutron Irradiated A 212B Pressure Vessel Material," ASTM 14th International Symposium on Effects of Radiation on Materials, Andover, MA, June 27-29, 1988.

8. NUREG/CR-5644, "Consequence Evaluation of Radiation Embrittlement of Trojan Reactor Pressure Vessel Supports," Lawrence Livermore National Laboratory, October 1990.

9. NUREG-0800, "Standard Review Plan for the Review of Safety Analysis Reports for Nuclear Power Plants, " LWR Edition, U.S. Nuclear Regulatory Commission, June 1987.

10. NUREG/CR-5748, "Radiation Embrittlement of the Neutron Shield Tank from the Shippingport Reactor," Argonne National Laboratory, October 1991.

11. NUREG/CR-6206, "Transport Calculations of Radiation Exposure to Vessel Support Structures in the Trojan Reactor," Oak Ridge National Laboratory, July 1994.

12. Met. \& Mat'ls. Trans., V. 25A, April 1994, p. $763 \mathrm{ff}$.

13. L. R. Greenwood and R. K. Smither, "Specter: Neutron Damage Calculations for Material Irradiations," ANL/FPP/TM-197, 1979. 
14. NUREG/CR-3320-Volume 5, "Simulated Void-Box-Capsule Charpy Impact Test Results," Fracture Control Corporation, for the U.S. NRC and the Electric Power Research Institute, Washington, D.C., August 1986.

15. NUREG/CR-6117, "Neutron Spectra at Different High Flux Isotope Reactor (HFIR) Pressure Vessel Surveillance Locations," Oak Ridge National Laboratory, December 1993.

16. S. Q. King and D. M. Gilliam, "Characterization of the Gamma Field in the B\&W Owners Group Cavity Dosimetry Benchmark Experiment," Reactor Dosimetry, ASTM STP 1228, Harry Ferrar IV, E. Parvin Lippincott, and John G. Williams, Eds., American Society for Testing and Materials, Philadelphia, Pennsylvania, 1994.

17. Letter from S. L. Anderson, Westinghouse Electric Corp., to R. E. Johnson, U.S. Nuclear Regulatory Commission, May 23, 1994.

18. ASME Boiler Pressure and Vessel Code, Section III, Division 1, American Society of Mechanical Engineers, New York, New York, 1989.

19. ASME Boiler and Pressure Vessel Code, Section XI, "Rules for Inservice Inspection of Nuclear Power Plant Components," American Society of Mechanical Engineers, New York, New York, 1989.

20. Regulatory Guide 1.60, "Design Response Spectra for Seismic Design of Nuclear Power Plants," Rev. 1, U.S. Nuclear Regulatory Commission, 1973.

21. Regulatory Guide 1.61, "Damping Values for Seismic Design of Nuclear Power Plants," U.S. Nuclear Regulatory Commission, 1973.

22. Regulatory Guide 1.122, "Development of Floor Design Response Spectra for Seismic Design of Floor-Supported Equipment or Components, " U.S. Nuclear Regulatory Commission, 1978.

23. NUREG-0484, Rev. 1, "Methodology for Combining Dynamic Responses, " U.S. Nuclear Regulatory Commission, May 1980.

24. E. Rybicki and R. B. Stonesifer, "Computation of Residual Stresses Due to Multipass Welds in Piping Systems," Journal of Pressure Vessel Technology, Vol. 101, pp. 149-154, May 1978.

25. ASTM E 208, "Standard Test Method for Conducting Drop-Weight Test to Determine Nil-Ductility Transition Temperature of Ferritic Steels," American Society for Testing and Materials, Philadelphia, PA 19103.

26. J. M. Barsom and S. T. Rolfe, "Fracture and Fatigue Control in Structures Application of Fracture Mechanics," Second Edition, Prentice-Hall, Inc., 1987. 
27. R. J. McElroy, T. J. Williams, F. M. D. Boydon and B. Hamsworth, "LowTemperature Embrittlement of LWR RPV Support Structures," OECD/NEA Workshop on Safety Assessment of RPVs, Espoo, Finland, October 8-9, 1990.

28. J. R. Hawthorne, "Temperature Dependence of Copper Influence on Radiation Embrittlement Sensitivity of Reactor Vessel Steels," American Nuclear Society (ANS), Transactions, Vol. 15, No. 2, 1972.

29. American National Standard, ANSI/ANS 58.2, "An Acceptable Simplified Method for Calculation of Fluid Thrust Forces," Appendix B, 1988.

30. Buzzard, R. J. Gross and J. E. Srawley, "Mode II Fatigue Crack Growth Specimen Development, " Fracture Mechanics: Seventeenth Symposium, ASTM STP 905, p. 239-345, American Society of Testing and Materials, Philadelphia, PA, 1986.

31. Leslie Banks-Sills and Mircea Arcan, "A Compact Mode II Fracture Specimen," Fracture Mechanics: Seventeenth Symposium, ASTM STP 905, American Society of Testing and Materials, Philadelphia, PA, 1986.

32. NUREG/CR-3009, "Fracture Toughness of PWR Component Supports, " Sandia National Laboratory, February 1983.

33. WASH-1400,"Reactor Safety Study," U.S. Nuclear Regulatory Commission, Washington, DC, 1975.

34. NUREG/CR-3568, "A Handbook for Value-Impact Assessment," Pacific Northwest Laboratory, PNL-4646, December 1983.

35. NUREG/CR-4627, "Generic Cost Estimates," Revision 1, February 1989.

36. B. Lopez and F. W. Sciacca, "FORECAST," 2.1 User Manual, Science and Engineering Associates, Inc., SEA Report No. 89-461-04-A:1, April 1990.

37. NUREG/CR-2800, "Guideline for Nuclear Power Plant Safety Issue Prioritization Information Development," Pacific Northwest Laboratory, 1983.

38. Letter from N. R. Anderson, Idaho National Engineering Laboratory, to R. E. Johnson, U. S. Nuclear Regulatory Commission, May 1, 1995, transmitting "Supplement to Technical Report, EGG-SSRE-9458, Cost/Benefit Analysis of GSI-15: Radiation Effects on Reactor Vessel Supports," April, 1995.

39. NUREG/CR-4731, "Reactor Pressure Vessel Supports for Pressurized-Water Reactors and Boiling-Water Reactors: Residual Life Assessment of Major Light Water Reactor Components-Overview, " Vol. 1, June 1987. 

Appendix A 
to 


\section{COST/BENEFIT ANALYSIS OF GSI-15: RADIATION EFFECTS ON REACTOR VESSEL SUPPORTS}

Final Report

R. E. Gregg

C. L. Smith

R. W. Garner

June 1994

EG\&G Idaho, Inc. Idaho Falls, Idaho 83415

Prepared for the

office of Nuclear Regulatory Research

U.S. Nuclear Regulatory Commission Washington, D.C. 20555

Under DOE Contract No. DE-AC07-76ID01570

FIN No. A1296 


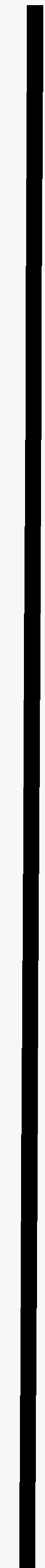




\begin{abstract}
This report provides a cost/benefit (value/impact) analysis for Generic Safety Issue 15 (GSI-15). It assesses the core damage frequency and the risk associated with neutron embrittlement of the reactor pressure vessel supports (RPVSs). Five options for the resolution of GSI-15 are also evaluated. It then calculates the cost/benefit ratio that would result from implementation of any of the proposed options.
\end{abstract}




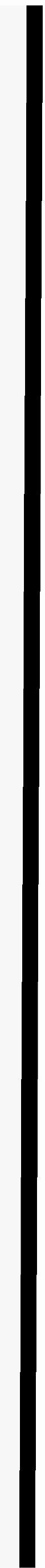




\section{SUMMARY}

Generic Safety Issue 15 (GSI-15) is concerned with neutron irradiation of the reactor pressure vessel supports (RPVSs). Neutron irradiation of structural materials causes embrittlement that may increase the probability of material failure due to a propagation of pre-existing flaws. The potential for neutron embrittlement of the RPVSs could be greater than was formerly anticipated. This report estimates the core damage frequency and the risk associated with RPVS failure, the cost involved in implementing any of five proposed resolutions, and the cost/benefit ratio that would be realized by implementation of each of the alternatives.

The five options proposed as resolutions for GSI-15 include: shielding the RPVSs from neutron irradiation, increasing the RPVS's operating temperature above the NDTT, replacing the RPVSs, heating the RPVSs sufficiently to anneal out any embrittlement, and strengthening or adding additional RPVSs.

The results indicate the estimated per plant costs range from a low value of $\$ 920,000$ to increase the operating temperature of the supports to a high value of $\$ 89,000,000$ to replace the existing supports. The low value takes into account averted onsite costs and assumes no replacement power would need to be purchased. The high value takes into account averted onsite costs, but assumes replacement power would have to be purchased for a 20 -week period.

The results of the benefit analysis indicate a per-plant offsite dose risk of 2.9 person-rem/year of remaining reactor lifetime. This risk includes all the risk associated with support failure after embrittlement occurs. It was assumed that the implementation of any of the proposed options would remove $100 \%$ of the risk associated with failure of an embrittled support. The core damage frequency was found to be $8.8 \times 10^{-5} / \mathrm{yr}$. This information provided cost/benefit ratios ranging from $\$ 54$ per person-rem to $\$ 3,100,000$ per person-rem. 


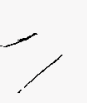




\section{CONTENTS}

ABSTRACT $\ldots \ldots \ldots \ldots \ldots \ldots \ldots \ldots \ldots \ldots \ldots \ldots \ldots \ldots \ldots \ldots$ ii

SUMMARY $\ldots \ldots \ldots \ldots \ldots \ldots \ldots \ldots \ldots \ldots \ldots \ldots \ldots \ldots \ldots \ldots \ldots$

ACRONYMS $\ldots \ldots \ldots \ldots \ldots \ldots \ldots \ldots \ldots \ldots \ldots \ldots \ldots \ldots \ldots \ldots \ldots \ldots$

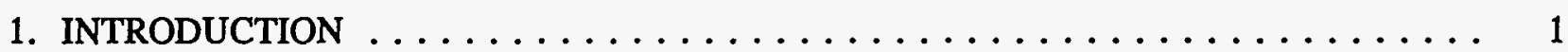

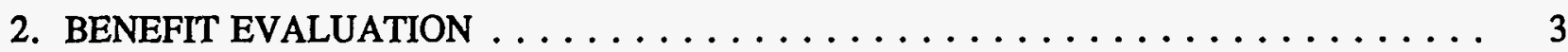

2.1. Event Tree Analysis . . . . . . . . . . . . . . . . . . 3

2.2. Safe Shutdown Earthquake Event Tree . . . . . . . . . . . . . . 3

2.3. Small Break Loss-Of-Coolant Accident Event Tree . . . . . . . . . . . . 8

2.4. Event Tree Results . . . . . . . . . . . . . . . . . . . . . . 10

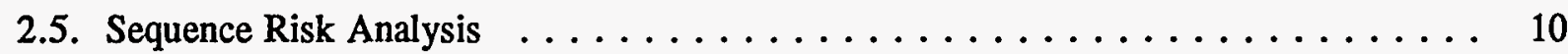

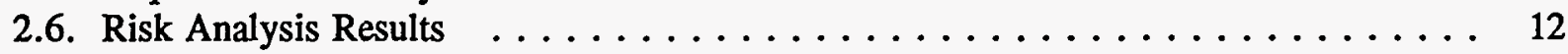

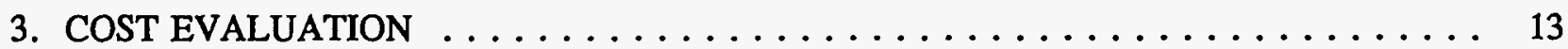

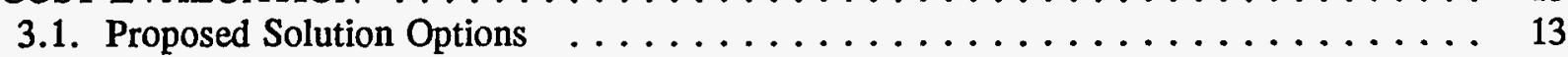

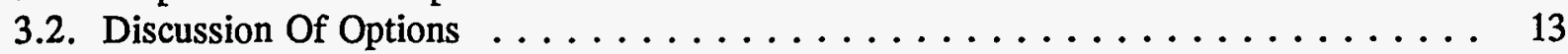

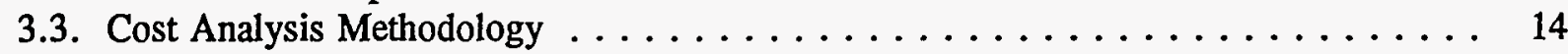

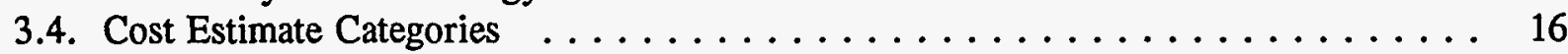

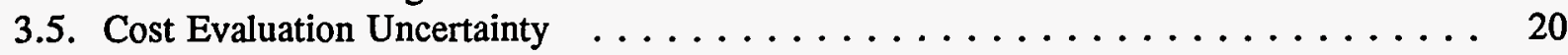

3.6. Plant Modification Cost Estimate Results $\ldots \ldots \ldots \ldots \ldots \ldots \ldots \ldots \ldots \ldots$

3.7. Radiation Exposure . . . . . . . . . . . . . . . . . . . 24

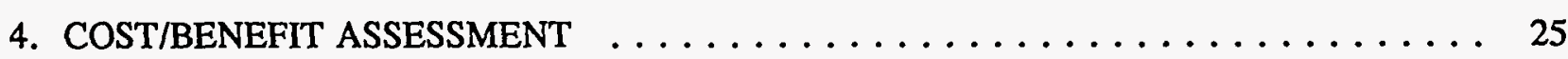

4.1. Dollar-to-Person-Rem Averted Ratio ... . . . . . . . . . . . . 25

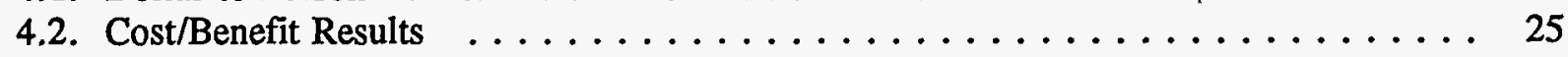

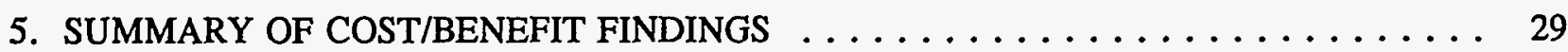

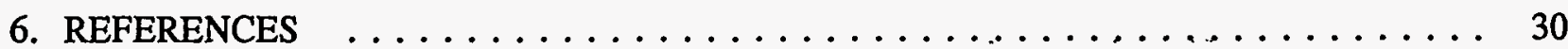

Appendix. A - GSI-15 Event Tree Uncertainty Analysis

Appendix B - GSI-15 Risk Sensitivity Analysis

Appendix C - Taylor Series Expansion (TSE) Program Verification

Appendix D - GSI-15 Cost/Benefit Ratio Graphs 


\section{ACRONYMS}

\begin{tabular}{ll} 
AOSC & averted onsite costs \\
BWR & boiling water reactor \\
COV & coefficient of variation \\
CSDSF & \multicolumn{1}{c}{ chemical shut down system failure } \\
DPR & dollar to person-rem averted ratio \\
ECCSF & \multicolumn{1}{c}{ emergency core cooling system failure } \\
EEDB & energy economic data base \\
EF & \multicolumn{1}{c}{ error factor } \\
EFPY & effective full power years \\
GSI-15 & Generic Safety Issue 15 \\
LBLOCA & large break loss-of-coolant accident \\
LOCA & loss-of-coolant accident \\
LWR & light water reactor \\
NDTT & nil ductility transition temperature \\
NNB & no net benefit \\
NRC & Nuclear Regulatory Commission \\
ORNL & Oak Ridge National Laboratory \\
PRA & probabilistic risk assessment \\
PWR & pressurized water reactor \\
QA/QC & quality assurance/quality control \\
RCF & reactor containment failure \\
RCS & reactor cooling system \\
RP & replacement power \\
RPSF & reactor protection system failure \\
RPV & reactor pressure vessel \\
RPVS & reactor pressure vessel support \\
RPVSF & reactor pressure vessel support failure \\
SBLOCA & small break loss-of-coolant accident \\
SF-PSD & safe plant shut down \\
SPRA & standard probabilistic risk assessment \\
SSE & safe shutdown earthquake \\
&
\end{tabular}




\section{COST/BENEFIT ANALYSIS OF GSI-15: RADIATION EFFECTS ON REACTOR VESSEL SUPPORTS}

\section{INTRODUCTION}

Neutron irradiation of structural materials causes embrittlement that may increase the probability of material failure due to a propagation of pre-existing flaws. In April 1988 data produced by Oak Ridge National Laboratory ${ }^{1}$ (ORNL) suggested that the potential for neutron embrittlement of reactor pressure vessel supports (RPVS) could be greater than was formerly anticipated.

The first part of this report estimates the core damage frequency and risk associated with RPVS failure. The second part of this report presents the cost/benefit ratio for implementation of any of five solutions.

Normally the potential for brittle fracture in a material is quantified in terms of the material's nil ductility transition (NDT) temperature. The NDT temperature for a material is the temperature at which the material becomes prone to brittle failure. If the material is kept at a higher operating temperature than its NDT temperature, brittle fracture of the material will be prevented. The possible corrective measures to the damaged pressure vessel supports would fall in one of five categories:

- The supports can be shielded to reduce the neutron radiation exposure.

- The operating temperature of the supports can be increased above the NDTT of the support material.

- The embrittled supports can be replaced.

- The supports can be heated such that the embrittlement is annealed out.

- The embrittled supports can be left in place and additional supports can be added.

The RPVS designs for light water reactors (LWR) have been divided into five different categories (Reference 1). The support categories are skirt, long column, shield tank, short column, and suspension. The skirt type supports are located far enough away from the reactor core such that embrittlement induced failure of the support is not anticipated. All operating boiling water reactors (BWRs) except Big Rock Point have skirt type supports; therefore, they are not included in this study. Big Rock Point Nuclear Plant is the only operating plant with suspension type supports; it was not included in this study because of its small size $(240 \mathrm{MWt})$ and low surrounding population density.

Table 1 lists the support type and the number of PWRs of each type in use. Since the skirt type supports are not likely to fail due to neutron embrittlement, they are removed from further consideration leaving 76 plants with susceptible supports. 
Table 1. PWR reactor pressure vessel support utilization.

\begin{tabular}{|c|c|}
\hline Support type & Number in use \\
\hline Skirt & 7 \\
\hline Long Column & 11 \\
\hline Short Column & 57 \\
\hline Shield Tank & 8 \\
\hline Total susceptible plants & 76 \\
\hline
\end{tabular}

The analysis first estimated the core damage frequency and the risk associated with operating the 76 PWRs with possible radiation damaged RPVSs. It is assumed that any one of the 76 PWRs could have suspect RPVSs. Therefore, the event tree analysis was very conservative to be able to bound the different failure modes for the four different support types. Also, it was assumed that modifying the supports would reduce the embrittlement risk.

The second part of the analysis estimated the costs associated with fixing the different support types. The reduction in risk is understood to be the benefit, while the expenditure in fixing the supports is the cost. The cost/benefit ratio is then used as a basis for recommending what action should be taken. Consideration is also given to the core damage frequency resulting from embrittled supports. 


\section{BENEFIT EVALUATION}

The benefit is defined as the reduction in risk obtained by fixing the neutron embrittled RPVS. To estimate the risk, two different scenarios were considered that could fail the supports. Event trees for each scenario were developed to obtain the associated probability of RPVS failure. The probability of RPVS failure was then multiplied by the associated consequence of the failure, thus obtaining the failure risk.

\subsection{Event Tree Analysis}

The GSI-15 event tree evaluation involves two different scenarios. The first scenario is a safe shutdown earthquake (SSE) as an initiating event and the potential failure of the RPVSs. The second scenario involves a small break loss-of-coolant-accident (SBLOCA) as the initiating event. The discussion of the scenarios includes the associated event tree and a detailed explanation of each event contained in the event tree.

Typical event tree methodology is used in the generation of the scenario event trees. At each branch node, the downward path represents the failure event that is listed above that node, while the upward path symbolizes the complement of the failure event. Each failure event portrays a phase in the scenario development and represents the failure of a particular safety function. Human errors and procedural guideline flaws are not incorporated into the event tree model.

The sequence outcomes are grouped into one of seven different categories. Table 2 lists the different categories along with a description of each category. The offsite release categories are taken from the WASH $-1400^{2}$ reactor safety report and classify various degrees of radioactive releases from containment. Each sequence was assigned to the offsite release category that best modeled its outcome. When a sequence could fall into one or more release categories (i.e., PWR 1 or PWR2, PWR 3 or PWR 4, etc.), the most conservative release category was selected.

\subsection{Safe Shutdown Earthquake Event Tree}

The first event tree is shown in Figure 1. The event tree models the occurrence of a SSE and the potential failure of the RPV supports. For this model, it is assumed that failure of the RPV supports may only cause a large break loss-of-coolant-accident (LBLOCA). Thus, a SBLOCA will not be considered as a contributor to the core-damage probability and will not be included in the event tree. This assumption is supported by the fact that the leak rate (less than $200 \mathrm{gpm}$ ) for a SBLOCA is easily replaced by various reactor makeup systems such as the high pressure safety injection system or the charging system. 
Table 2. Event tree sequence end state categories.

\begin{tabular}{|c|c|}
\hline Consequence Label & Explanation \\
\hline SPRA & $\begin{array}{l}\text { The sequence results in an event sequence whose risks are not associated } \\
\text { with GSI-15. The sequence is not further developed on the event tree. }\end{array}$ \\
\hline SF-PSD & $\begin{array}{l}\text { The sequence results in an emergency plant shutdown. Thus, the plant is } \\
\text { safe and in a shutdown mode. }\end{array}$ \\
\hline PWR 1 & $\begin{array}{l}\text { The sequence results in core meltdown followed by a steam explosion. } \\
\text { The containment sprays and heat removal systems are assumed to have } \\
\text { failed. Radioactivity is released over a } 10 \text { minute period. The total } \\
\text { release contains approximately } 70 \% \text { of the iodines and } 40 \% \text { of the alkali } \\
\text { metals present in the core at the time of release. }\end{array}$ \\
\hline PWR 3 & $\begin{array}{l}\text { The sequence results in containment failure prior to commencement of } \\
\text { core melting. Core melting would cause radioactive materials to be } \\
\text { released through a ruptured containment barrier. Approximately } 20 \% \text { of } \\
\text { the iodines and } 20 \% \text { of the alkali metals present in the core at the time of } \\
\text { release would be unleashed to the atmosphere. The release time would be } \\
\text { approximately } 1.5 \text { hours. }\end{array}$ \\
\hline PWR 7 & $\begin{array}{l}\text { The sequence results in core meltdown but is mitigated due to the fact that } \\
\text { the containment barrier retains its integrity until the molten core melts } \\
\text { through the containment. The release involves } 0.002 \% \text { of the iodines and } \\
0.001 \% \text { of the alkali metals present in the core at the time of release. The } \\
\text { release time would be } 10 \text { hours. }\end{array}$ \\
\hline PWR 8 & $\begin{array}{l}\text { The sequence results in large pipe break with failure of containment. The } \\
\text { core would not melt. The release would involve } 0.01 \% \text { of the iodines and } \\
0.05 \% \text { of the alkali metals. Most of the release would occur in } 0.5 \text {-hours. }\end{array}$ \\
\hline PWR 9 & $\begin{array}{l}\text { The sequence results in a large pipe break. The core would not melt, and } \\
\text { the containment would not fail. The release would contain } 0.00001 \% \text { of } \\
\text { the iodines and } 0.00006 \% \text { of the alkali metals. The release would occur } \\
\text { over a } 0.5 \text {-hour time period. }\end{array}$ \\
\hline
\end{tabular}


The events for the SSE sequence event tree are defined below. The probability for each event is given as a mean value. The uncertainty analysis for the event trees is contained in Appendix A.

SSE. The event SSE models the initiating event of a safe shutdown earthquake. From NUREG- $1211^{3}$, it is assumed that frequency of occurrence is $2.5 \times 10^{-4} / R Y$ and the initiating event probability can be modeled as a Poisson distribution. Thus, the dimensionless parameter $\nu$ for the Poisson distribution for one-year is $2.5 \times 10^{-4}$.

It is commonly accepted that earthquakes producing lower loads on structures occur more often than those resulting in higher loads, such as the SSE. Also, if plastic design methods are used, as described in Chapter $\mathrm{N}$ of the AISC Manual ${ }^{4}$, the allowable stress in the load combinations including SSE is $0.9 \mathrm{xF}_{\mathrm{y}}{ }^{5}$, i.e., for A36 steel this would result in about $30 \mathrm{ksi}$. Taking $6 \mathrm{ksi}$ as the minimum stress corresponding to the threshold of embrittlement, the ratio of the stresses (the stress at the SSE and the minimum stress which might be considered for brittle fracture) would be equal to five. Since force is proportional to acceleration, and stress is proportional to force, it may be inferred that the stresses induced by an earthquake will be in the same proportion as peak ground acceleration (PGA) for different earthquakes.

Examination of the seismic hazard curves, relating annual frequency of exceedance of SSE and $\mathrm{PGA}^{6}$, indicates that frequency of occurrence of the earthquake corresponding to $6 \mathrm{ksi}$ would be about five times that of the frequency of occurrence of the PGA for the SSE. Reducing the stress threshold by a factor of five has the effect of increasing the frequency of the earthquake by about a factor of five. Consequently, it is justifiable to increase the dimensionless parameter $\nu$ for the Poisson distribution for one year by a factor of five, to $\nu=1.25 \times 10^{-3}$. The probability of at least one damaging earthquake is then:

$$
P(S S E)=1-P(x=0)=1-\frac{\nu^{x} e^{-y}}{x !}=1-e^{-1.25 \times 10^{-3}}=1.25 \times 10^{-3}
$$

RPVSF. $\quad$ Event RPVSF represents the failure of the RPV supports if a damaging earthquake occurs. The calculation for the probability of RPVSF should be site specific due to variables such as RPV support design and material composition, plant age and operating history, and RPV load before and after the earthquake. In order to keep the analysis generic, the conditional probability of RPVSF is conservatively estimated to equal 0.5 . This assumption implies that if a damaging earthquake occurs, fifty percent of the time the RPV supports will fail. Also, it implies that below the damaging earthquake level the RPV supports will not fail. In the sensitivity analysis contained in Appendix B, the frequency of having a damaging earthquake was increased by a factor of 10 to account for the possibility of a lower peak-ground acceleration level earthquake which results in RPV support failure.

LBLOCA. The event LBLOCA models a large break LOCA if the RPV support system undergoes a failure. If the RPV support does fail, the resulting load on the reactor cooling system (RCS) piping may cause a rupture. A conservative estimate of the probability of a LBLOCA is assumed to be 0.5 . The sensitivity analysis in Appendix B investigated the worst case of RPV support failure coupled with a LBLOCA by setting both probabilities to 1 . 


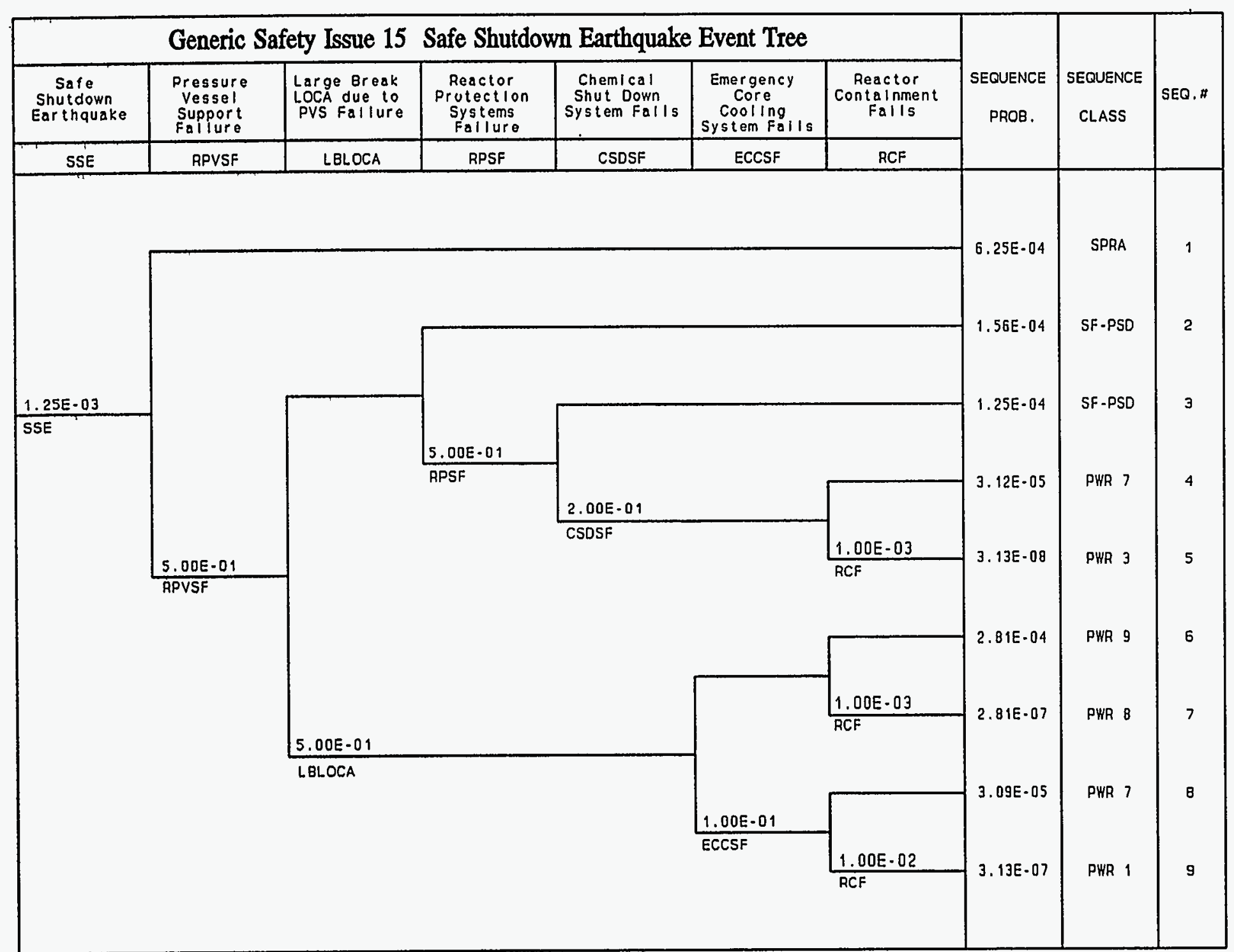

Figure 1. Safe Shutdown Earthquake Sequence Event Tree. 
RPSF. The event RPSF models the failure of the reactor protection system. In the event of a SSE, the operator will attempt to manually scram the reactor. However, it is possible that the protection system will fail due to the tilting of the RPV, which causes the reactor control rods to become mechanically jammed. Thus, detailed analysis for this event should include both possible mechanical failures and human errors of commission.

Event RPSF is conditional on a LBLOCA not occurring. If a LBLOCA does occur, the moderator for the reactor will be removed and the reactor will shut down due to voiding of the core. Consequently, if a LBLOCA does not occur and the reactor protection system fails, the core will eventually melt even though the reactor coolant is still present. It is conservatively assumed that the probability of RPSF is 0.5 . The sensitivity analysis in Appendix B investigated the worst case scenario by setting both RPVSF and RPSF to one. This would model coupled failure of both the RPV supports and the reactor protection system.

CSDSF. The event CSDSF models the failure of the chemical shutdown system. Typically, precise analysis of this event would include both the possible mechanical failures and human errors. For this analysis, the probability of CSDSF was found from the Sequoyah PRA ${ }^{7}$ and is equal to 0.2. The sensitivity analysis in Appendix B investigated the worst case scenario by setting the probability of CSDSF failure to one.

ECCSF. Event ECCSF models the failure of the emergency core cooling system. If the emergency core cooling system works, it can prevent core melt even if a large break LOCA occurs. The probability of failure for this event is based upon typical PRA analysis. Based upon the Sequoyah PRA, the conditional probability of ECCSF is equal to 0.02 . This mean conditional probability measures the failure probability of the systems (including human and mechanical) comprising the ECCS. Failure of ECCS following RPVS failure and the resulting RPV displacement and increased primary piping stresses would result in higher stresses on ECCS piping and components and would increase the conditional failure probability. Therefore, the event ECCSF probability was increased by a factor of five to 0.1 . The sensitivity analysis in Appendix B investigated the worst case scenario (where the ECCS always fails given the appropriate initiating event) by setting the probability of CSDSF failure to one.

RCF. The event RCF represents the failure of the containment heat removal system along with the containment structure and containment isolation. Since the reactor containment and most of the systems in it have a median capacity of $1.5-2 \mathrm{~g}$ peak ground acceleration, a SSE should not have a noticeable effect on the containment failure rate. Therefore, a typical PRA based failure rate is assumed for the reactor containment. Based upon the Sequoyah PRA, the probability of RCF is $1 \times 10^{-}$ ${ }^{3}$ in the mission time of one year. For those cases where ECCS has failed, the probability of RCF was assumed to be $1 \times 10^{-2}$, which accounts for the possibility of a dependent ECCS/RCF failure mode.

Also, the Salem Nuclear Generating Station PRA ${ }^{8}$ was used to compare the failure rates of the mechanical components for the analysis of both event trees. 


\subsection{Small Break Loss-Of-Coolant Accident Event Tree}

The second event tree is shown in Figure 2. The event tree models the occurrence on a nonseismic induced SBLOCA and the resulting failure of the RPV supports. Given that a SBLOCA occurs, the resulting load normally carried by the fractured pipes will be transferred to the RPVSs thereby causing an additional load on the supports. If the supports have undergone neutron embrittlement, the addition of the SBLOCA induced load may cause the RPVSs to fail. If the RPVSs do fail, a large break LOCA may occur.

As can be seen in Figure 2, the SBLOCA event tree is similar to that from the SSE sequence discussed above. The basis for using a similar event tree with identical event probabilities is that if the RPVSs fail, the possible resulting LBLOCA, reactor protection system failure, chemical shutdown system failure, emergency core cooling system failure, and reactor containment failure events will most likely fall within the same realm regardless of the cause of the RPVSs failing. Thus, the only difference between the two event trees is the initiating event and its associated frequency.

SBLOCA. The initiating event for the second event tree is the occurrence of a small break LOCA. The frequency of occurrence was obtained from the Sequoyah PRA ${ }^{7}$ source numbers. The nominal frequency for a small break LOCA is found to be $1 \times 10^{-3}$. The assumption was made that only one-half of the possible small pipe breaks were close enough to the RPV to load the RPV supports such that failure of the supports may occur. Therefore, the frequency of occurrence for a SBLOCA is estimated to be equal to the nominal SBLOCA frequency multiplied by one-half, or $5 \times 10^{-4} / \mathrm{RY}$. Assuming the SBLOCA event can be modeled as a Poisson event, the probability of a SBLOCA in the mission time of one year is equal to $5 \times 10^{-4}$.

The remaining events in the SBLOCA event tree have previously been defined and wiil not be reviewed. In both the SSE and SBLOCA sequences the following preexisting conditions must be met before the RPVSs can fail:

- The support must contain a critically sized flaw.

- The support must have been subjected to enough radiation for embrittlement to occur.

- Sufficient stresses must be present to cause brittle fracture.

Requirements for toughness were implemented after some plants were built. Therefore, some older plants may have been at or near the NDT temperature at the beginning of plant life. If this is the case, they may be susceptible to brittle failures without significant exposure to neutron radiation. 


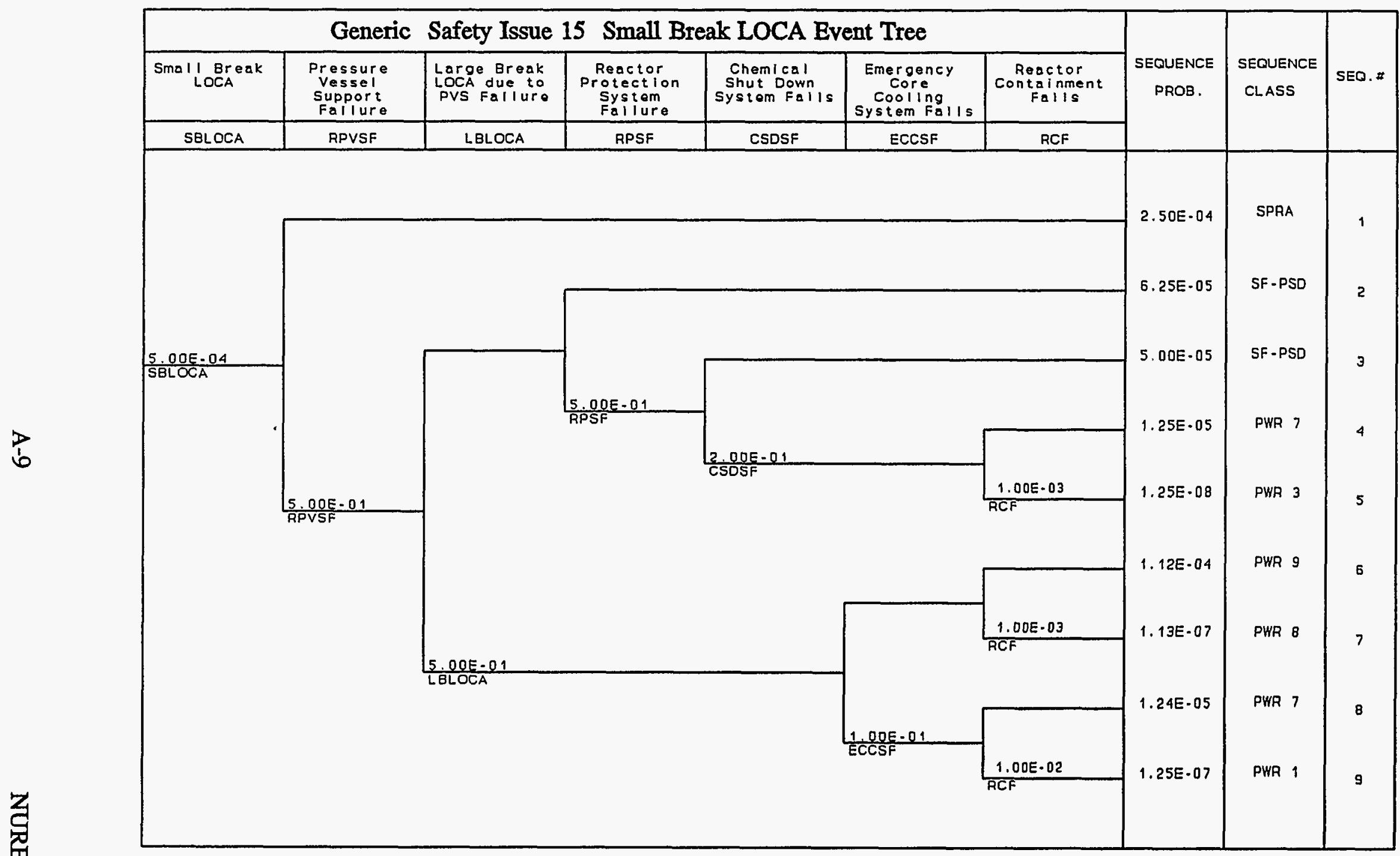

Figure 2. Small Break LOCA Event Tree. 


\subsection{Event Tree Results}

Since the two event trees lead to similar sequence outcomes, the identical outcomes from each tree can be combined to form a total probability of a particular end state. The end states can occur with either the SSE or the SBLOCA as the initiator. Thus, the end state probability for the PWR 1 category is calculated by:

$$
\begin{aligned}
P(P W R 1)_{\text {total }} & =P\left((P W R 1)_{S S E} \bigcup(P W R 1)_{S B L O C A}\right) \\
& \approx P(P W R 1)_{S S E}+P(P W R 1)_{S B L O C A} \quad(\text { if } P(P W R 1)<<1) .
\end{aligned}
$$

Table 3 lists the sequence end states and the expected probability of occurrence for the mission time of one year. Since the expected probability is calculated by multiplying several random variables together, the probability distribution for the resultant product would tend to be log-normally distributed. As seen in Table 3, the total core damage frequency due to RPVS failure is $8.8 \times 10^{-5} / \mathrm{yr}$.

Table 3. Event tree end state analysis results.

\begin{tabular}{|c|c|c|c|}
\hline $\begin{array}{c}\text { Sequence } \\
\text { end state }\end{array}$ & $\begin{array}{c}\text { Expected probability } \\
\text { (per year) }\end{array}$ & Core damage & $\begin{array}{c}\text { Total cored damage } \\
\text { frequency (per year) }\end{array}$ \\
\hline SPRA & $8.8 \times 10^{-4}$ & No & \multirow{2}{*}{ N/A } \\
\hline SF-PSD & $3.9 \times 10^{-4}$ & No & No \\
\hline PWR 9 & $3.9 \times 10^{-4}$ & No & \multirow{2}{*}{$8.8 \times 10^{-5}$} \\
\hline PWR 8 & $3.9 \times 10^{-7}$ & Yes & \\
\hline PWR 7 & $8.7 \times 10^{-5}$ & Yes & \\
\hline PWR 3 & $4.4 \times 10^{-8}$ & Yes & \\
\hline PWR 1 & $4.4 \times 10^{-7}$ & &
\end{tabular}

\subsection{Sequence Risk Analysis}

The risk is defined as the probability of occurrence of an event multiplied by the radioactive release consequence associated with the event. The risk is then extrapolated over the estimated remaining lifetime of a typical reactor. The risk from each event sequence is then summed to provide an upperbound total risk.

The fracture mechanics analysis reported in NUREG/CR-5320 described radiation embrittlement as a credible end-of-life failure mode, assuming 32 Effective Full Power Years (EFPY). Given the current "40-year license lifetime" and assuming an average plant is twenty years 
old, it is assumed that a remaining plant lifetime is 20 years, with the last 10 plant years encompassing the plausible radiation embrittlement failure mode.

Table 4 lists the consequence associated with each end state category. The consequence data quantify the WASH-1400 end states and are taken from NUREG/CR-2800'. The consequences for the SPRA and SF-PSD end states are both assumed to be zero (no additional risk).

Table 4. End state radioactive release consequences (from NUREG/CR-2800).

\begin{tabular}{||c|c|c||}
\hline \multirow{2}{*}{ Category } & \multicolumn{2}{|c|}{$\begin{array}{c}\text { Whole body dose consequence } \\
\text { factor (person-rem) }\end{array}$} \\
\cline { 2 - 3 } & Core melt & Non-core melt \\
\hline PWR 1 & $5.4 \times 10^{6}$ & \\
\hline PWR 3 & $5.4 \times 10^{6}$ & \\
\hline PWR 7 & $2.3 \times 10^{3}$ & $7.5 \times 10^{4}$ \\
\hline PWR 8 & & $1.2 \times 10^{2}$ \\
\hline PWR 9 & & 1.2 \\
\hline
\end{tabular}

The WASH-1400 release categories were assigned to those event tree sequences that resulted in a radioactive release not covered by the normal plant specific design PRA. The release category that best fit each sequence was used to obtain an offsite dose for that sequence. As discussed in NUREG-2800, the total offsite radioactive dose was calculated based on the following assumptions:

1. Calculations were based on a typical midwest site, adjusted to reflect the population density within a 50-mile radius of U.S. nuclear power plants.

2. Dose consequences represent whole-body population dose commitment (person-rem) received within 50 miles of the site.

3. A 1/2-mile exclusion area was assumed, with a uniform population density of $\mathbf{3 4 0}$ persons per square mile from the exclusion area to the 50 -mile exposure radius.

4. Evacuation was not considered.

5. Meteorological data were taken from the U.S. Weather Service station at Moline, Illinois.

6. Core inventory at accident initiation time was assumed to be represented by a 3412 MWt (1120 MWe) plant.

7. All exposure pathways except ingestion were included. 


\subsection{Risk Analysis Results}

Table 5 lists the results of the risk analysis. The end state release consequence (Table 4) is multiplied by the end state probability (Table 3 ) to get an end state risk. The risk is then summed and multiplied by the remaining reactor lifetime to get the total additional population risk associated with the possible RPVS failure due to a SSE or a SBLOCA.

As shown in Table 5, the expected risk is 2.9 person-rem/year for the remaining plant lifetime after embrittlement occurs. The 2.9 person-rem/year risk is based on the operation of one reactor and is estimated using very conservative event probabilities. To get a total industry-wide risk value, the 2.9 person-rem/year should be multiplied by the total number of embrittlement susceptible plants and their respective remaining lifetimes. Assuming seventy-six susceptible plants, the total industry- wide risk value would be 2200 person-rem for a ten-year time period. If every embrittled support in the seventy-six plants were repaired, the expected total benefit from the reduction in risk would be 2200 person-rem.

Table 5. Risk analysis results.

\begin{tabular}{|c|c||}
\hline Category & $\begin{array}{c}\text { Expected risk } \\
\text { (person-rem) }\end{array}$ \\
\hline SPRA & 0/year \\
\hline SF-PSD & 0/year \\
\hline PWR 9 & $0.047 /$ year \\
\hline PWR 8 & $0.029 /$ year \\
\hline PWR 7 & $0.20 /$ year \\
\hline PWR 3 & $0.24 /$ year \\
\hline PWR 1 & $2.4 /$ year \\
\hline$\Sigma=$ & $2.9 /$ year \\
\hline$\times 10$ years & 29 \\
\hline$\times 20$ years & 58 \\
\hline$\times 40$ years & 120 \\
\hline$\times 60$ years & 170 \\
\hline
\end{tabular}




\section{COST EVALUATION}

The proposed resolution modifications will have the effect of either preventing embrittlement from occurring, replacing or repairing potentially failed components, or changing the operating environment of embrittled components such that further embrittlement cannot occur. The risk reduction possible from the implementation of any of the proposed modifications is obtained from the event trees developed in Section 2.

\subsection{Proposed Solution Options}

Five possible options or alternatives were proposed as resolutions for GSI-15. It should be kept in mind that these are only potential solutions. A substantial engineering effort will be required before the feasibility of implementing any of these solutions at any given nuclear power plant is shown to be practical. The five options are:

1. Shielding the RPVSs from neutron radiation. This would prevent the RPVSs from becoming embrittled.

2. Increasing the operating temperature of the RPVSs above the new (embrittled) NDTT. This would remove the brittle fracture failure mode.

3. Replacing the existing RPVSs before embrittlement occurs.

4. Annealing the RPVSs to remove the effects of the embrittlement.

5. Strengthening the existing RPVSs or adding new supports.

\subsection{Discussion Of Options}

Before any proposed modification could be made to resolve this issue, an extensive engineering analysis would be required on a plant-by-plant basis. Included in this effort, the analysis would have to: assess the effects of neutron embrittlement on a plant-specific basis, calculate the risk associated with the possible embrittlement, insure that the implementation of any proposed modification is possible and that it will actually solve the problem, perform the design and engineering work for any proposed modification, pass the required engineering reviews, and obtain NRC design approval.

It should be noted that the RPVSs are located in an area of high radiation with extremely limited access. Even the act of visually inspecting them would be a major undertaking, which would result in a considerable occupational exposure. Therefore, any proposed solution needs to be evaluated both on the merits of its cost-to-benefit ratio and in light of the additional occupational exposure that would result from its implementation.

Option 1 is to shield the RPVSs from neutron radiation. This would prevent the RPVSs from becoming embrittled. Because of the limited space available in the area of the RPVSs, adding 
shielding would not be practical unless a shielding with an extremely large neutron absorption crosssection is used. The procurement of suitable shielding would probably be expensive. Also, the shielding must not interfere with the normal, inherent heat transfer mechanisms of the RPVSs.

Option 2 is to increase the operating temperature of the RPVSs above the new (embrittled) NDTT. This would remove the brittle fracture failure mode. It is questionable if this option is applicable to the short column RPVSs. The short column supports have a small profile with a large temperature differential. In NUREG/CR-5320 it is estimated that for the Trojan plant, after 32 EFPY, there will be a $75^{\circ} \mathrm{F}$ shift in the NDTT in the area most likely to contain a critically-sized flaw. In order to elevate the RPVS's operating temperature sufficiently to accommodate this shift, it would probably require exceeding the temperature limit of the supporting concrete. This would have the effect of changing the failure mechanism from failure of the RPVS to failure of the supporting concrete structure.

Option 3 is to replace the existing RPVSs before embrittlement occurs. It is unlikely that this option could be completed during a scheduled shutdown. It would, therefore, involve the buying of replacement power. Because the RPVSs are keyed to the RPV nozzles, the replacement of the RPVSs would most likely involve either lifting or removing the RPV until the supports are replaced.

Option 4 is to anneal the RPVSs to remove the effects of neutron induced embrittlement. There are two methods by which the RPVSs could be annealed. The possibilities are either in-place annealing of the supports or removing the supports and annealing at a remote location. In-place annealing would probably be the most cost effective; however, for those RPVSs that are attached to or imbedded in concrete (i.e. short column RPVSs) this may not be possible due to the temperature limit of the supporting concrete. Option 4 is calculated in two ways; the first way (Option 4A) takes into account removal of the RPVSs to an out-of-containment location for annealing, and the second way (Option 4B) calculates the cost of in-place annealing. Like Option 3, both options would most likely involve the buying of replacement power.

Option 5 is to strengthen the existing RPVSs or add new supports. It is questionable whether or not this option is possible. For most reactors, all the locations that can be used to support the RPV are currently in use, and any attempt to strengthen the existing supports would be akin to replacing the RPVSs, with all the implementation problems associated with Option 3. Like Options 3 and 4 , this option would involve the buying of replacement power during the modification downtime.

\subsection{Cost Analysis Methodology}

The cost estimates of the five options were developed using the guidelines of NUREG/CR3568" ${ }^{10}$ "A Handbook for Value-Impact Assessment," and NUREG/CR-4627"1, Revision 2, "Generic Cost Estimates," and the computer code FORECAST 2.1 ${ }^{12}$, which incorporates the cost evaluation information. FORECAST was developed under the auspices of the NRC. It has been used as the basis for estimating costs in several cost/benefit analyses prepared for the NRC. Cost estimation involved making an evaluation of each proposed modification, identifying equipment and materials necessary to make the proposed modifications, and assessing the work area in which the proposed modifications would be made. The following assumptions were included in the cost estimates: 
1. If implemented, the solution would resolve the problem with $100 \%$ assurance.

2. Options $3,4 \mathrm{~A}$, and 5 probably cannot be implemented without replacement power costs. Options 1,2 , and 4B may possibly be implemented without buying replacement power.

3. Socio-economic impacts will be considered minimal and will not be included as an increment of cost.

4. Costs were calculated using 1991 dollars.

5. Costs were calculated assuming that modifications would be required on the total support system.

6. For Option 1, shielding would have to be constructed from an alloy of cadmium. Based upon engineering judgement, material costs would be approximately $\$ 50,000$ per support, for a total cost of $\$ 200,000$ for four supports.

7. Option 4 has no equipment or materials costs.

8. Options 1,2, and 5 have no removal labor costs associated with them. Option 4B removal costs would be the cost associated with removal of the annealing equipment and is estimated to be one-third of the installation cost.

9. Due to the high radiation dose present in the area containing the RPVSs, no modifications could be made without first defueling and draining the reactor vessel.

10. For Option 2, NUREG-0933 $3^{13}$ estimated that some plants would have material costs as low as $\$ 5200$ and labor costs as low as $\$ 25,000$. The numbers were calculated based on the assumption that the temperature of the RPVSs could be raised above the new NDTT by simply adjusting cooling flow to the RPVSs. We feel that even if this fix is possible, it would require the installation of additional temperature monitoring equipment, such that the cost would be similar to the costs associated with the installation of heating systems discussed in NUREG-0933.

11. The cost of buying replacement power was made on the assumption that Options 1,2 , and $4 \mathrm{~B}$ would require an additional 4 weeks of outage time, Options 3 and $4 \mathrm{~A}$ would require an additional 20 weeks, and Option 5 would require an additional 16 weeks.

Expenses were calculated in accordance with FORECAST 2.1. The total cost of a modification is the sum of many different types of expenditures. The costs that were analyzed were limited to the following categories:

1. Equipment and material costs.

2. Labor costs associated with installation and/or removal.

3. Costs associated with engineering and quality control and quality assurance (QA/QC). 
4. Radiation exposure.

5. Costs associated with health physics.

6. The costs to defuel, drain, and restore the reactor.

7. Replacement power costs.

8. Total NRC costs, both one-time and recurring costs.

9. Averted onsite costs (AOSC).

\subsection{Cost Estimate Categories}

\section{Labor, Equipment, and Material Costs}

The Energy Economic Data Base (EEDB), which is built into the FORECAST code, provided the basis for the equipment costs, material costs, and labor estimates. The EEDB incorporates "asbuilt" cost information (both the material unit cost and the installation or removal labor hours) for nuclear plant activities. Additionally, for operating nuclear power plants there are a number of workplace characteristics which significantly reduce the level of productivity and thus increase the number of labor hours required to accomplished a task. These characteristics, discussed in detail in FORECAST 2.1, include access, congestion and interference, radiation, task management, etc. Since the EEDB reflects only new (or "as-built") plant conditions, the installation labor hours were adjusted using FORECAST 2.1 to properly consider actual working conditions existing at operating nuclear plants. FORECAST 2.1 can modify the EEDB to take into account the factors that reduce worker productivity.

The total labor costs associated with the proposed modifications include overhead charges to account for contractor management, administrative support, rent, insurance, etc. Options 1, 2, and 4B installation labor hours were estimated based on 105 man-weeks obtained from Reference 13 . The labor hours and material costs associated with Option 3 were obtained directly from the EEDB. Option 4A labor hours were assumed to be the same as Option 3, but its material costs were assumed to be zero. Option 5 material costs were assumed to be the same as Option 3, but the labor hours were adjusted to reflect that there would be no removal costs associated with Option 5 .

\section{Costs Associated with Engineering and QA/QC}

These costs reflect the cost of engineering and design, as well as quality assurance and quality control (QA/QC) activities associated with implementing the requirements. For requirements affecting structures or systems already in-place (operating plants), the guidelines of Abstract 6.4 of FORECAST recommend a 25\% engineering and QA/QC factor be applied to the direct cost (i.e., the labor and materials cost without any overhead charges). All cost estimates developed in this study include this engineering and QA/QC cost component. In the case of Options 1, 2, and 4B, a large analytical effort would be required to insure that the implementation of any proposed modification is possible, that it will actually solve the problem, and that it can acquire NRC design approval. 
Therefore, for these two options a 40\% engineering and QA/QC factor was applied.

\section{Radiation Exposure Estimation}

Worker radiation exposure estimates were derived based on guidelines presented in FORECAST. The collective radiation exposure associated with the implementation of a proposed plant modification is estimated by taking the product of the in-field labor hours necessary to perform the task and the work area dose rate associated with that particular task.

In this study, the work area in which the modifications would take place is considered to be high-dose contaminated area (inside the biological shield). Based on engineering judgement, radiation exposure level (with the reactor's fuel removed) is estimated to be $10 \mathrm{mrem} / \mathrm{hour}$ for the proposed modifications.

\section{Costs Associated with Health Physics}

Health physics requirements for the potential plant modifications were developed based on information and guidelines presented in Abstract 2.1.6 of Reference 12. Two factors were considered: the size of the work crew and the magnitude of the radiation field. The plant health physicist (HPs) monitor personnel radiation doses, perform radiological surveys throughout the modification duration, staff radiological checkpoints, set up anti-contamination clothing removal areas, as well as determine allowable stay times and badging requirements.

\section{Cost to Defuel, Drain, and Restore the Reactor}

If the nuclear reactor core is left in place, high radiation levels $(2-3 \mathrm{REM} / \mathrm{hr})^{\mathrm{a}}$ would be experienced in the area where the modifications would be made. Therefore, if any modification is to be made, the reactor must be defueled and drained and then refueled after the modifications are completed. In accordance with Abstract 2.1.3 of Reference 12, these defueling and restoring costs were developed for a typical PWR. Not included in these costs are the costs associated with fuel sipping and vessel surveillance and inspection.

\section{Replacement Power Costs}

Replacement power costs for the potential plant modifications were developed based on information and guidelines presented in Abstract 2.1.2 of Reference 12. A best estimate of $\$ 500,000 /$ day was used, with high and low values of $\$ 900,000 /$ day and $\$ 150,000 /$ day, respectively.

a As measured in the area of the reactor vessel nozzle's at the Trojan Nuclear Power Plant, per telephone conversation between R.W. Garner of the INEL and Arnie Fero of Westinghouse Electric on $5 / 16 / 90$. 


\section{Total NRC Costs}

The total NRC costs include the one-time cost associated with supporting the implementation of any proposed modifications and the recurring costs associated with reviewing the operation and maintenance of a modification after it is implemented.

NUREG-2800 estimated it would take 16 man-weeks of staff effort to develop possible solutions. At a rate of $\$ 45.35$ per hour, this amounts to $\$ 29,000$. Supplementary contractor support was estimated to cost an additional $\$ 500,000$, for a total cost of $\$ 529,000$ for all 76 affected plants (or $\$ 6960 /$ plant).

NRC efforts to support and review implementation of any modification was estimated by NUREG-2800 to be 15 man-weeks/plant. Also, it was estimated that for some modifications only 2 man-weeks would be required. However, due to the complicated issues involved in all of the proposed modifications, we feel the 15 week figure applies to all modifications. At a rate of $\$ 45.35$ per hour, the 15 man-weeks/plant totals $\$ 27,000$ per plant.

Recurring costs were estimated to be 1 man-week/RY per plant. Given ten years of remaining reactor life, at a cost of $\$ 45.35$ per hour, this amounts to $\$ 18,100$ per plant. Based on the above estimates, the total NRC cost per plant is given by:

$\$(6960+27,000+18,100)=\$ 52,000$

\section{Averted Onsite Costs (AOSC)}

In addition to the costs associated with the modification, the potential reduction of severe onsite consequences was evaluated. A Handbook for Value-Impact Assessment was used as the reference for this evaluation. The AOSC was calculated using the following equation:

where

$$
\mathrm{V}_{\mathrm{op}}=\mathrm{NU}\left(\mathrm{F}_{\mathrm{o}}-\mathrm{F}_{\mathrm{N}}\right)
$$

be zero)

$\mathrm{V}_{\mathrm{op}} \quad=\quad$ the cost of avoided onsite property damage

$\mathrm{N} \quad=\quad$ the number of affected facilities (on a per plant basis, $\mathrm{N}=1$ )

$\mathrm{U}=$ the present value of onsite property damage given a release

$\mathrm{F}_{\mathrm{O}} \quad=\quad$ the original core damage frequency (base case)

$\mathrm{F}_{\mathrm{N}} \quad=\quad$ the core damage frequency after implementing an option (assumed to

$\mathrm{F}_{\mathrm{O}}-\mathrm{F}_{\mathrm{N}}=\quad 8.8 \mathrm{E}-5$ (from summation of core melt frequencies contained in Table 3)

and

$$
U=\frac{C}{m}\left[\frac{e^{-n_{1}}}{r^{2}}\right]\left(1-e^{-r\left(t_{f}-t_{i}\right)}\right)\left(1-e^{-r m}\right)
$$


where

C $=\quad$ cleanup, repair, and replacement power costs $\left(\$ 1.65 \times 10^{9}\right.$, the data associated with scenario 3)

$t_{\mathrm{f}} \quad=\quad$ years remaining until end of plant life (10 years)

$t_{i} \quad=\quad$ years before reactor begins operation ( 0 years)

$\mathrm{m} \quad=\quad$ period of time over which damage costs are paid out (10 years)

r

$=$ discount rate (for $10 \%, r=0.10$ ).

When uncertainty in the calculation of $\mathrm{V}_{\text {op }}$ is considered, it is appropriate to calculate a low, best, and high estimate for the value of $U$. These values can then be multiplied by the change in core damage frequency to yield a low, best, and high value for $V_{\text {op. }}$. The cost handbook was used as a guide, and the best, high, and low estimate values for $U$ were determined by:

1. The best estimate was calculated as discussed above.

2. The high estimate was assumed to be three times the best estimate.

3. The low estimate was calculated using data from scenario 2 ( $\$ 103.5 \mathrm{M}$ over 7.5 years).

A Handbook for Value-Impact Assessment states that "the quantity, U, must be interpreted carefully to avoid misunderstandings. It does not represent the expected onsite property damage due to a single accident, Rather, it is the present value of a stream of potential losses extending over the remaining lifetime of the reactor. Thus, it reflects the expected loss due to a single accident, the possibility that such an accident could occur with some small probability at any time over the remaining reactor life, and the effects of discounting these potential future losses to present value. When the quantity, $U$, is multiplied by the accident frequency, the result is the expected loss over the reactor life, discounted to present value."

The best, high, and low present onsite property damage costs (including cleanup cost, repair and refurbishment cost, and replacement energy cost) given a release were calculated as:

Low estimate of $\mathrm{U}=\$ 4.6 \times 10^{8} /$ severe accident event

Best estimate of $U=\$ 6.6 \times 10^{9} /$ severe accident event

High estimate of $U=\$ 2.0 \times 10^{10} /$ severe accident event

These values were then applied to the potential change in accident frequency to obtain dollar values for AOSC, as follows:

$$
\begin{aligned}
& V_{\text {op }}(\text { Low Estimate })=\quad \$ 40,500^{2} \\
& V_{\text {op }}(\text { Best Estimate })=\$ 581,000^{\circ} \\
& V_{\text {op }}(\text { High Estimate })=\$ 1,760,000^{2}
\end{aligned}
$$

a $V_{o p}$ is dependent on the remaining plant lifetime $\left(t_{f}\right)$. These values were obtained using a 10-year $t_{r}$. If the remaining plant lifetime increases to 60 years, the best estimate of $V_{o p}$ increases to $\$ 922,000$. This will not have a significant impact on the cost/benefit results. Therefore, only the 10 -year remaining lifetime AOSC value was used. 


\subsection{Cost Evaluation Uncertainty}

following:

The areas of uncertainty associated with the cost estimating model for this study included the

1. Labor rate variations due to plant site location,

2. Variability of in-plant work environment conditions,

3. Variations in the cost of replacement power,

4. NRC procedural/administrative/analytical cost,

5. Equipment and material costs variations,

6. The degree of engineering effort required to obtain NRC approval of any proposed modification.

Each proposed option's cost estimate was evaluated to determine the areas of uncertainty. For the cost analysis uncertainty, the following assumptions were made:

1. Labor rate variations due to plant site location are considered when calculating labor costs. In accordance with FORECAST recommendation for labor cost variations, the assumed labor rate variation was as follows: best estimate is $100 \%$ of the labor cost, the high cost estimate is $112 \%$, and the low cost estimate is $88 \%$. These variations are applicable to installation and removal labor, health physics labor, NRC labor, and the costs associated with defueling the reactor.

2. Equipment and material costs were obtained from the FORECAST data base (or, in the case of Option 2, from NUREG-2800). The low estimate was assumed to be $75 \%$ of the best estimate and the high value was assumed to be $125 \%$ of the best estimate.

3. Best estimates for engineering QA-QC costs were obtained using FORECAST. However, due to the large uncertainty in the degree of the engineering effort required to obtain NRC approval of any proposed modification, the low estimate was assumed to be $50 \%$ of the best estimate and the high estimate was assumed to be $150 \%$ of the best estimate.

4. Cost estimates for buying replacement power were found from the FORECAST data base. A best estimate of $\$ 500,000 /$ day was used, with high and low estimates of $\$ 900,000 /$ day and $\$ 150,000 /$ day, respectively.

Table 6 shows the mean, the coefficient-of-variation (COV), and the standard deviation of each cost category for the five different proposed modifications. The COV is defined as the standard deviation divided by the mean and is a measure of the possible variation in the cost. For a detailed discussion of uncertainty calculations, see Appendix A. 


\subsection{Plant Modification Cost Estimate Results}

A mean and standard deviation for the total cost of each option was calculated for each modification by using a numerical Taylor series expansion routine. Table 7 lists the cost results for the various modifications. Included in the table are the total cost estimate without AOSC or replacement power, the total cost including AOSC without replacement power, and the total cost with both AOSC and replacement power.

It should be noted that the normal costs are considered to be positive dollars. The AOSC cost is measured in negative dollars, thereby helping to lower the total costs. 
Table 6. Cost analysis category parameters.

\begin{tabular}{|c|c|c|c|c|c|c|c|c|c|c|c|c|c|}
\hline \multirow[b]{2}{*}{$\begin{array}{c}\text { Cost } \\
\text { Category }\end{array}$} & \multirow[b]{2}{*}{$\mathrm{COV}$} & \multicolumn{2}{|c|}{ Optiona 1} & \multicolumn{2}{|c|}{ Option 2} & \multicolumn{2}{|c|}{ Option 3} & \multicolumn{2}{|c|}{ Option 4A } & \multicolumn{2}{|c|}{ Option 4B } & \multicolumn{2}{|c|}{ Option 5} \\
\hline & & $\begin{array}{c}\text { Mean } \\
(\$)\end{array}$ & Std. dev. & $\begin{array}{c}\text { Mean } \\
(\$)\end{array}$ & $\begin{array}{l}\text { Std. } \\
\text { dev. }\end{array}$ & $\begin{array}{c}\text { Mean } \\
(\$)\end{array}$ & Std. dev. & $\begin{array}{l}\text { Mean } \\
(\$)\end{array}$ & Std. dev. & $\begin{array}{c}\text { Mean } \\
(\$)\end{array}$ & Std. dev.. & $\begin{array}{c}\text { Mean } \\
(\$)\end{array}$ & Std. dev. \\
\hline $\begin{array}{l}\text { Equipment and } \\
\text { Materials }\end{array}$ & $25 \%$ & $200 K^{b}$ & $50 \mathrm{~K}$ & $52 \mathrm{~K}$ & $13 \mathrm{~K}$ & $1 \mathrm{M}$ & $250 \mathrm{~K}$ & $\mathrm{n} / \mathrm{a}$ & $\mathrm{n} / \mathrm{a}$ & $\mathrm{n} / \mathrm{a}$ & $\mathrm{n} / \mathrm{a}$ & $1 \mathrm{M}$ & $250 \mathrm{~K}$ \\
\hline $\begin{array}{l}\text { Installation } \\
\text { Labor }\end{array}$ & $12 \%$ & $770 \mathrm{~K}$ & $92 \mathrm{~K}$ & $770 \mathrm{~K}$ & $92 \mathrm{~K}$ & $10 \mathrm{M}$ & $1.2 \mathrm{M}$ & $10 \mathrm{M}$ & $1.2 \mathrm{M}$ & $770 \mathrm{~K}$ & $92 \mathrm{~K}$ & $10 \mathrm{M}$ & $1.2 \mathrm{M}$ \\
\hline Removal Labor & $12 \%$ & $\mathrm{n} / \mathrm{a}$ & $\mathrm{n} / \mathrm{a}$ & $\mathrm{n} / \mathrm{a}$ & $n / a$ & $3.4 \mathrm{M}$ & $408 \mathrm{~K}$ & $3.4 \mathrm{M}$ & $408 \mathrm{~K}$ & $250 \mathrm{~K}$ & $30 \mathrm{~K}$ & $\mathrm{n} / \mathrm{a}$ & $\mathrm{n} / \mathrm{a}$ \\
\hline $\begin{array}{c}\text { Engineering } \\
\text { QA/QC }\end{array}$ & $50 \%$ & $390 \mathrm{~K}$ & $195 \mathrm{~K}$ & $330 \mathrm{~K}$ & $165 \mathrm{~K}$ & $1.9 \mathrm{M}$ & $950 \mathrm{~K}$ & $1.8 \mathrm{M}$ & $900 \mathrm{~K}$ & $410 \mathrm{KM}$ & $205 \mathrm{~K}$ & $1.5 \mathrm{M}$ & $750 \mathrm{~K}$ \\
\hline Health Physics & $12 \%$ & $150 \mathrm{~K}$ & $18 \mathrm{~K}$ & $150 \mathrm{~K}$ & $18 \mathrm{~K}$ & $3.1 \mathrm{M}$ & $372 \mathrm{~K}$ & $3.1 \mathrm{M}$ & $372 K$ & $200 \mathrm{~K}$ & $24 \mathrm{~K}$ & $2.5 \mathrm{M}$ & $300 \mathrm{~K}$ \\
\hline $\begin{array}{c}\text { Defuel, Drain, } \\
\text { and Recover }\end{array}$ & $12 \%$ & $165 \mathrm{~K}$ & $20 \mathrm{~K}$ & $165 \mathrm{~K}$ & $20 \mathrm{~K}$ & $165 \mathrm{~K}$ & $20 \mathrm{~K}$ & $165 \mathrm{~K}$ & $20 \mathrm{~K}$ & $165 \mathrm{~K}$ & $20 \mathrm{~K}$ & $165 \mathrm{~K}$ & $20 \mathrm{~K}$ \\
\hline $\begin{array}{l}\text { Replacement } \\
\text { Power }\end{array}$ & c & $14 \mathrm{M}$ & $3.5 \mathrm{M}$ & $14 \mathrm{M}$ & $3.5 \mathrm{M}$ & $70 \mathrm{M}$ & $18 \mathrm{M}$ & $70 \mathrm{M}$ & $18 \mathrm{M}$ & $14 \mathrm{M}$ & $3.5 \mathrm{M}$ & $56 \mathrm{M}$ & $14 \mathrm{M}$ \\
\hline NRC Cost & $12 \%$ & $52 \mathrm{~K}$ & $6.2 \mathrm{~K}$ & $52 \mathrm{~K}$ & $6.2 \mathrm{~K}$ & $52 \mathrm{~K}$ & $6.2 \mathrm{~K}$ & $52 \mathrm{~K}$ & $6.2 \mathrm{~K}$ & $52 \mathrm{~K}$ & $6.2 \mathrm{~K}$ & $52 \mathrm{~K}$ & $6.2 \mathrm{~K}$ \\
\hline $\operatorname{AOSC}(-\$)$ & c & $581 \mathrm{~K}$ & $226 \mathrm{~K}$ & $581 \mathrm{~K}$ & $226 \mathrm{~K}$ & $581 \mathrm{~K}$ & $226 \mathrm{~K}$ & $581 \mathrm{~K}$ & $226 \mathrm{~K}$ & $581 \mathrm{~K}$ & $226 \mathrm{~K}$ & $581 \mathrm{~K}$ & $226 \mathrm{~K}$ \\
\hline
\end{tabular}

${ }^{2}$ For a description of the different options refer to Section 3.1.

${ }^{b} \mathrm{~K}=$ thousand, $\mathrm{M}=$ million.

- Standard deviation is found by $3 \sigma=([$ High value-Best $]+[$ Best - Low value $]) / 2$, where $\sigma=$ standard deviation. 
Table 7. Cost analysis results.

\begin{tabular}{|c|c|c|c|c|c|c|c|c|c|c|c|c|}
\hline \multirow{2}{*}{ Cost type } & \multicolumn{2}{|c|}{ Option 1} & \multicolumn{2}{|c|}{ Option 2} & \multicolumn{2}{|c|}{ Option 3} & \multicolumn{2}{|c|}{ Option 4A } & \multicolumn{2}{|c|}{ Option 4B } & \multicolumn{2}{|c|}{ Option 5} \\
\hline & $\begin{array}{c}\text { Mean } \\
(\$)\end{array}$ & $\begin{array}{l}\text { Std. } \\
\text { Dev. }\end{array}$ & $\begin{array}{c}\text { Mean } \\
(\$)\end{array}$ & $\begin{array}{l}\text { Std. } \\
\text { Dev. }\end{array}$ & $\begin{array}{c}\text { Mean } \\
(\$)\end{array}$ & $\begin{array}{l}\text { Std. } \\
\text { Dev. }\end{array}$ & $\begin{array}{c}\text { Mean } \\
(\$)\end{array}$ & $\begin{array}{l}\text { Std. } \\
\text { Dev. }\end{array}$ & $\begin{array}{c}\text { Mean } \\
(\$)\end{array}$ & $\begin{array}{l}\text { Std. } \\
\text { Dev. }\end{array}$ & $\begin{array}{c}\text { Mean } \\
(\$)\end{array}$ & $\begin{array}{l}\text { Std. } \\
\text { Dev. }\end{array}$ \\
\hline $\begin{array}{c}\text { Total Cost w/o } \\
\text { AOSC \& w/o } \\
\text { RP }^{a}\end{array}$ & $1.7 \mathrm{M}^{\mathrm{b}}$ & $220 \mathrm{~K}$ & $1.5 \mathrm{M}$ & $190 \mathrm{~K}$ & $20 \mathrm{M}$ & $1.6 \mathrm{M}$ & $19 \mathrm{M}$ & $1.6 \mathrm{M}$ & $1.8 \mathrm{M}$ & $230 \mathrm{~K}$ & $15 \mathrm{M}$ & $1.5 \mathrm{M}$ \\
\hline $\begin{array}{c}\text { Total Cost w/o } \\
\text { RP }\end{array}$ & $1.1 \mathrm{M}$ & $320 \mathrm{~K}$ & $920 \mathrm{~K}$ & $300 \mathrm{~K}$ & $19 \mathrm{M}$ & $1.6 \mathrm{M}$ & $18 \mathrm{M}$ & $1.6 \mathrm{M}$ & $1.3 \mathrm{M}$ & $320 \mathrm{~K}$ & $15 \mathrm{M}$ & $1.5 \mathrm{M}$ \\
\hline Total Cost & $15 \mathrm{M}$ & $3.5 \mathrm{M}$ & $15 \mathrm{M}$ & $3.5 \mathrm{M}$ & $89 \mathrm{M}$ & $18 \mathrm{M}$ & $88 \mathrm{M}$ & $18 \mathrm{M}$ & $16 \mathrm{M}$ & $3.5 \mathrm{M}$ & $71 \mathrm{M}$ & $14 \mathrm{M}$ \\
\hline
\end{tabular}

a $\mathrm{RP}=$ replacement power.

${ }^{\mathrm{b}} \mathrm{K}=$ thousand $\mathrm{M}=$ million. 


\subsection{Radiation Exposure}

The occupational radiation exposure results are presented in Table 8. These doses were calculated based on a $10 \mathrm{mrem} / \mathrm{hour}$ radiation field. This dose rate was applied only to those installation or removal labor hours that were estimated to be performed in the radiation area $37.5 \%$ of total installation or removal labor hours). Due to the congested nature of the area where the work would be performed, the installation of additional shielding to lower the exposure would not be possible.

Table 8. Total occupational radiation exposure.

\begin{tabular}{|c|c|c|c|c|c|c|}
\hline Exposure & Option 1 & Option 2 & Option 3 & Option 4A & Option 4B & Option 5 \\
\hline $\begin{array}{c}\text { Total labor } \\
\text { hours }\end{array}$ & $4,200^{\circ}$ & $4,200^{\circ}$ & $90,000^{\circ}$ & $90,000^{\circ}$ & $5,600^{\mathrm{b}}$ & $71,000^{\mathrm{b}}$ \\
\hline $\begin{array}{c}\text { Labor hours in } \\
\text { radiation zone }\end{array}$ & 1,600 & 1,600 & 33,000 & 33,000 & 21,000 & 25,000 \\
\hline $\begin{array}{c}\text { Total exposure } \\
\text { (person rem) }\end{array}$ & 16 & 16 & 330 & 330 & 21 & 250 \\
\hline
\end{tabular}

a Estimated from Reference 13.

${ }^{b}$ Estimated from FORECAST data base.

The total exposures presented in Table 8 represent the total dose that would be received by the labor force. This total dose would be distributed throughout the work force performing the implementation of an option. The site as-low-as-reasonable-achievable (ALARA) program should ensure that none of the individual workers exceeds the maximum dose rates set by 10 CFR Part 20 . 


\section{COST/BENEFIT ASSESSMENT}

\subsection{Dollar-to-Person-Rem Averted Ratio}

One measure of the benefit achieved by modifying a plant, is the Dollar-to-Person-Rem Averted Ratio (DPR) as described in Reference 11. A value of $\$ 1000$ per person-rem is generally used by the NRC as an upperbound guideline in deciding whether corrective measures may be appropriate. The DPR is calculated as the modification cost divided by the offsite person-rem averted if the modification is performed, or:

$$
D P R=\frac{\text { Modification cost }}{\text { Averted Offsite Dose }}
$$

NRC policy recommends inclusion of the AOSC in the expression for the DPR. The inclusion of averted onsite costs reduces the cost of the modification, causing the cost benefit ratio to becomes more favorable. The DPR could then be calculated by:

$$
D P R=\frac{\text { Modification Cost }- \text { AOSC }}{\text { Averted Offsite Dose }}=\frac{\text { Total Costs }}{\text { Averted Offsite Dose }}
$$

\subsection{Cost/Benefit Results}

The results of the cost/benefit analysis were calculated using the formulas presented above, the modification costs developed in Section 3, and the offsite doses developed in Section 2. Tables 9 through 14 show the cost/benefit results for the GSI-15 modifications (options 1-5), including the case where the occupational exposure is included in the calculation. Inclusion of the occupational dose is accomplished by subtracting the occupational exposure from the averted offsite dose, or:

$$
D P R=\frac{\text { Total Costs }}{\text { Averted Offsite Dose-Occupational Dose }}
$$

For those cases where the occupational exposure exceeds the averted offsite dose, no net benefit (NNB) is reported as the result. This is done because once the benefit becomes zero or less, the cost/benefit ratio indicates that performing the modification will result in a larger occupational dose than what would be expected for the populational dose if the modification is not implemented.

Tables 9 through 14 include the best estimates for 10 year, 20 year, 40 year, and 60 year remaining lifespans (see Appendix $\mathrm{A}$ and Appendix $\mathrm{C}$ for an example of the uncertainty calculations). The remaining lifespan is the time left to operate the plant after the supports have become brittle. The results in the tables are calculated for the three cost categories: without either AOSC or replacement power, with AOSC but without replacement power, and with both AOSC and replacement power. The calculated values are considered to be best estimate values. Graphical results are presented in Appendix D. The graphs are given to assist in evaluating the relative cost/benefit magnitudes between the different options and the different cost categories. 
Table 9. Cost/Benefit results for Option 1.

\begin{tabular}{||c|c|c|c|c|c|c||}
\hline \multirow{2}{*}{$\begin{array}{c}\text { Years after } \\
\text { embrittlement }\end{array}$} & \multicolumn{2}{|c|}{$\begin{array}{c}\text { Cost/Benefit (without occupational } \\
\text { dose) [\$/person-rem] }\end{array}$} & \multicolumn{2}{c|}{$\begin{array}{c}\text { Cost/Benefit (with occupational } \\
\text { dose) [\$/person-rem] }\end{array}$} \\
\cline { 2 - 7 } & $\begin{array}{c}\text { Total w/o } \\
\text { AOSC \& } \\
\text { w/o RP }\end{array}$ & $\begin{array}{c}\text { Total w/o } \\
\text { RP }\end{array}$ & Total & $\begin{array}{c}\text { Total w/o } \\
\text { AOSC \& } \\
\text { w/o RP }\end{array}$ & $\begin{array}{c}\text { Total w/o } \\
\text { RP }\end{array}$ & Total \\
\hline 10 & $59 \mathrm{~K}^{\mathrm{b}}$ & $38 \mathrm{~K}$ & $520 \mathrm{~K}$ & $130 \mathrm{~K}$ & $86 \mathrm{~K}$ & $1.2 \mathrm{M}$ \\
\hline 20 & $30 \mathrm{~K}$ & $19 \mathrm{~K}$ & $260 \mathrm{~K}$ & $41 \mathrm{~K}$ & $26 \mathrm{~K}$ & $360 \mathrm{~K}$ \\
\hline 40 & $15 \mathrm{~K}$ & $9.5 \mathrm{~K}$ & $130 \mathrm{~K}$ & $17 \mathrm{~K}$ & $11 \mathrm{~K}$ & $150 \mathrm{~K}$ \\
\hline 60 & $9.8 \mathrm{~K}$ & $6.3 \mathrm{~K}$ & $87 \mathrm{~K}$ & $11 \mathrm{~K}$ & $7.0 \mathrm{~K}$ & $96 \mathrm{~K}$ \\
\hline
\end{tabular}

${ }^{\mathrm{a}} \mathrm{RP}=$ Replacement Power

${ }^{\mathrm{b}} \mathrm{K}=$ thousand, $\mathrm{M}=$ million

Table 10. Cost/Benefit results for Option 2.

\begin{tabular}{||c|c|c|c|c|c|c||}
\hline \multirow{2}{*}{$\begin{array}{c}\text { Years after } \\
\text { embrittlement }\end{array}$} & \multicolumn{2}{|c|}{$\begin{array}{c}\text { Cost/Benefit (without occupational } \\
\text { dose) [\$/person-rem] }\end{array}$} & \multicolumn{2}{c|}{$\begin{array}{c}\text { Cost/Benefit (with occupational } \\
\text { dose) [\$/person-rem] }\end{array}$} \\
\cline { 2 - 7 } & $\begin{array}{c}\text { Total w/o } \\
\text { AOSC \& } \\
\text { w/o RP }\end{array}$ & $\begin{array}{c}\text { Total w/o } \\
\text { RP }\end{array}$ & Total & $\begin{array}{c}\text { Total w/o } \\
\text { AOSC \& } \\
\text { w/o RP }\end{array}$ & $\begin{array}{c}\text { Total w/o } \\
\text { RP }\end{array}$ & Total \\
\hline 10 & $52 \mathrm{~K}^{\mathrm{b}}$ & $32 \mathrm{~K}$ & $520 \mathrm{~K}$ & $120 \mathrm{~K}$ & $72 \mathrm{~K}$ & $1.2 \mathrm{M}$ \\
\hline 20 & $26 \mathrm{~K}$ & $16 \mathrm{~K}$ & $260 \mathrm{~K}$ & $36 \mathrm{~K}$ & $22 \mathrm{~K}$ & $360 \mathrm{~K}$ \\
\hline 40 & $13 \mathrm{~K}$ & $8 \mathrm{~K}$ & $130 \mathrm{~K}$ & $15 \mathrm{~K}$ & $9.3 \mathrm{~K}$ & $150 \mathrm{~K}$ \\
\hline 60 & $8.7 \mathrm{~K}$ & $5.3 \mathrm{~K}$ & $87 \mathrm{~K}$ & $9.6 \mathrm{~K}$ & $5.9 \mathrm{~K}$ & $96 \mathrm{~K}$ \\
\hline
\end{tabular}

${ }^{\text {a }} \mathrm{RP}=$ Replacement Power

${ }^{\mathrm{b}} \mathrm{K}=$ thousand, $\mathrm{M}=$ million 
Table 11. Cost/Benefit results for Option 3.

\begin{tabular}{||c|c|c|c|c|c|c||}
\hline \multirow{2}{*}{$\begin{array}{c}\text { Years after } \\
\text { embrittlement }\end{array}$} & \multicolumn{2}{|c|}{$\begin{array}{c}\text { Cost/Benefit (without occupational } \\
\text { dose) [\$/person-rem] }\end{array}$} & \multicolumn{2}{|c|}{$\begin{array}{c}\text { Cost/Benefit (with occupational } \\
\text { dose) [\$/person-rem] }\end{array}$} \\
\cline { 2 - 7 } & $\begin{array}{c}\text { Total w/o } \\
\text { AOSC \& } \\
\text { w/o RP }\end{array}$ & $\begin{array}{c}\text { Total w/o } \\
\text { RP }\end{array}$ & Total & $\begin{array}{c}\text { Total w/o } \\
\text { AOSC \& } \\
\text { w/o RP }\end{array}$ & $\begin{array}{c}\text { Total w/o } \\
\text { RP }\end{array}$ & Total \\
\hline 10 & $690 \mathrm{~K}^{\mathrm{b}}$ & $660 \mathrm{~K}$ & $3.1 \mathrm{M}$ & NNB $^{\mathrm{c}}$ & NNB & NNB \\
\hline 20 & $350 \mathrm{~K}$ & $330 \mathrm{~K}$ & $1.6 \mathrm{M}$ & NNB & NNB & NNB \\
\hline 40 & $170 \mathrm{~K}$ & $170 \mathrm{~K}$ & $780 \mathrm{~K}$ & NNB & NNB & NNB \\
\hline 60 & $120 \mathrm{~K}$ & $110 \mathrm{~K}$ & $520 \mathrm{~K}$ & NNB & NNB & NNB \\
\hline
\end{tabular}

${ }^{2} \mathrm{RP}=$ Replacement Power

${ }^{b} \mathrm{~K}=$ thousand, $\mathrm{M}=$ million

${ }^{\circ} \mathrm{NNB}=$ no net benefit

Table 12. Cost/Benefit results for Option 4A.

\begin{tabular}{||c|c|c|c|c|c|c||}
\hline \multirow{2}{*}{$\begin{array}{c}\text { Years after } \\
\text { embrittlement }\end{array}$} & \multicolumn{2}{|c|}{$\begin{array}{c}\text { Cost/Benefit (without occupational } \\
\text { dose) [\$/person-rem] }\end{array}$} & \multicolumn{2}{c|}{$\begin{array}{c}\text { Cost/Benefit (with occupational } \\
\text { dose) [\$/person-rem] }\end{array}$} \\
\cline { 2 - 7 } & $\begin{array}{c}\text { Total w/o } \\
\text { AOSC \& } \\
\text { w/o RP }\end{array}$ & $\begin{array}{c}\text { Total w/o } \\
\text { RP }\end{array}$ & Total & $\begin{array}{c}\text { Total w/o } \\
\text { AOSC \& } \\
\text { w/o RP }\end{array}$ & $\begin{array}{c}\text { Total w/o } \\
\text { RP }\end{array}$ & Total \\
\hline 10 & $660 \mathrm{~K}^{\mathrm{b}}$ & $630 \mathrm{~K}$ & $3.1 \mathrm{M}$ & NNB $^{\mathrm{c}}$ & NNB & NNB \\
\hline 20 & $330 \mathrm{~K}$ & $320 \mathrm{~K}$ & $1.6 \mathrm{M}$ & NNB & NNB & NNB \\
\hline 40 & $170 \mathrm{~K}$ & $160 \mathrm{~K}$ & $780 \mathrm{~K}$ & NNB & NNB & NNB \\
\hline 60 & $110 \mathrm{~K}$ & $110 \mathrm{~K}$ & $520 \mathrm{~K}$ & NNB & NNB & NNB \\
\hline \hline
\end{tabular}

${ }^{2} \mathrm{RP}=$ Replacement Power

${ }^{b} \mathrm{~K}=$ thousand, $\mathrm{M}=$ million

c $\mathrm{NNB}=$ no net benefit 
Table 13. Cost/Benefit results for Option 4B.

\begin{tabular}{||c|c|c|c|c|c|c||}
\hline \multirow{2}{*}{$\begin{array}{c}\text { Years after } \\
\text { embrittlement }\end{array}$} & \multicolumn{2}{|c|}{$\begin{array}{c}\text { Cost/Benefit (without occupational } \\
\text { dose) [\$/person-rem] }\end{array}$} & \multicolumn{2}{c|}{$\begin{array}{c}\text { Cost/Benefit (with occupational } \\
\text { dose) [\$/person-rem] }\end{array}$} \\
\cline { 2 - 7 } & $\begin{array}{c}\text { Total w/o } \\
\text { AOSC \& } \\
\text { w/o RP }\end{array}$ & $\begin{array}{c}\text { Total w/o } \\
\text { RP }\end{array}$ & Total & $\begin{array}{c}\text { Total w/o } \\
\text { AOSC \& } \\
\text { w/o RP }\end{array}$ & $\begin{array}{c}\text { Total w/o } \\
\text { RP }\end{array}$ & Total \\
\hline 10 & $63 \mathrm{~K}^{\mathrm{b}}$ & $45 \mathrm{~K}$ & $560 \mathrm{~K}$ & $230 \mathrm{~K}$ & $170 \mathrm{~K}$ & $2.1 \mathrm{M}$ \\
\hline 20 & $32 \mathrm{~K}$ & $23 \mathrm{~K}$ & $280 \mathrm{~K}$ & $49 \mathrm{~K}$ & $36 \mathrm{~K}$ & $440 \mathrm{~K}$ \\
\hline 40 & $16 \mathrm{~K}$ & $11 \mathrm{~K}$ & $140 \mathrm{~K}$ & $19 \mathrm{~K}$ & $14 \mathrm{~K}$ & $170 \mathrm{~K}$ \\
\hline 60 & $11 \mathrm{~K}$ & $7.5 \mathrm{~K}$ & $93 \mathrm{~K}$ & $12 \mathrm{~K}$ & $8.6 \mathrm{~K}$ & $110 \mathrm{~K}$ \\
\hline
\end{tabular}

a RP = Replacement Power

${ }^{b} \mathrm{~K}=$ thousand, $\mathrm{M}=$ million

Table 14. Cost/Benefit results for Option 5.

\begin{tabular}{||c|c|c|c|c|c|c||}
\hline \multirow{2}{*}{$\begin{array}{c}\text { Years after } \\
\text { embrittlement }\end{array}$} & \multicolumn{3}{|c|}{$\begin{array}{c}\text { Cost/Benefit (without occupational } \\
\text { dose) }\end{array}$} & \multicolumn{3}{c|}{$\begin{array}{c}\text { Cost/Benefit (with occupational } \\
\text { dose) }\end{array}$} \\
\cline { 2 - 7 } & $\begin{array}{c}\text { Total w/o } \\
\text { AOSC \& } \\
\text { w/o RP }\end{array}$ & $\begin{array}{c}\text { Total w/o } \\
\text { RP }\end{array}$ & Total & $\begin{array}{c}\text { Total w/o } \\
\text { AOSC \& } \\
\text { w/o RP }\end{array}$ & $\begin{array}{c}\text { Total w/o } \\
\text { RP }\end{array}$ & Total \\
\hline 10 & $520 \mathrm{~K}$ & $520 \mathrm{~K}$ & $2.5 \mathrm{M}$ & NNB $^{\mathrm{c}}$ & NNB & NNB \\
\hline 20 & $260 \mathrm{~K}$ & $260 \mathrm{~K}$ & $1.3 \mathrm{M}$ & NNB & NNB & NNB \\
\hline 40 & $130 \mathrm{~K}$ & $130 \mathrm{~K}$ & $630 \mathrm{~K}$ & NNB & NNB & NNB \\
\hline 60 & $87 \mathrm{~K}$ & $87 \mathrm{~K}$ & $420 \mathrm{~K}$ & NNB & NNB & NNB \\
\hline
\end{tabular}

${ }^{2} \mathrm{RP}=$ Replacement Power

${ }^{b} \mathrm{~K}=$ thousand, $\mathrm{M}=$ million

${ }^{c} \mathrm{NNB}=$ no net benefit 


\section{SUMMARY OF COST/BENEFIT FINDINGS}

The cost results (see Table 7) indicate the estimated per plant costs range from a low value of $\$ 920,000$ for Option 2 (increasing the operating temperature of the supports) to a high value of $\$ 89,000,000$ for Option 3 (replacing the existing supports). The low value takes into account averted onsite costs and assumes no need to purchase replacement power. The high value also takes into account averted onsite costs, but assumes replacement power would have to be purchased for a 20 week period.

The results of the benefit analysis indicate a per plant offsite dose risk of 2.9 person-rem/year with a calculated core damage frequency of $8.8 \times 10^{-5} / \mathrm{yr}$. The risk value includes all the risk associated with support failure after embrittlement occurs. It was assumed that the implementation of any of the proposed options would remove $100 \%$ of the risk associated with failure of an embrittled support.

The above information provided best estimate cost/benefit ratios ranging from $\$ 5,300$ per person-rem (Option 2 with AOSC and without replacement power and occupational dose over a 60 year embrittlement period) to $\$ 3,100,000$ per person-rem (Options 3 and 4 with AOSC and replacement power and without occupational dose over a ten year embrittlement period). When the occupational dose is considered, the cost benefit ratios increase. In those cases where the occupational dose exceeds the averted offsite dose, no net benefit is obtained.

Appendix B presents a number of sensitivity studies to show how the results can change given changes in the modeling data. Table B-2 gives four extreme cases of cost/benefit. It should be pointed out that these extreme cases represent the worst possible case for the cost/benefit analysis. In the case of minimum cost/maximum benefit, a potential cost/benefit ratio of $\$ 54$ per person-rem is obtained. This represents the case where the minimum-cost option would correct the problem for a plant located in an area of high populational density (assuming no occupational dose and a 60-year embrittlement period). 


\section{REFERENCES}

1. Cheverton, R. D., et al., Impact of Radiation Embrittlement on Integrity of Pressure Vessel Supports for Two PWR Plants, Oak Ridge National Laboratory, NUREG/CR5320, ORNL/Tm-10966, January 1989.

2. Reactor Safety Study, U.S. NRC, WASH-1400, 1975.

3. Chang, T. Y. and N. R. Anderson, Regulatory Analysis for Resolution of Unresolved Safety Issues A-46, Seismic Qualification of Equipment in Operating Plants, NUREG1211, February 1987.

4. American Institute of Steel Construction, Manual of Steel Construction, Allowable Stress Design, 9th Ed.

5. NUREG-0800, Standard Review Plan, Section 3.8.3, Concrete and Steel Internal Structures of Steel or Concrete Containments, Rev. 1, U.S. Nuclear Regulatory Commission, July 1981.

6. NUREG/CR-4885, Seismic Characterization of the Eastern United States: Comparative Evaluation of the LLNL and EPRI Studies, U.S. Nuclear Regulatory Commission, May 1987.

7. Bertucio, R. C. and S. R. Brown, Analysis of Core Damage Frequency: Sequoyah, Unit 1, Internal Events, Sandia National Laboratory, NUREG/CR-4550, Revision 1, Volume 5, June 1989.

8. Public Service Electric and Gas Company, Salem Nuclear Generating Station Probabilistic Risk Assessment, EI International, Inc., October 1988.

9. Andrews, W., et al., Guideline for Nuclear Power Plant Safety Issue Prioritization Information Development, Pacific Northwest Laboratory, NUREG/CR-2800, 1983.

10. Heaberlin, S. W., et al., A Handbook for Value-Impact Assessment, Pacific Northwest Laboratory, NUREG/CR-3568, PNL-4646, December 1983.

11. Claiborne, E. et al., Generic Cost Estimates, NUREG/CR-4627, Revision 1, February 1989.

12. Lopez, B. and F. W. Sciacca, "FORECAST", 2.1 User Manual, Science and Engineering Associates, Inc., SEA Report No. 89-461-04-A:1, April 1990.

13. Emrit, R. et al., A Prioritization of Generic Safety Issues, NUREG-0933, Revision 2, December 1989. 


\section{APPENDIX A - GSI-15 Event Tree Uncertainty Analysis}

The event tree uncertainty analysis was initiated by assigning an appropriate uncertainty to each event in both of the event tree sequences. Table A.1 lists each event with its mean value, standard deviation, and assumed underlying probability distribution type. The source listed in the table is the source of the event mean value. The standard deviation value for the two Poisson

initiating events were calculated by the relationship of: standard deviation $=\sqrt{\text { mean }} .{ }^{2}$ The standard deviation value for the log-normal distributions in the table were estimated based upon engineering judgement.

Table A.1. Sequence Event Uncertainty Parameters.

\begin{tabular}{||c|c|c|c|c||}
\hline Event & Mean & $\begin{array}{c}\text { Standard } \\
\text { deviation }\end{array}$ & $\begin{array}{c}\text { Distribution } \\
\text { type }\end{array}$ & Source \\
\hline SSE & $1.25 \times 10^{-3}$ & $3.5 \times 10^{-2}$ & Poisson & Ref. 3 \\
\hline SBLOCA & $5.0 \times 10^{-4}$ & $2.2 \times 10^{-2}$ & Poisson & Ref. 7 \\
\hline RPVSF & $5.0 \times 10^{-1}$ & $2.0 \times 10^{-1}$ & Log-normal & EJ $^{\mathbf{b}}$ \\
\hline LBLOCA & $5.0 \times 10^{-1}$ & $2.0 \times 10^{-1}$ & Log-normal & EJ \\
\hline RPSF & $5.0 \times 10^{-1}$ & $2.0 \times 10^{-1}$ & Log-normal & EJ \\
\hline CSDSF & $2.0 \times 10^{-1}$ & $1.0 \times 10^{-1}$ & Log-normal & Ref. 7 \\
\hline ECCSF & $1.0 \times 10^{-1}$ & $1.0 \times 10^{-1}$ & Log-normal & EJ \\
\hline \multirow{2}{*}{ RCF } & $1.0 \times 10^{-3}$ & $5.0 \times 10^{-3}$ & \multirow{2}{*}{ Log-normal } & Ref. 7 \\
\cline { 2 - 3 } & $1.0 \times 10^{-2}$ & $5.0 \times 10^{-2}$ & & EJ \\
\hline
\end{tabular}

${ }^{\mathrm{b}} \mathrm{EJ}=$ Engineering Judgement.

Normally probabilistic risk assessments assign log-normal distributions to the individual events contained in event trees. This arbitrary assignment of distributions stems from the fact that the lognormal distribution efficiently models events with low probabilities. But, for unlikely events (such as an earthquake) that occur at a constant rate and that change the system once the event does occur, a Poisson distribution is frequently used as the underlying distribution ${ }^{b}$.

a This relationship is only valid on Poisson distributed events.

b The PRA Procedures Guide, USNRC Report NUREG/CR-2300, Jan. 1983, illustrates calculating the occurrence of earthquakes by using the Poisson distribution. Other probability and statistics texts and seismic reports verify that events such as an earthquake may be modeled by the Poisson distribution. 
In Table A.1, event RCF is listed as having two parameters. The first parameter $\left(1.0 \times 10^{-3}\right)$ models the normal, independent failure of the containment, while the second parameter $\left(1.0 \times 10^{-2}\right)$ models the correlated failure mode of the emergency core cooling system and the reactor containment.

The event tree sequences were analyzed using a numerical Taylor series expansion routine to find the mean and standard deviation for each sequence outcome. The Taylor series expansion program was written by one of the authors (Smith) and was verified, both by hand calculations and textbook problems, before use on this project. Appendix C presents two samples of the program verification.

Table A.2 lists the sequence end states expected probability, 95th percentile probability, and standard deviation. The probability distribution for each sequence outcome is assumed to be lognormally distributed due to the multiplication of several events. The expected probability and standard deviation were obtained from the Taylor series expansion program. The 95th percentile valve was calculated using the obtained expected value and standard deviation and the assumption that the resulting distribution was log-normal.

Table A.2. Event tree sequence end state results.

\begin{tabular}{||c|c|c|c|}
\hline Sequence end state & $\begin{array}{c}\text { Mean probability } \\
\text { (per year) }\end{array}$ & $\begin{array}{c}95 \text { th percentile } \\
\text { (per year) }\end{array}$ & $\begin{array}{c}\text { Standard deviation } \\
\text { (per year) }\end{array}$ \\
\hline SPRA & $8.8 \times 10^{-4}$ & $2.3 \times 10^{-3}$ & $2.1 \times 10^{-2}$ \\
\hline SF-PSD & $3.9 \times 10^{-4}$ & $1.2 \times 10^{-3}$ & $6.6 \times 10^{-3}$ \\
\hline PWR 9 & $3.9 \times 10^{-4}$ & $1.0 \times 10^{-3}$ & $9.3 \times 10^{-3}$ \\
\hline PWR 8 & $3.9 \times 10^{-7}$ & $1.0 \times 10^{-6}$ & $9.4 \times 10^{-6}$ \\
\hline PWR 7 & $8.7 \times 10^{-5}$ & $2.6 \times 10^{-4}$ & $1.5 \times 10^{-3}$ \\
\hline PWR 3 & $4.4 \times 10^{-8}$ & $1.2 \times 10^{-7}$ & $1.0 \times 10^{-6}$ \\
\hline PWR 1 & $4.4 \times 10^{-7}$ & $1.2 \times 10^{-6}$ & $1.0 \times 10^{-5}$ \\
\hline
\end{tabular}

Table A.2 lists the 95th percentile values for the sequence end state distribution. The different percentile values (5th, 50th, and 95th) and error factor (EF) for a log-normal distribution are calculated using the equations below. Traditionally, the 5th percentile is considered a lower bound while the 95th percentile is an upper bound.

$$
\begin{gathered}
E F=e^{1.645\left(\ln \left[1+(\sigma / \mu)^{2}\right]\right)^{2 / 2}} \\
\text { median }=50 \text { th }=\frac{\mu}{\left[1+(\sigma / \mu)^{2}\right]^{1 / 2}}
\end{gathered}
$$




$$
\begin{gathered}
95 t h=\text { median } \cdot E F \\
5 t h=\frac{\text { median }}{E F}
\end{gathered}
$$

where

$\sigma=$ log-normal standard deviation

$\mu=\log$-normal mean

The risk is defined as the probability of an event multiplied by the release consequence of the event. The risk is then extrapolated over the estimated remaining lifetime of a typical reactor. Most of the embrittlement of the RPVSs occur early in the lifetime of a plant. For the purpose of illustration in this appendix, the analysis assumes that the plant has a 10 year remaining lifetime. The risk from each event sequence is then summed for the 10 years to get an upperbound total risk.

Table A.3 lists the whole body dose consequence associated with each end state category. The consequence data quantifies the WASH-1400 end states and is taken from NUREG/CR-2800. The consequence for the SPRA and SF-PSD end state are both assumed to be zero (no additional risk). The consequence dose values are not treated as uncertain variables. Rather, the values are handled as upper bound numbers, which requires the values to be treated as conservative point estimates.

Table A.3. End state radioactive release consequences.

\begin{tabular}{|c|c|c||}
\hline \multirow{2}{*}{ Category } & \multicolumn{2}{|c|}{ Consequence factor (person-rem) } \\
\cline { 2 - 3 } & Core Melt & Non Core Melt \\
\hline PWR 1 & $5.4 \times 10^{6}$ & \\
\hline PWR 3 & $5.4 \times 10^{6}$ & \\
\hline PWR 7 & $2.3 \times 10^{3}$ & \\
\hline PWR 8 & & $7.5 \times 10^{4}$ \\
\hline PWR 9 & & $1.2 \times 10^{2}$ \\
\hline
\end{tabular}

Table A.4 lists the results of the risk analysis. The end state release consequence is multiplied by the end state probability to get an end state risk. The risk is then summed and multiplied by the 10-year duration to get the total additional population risk associated with the possible RPV support failure due to a SSE or a SBLOCA. 
Table A.4. Risk analysis uncertainty results.

\begin{tabular}{|c|c|c|c||}
\hline Category & $\begin{array}{c}\text { Expected risk } \\
\text { (person-rem) }\end{array}$ & $\begin{array}{c}\text { Standard deviation } \\
\text { (person-rem) }\end{array}$ & $\begin{array}{c}\text { 95th Percentile risk } \\
\text { (person-rem) }\end{array}$ \\
\hline SPRA & 0/year & 0/year & 0/year \\
\hline SF-PSD & 0/year & 0/year & 0/year \\
\hline PWR 9 & $0.047 /$ year & $1.12 /$ year & $0.12 /$ year \\
\hline PWR 8 & $0.029 /$ year & $0.71 /$ year & $0.077 /$ year \\
\hline PWR 7 & $0.20 /$ year & $3.5 /$ year & $0.58 /$ year \\
\hline PWR 3 & $0.24 /$ year & $5.4 /$ year & $0.65 /$ year \\
\hline PWR 1 & $2.4 /$ year & $54.0 /$ year & $6.4 /$ year \\
\hline \hline$\Sigma=$ & $2.9 /$ year & $54 /$ year & 8.2 /year \\
\hline$\times 10$ years & 29 & 540 & 82 \\
\hline
\end{tabular}

Table A.4 shows the expected risk is 29 person-rem for the entire ten year embrittlement duration. Accounting for the uncertainties in the event tree analysis gives a 95 th percentile risk of 82 person-rem.

Figure A.1 shows the cumulative probability distribution curve for the base case risk. The base case median risk value can be found by taking 10 to the power of the 0.50 -probability-risk-value (since the $\log$ scale is on a base 10 ). From the graph, the 0.50 -probability-risk-value is approximately -0.8 . Thus, the median risk is calculated to be:

$$
\text { Risk }_{\text {median }}=10^{-0.8}=0.16 \text { person }- \text { rem } / \text { year }
$$

or 1.6 person-rem for the ten year embrittlement duration. The difference between the median and the 95th values illustrates how the uncertainty can skew the calculated values. But even though the uncertainty may result in a wide range of values, the best estimate should be used in decisionmaking due to the conservative nature of the analysis. 


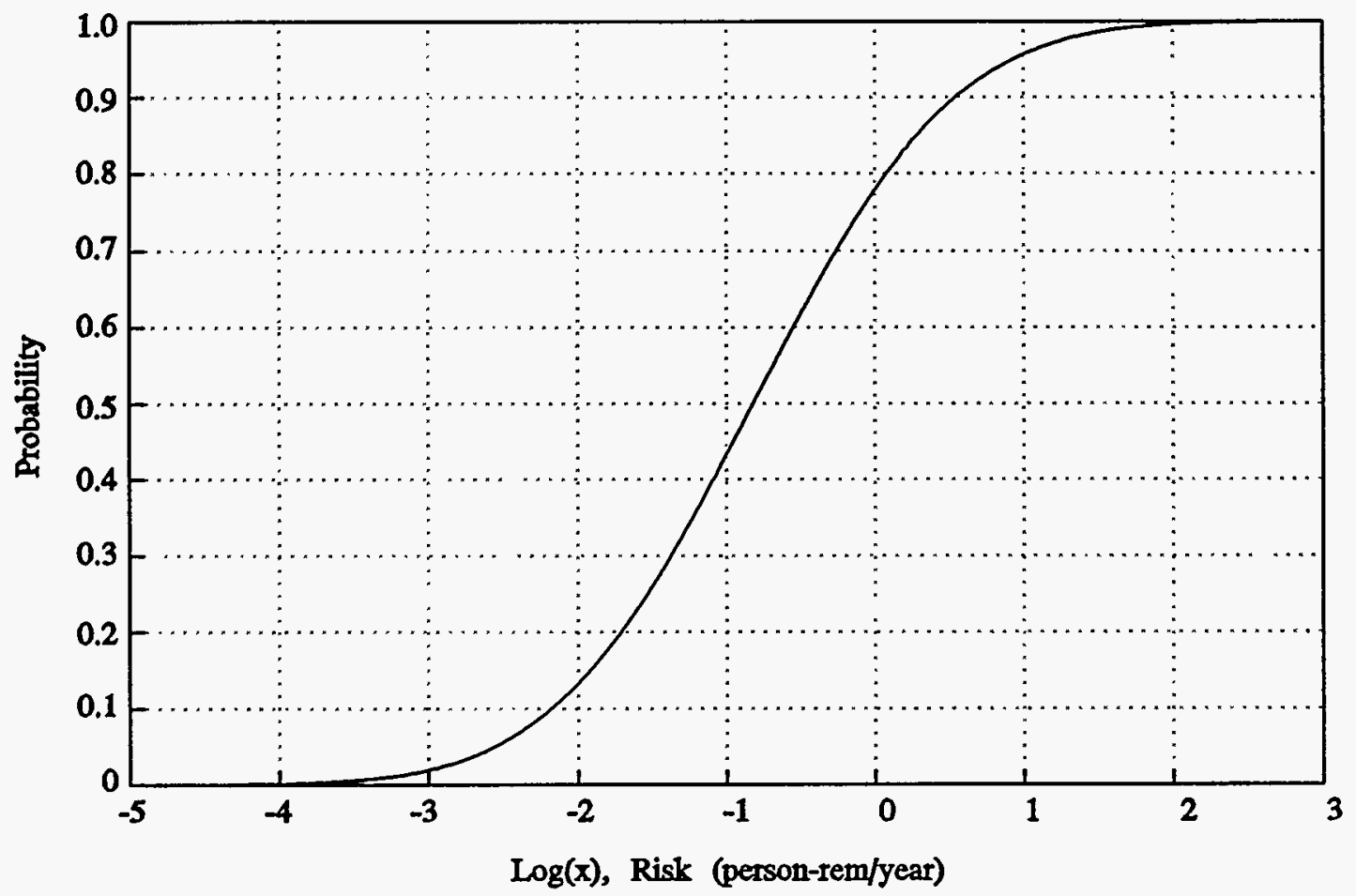

Figure A.1 : Base Case Risk Cumulative Probability Curve. 


\section{APPENDIX B - GSI-15 Risk Sensitivity Analysis}

To judge how sensitive the results of the GSI-15 risk calculations (benefit evaluation) were to the values used for event tree quantification, several supplemental cases were evaluated with even more conservative estimates of failure probabilities. Seven cases were evaluated as discussed below.

Case 1 Increase the frequency of an SSE by a factor of ten. For most plants, this will have the same effect as assuming that a $0.05 \mathrm{~g}$ earthquake will have sufficient force to potentially result in RPVS failure.

Case 2 Increase offsite dose rates by a factor of 100 . This will show the potential results for a plant located in an area of high population density.

Case 3 Increase the probabilities of RPVSF and LBLOCA to 1. This will show the maximum uncertainty in the RPVS failure mechanisms.

Case 4 Increase the probabilities of RPVSF and RPSF to 1 and decrease the probability of LBLOCA to 0 . This will show the maximum uncertainty in the reactor protection system failure mechanisms.

Case 5 Increase the probability of ECCSF and CSDSF to 1. This will show the maximum uncertainty involved in initiating event-induced failure of these safety systems.

Case 6 Increase the probabilities of LBLOCA and ECCSF to 1. This will show the maximum uncertainty involving the dependence of a LBLOCA and ECCS failure on RPVS failure. In other words, it simulates the pressure vessel falling sufficiently (following RPVS failure) to allow the ECCS injection lines to break or become inoperable.

Case 7 Set the probabilities of RPVSF, LBLOCA, RPSF, CSDSF, and ECCSF to 1. This allows for a worst case model of complete failure of the entire reactor protection system with the exception of the containment. This scenario should be considered to be a worst case scenario where the RPVSs and RPV supporting piping are embrittled. Following the initiating event, the subsequent shifting of the RPV results in failure of all core protection systems.

Table B.1. shows the risk results for each of the seven cases and the base case. The results for each case are given in terms of core melt frequency and expected offsite dose (person-rem) per year per plant. Also included in the table are the risks associated with ten, twenty, forty, and sixty years of cumulative operation in a condition where the RPVSs are susceptible to failure. 
Table B.1. Sensitivity analysis results.

\begin{tabular}{|c|c|c|c|c|c|c|}
\hline Case & $\begin{array}{l}\text { Core melt } \\
\text { frequency } \\
\text { (per year) }\end{array}$ & $\begin{array}{c}\text { Risk } \\
\text { (per year) } \\
\text { [person-rem] }\end{array}$ & $\begin{array}{c}\text { Risk } \\
\text { (10 years) } \\
\text { [person-rem] }\end{array}$ & $\begin{array}{c}\text { Risk } \\
\text { (20 years) } \\
\text { [person-rem] }\end{array}$ & $\begin{array}{c}\text { Risk } \\
\text { (40 years) } \\
\text { [person-rem] }\end{array}$ & $\begin{array}{c}\text { Risk } \\
\text { (60 years) } \\
\text { [person-rem] }\end{array}$ \\
\hline 1 & $6.5 \times 10^{-4}$ & 21 & 210 & 420 & 840 & 1,300 \\
\hline 2 & $8.8 \times 10^{-5}$ & 290 & 2,900 & 5,800 & 12,000 & 17,000 \\
\hline 3 & $1.8 \times 10^{-4}$ & 10 & 100 & 200 & 400 & 600 \\
\hline 4 & $3.5 \times 10^{-4}$ & 2.7 & 27 & 54 & 110 & 160 \\
\hline 5 & $6.6 \times 10^{-4}$ & 26 & 260 & 520 & 1,000 & 1,600 \\
\hline 6 & $8.8 \times 10^{-4}$ & 49 & 490 & 980 & 2,000 & 2,900 \\
\hline 7 & $1.8 \times 10^{-3}$ & 98 & 980 & 2,000 & 3,900 & 5,900 \\
\hline Base & $8.8 \times 10^{-5}$ & 2.9 & 29 & 58 & 120 & 170 \\
\hline
\end{tabular}


Four extreme cases of cost/benefit were calculated from the results of Table B.1 and the costs from Table 7. The four extreme cases were:

$$
\begin{array}{cc}
\text { I. } \frac{\text { maximum cost }}{\text { minimum benefit }} & \text { II. } \frac{\text { maximum cost }}{\text { maximum benefit }} \\
\text { III. } \frac{\text { minimum cost }}{\text { minimum benefit }} & \text { IV. } \frac{\text { minimum cost }}{\text { maximum benefit }}
\end{array}
$$

For the above case, the minimum benefit was assumed to be 27 person-rem (Table B.1, case 4 , for 10 years), the maximum benefit was assumed to be 17,400 person-rem (Table B.1, case 2 , for 60 years), the minimum cost was assumed to be $\$ 920,000$ (Table 7 , Option 2, with AOSC but without replacement power), and the maximum cost was assumed to be $\$ 89 \mathrm{M}$ (Table 7 , Option 3 , with AOSC and replacement power). The results of the four extreme cost/benefit cases are presented in Table B.2.

Table B.2. Extreme Cost/Benefit results.

\begin{tabular}{|c|c|c|}
\hline Case & Case description & $\begin{array}{c}\text { Cost/Benefit } \\
(\$ / \text { person-rem })\end{array}$ \\
\hline I & maximum cost/minimum benefit & $3,100,000$ \\
\hline II & maximum cost/maximum benefit & 5,300 \\
\hline III & minimum cost/minimum benefit & 34,000 \\
\hline IV & minimum cost/maximum benefit & 54 \\
\hline
\end{tabular}




\section{APPENDIX C - Taylor Series Expansion Program Verification}

To assist with the analysis contained in this report, a computer program (TSE) was used to evaluate the Taylor series expansion expressions. As a check for the program, several sample problems were entered in the program to be verified. Also, portions of the analysis in this report were hand calculated to check the numerical results. The remainder of this appendix illustrates how the Taylor series calculations are made and two sample problems are given.

Two equations from the Taylor series expansion arise depending on whether the resulting variable is calculated by a product or a summation. For the case of the product $Z=X_{1} \cdot X_{2} \cdot X_{3} \cdot \ldots \cdot X_{n}$, the mean and standard deviation are found by:

$$
\begin{gathered}
\text { mean of } z=\mu_{Z}=\mu_{X_{1}} \cdot \mu_{X_{2}} \cdot \mu_{X_{3}} \cdot \ldots \cdot \mu_{X_{n}} \\
\text { standard deviation of } z=\sigma_{Z}=\left[\sum_{i=1}^{n}\left[\frac{\partial z}{\partial X_{i}}\right]^{2}\left(\sigma_{X_{i}}\right)^{2}\right]^{1 / 2}
\end{gathered}
$$

For the case of the summation, if $Z=X_{1}+X_{2}+X_{3}+\ldots+X_{n}$, the mean and standard deviation are found by:

$$
\begin{gathered}
\text { mean of } z=\mu_{Z}=\mu_{X_{1}}+\mu_{X_{2}}+\mu_{X_{3}}+\ldots+\mu_{X_{*}} \\
\text { standard deviation of } z=\sigma_{z}=\left[\sum_{i=1}^{n}\left(\sigma_{X_{i}}\right)^{2}\right]^{1 / 2}
\end{gathered}
$$

The TSE program will calculate the mean and standard deviation for any function that can be entered into the program. The partial derivatives are numerically calculated within the program, thereby reducing the analysis time.

For the first sample problem to verify the TSE program, a problem from the statistics book Statistical Models in Engineering by G. Hahn and S. Shapiro was evaluated. The problem asks to calculate the electron current for the circuit given in Figure C.1. The equation to calculate the current is:

$$
I=V\left(\frac{1}{R_{A}}+\frac{1}{R_{B}}+\frac{1}{R_{C}}\right)
$$

" Hahn, G. J. and S. S. Shapiro, Statistical Models in Engineering, John Wiley \& Sons, Inc., 1967, pp. 230-232. 


$$
\text { where } \begin{aligned}
I & =\text { current (amps) } \\
V & =\text { voltage (volts) } \\
\mathrm{R} & =\text { resistance (ohms) }
\end{aligned}
$$

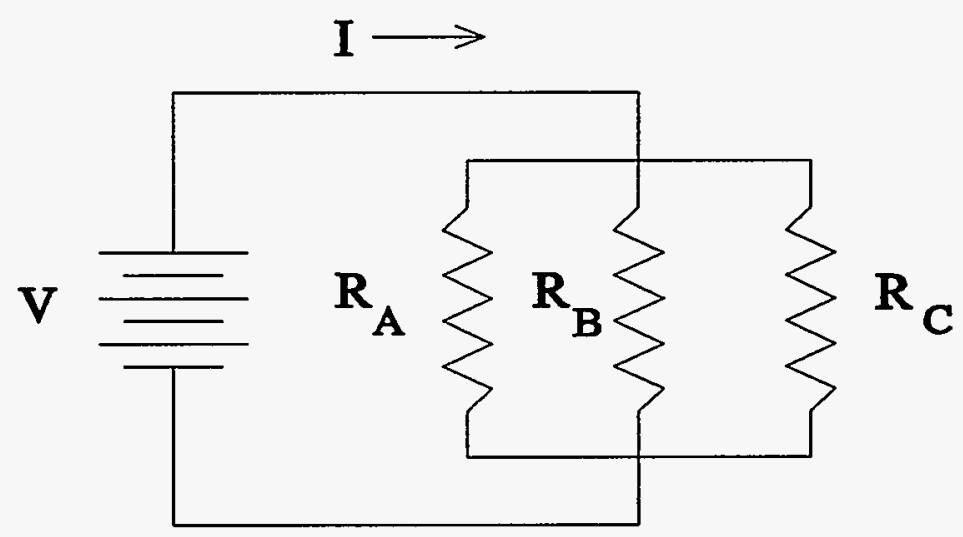

Figure C.1. Circuit Diagram for Example Problem \#1.

Each of the parameters in the equation above are statistical variables. Table C.1 lists each variable with its mean and standard deviation. Hahn and Shapiro gave the answer for the current as a mean of 26.19 and a standard deviation of 1.616. The TSE program calculates the mean as 26.1 and the standard deviation as 1.61 . Thus, very close agreement between the two answers is evident.

Table C.1. Variable parameters for the circuit problem.

\begin{tabular}{|c|c|c|}
\hline Variable & Mean & Standard deviation \\
\hline $\mathrm{V}$ & 120 & 3.873 \\
\hline $\mathrm{R}_{\mathrm{A}}$ & 10 & 1 \\
\hline $\mathrm{R}_{\mathrm{B}}$ & 15 & 1 \\
\hline $\mathrm{R}_{\mathrm{C}}$ & 20 & 1.414 \\
\hline
\end{tabular}


The second example problem is a hand calculation of the PWR 9 sequence for the analysis in this report. The PWR 9 sequence is contained within both the SSE event tree and the SBLOCA event tree (Figure 1 and Figure 2, respectively). For the SSE event tree, the PWR 9 sequence can be written as:

$$
z_{1}=S S E \cdot R P V S F \cdot L B L O C A \cdot E C C S F \cdot R C F
$$

where the bar over the event denotes the compliment of the event. Before evaluating this sequence, the event parameters must be known. From Appendix A, the parameters are shown in Table C.2. It should be pointed out that the numerically calculated results are shown in this Appendix with three significant digits for calculational purposes only.

Table C.2. Variable parameters for PWR 9 sequence.

\begin{tabular}{|c|c|c|}
\hline Event & Mean & Standard deviation \\
\hline SSE & $1.25 \times 10^{-3}$ & $3.5 \times 10^{-2}$ \\
\hline SBLOCA & $5.0 \times 10^{-4}$ & $2.2 \times 10^{-2}$ \\
\hline RPVSF & $5.0 \times 10^{-1}$ & $2.0 \times 10^{-1}$ \\
\hline LBLOCA & $5.0 \times 10^{-1}$ & $2.0 \times 10^{-1}$ \\
\hline ECCSF & $1.0 \times 10^{-1}$ & $1.0 \times 10^{-1}$ \\
\hline RCF & $1.0 \times 10^{-3}$ & $5.0 \times 10^{-3}$ \\
\hline
\end{tabular}

From page $\mathrm{C}-1$, the mean and standard deviation for the equation $\mathrm{Z}_{1}$ can be calculated as:

$$
\begin{gathered}
\mu_{Z_{\mathrm{t}}}=\mu_{S S E} \cdot \mu_{R P V S F} \cdot \mu_{L B L O C A} \cdot \mu_{E C C S F} \cdot \mu_{K C F} \\
\sigma_{Z_{1}}=\left[\sum_{i=1}^{N}\left[\frac{\partial Z_{1}}{\partial X_{i}}\right]^{2}\left(\sigma_{X_{i}}\right)^{2}\right]^{1 / 2}
\end{gathered}
$$

Evaluating the mean results in:

$$
\begin{aligned}
\mu_{z_{1}} & =\left(1.25 \times 10^{-3}\right)(0.5)(0.5)(1-0.1)\left(1-\left(1.0 \times 10^{-3}\right)\right) \\
& =2.81 \times 10^{-4}
\end{aligned}
$$


Taking the equation for the standard deviation, each term will be written out and evaluated separately. Thus, we find:

$$
\begin{aligned}
\sigma_{z_{1}}{ }^{2}= & {\left[\frac{\partial z_{1}}{\partial S S E}\right]^{2}\left(\sigma_{S S E}\right)^{2}+\left[\frac{\partial z_{1}}{\partial R P V S F}\right]^{2}\left(\sigma_{R P V S F}\right)^{2}+\left[\frac{\partial z_{1}}{\partial L B L O C A}\right]^{2}\left(\sigma_{L B L O C A}\right)^{2} } \\
& +\left[\frac{\partial z_{1}}{\partial E C C S F}\right]^{2}\left(\sigma_{E C C S F}\right)^{2}+\left[\frac{\partial z_{1}}{\partial R C F}\right]^{2}\left(\sigma_{K C F}\right)^{2}
\end{aligned}
$$

Evaluating the first term in the equation above yields:

$$
\left[\frac{\partial Z_{1}}{\partial S S E}\right]^{2}\left(\sigma_{S S E}\right)^{2}=\left(\mu_{R P V S F} \cdot \mu_{L B L O C A} \cdot \mu_{E C C S F} \cdot \mu_{R C F}\right)^{2}\left(\sigma_{S S E}\right)^{2}
$$

Substituting the appropriate mean values results in:

$$
\begin{aligned}
{\left[\frac{\partial Z_{1}}{\partial S S E}\right]^{2}\left(\sigma_{S S E}\right)^{2} } & =\left[(0.5)(0.5)(1-0.1)\left(1-\left(1.0 \times 10^{-3}\right)\right)\right]^{2}\left(3.5 \times 10^{-2}\right)^{2} \\
& =6.19 \times 10^{-5}
\end{aligned}
$$

The four remaining terms are:

$$
\begin{aligned}
{\left[\frac{\partial Z_{1}}{\partial R P V S F}\right]^{2}\left(\sigma_{R P V S F}\right)^{2} } & =\left(\mu_{S S E} \cdot \mu_{L B L O C A} \cdot \mu_{E C C S F} \cdot \mu_{K C F}\right)^{2}\left(\sigma_{R P V S F}\right)^{2} \\
& =\left[\left(1.25 \times 10^{-3}\right)(0.5)(1-0.1)\left(1-\left(1.0 \times 10^{-3}\right)\right)\right]^{2}(0.2)^{2} \\
& =1.26 \times 10^{-8}
\end{aligned}
$$

$$
\begin{aligned}
{\left[\frac{\partial Z_{1}}{\partial L B L O C A}\right)^{2}\left(\sigma_{L B L O C A}\right)^{2} } & =\left(\mu_{S S E} \cdot \mu_{R P V S F} \cdot \mu_{E C C S F} \cdot \mu_{R C F}\right)^{2}\left(\sigma_{L B L O C A}\right)^{2} \\
& =\left[\left(1.25 \times 10^{-3}\right)(0.5)(1-0.1)\left(1-\left(1.0 \times 10^{-3}\right)\right)\right]^{2}(0.2)^{2} \\
& =1.26 \times 10^{-8} \\
{\left[\frac{\partial Z_{1}}{\partial E C C S F}\right]^{2}\left(\sigma_{E C C S F}\right)^{2} } & =\left(-\left(\mu_{S S E} \cdot \mu_{R P V S F} \cdot \mu_{L B L O C A} \cdot \mu_{R C F}\right)\right)^{2}\left(\sigma_{E C C S F}\right)^{2} \\
& =\left[-\left(1.25 \times 10^{-3}\right)(0.5)(0.5)\left(1-\left(1.0 \times 10^{-3}\right)\right)\right]^{2}(0.1)^{2} \\
& =9.75 \times 10^{-10}
\end{aligned}
$$




$$
\begin{aligned}
{\left[\frac{\partial z_{1}}{\partial R C F}\right]^{2}\left(\sigma_{K C F}\right)^{2} } & =\left(-\left(\mu_{S S E} \cdot \mu_{R P U S F} \cdot \mu_{L B L O C A} \cdot \mu_{E C C S F}\right)\right)^{2}\left(\sigma_{R C F}\right)^{2} \\
& =\left[-\left(1.25 \times 10^{-3}\right)(0.5)(0.5)(1-0.1)\right]^{2}\left(5.0 \times 10^{-3}\right)^{2} \\
& =1.98 \times 10^{-12}
\end{aligned}
$$

From the five above terms, the standard deviation of $Z_{1}$ is found by:

$$
\begin{aligned}
\sigma_{z_{1}} & =\left(6.19 \times 10^{-5}+1.26 \times 10^{-8}+1.26 \times 10^{-8}+9.75 \times 10^{-10}+1.98 \times 10^{-12}\right)^{1 / 2} \\
& =7.87 \times 10^{-3}
\end{aligned}
$$

Now, the PWR 9 sequence from the SBLOCA event tree will be analyzed in a similar manner. The PWR 9 sequence for the SBLOCA event tree can be written as:

$$
Z_{2}=S B L O C A \cdot R P V S F \cdot L B L O C A \cdot E C C S F \cdot R C F
$$

The mean and standard deviation of the SBLOCA PWR 9 sequence are:

$$
\begin{gathered}
\mu_{\mathrm{Z}_{2}}=\mu_{S B L O C A} \cdot \mu_{R P V S F} \cdot \mu_{L B L O C A} \cdot \mu_{E C C S F} \cdot \mu_{K C F} \\
\sigma_{Z_{2}}{ }^{2}=\left[\frac{\partial z_{2}}{\partial S B L O C A}\right]^{2}\left(\sigma_{S B L O C A}\right)^{2}+\left[\frac{\partial z_{2}}{\partial R P V S F}\right]^{2}\left(\sigma_{R P V S F}\right)^{2}+\left[\frac{\partial Z_{2}}{\partial L B L O C A}\right]^{2}\left(\sigma_{L B L O C A}\right)^{2} \\
+\left(\frac{\partial z_{2}}{\partial E C C S F}\right]^{2}\left(\sigma_{E C C S F}\right)^{2}+\left[\frac{\partial Z_{2}}{\partial R C F}\right]^{2}\left(\sigma_{R C F}\right)^{2}
\end{gathered}
$$


Calculating the mean value results in:

$$
\begin{aligned}
\mu_{Z_{2}} & =\left(5.0 \times 10^{-4}\right)(0.5)(0.5)(1-0.1)\left(1-\left(1.0 \times 10^{-3}\right)\right) \\
& =1.12 \times 10^{-4}
\end{aligned}
$$

Calculating the five terms for use in the standard deviation equation results in:

$$
\begin{aligned}
& {\left[\frac{\partial Z_{2}}{\partial S B L O C A}\right]^{2}\left(\sigma_{S B L O C A}\right)^{2}=2.45 \times 10^{-5}} \\
& {\left[\frac{\partial z_{2}}{\partial R P V S F}\right]^{2}\left(\sigma_{R P V F F}\right)^{2}=2.02 \times 10^{-9}} \\
& {\left[\frac{\partial z_{2}}{\partial L B L O C A}\right]^{2}\left(\sigma_{L B L O C A}\right)^{2}=2.02 \times 10^{-9}} \\
& {\left[\frac{\partial z_{2}}{\partial E C C S F}\right]^{2}\left(\sigma_{E C L S F}\right)^{2}=1.56 \times 10^{-10}} \\
& \left(\frac{\partial Z_{2}}{\partial R C F}\right]^{2}\left(\sigma_{R C F}\right)^{2}=3.16 \times 10^{-13}
\end{aligned}
$$


Therefore, the standard deviation of $Z_{2}$ is found by:

$$
\begin{aligned}
\sigma_{z_{2}} & =\left(2.45 \times 10^{-5}+2.02 \times 10^{-9}+2.02 \times 10^{-9}+1.56 \times 10^{-10}+3.16 \times 10^{-13}\right)^{1 / 2} \\
& =4.95 \times 10^{-3}
\end{aligned}
$$

Now, the total PWR 9 sequence probability is calculated by adding the SSE results to the SBLOCA results:

$$
\text { PWR } 9_{\text {TOTAL }}=P W R 9_{S S E}+P W R 9_{S B L O C A}
$$

From page $\mathrm{C}-1$, when two variables are added, the mean and standard deviation can be calculated from:

$$
\begin{aligned}
& \mu_{P W R 9_{\text {soul }}}=\mu_{P W R 9_{\text {SII }}}+\mu_{P W R 9_{\text {smoc }}} \\
& =2.81 \times 10^{-4}+1.12 \times 10^{-4}=3.93 \times 10^{-4} \\
& \sigma_{P W R 9_{\text {rove }}}=\left(\left(\sigma_{P W R 9_{\text {sed }}}\right)^{2}+\left(\sigma_{P W R 9_{\text {srool }}}\right)^{2}\right)^{1 / 2} \\
& =\left(\left(7.87 \times 10^{-3}\right)^{2}+\left(4.95 \times 10^{-3}\right)^{2}\right)^{1 / 2} \\
& =9.30 \times 10^{-3}
\end{aligned}
$$

Table A.2 lists the calculated sequence end states from the TSE program. For the total PWR 9 sequence, the calculated mean is $3.9 \times 10^{-4}$ and the calculated standard deviation is $9.3 \times 10^{-3}$. These calculated results confirm the above hand calculated values. 


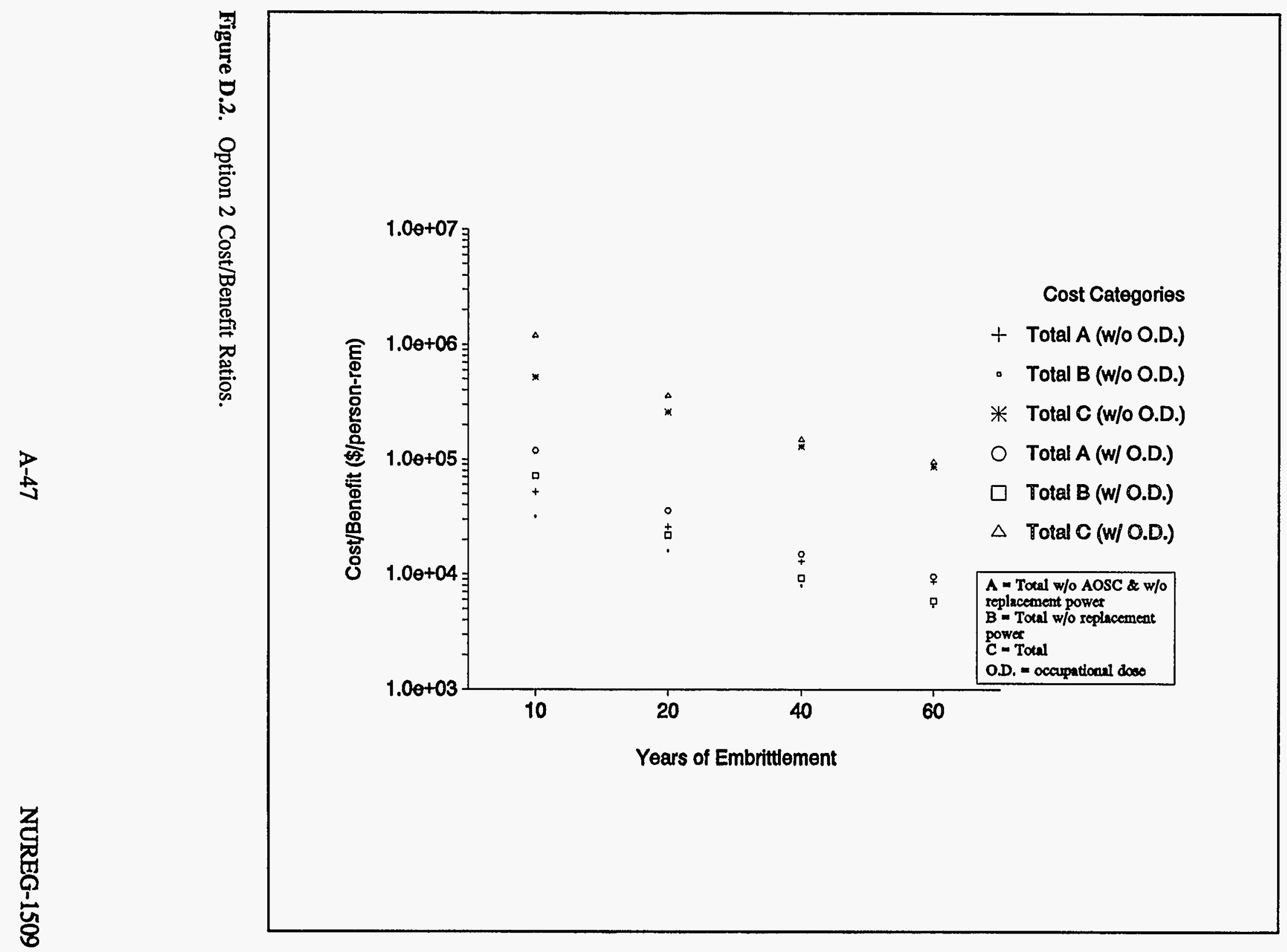




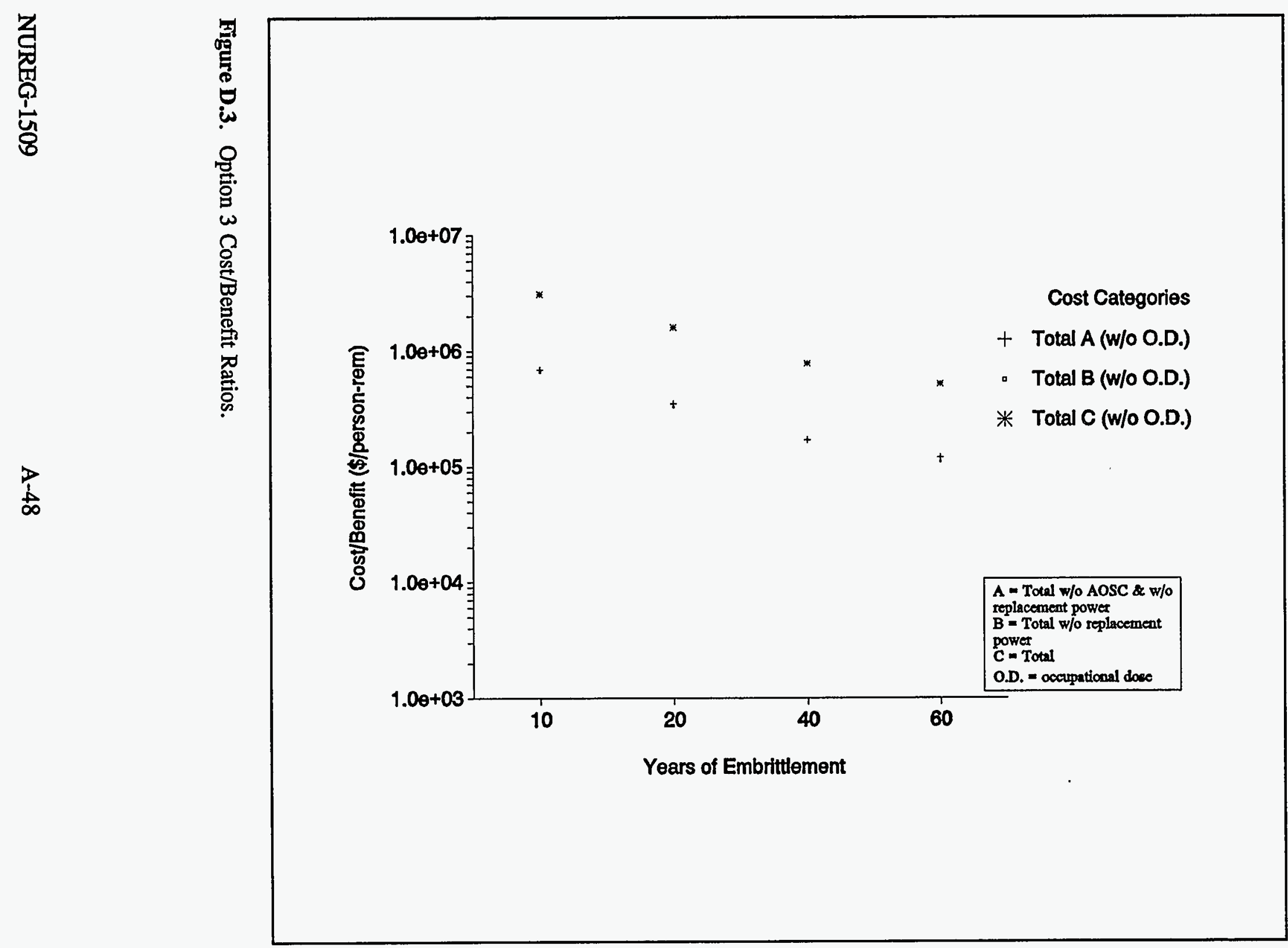




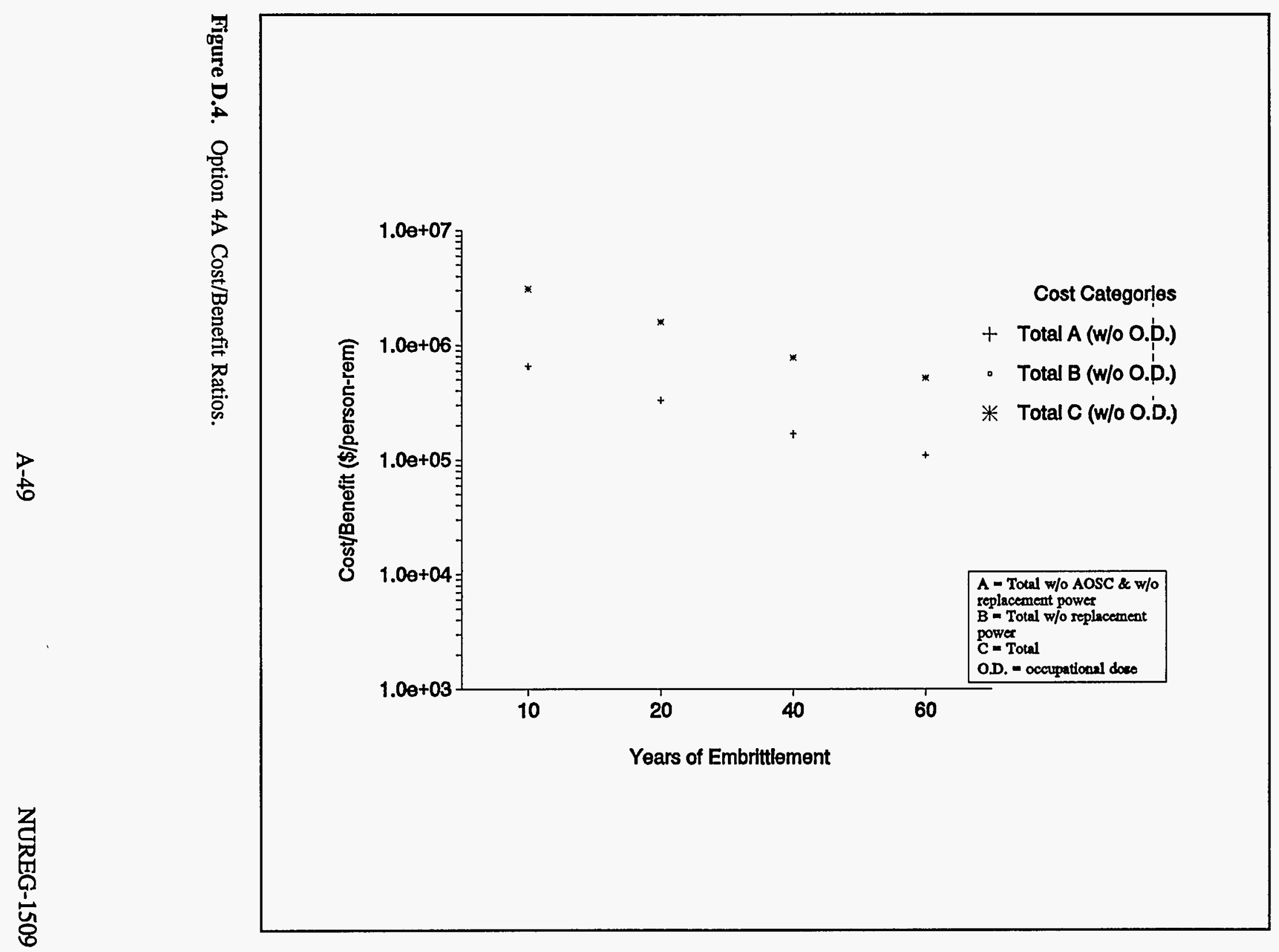




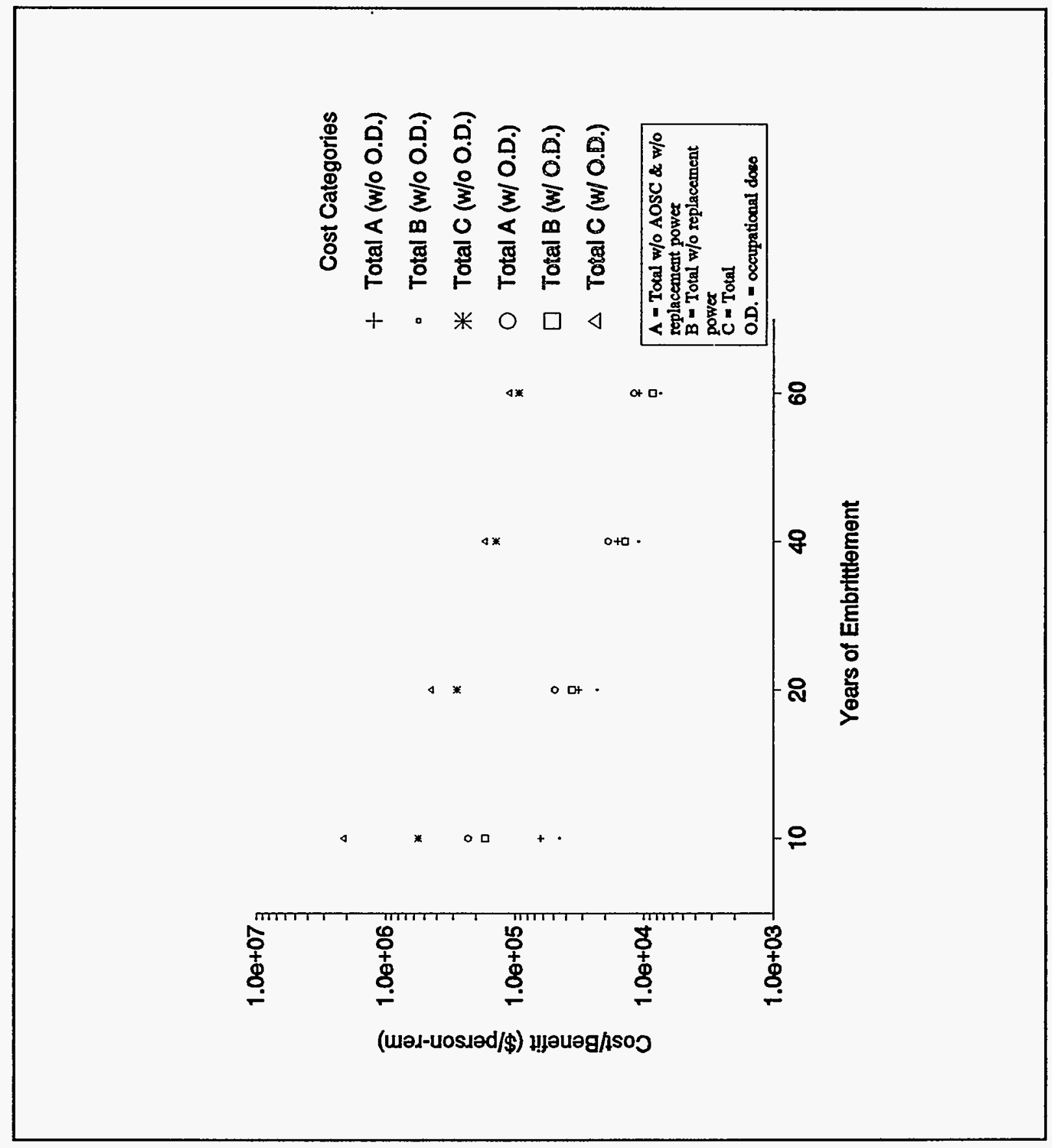

Figure D.5. Option 4B Cost/Benefit Ratios. 


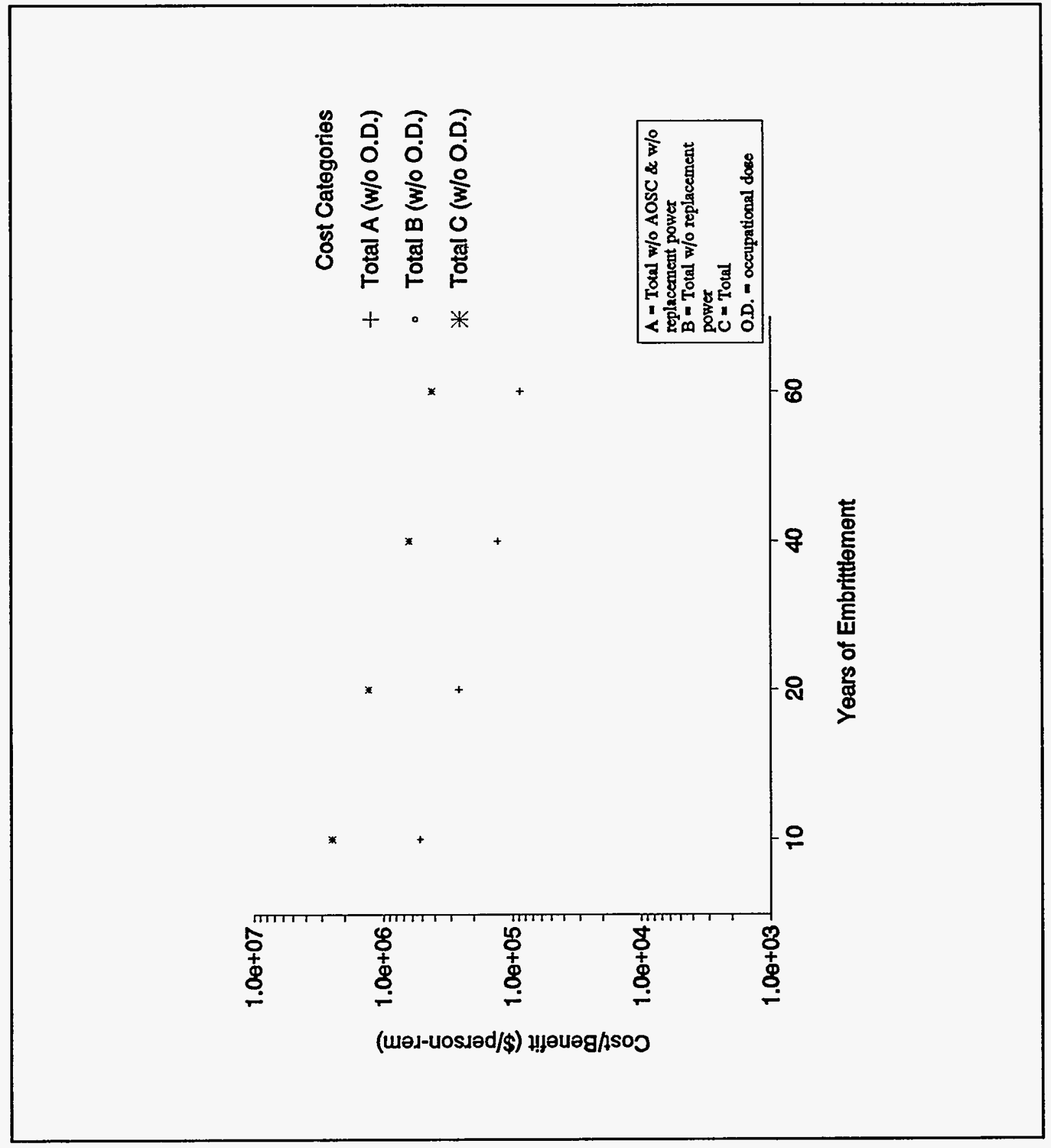

Figure D.6. Option 5 Cost/Benefit Ratios. 

Appendix B 


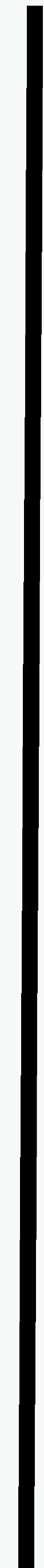




\title{
APPENDIX B
}

\section{SHIPPINGPORT VESSEL/SHIELD-TANK FLUENCE CALCULATIONS}

\author{
Craig A. Hrabal
}

\subsection{INTRODUCTION}

The Shippingport reactor vessel and neutron shield tank (NST) provided an independent source of measured data for evaluating $\triangle$ NDTT correlations and dependencies. The Shippingport NST was fabricated of ASTM A 212 carbon steel. The same steel specification was used in the HFIR pressure vessel. Both the Shippingport NST and the HFIR reactor vessel were exposed to a low neutron flux/high fluence radiation field. Despite this, the initial evaluation of the Shippingport materials suggested that the $\triangle$ NDT was much less than observed in the HFIR tests. Therefore, the principal objective of the study conducted by the Brookhaven National Laboratory (BNL) and reported here was to provide accurate estimates of the neutron fluence and spectra for the Shippingport vessel and NST to aid in the interpretation of materials property test data. This effort was further motivated by fairly large initial calculation-to-measurement differences for the fluence, the availability of newer codes, and improvements in methods relative to those used in the initial evaluations by the Bettis Laboratory.

The Shippingport reactor vessel and shield tank geometry are shown in elevation and plan views in Figures 1.1 through 1.4. Note that while the vessel and ex-vessel geometries remain unchanged, the details of the core geometry and layout of the internals varied for the three cores, PWR-1, PWR-2, and the LWBR (Refs. 1-3).

The approach used to analyze each of the core configurations (cf. Figures $1.2-1.4$ ) will be described in Section 2; the resulting for energy spectra and fluence distributions at the vessel and selected shield tank locations will be given in Section 3.

\subsection{CALCULATIONAL METHODOLOGY}

The calculational methodology for determining the energy spectra and fluence distributions at the Shippingport reactor pressure vessel and neutron shield tank consisted of the six basic tasks summarized in Figure 2.1. These tasks were performed by BNL. Briefly, the initial task consisted of collecting the geometry, materials, and power distribution data that describe the three core-vessel-NST configurations and operating histories. Following that, one-dimensional multi-group discrete ordinates calculations were performed for each core to provide initial estimates of the fluence and energy spectra at locations of interest, as well as few-group, region-dependent cross sections for subsequent detailed two-dimensional analyses. Following the two-dimensional planar calculations for each core, the three-dimensional fluence at radial and azimuthal locations of interest was constructed based on axial factors, and operating power level and history data. The corresponding detailed energy dependent spectra were then determined from an auxiliary series of calculations performed in one-dimensional geometry with a multi-group library designed for LWR slowing down calculations.

A summary of the above steps in flow-chart format is shown in Figure 2.2.

\subsection{ONE-DIMENSIONAL CALCULATIONS}


One dimensional calculations for the core-internals-vessel-NST geometry were performed with the ANISN discrete ordinates transport code (Ref. 4). An S-8 symmetric quadrature was assumed, and P-3 expansion cross sections from the BUGLE-80 (Ref. 5) library distributed by RSIC were employed. This library is based on ENDF/B-IV (Ref. 6), and contains cross section data in 47 neutron and 20 gamma groups. The BUGLE-80 library was selected for the baseline fluence determinations because it had been developed primarily for pressure vessel damage fluence calculations; consequently, while it has a relatively fine energy resolution above approximately 0.1 $\mathrm{MeV}$, the remainder of the energy range is fairly sparsely covered, with only 2 groups below 0.414 $\mathrm{eV}$. The primary purpose of the one-dimensional analyses was to generate few group cross sections for the subsequent two-dimensional calculations which cannot be performed, as a practical matter, with so many groups. The one-dimensional models served two other functions: 1) "sensitivity" type analyses to determine the optimal collapsed few group structure and the spatial mesh, and 2) determination of the full range energy spectra. As noted earlier, while the BUGLE-80 library is well suited to the evaluation of high energy neutron transport in LWR geometries, its treatment of lower energies (especially thermal) is crude. Consequently, since one of the primary objectives of the current analyses was to determine the full energy range spectra, a more appropriate cross section library was required. The MATXS-7, 69 neutron group library (Ref. 7), was selected for this purpose. This library contains 42 groups below $4.0 \mathrm{eV}$, is based on ENDF/B-V (Ref. 8), and was generated by LANL for EPRI for use in LWR slowing down spectrum codes. Therefore, it is well suited to the present application.

The ANISN models for the three Shippingport configurations were used to collapse the 47 group BUGLE- 80 cross sections, by region, to few group macroscopic cross sections which preserved the essential characteristics of the greater than $0.1 \mathrm{MeV}$ neutron flux spectra throughout the problem. It was found that the 18-group structure shown in Table 1 was sufficient for this purpose.

\subsection{TWO-DIMENSIONAL CALCULATIONS}

The two-dimensional calculations were performed with the DORT (Ref. 9) discrete ordinates transport code in $(r, \theta)$ geometry: an S-8 fully symmetric quadrature was employed with the 18-group region and core-configuration-specific cross sections generated by the one-dimensional analyses described above. As previously noted, an adequate radial mesh for the bulk of the problem (which is truly radial in character) was determined from the one-dimensional calculations. However, in order to determine an adequate $(r, \theta)$ spatial mesh to model the rectangular assemblies of the two PWR cores, or the pseudo-hexagonal LWBR core, the BNL developed MESH code (Ref. 10) was employed. This program allocates $(r, \theta)$ geometry mesh blocks to the appropriate $(x, y)$ or hexagonal assembly, and creates the spatial and energydependent source used in the fixed source DORT calculations.

\subsection{SYNTHESIS OF 3-D FLUENCE}

The three-dimensional fluence at specific locations was obtained by combining the few-group flux results from the three core-dependent DORT calculations with the appropriate power level, EFPH, and axial peaking factors. This task was performed by the FLUENCE program which also accounts for the individual symmetries of the PWR and LWBR configurations. The full energy range fluence spectra were obtained by scaling the one-dimensional MATXS7 results at the required radial location such that the flux greater than $1.0 \mathrm{MeV}$ matched that obtained from the BUGLE-80 based calculation(s).

\subsection{RESULTS}


The results of the BNL calculations, presented in the following, consisted of neutron energy spectra, radial and azimuthal fast neutron $(E>1.0 \mathrm{MeV}$ ) fluxes at selected radial and angular sectors and radial zones, respectively, and core specific and total azimuthal fast neutron fluences at the pressure vessel and NST locations. The pressure vessel and NST fluxes were determined at the elevations where flux measurements had been carried out. As noted earlier, the two-dimensional $(r, \theta)$ discrete ordinate transport calculations were carried out using a collapsed 18-energy group cross section set derived from a 47-group BUGLE library. The adequacy of the 18-group set had been demonstrated by comparing neutron energy spectra in 18 groups and 47 groups in each of the 18 regions of each Shippingport configuration. Figures 3.1 and 3.2 show the 47- and 18-group spectra, respectively, in the inner blanket region of the PWR-2 core. The 47-group and 18-group spectra in the pressure vessel are shown in Figures 3.3 and 3.4, respectively. The $(r, \theta)$ mesh representation of one octant in the Shippingport DORT model for the PWR-2 configuration is shown in Figure 3.5. This model consists of 221 radial mesh intervals and 45 angular mesh intervals. Regions 1 through 5 represent the core octant. Region "E" represents the pressure vessel.

Eighteen-group radial and azimuthal neutron fluxes were obtained at each $(r, \theta)$ mesh point shown in Figure 3.5. Fast neutron $(E>1.0 \mathrm{MeV})$ fluxes at a desired $(r, \theta)$ mesh were obtained by summing over the energy groups above $1.0 \mathrm{MeV}$ at that mesh. Radial flux distributions at $1^{\circ}$ (flats), $24^{\circ}$ and $45^{\circ}$ are shown in Figures 3.6 through 3.8, respectively. Azimuthal fast neutron fluxes are shown at the core edge and at the inner and outer surfaces of the pressure vessel, in Figures 3.9, 3.10 and 3.11 , respectively. The flattening of the azimuthal fluxes with increasing distance from the core was noted.

Based on Bettis and Duquesne Power accumulated exposure data, the fast neutron (E $>1.0 \mathrm{MeV})$ fluence from each individual Shippingport core has been determined. Using Bettis axial flux distributions, azimuthal fluences were determined at the six elevations at which measured materials data were available: $687.5 \mathrm{ft}, 689.0 \mathrm{ft}, 690.0 \mathrm{ft}, 690.5 \mathrm{ft}, 692.5 \mathrm{ft}$ and $693.0 \mathrm{ft}$. Figure 3.12 shows schematically the $689.0,690.0$, and $692.5 \mathrm{ft}$ elevations relative to the positions of the three Shippingport cores. Figures 3.13 through 3.15 show the individual azimuthal fluences of the PWR-1, PWR-2 and LWBR cores as well as the total fluence at the pressure vessel at $689.0 \mathrm{ft} ., 690.5 \mathrm{ft}$., and $692.5 \mathrm{ft}$., respectively. Similarly, at these elevations, plots of individual and total azimuthal fluences at the NST are given in Figures 3.16 through 3.18, for the inside surface, and in Figures 3.19 through 3.21, for the outside surface.

The results of the full energy (69-group) spectra calculations at the pressure vessel inner wall and at the NST inside and outside surfaces are presented in Table 3.1 and shown in Figures 3.22 through 3.24. The results of the neutron fluence calculations at the pressure vessel inner wall, at the inside and outside surface of the shield tank inner wall, and at the inside and outside surface of the shield tank outer wall are presented in Tables 3.2 through 3.6 for the locations where samples were taken. Also, the fluence values in Tables 3.2 through 3.6 are given in terms of the fast fluence $(E>1.0 \mathrm{MeV})$, the fast fluence $(\mathrm{E}>0.1 \mathrm{MeV})$, the thermal fluence $(\mathrm{E}<0.4 \mathrm{eV})$, and the total fluence. 


\subsection{REFERENCES}

1. "The Shippingport Pressurized Water Reactor," Naval Reactors Branch, U.S.A.E.C., Westinghouse Electric Corporation and Duquesne, Addison-Wesley Publishing Co., Inc., 1958.

2. "Shippingport Operations During PWR Core 2 Depletion," (April 1965 to February 1974), WAPD-335, 1983.

3. "Shippingport Operations With the Light Water Breeder Reactor Core," WPAD-TM-1542, 1986.

4. W.W. Engle, Jr., "A Users Manual for Manual for ANISN," K-1693, Oak Ridge National Laboratory, 1967.

5. R.W. Roussin, "BUGLE-80, Coupled 47 Neutron, 20 Gamma-Ray, $P_{3}$, Cross Section Library for LWR Shielding Calculations" Oak Ridge National Laboratory, DLC-75, 1980.

6. ENDF-102 Data Formats and Procedures for the Evaluated Nuclear Data File, ENDF, BNL-NCS-50496, 1975.

7. R.E. MacFarlane, "TRANSX-CTR: A Code for Interfacing MATRIX Cross-Section Libraries to Nuclear Transport Codes for Fusion Systems Analysis, " LA-9863 Los Alamos National Laboratory, 1984.

8. R. Kinsey, Ed., "ENDF-102, Data Formats and Procedures for the Evaluated Nuclear Data File, ENDF," Brookhaven National Laboratory, report BNL-NCS-50496 (ENDF-102) 2nd Edition (ENDF-102) 2nd Edition (ENDF/B-V), Revised, 1983.

9. "DORT, Two-Dimensional Discrete Ordinates Transport Code," RSIC Computer Code Collection, CCC-484, Oak Ridge National Laboratory, 1988.

10. M.D. Zentner, "MESH-A Code for Determining the DOT Fixed Neutron Source," BNL memorandum, August 25, 1981. 


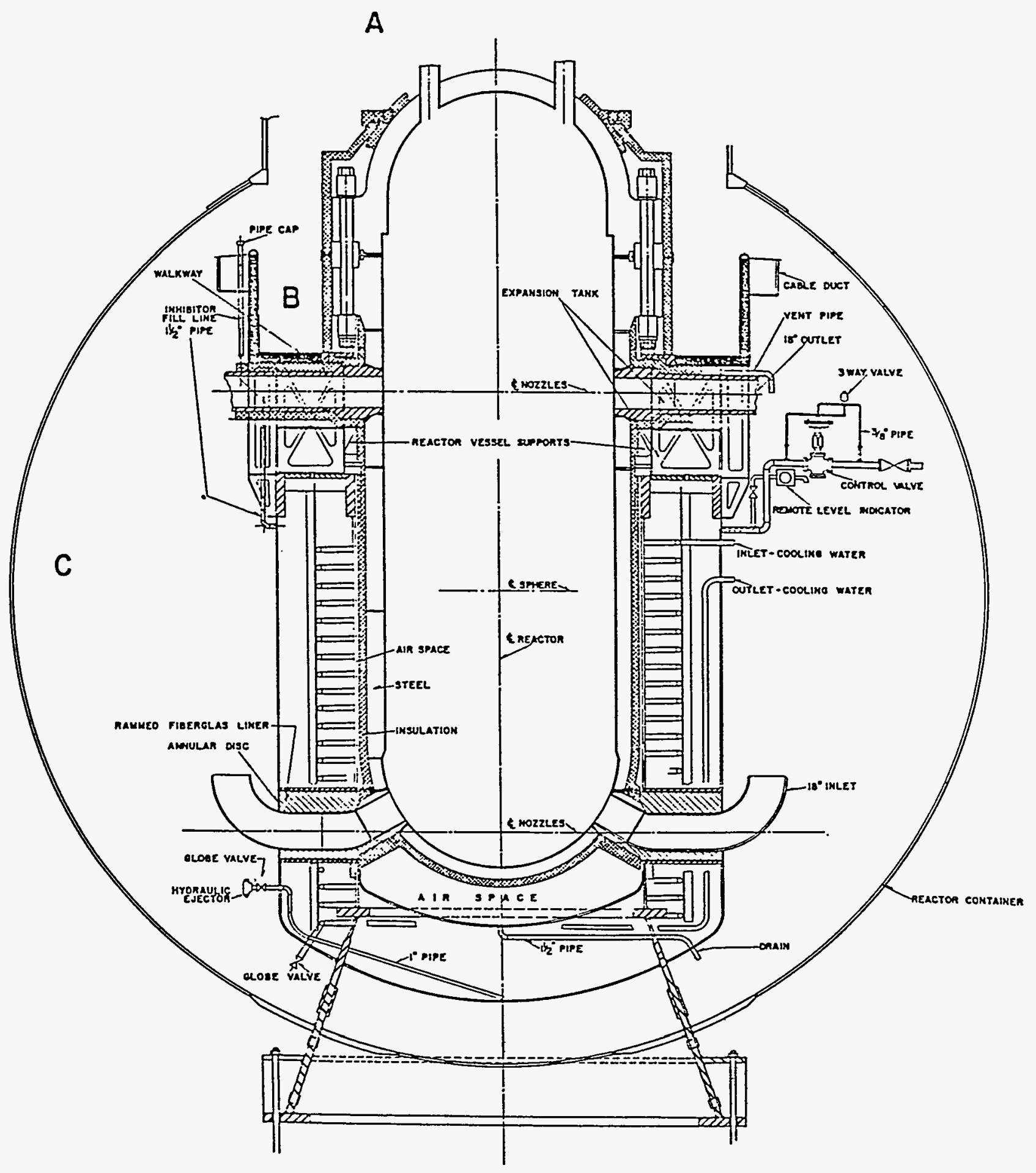

NEUTRO ! SHIEIJ TANK

Figure 1.1 


\section{PWR-1 BLANKET ORIFICE REGIONS}

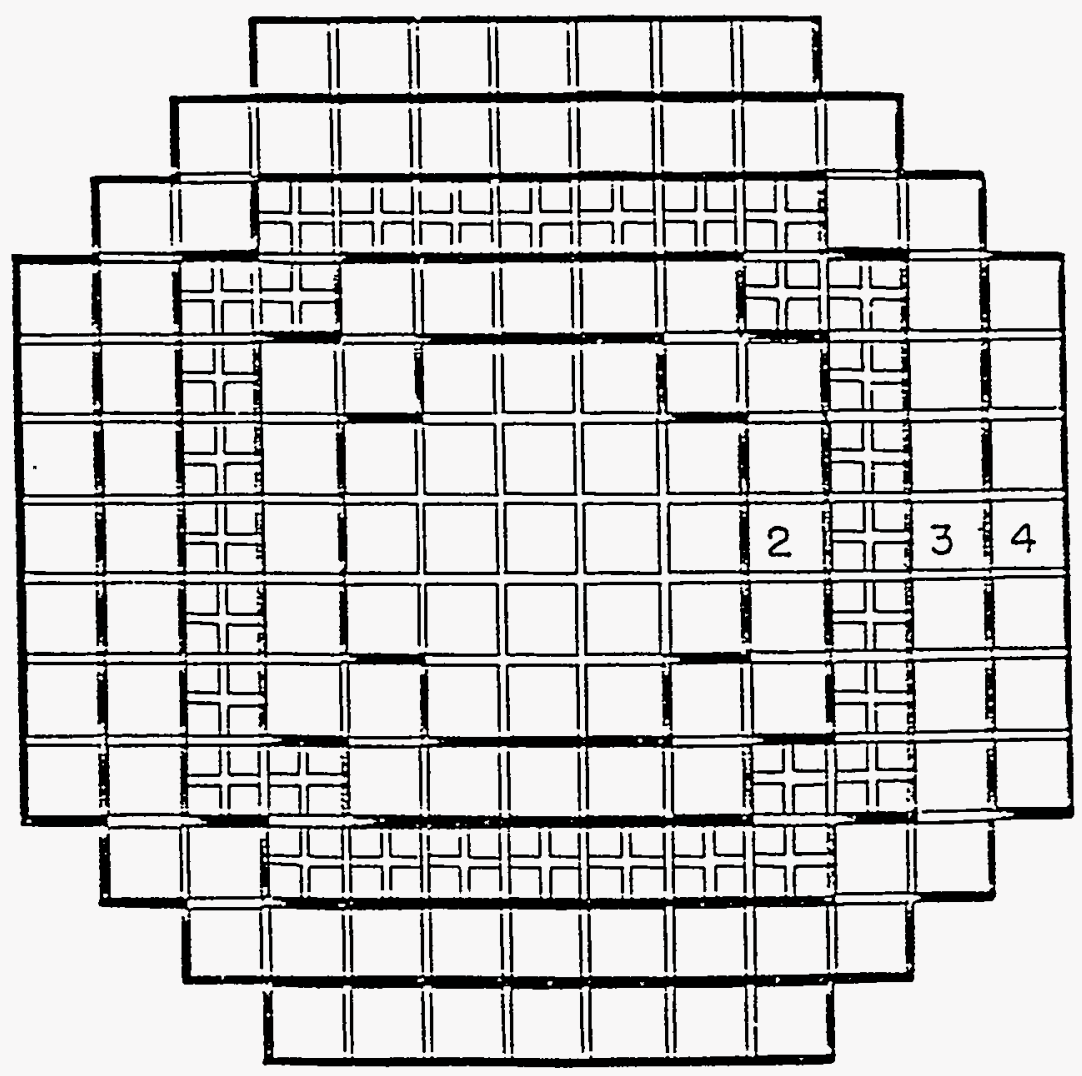

$$
\begin{array}{ll}
\text { REGION } 1-21 \text { ASSEMBLIES } \\
2-24 \\
3-40 \\
4-28 \\
4 \text { SEED (t) } 32
\end{array}
$$

Figure 1.2 
PHR COREZ

(8)

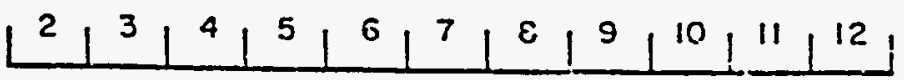

(A)

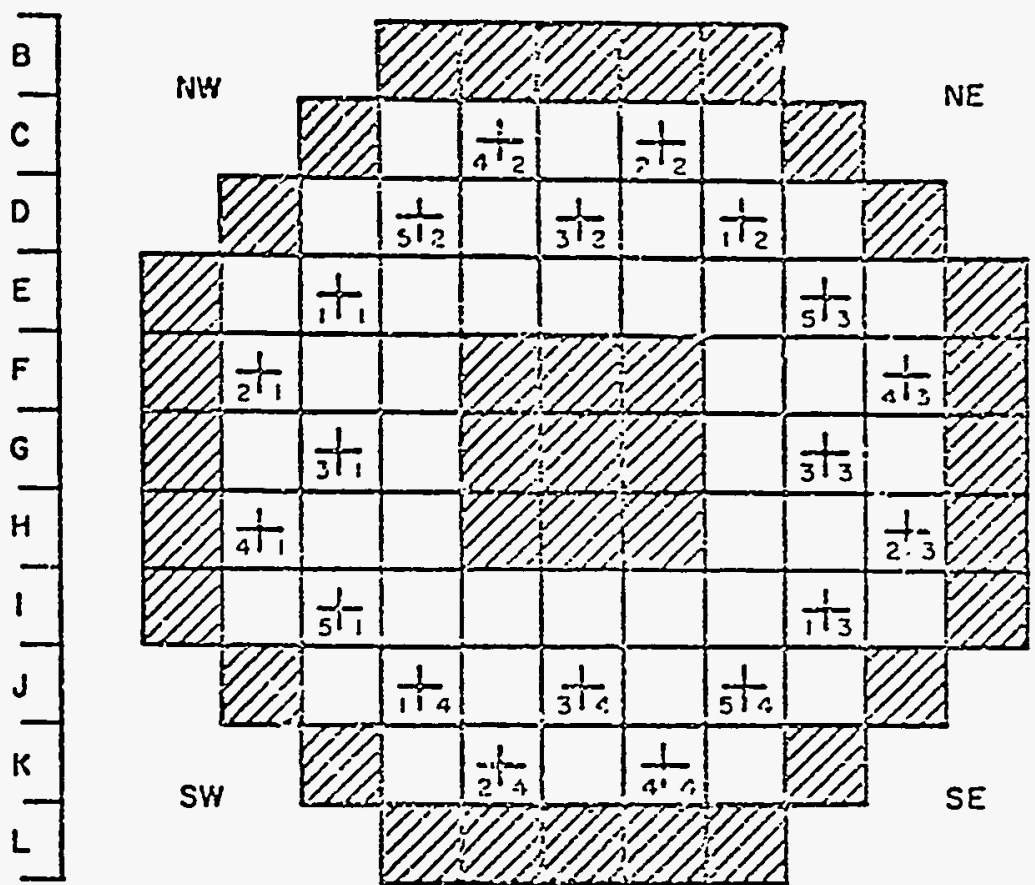

NORMAL CONTROLLIIEG WITHORAWAL SEQUENCE

GF.OUPI-CENTER ROD GROUP - ALL RODS NUWBERED 2,4
GROUPII-DIAGONAL POD GROUP-ALL RODS NUWBERED 1,5
GROUPII-INSET ROD GROUP - ALL RODS NUMBERED 3

O nUCLear instrukientation chanNels

† 20 CONTROL RODS AND SEED ClUSTERS

Z7 37 SECCND PASS BLANKET CLUSTERS

40 FIRST PASS BLANKET CLUSTERS

Figure 1.3 
LWBR Core Cross Section Through the Fuel Bearing Region

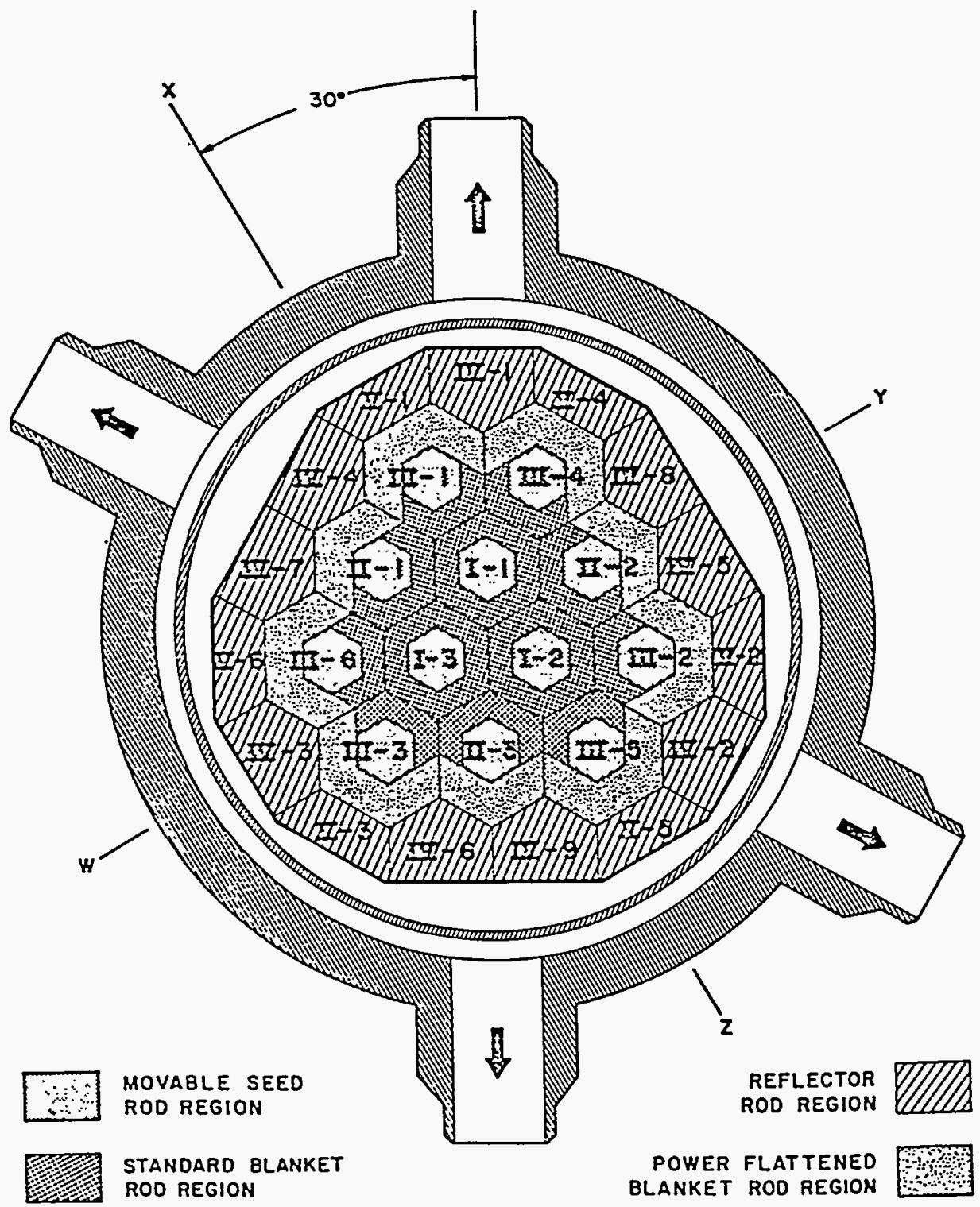

Figure 1.4 


\section{SHIPPINGPORT VESSEL/SHIELD-TANK FLUENCE CALCULATIONS CALCULATIONAL METHOD}

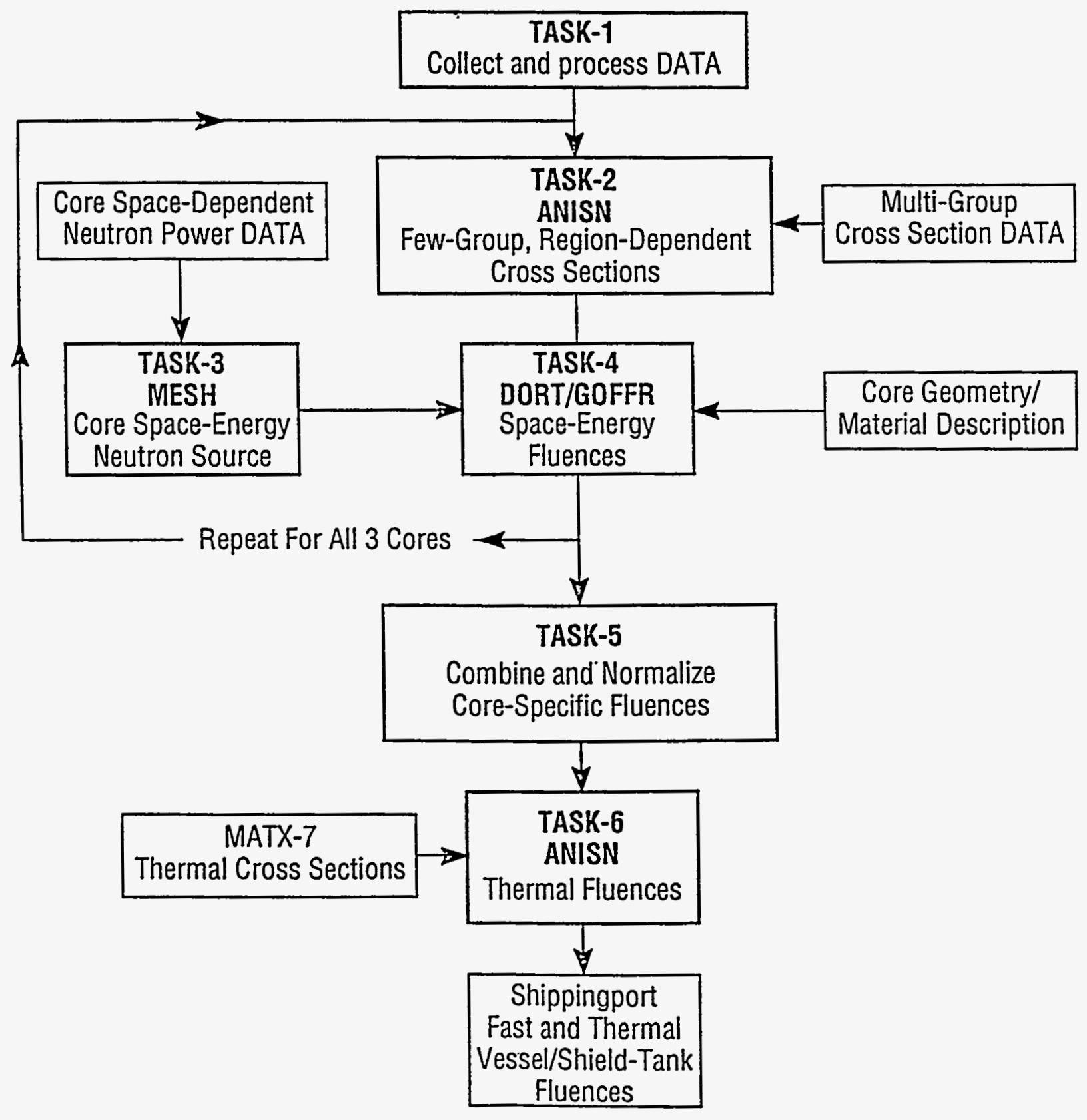

Figure 2.1 


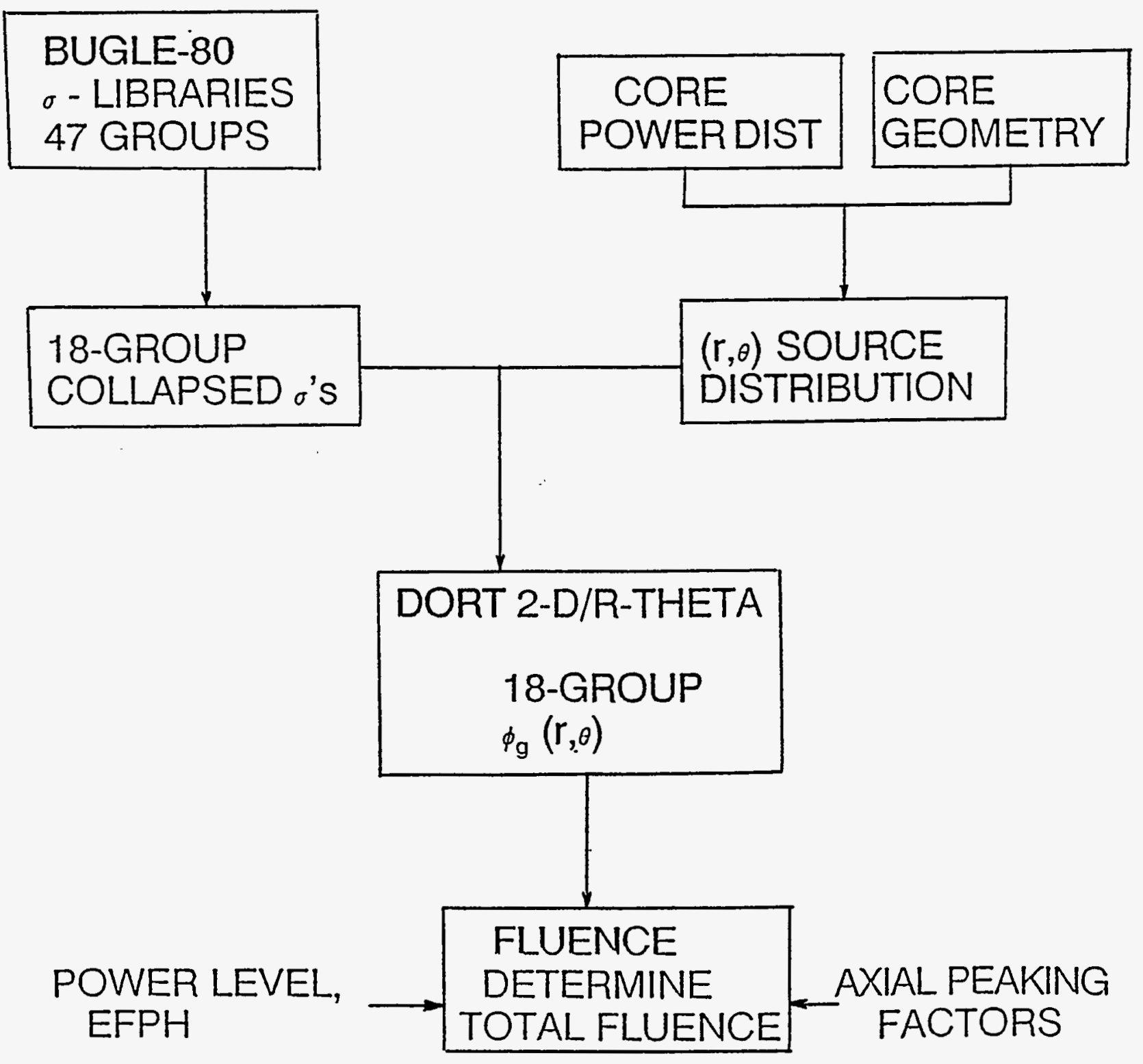

Figure 2.2 
Table 1

BNL 18-GROUP CROSS SECTION SET

COLLAPSED FROM BUGLE-80 47-GROUP LIBRARY

ENERGY BREAK POINTS

GROUP

NUMBER

1

2

3

4

5

6

7

8

9

10

11

12

13

14

15

16

17

18
$E_{\text {high }}$

(ev)

$1.7333+07$

$8.6070+06$

$4.9659+06$

$3.0120+06$

$2.4660+06$

$2.2310+06$

$1.9200+06$

$1.0026+06$

$4.9790+05$

$1.1110+05$

$3.3550+03$

$4.5400+02$

$1.0310+02$

$3.7260+01$

$1.0678+01$

$5.0430+00$

$0.4140+00$

$0.1000+00$ 


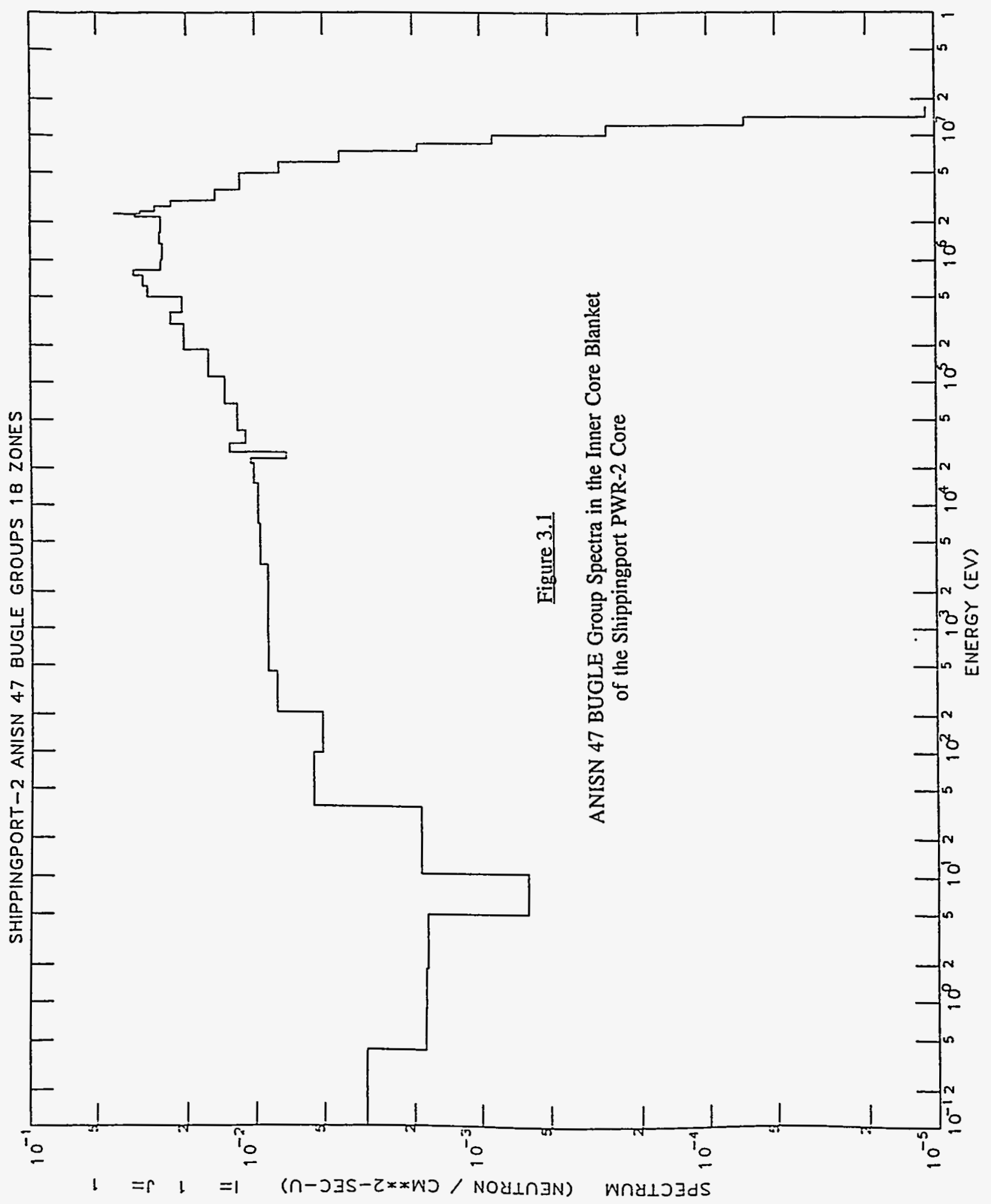




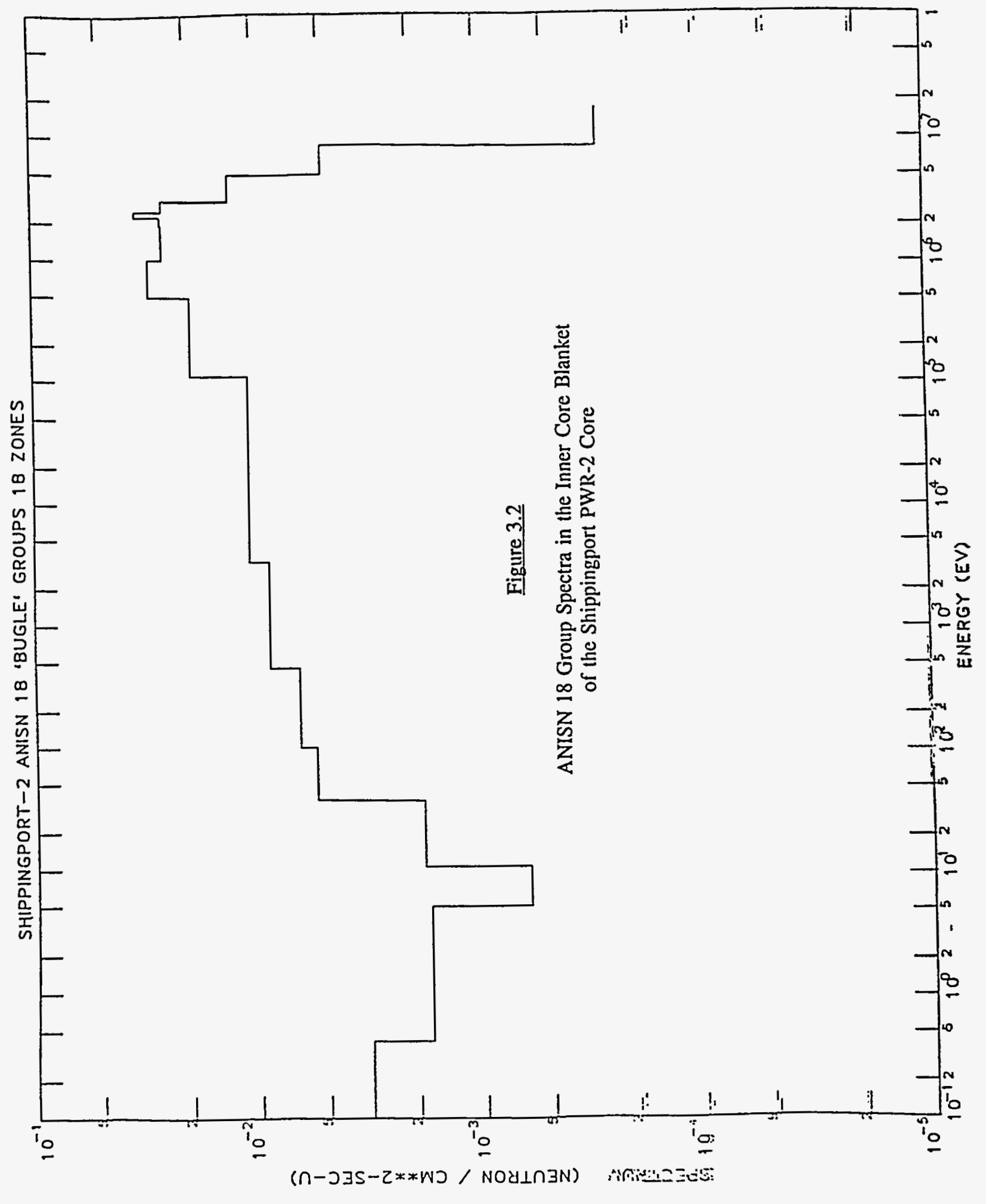




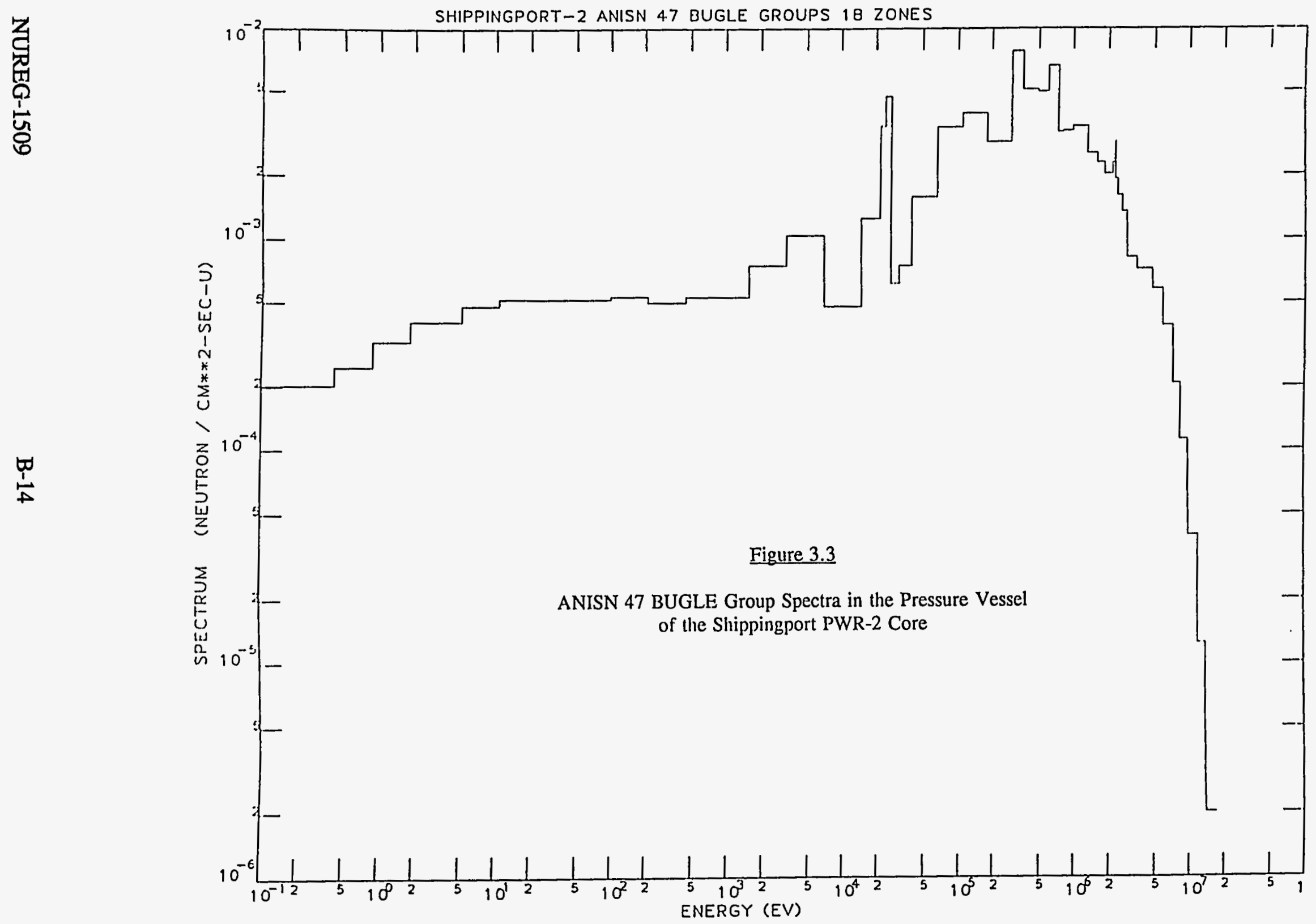




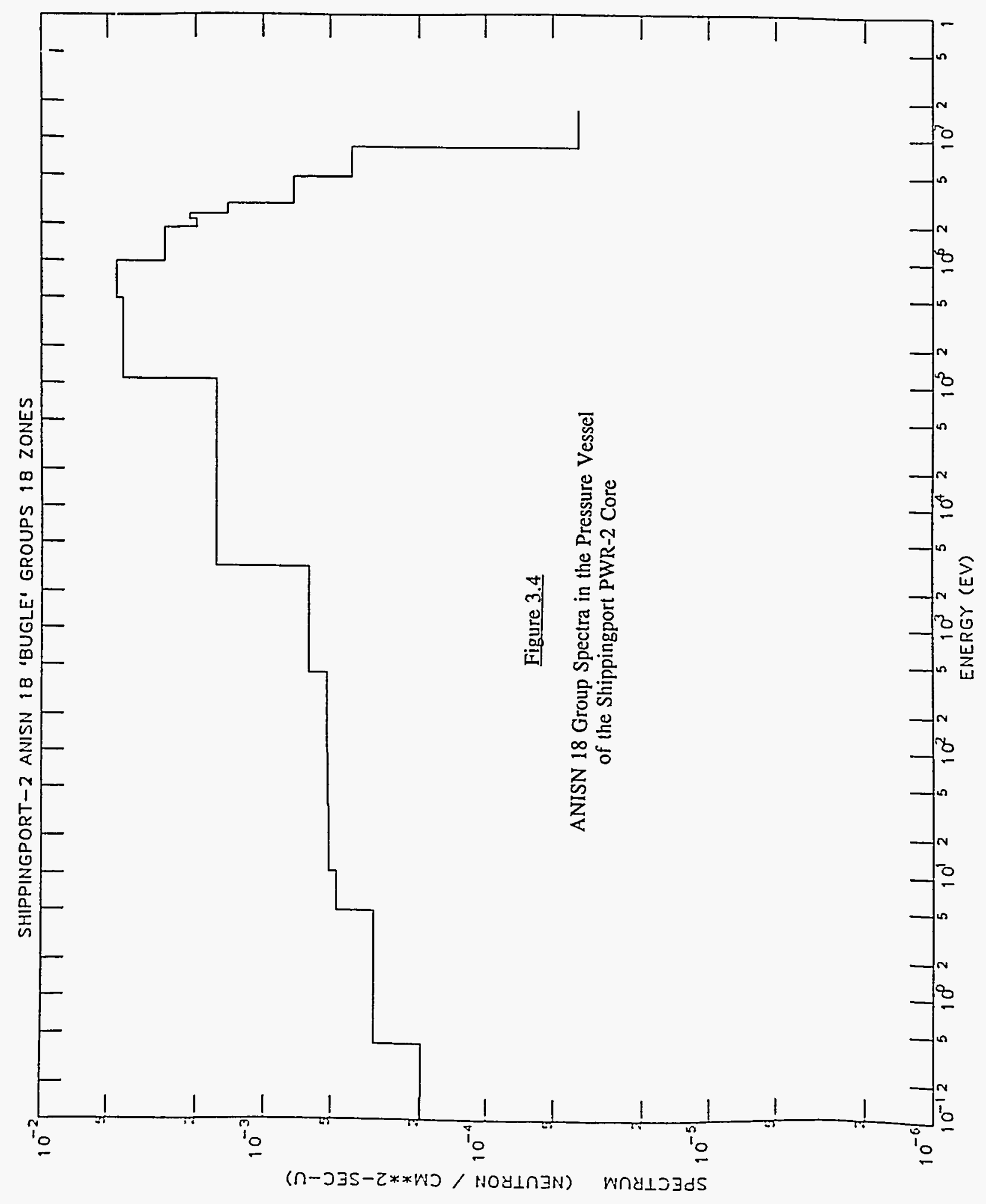




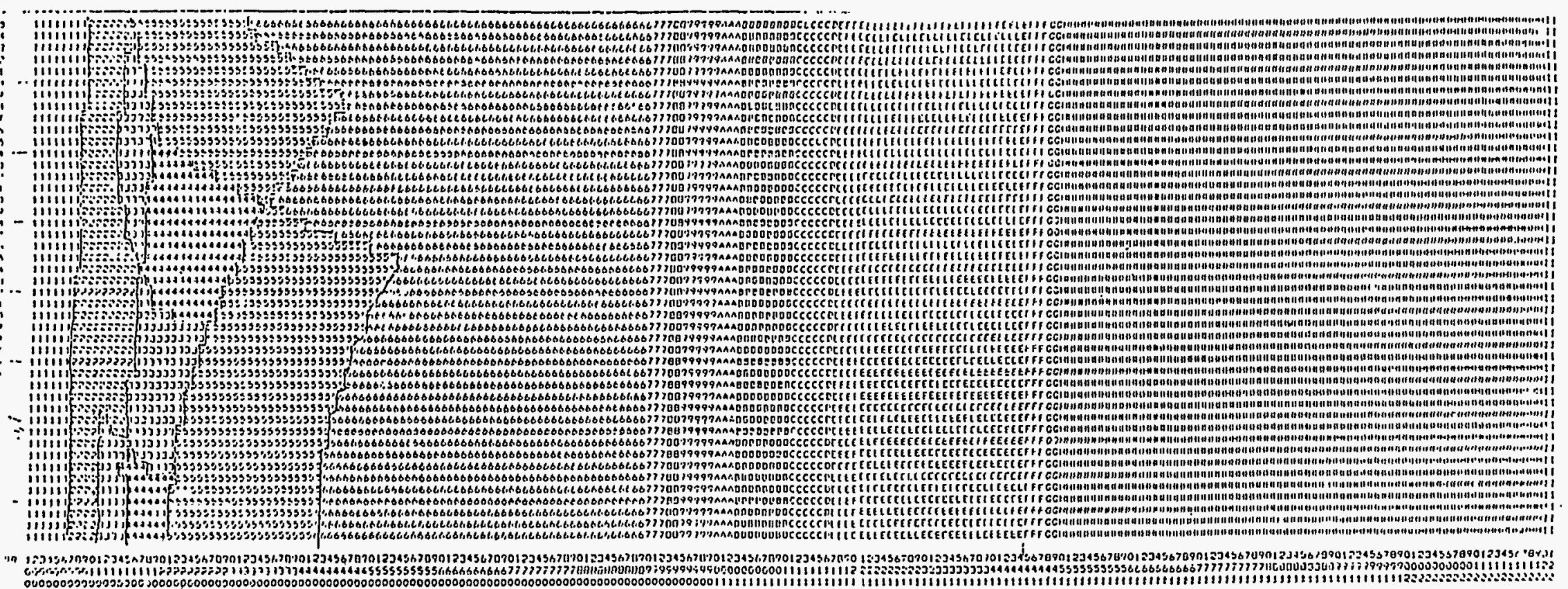

\section{Figure 3.5}

Shippingport DORT Model of PWR-2

Core Region: 1 through 5 Pressure Vessel: E 


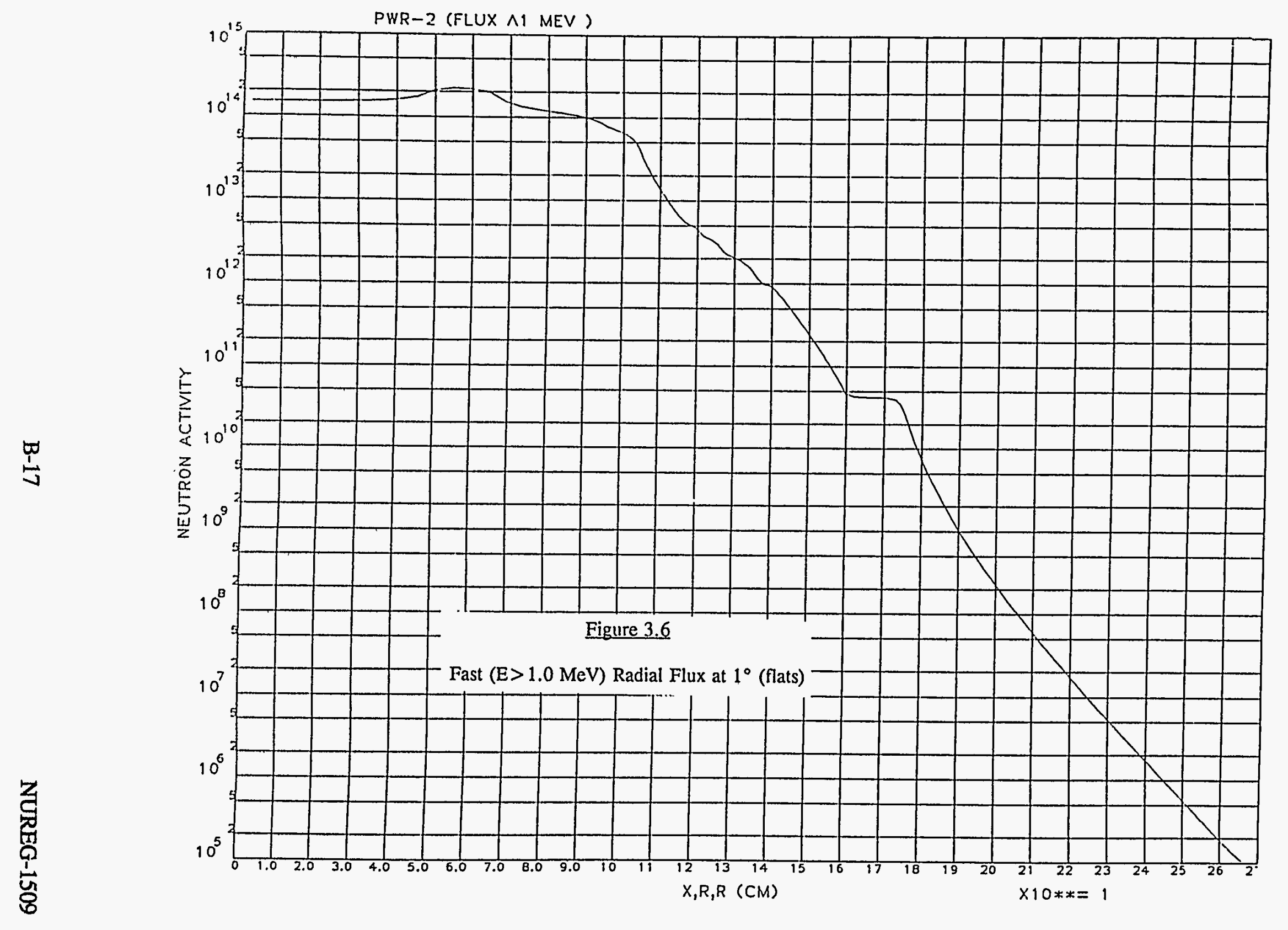




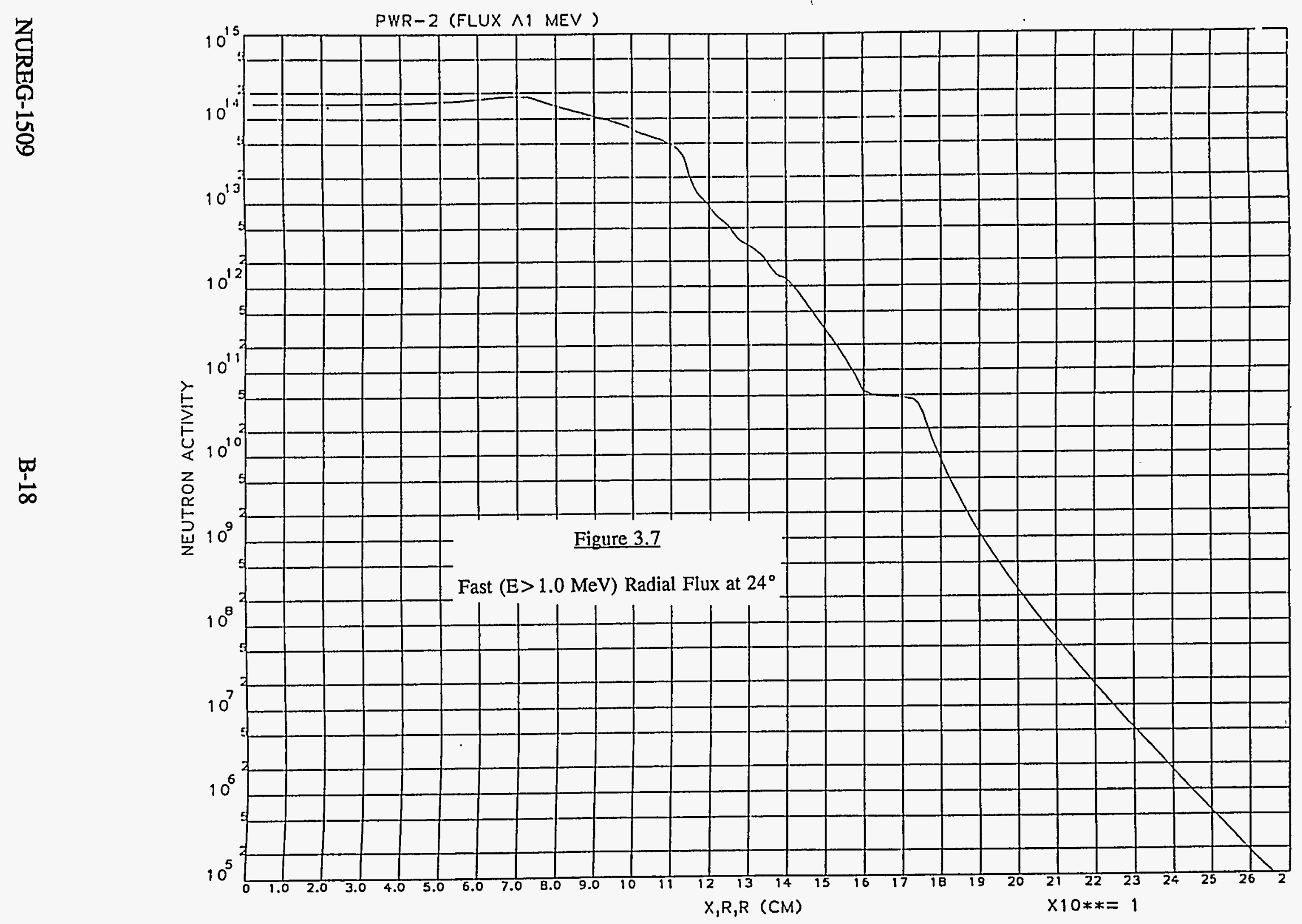




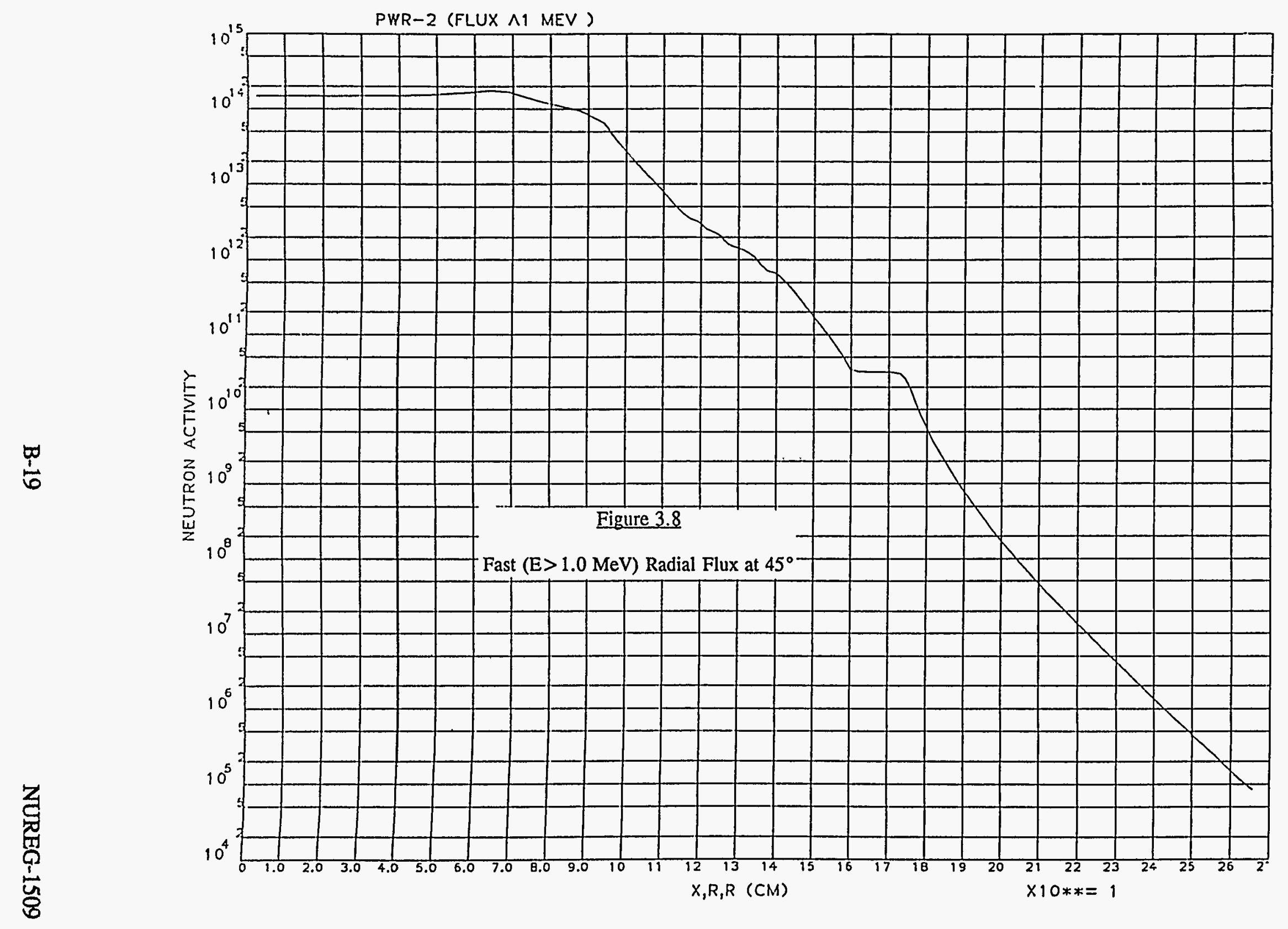




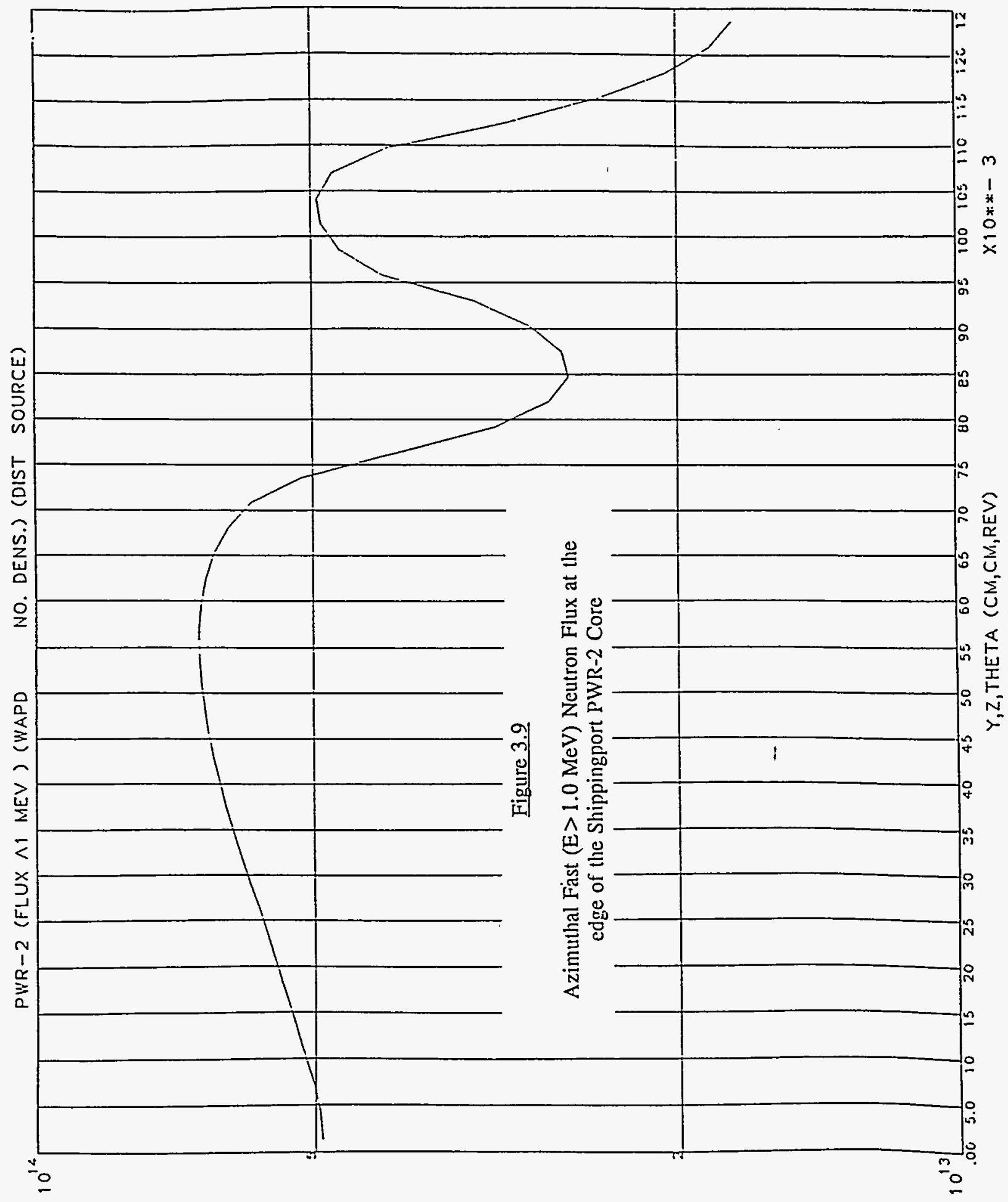

LLINIJY NOdLIBZN 


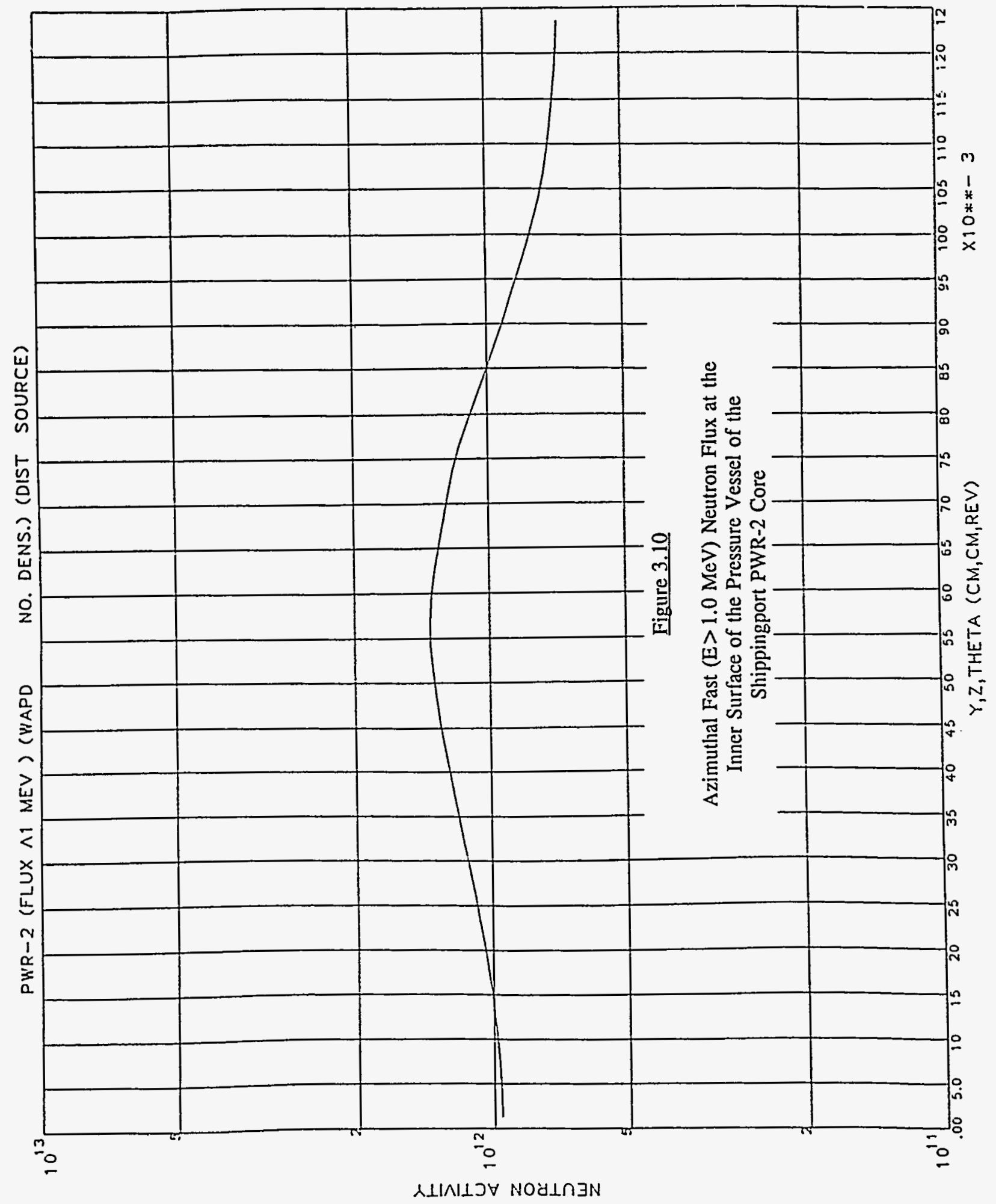




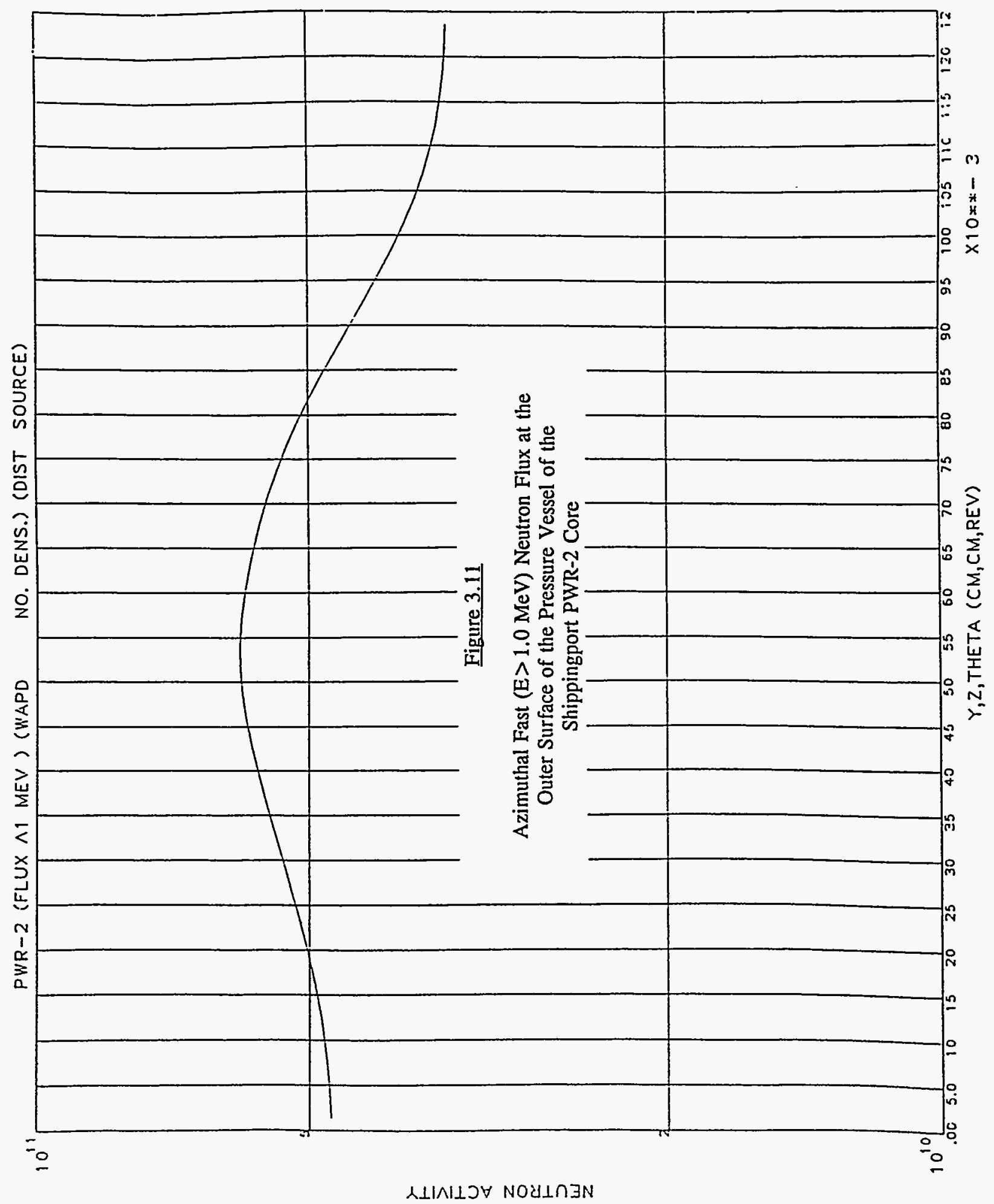


Figure 3.12

Relative Axial Positions of the Three Shippingport

Cores and Elevations at which Measurements were made.

Pressure Vessel Samples Nos. 8, 9, and 11 were obtained

at $20^{\circ}$ and Nos. 2, 3, and 5 were obtained at $200^{\circ}$
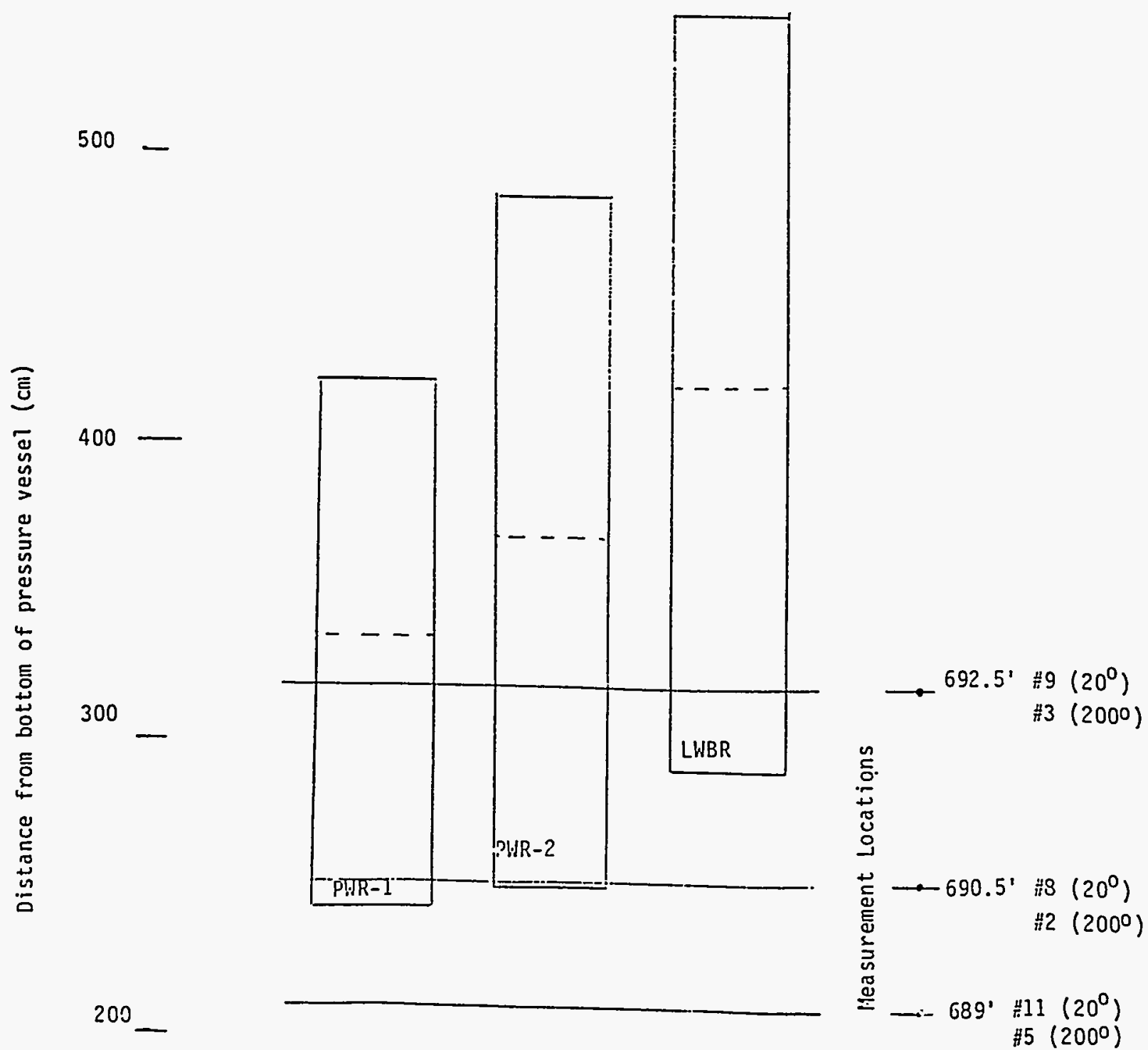


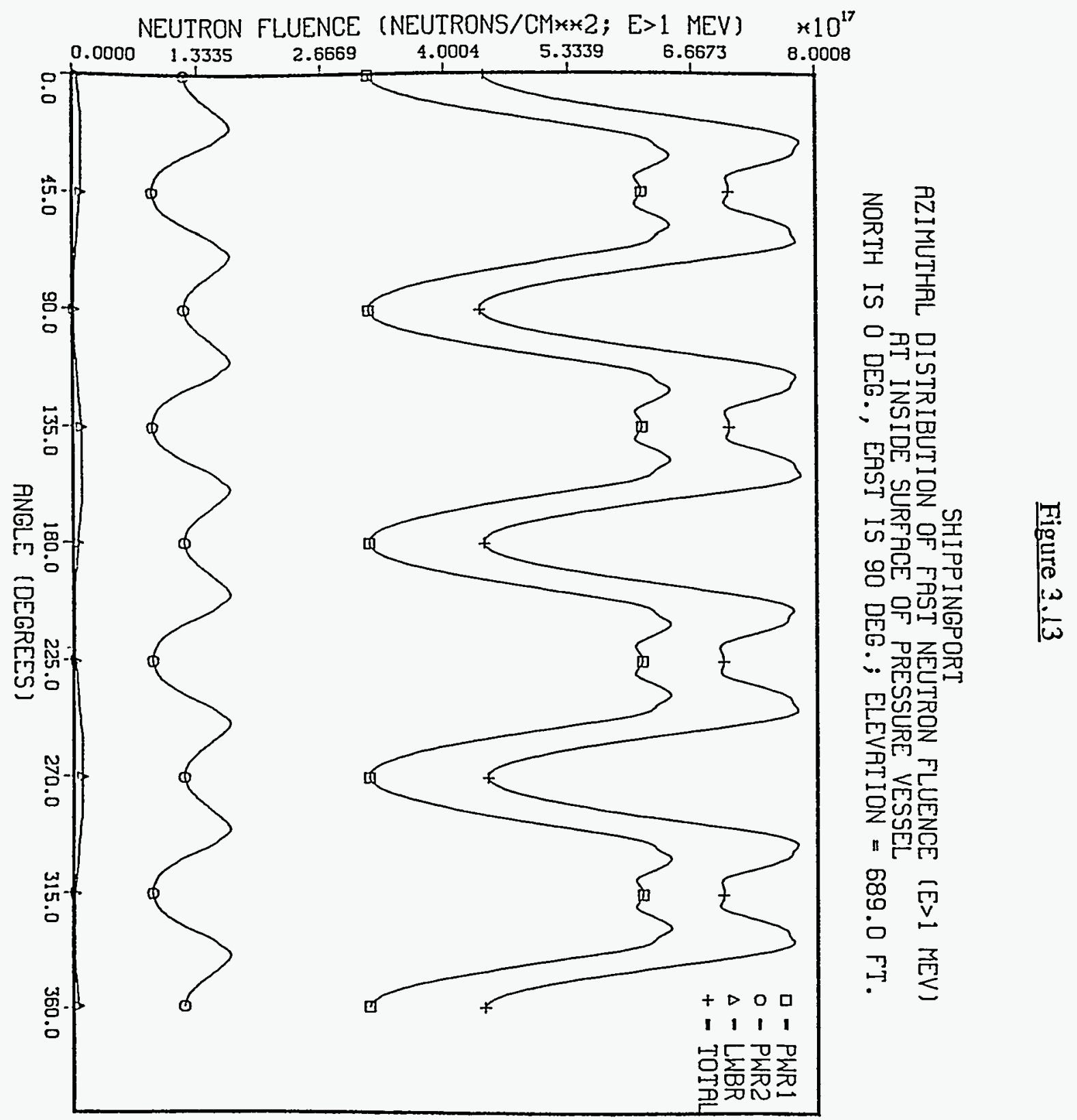




\section{Figure 3.14}

SHIPPINGPORT

AZIMUTHAL DISTRIBUTION OF FAST NEUTRON FLUENCE ( $E>1$ MEV) AT INSIDE SURFACE OF PRESSURE VESSEL

NORTH IS O DEG., EAST IS 90 DEG.; ELEVATION $690.5 \mathrm{FT}$.

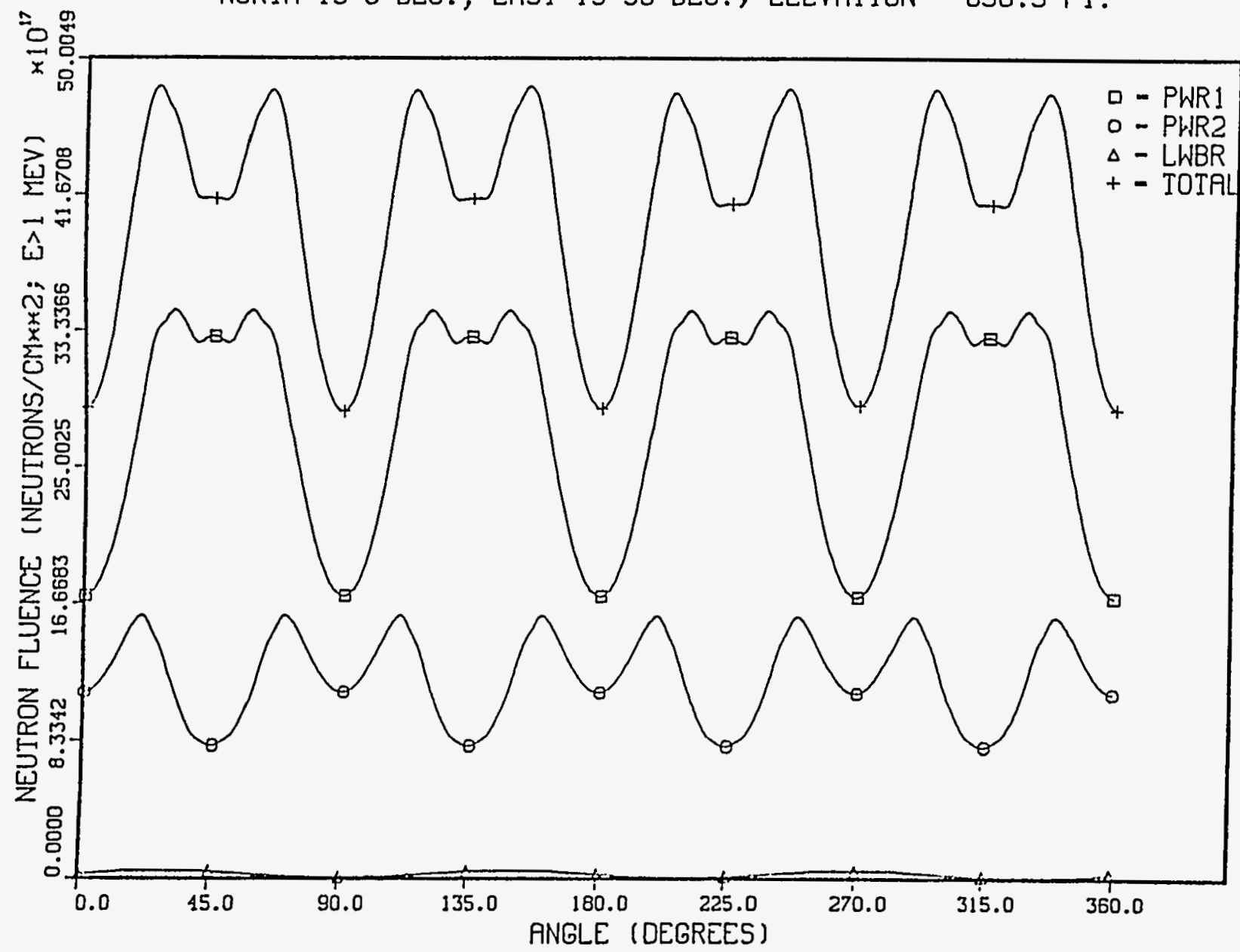


SHIPPINGPORT

AZIMUTHAL DISTRIBUTION OF FAST NEUTRON FLUENCE ( $>>1$ MEV) AT INSIDE SURFACE OF PRESSURE VESSEL

NORTH IS O DEG., EAST IS 90 DEG.; ELEVRTION = $692.5 \mathrm{FT}$.

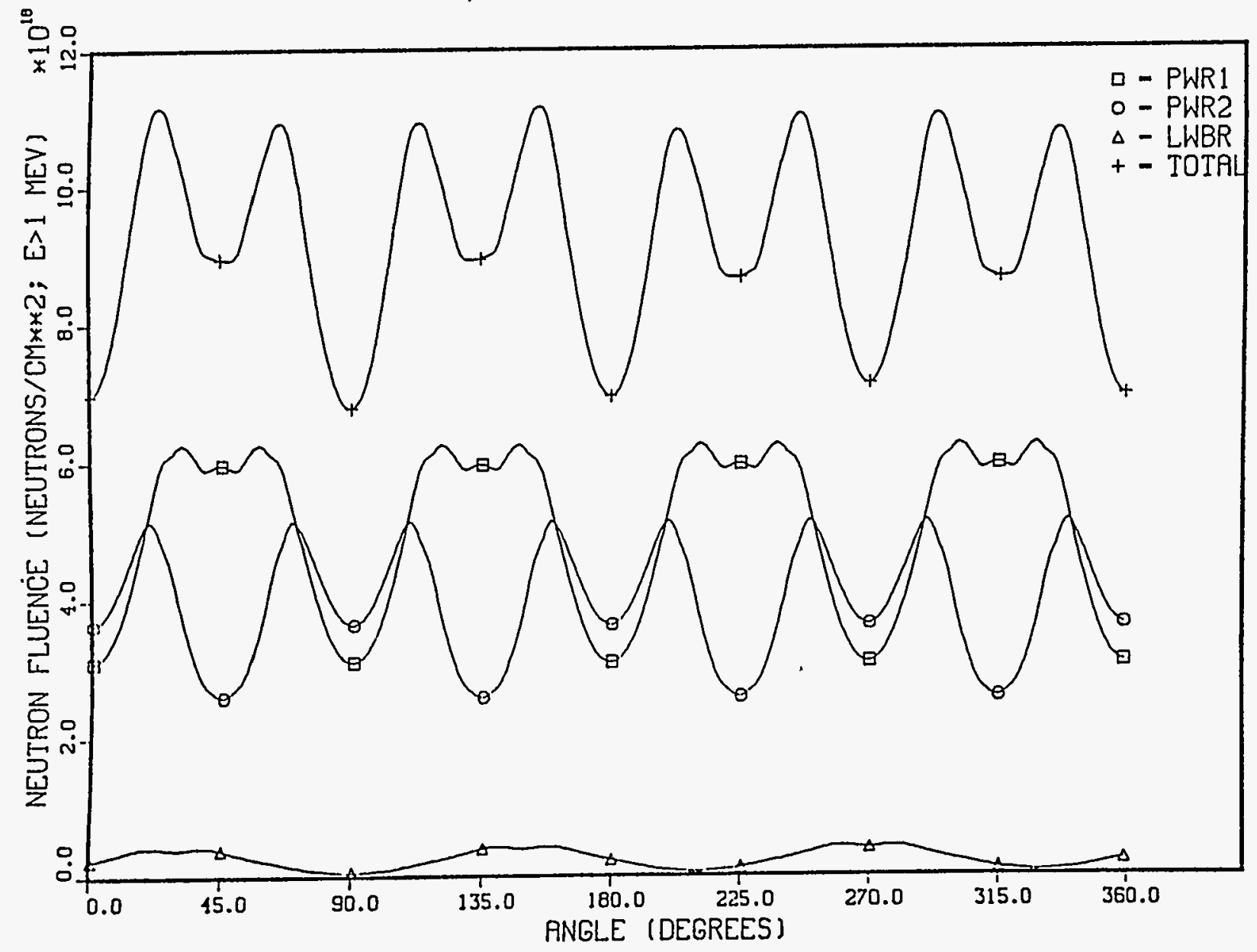




\section{Figure 3.16}

SHIPPINGPORT

AZIMUTHRL DISTRIBUTION OF FAST NEUTRON FLUENCE (E>1 MEV) AT INSIDE OF SHIELD TANK INISER WAL! :
NORTH IS O DEG., EASI IS 90 DEG.; ELEVATION = $689.0 \mathrm{FT}$.

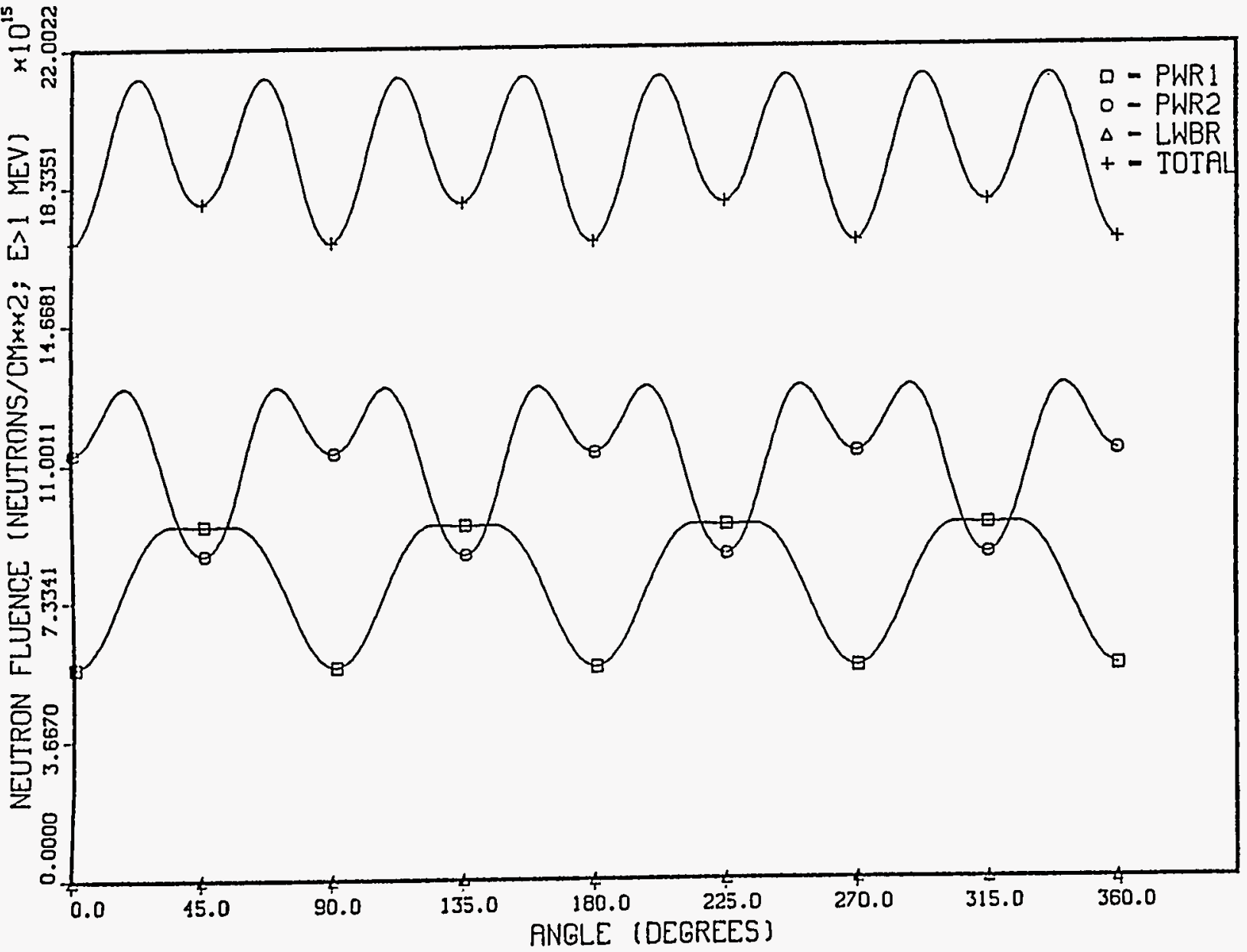

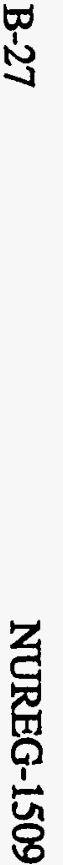




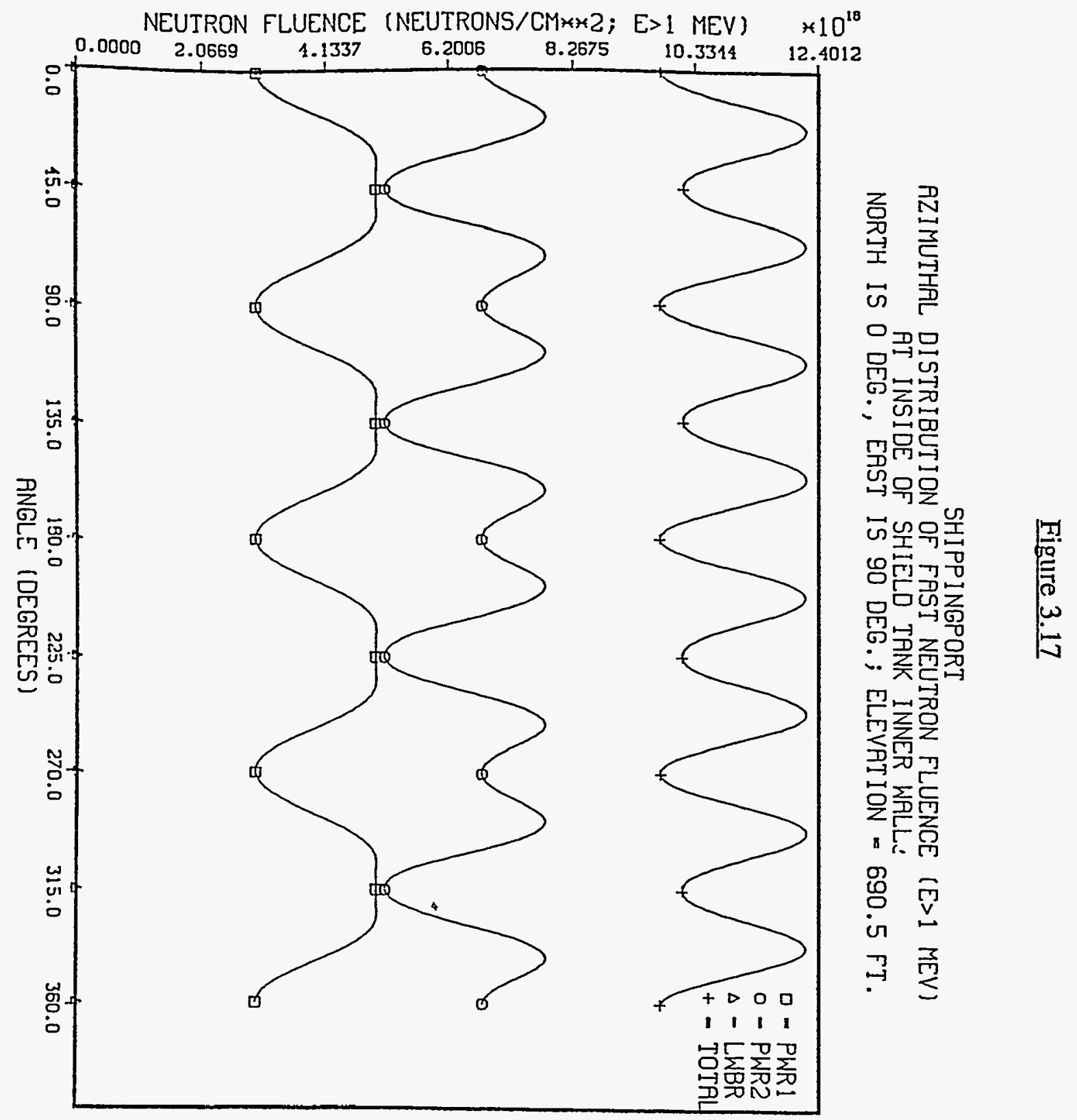




\section{Figure 3.18}

SHIPPINGPORT

RZIMUTHAL DISTRIBUTION OF FAST NEJTRON FLUENC: :E>1 MEV) AT INSIDE OF SHIEID TAINK INNER WALL

NORTH IS O DEG., EAST IS 90 DEG.; ELEVATION = $692.5 \mathrm{FT}$.

ஸั่

足

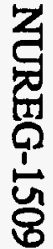

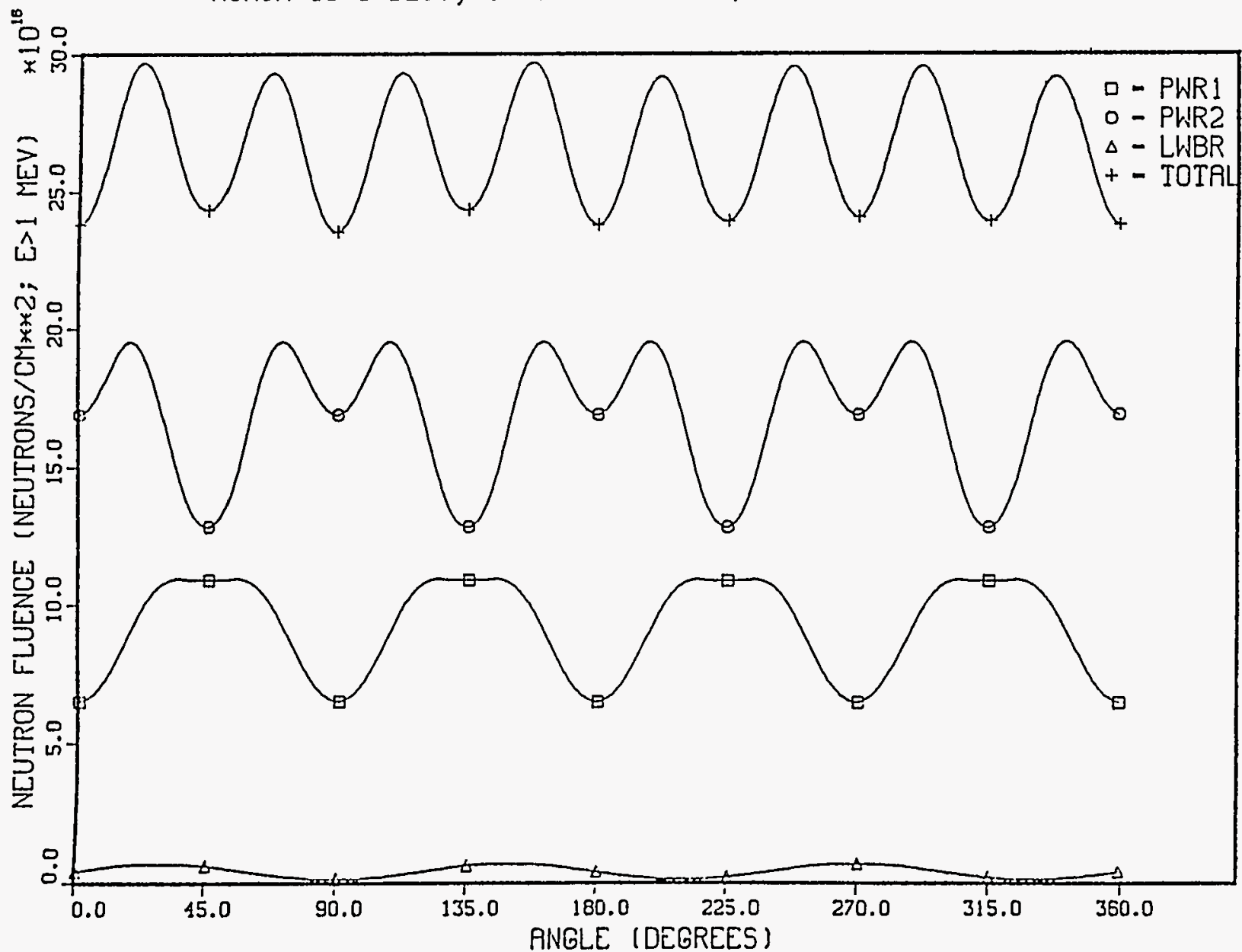


SHIPPINGPORT

AZIMUTHRL DISTRIBUTION OF FAST NEUTRON FLUENCE (E>1 MEV) AT OUTSIDE OF SHIELD TAINK INNER WRLL.

NORTH IS O DEG., EAST IS 90 DEG.; ELEVATION = $689.0 \mathrm{fT}$.

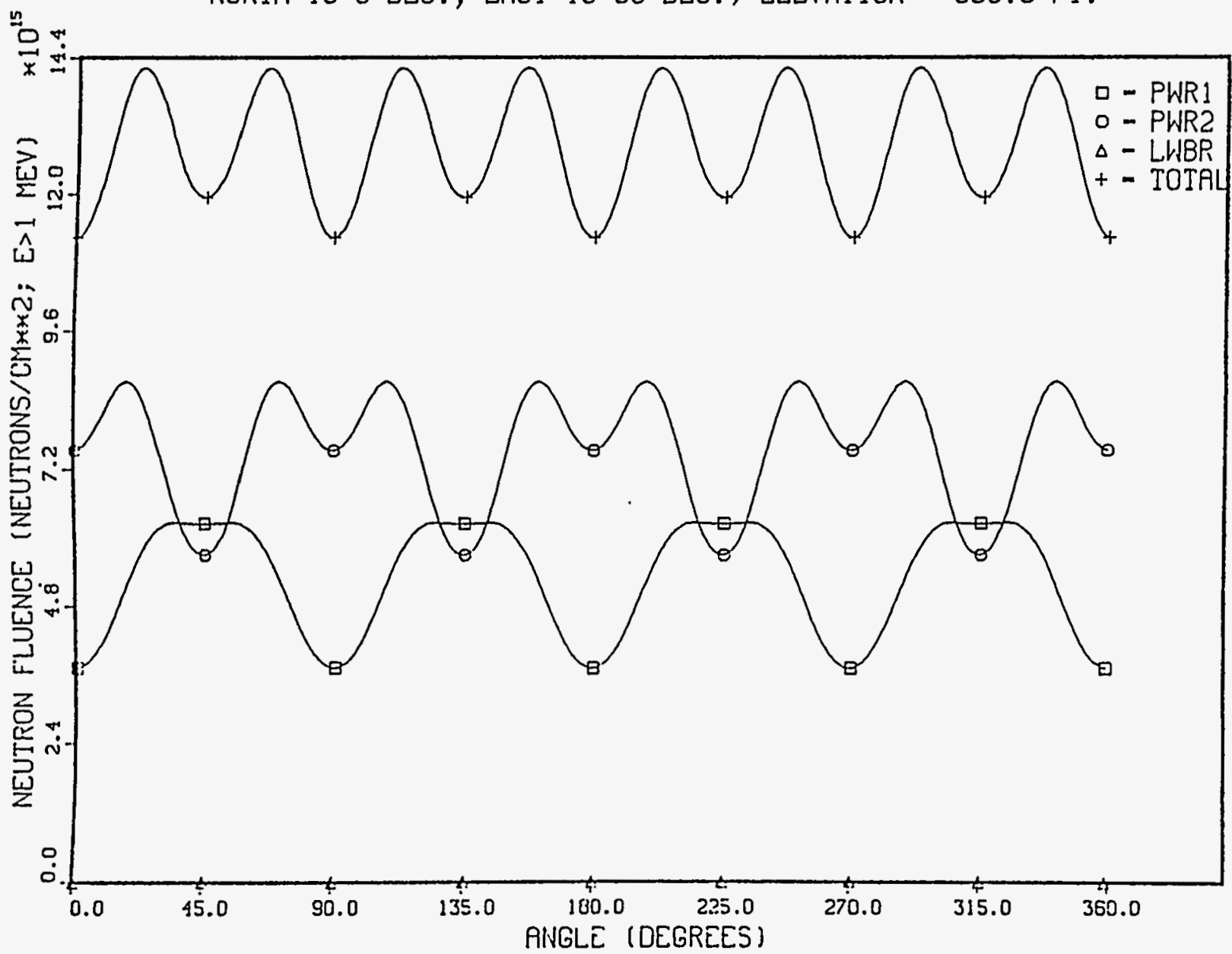




\section{Figure 3.20}

SHIPPINGPORT

AZIMUTHAL DISTRIBUTION OF FAST NEUTRON FLUENCE (E>1 MEV) AT OUTSIDE OF SHIELD TANK INNER WALLS

NORTH IS 0 DEG., ERST IS 90 DEG.; ELEVATION = $690.5 \mathrm{FT}$.

芯

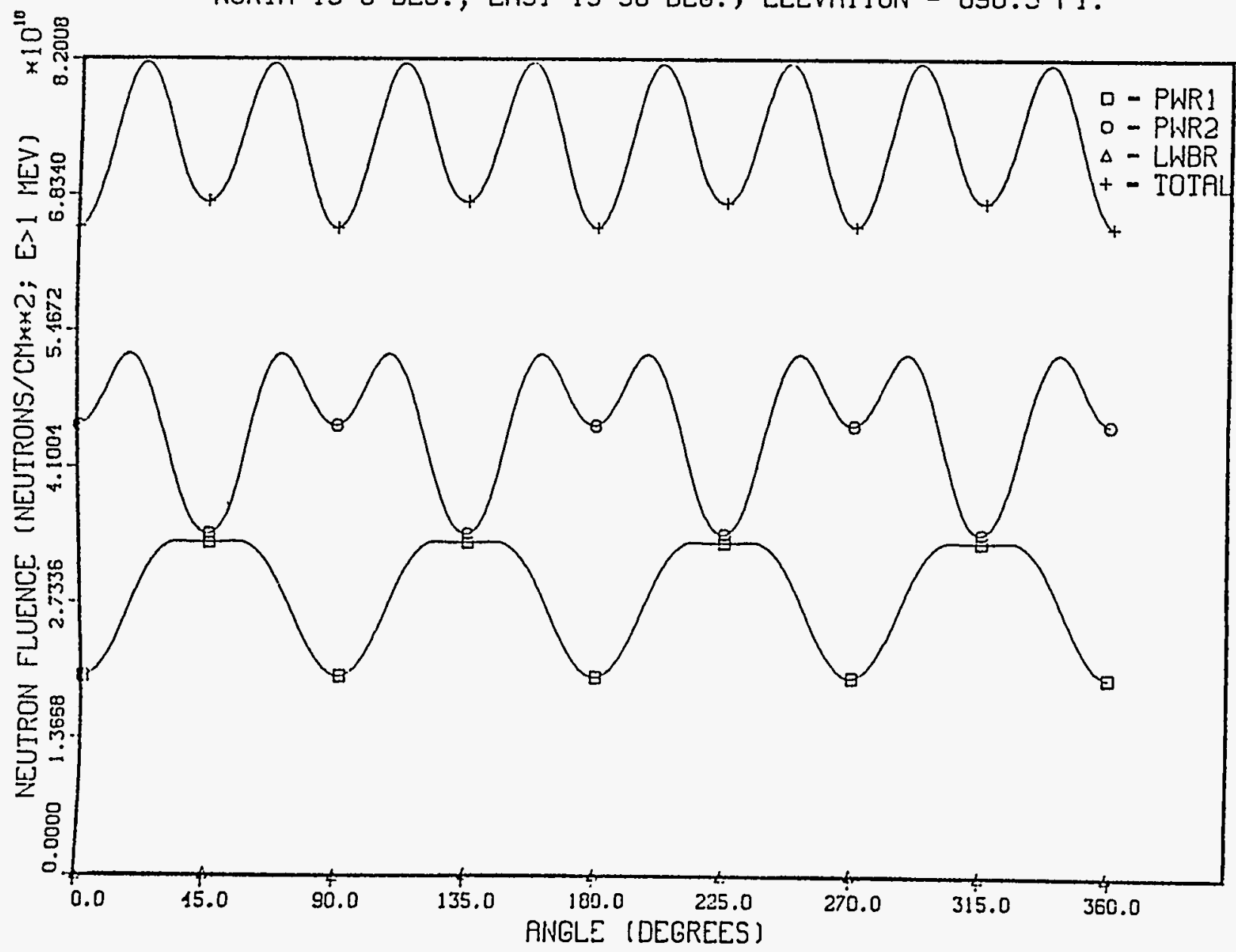


SHIPPINGPORT

AZIMUTHAL DISTRIBUTION OF FAST NEUTRON FLUENCE (E $>1$ MEV)

AT OUTSIDE OF SHIELD TANK INNER WRLLS
NORTH IS O DEG., EAST IS 90 DEG.; ELEVATION $=692.5 \mathrm{FT}$.

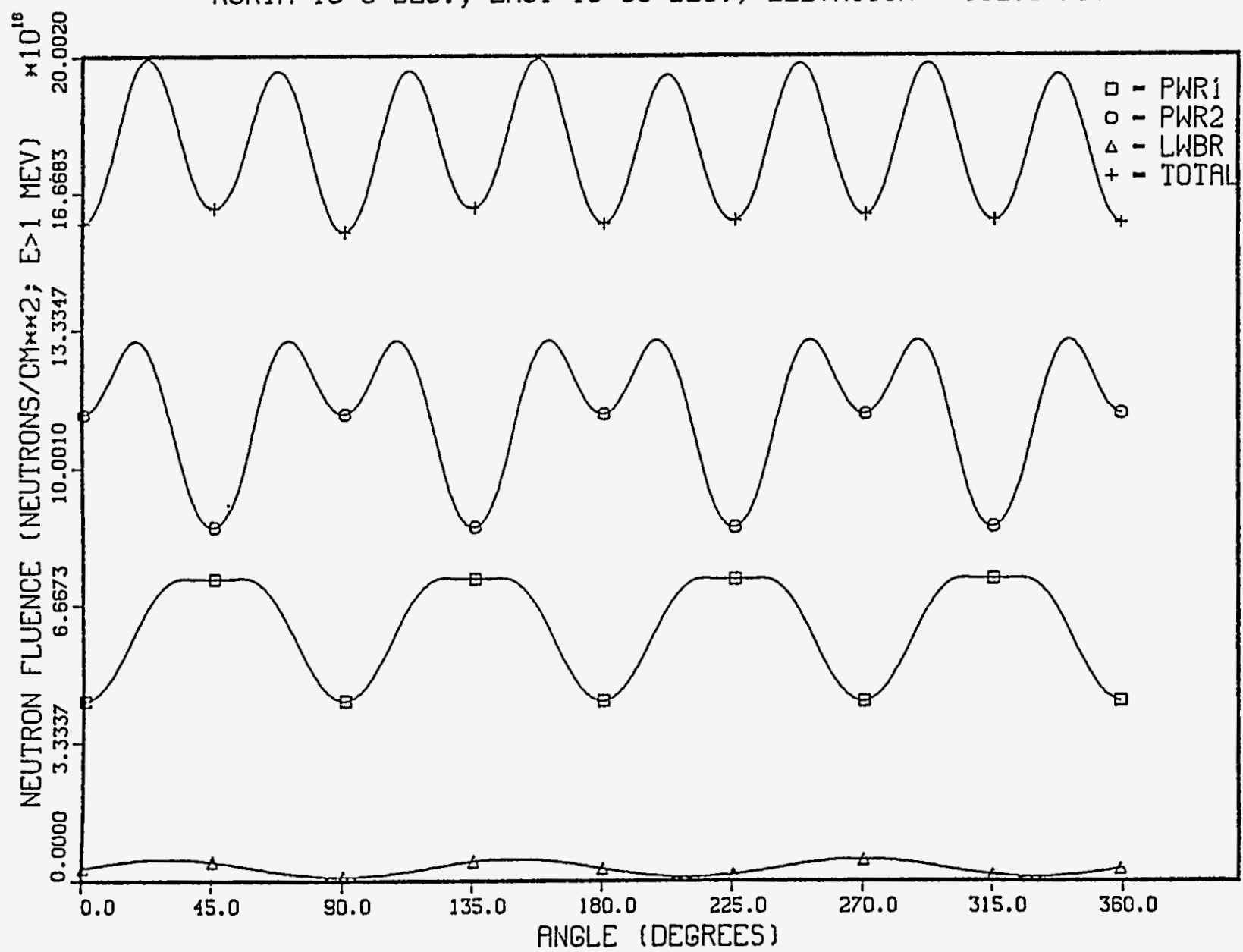


Table 3.1

Flux Per Unit Lethargy

(Normalized To One Neutron Above 1-Mev)

Energy At

Top End

Group Of Group

$1.00000 \mathrm{E}+07$

$6.06550 \mathrm{E}+06$

3.67900E+06

$2.23100 \mathrm{E}+06$

$1.35300 \mathrm{E}+06$

8.21000E+05

$5.00000 \mathrm{E}+05$

$3.02500 \mathrm{E}+05$

$1.83000 \mathrm{E}+05$

1. $11000 \mathrm{E}+05$

$6.73400 \mathrm{E}+04$

$4.08500 \mathrm{E}+.04$

$2.47800 \mathrm{E}+04$

$1.50300 \mathrm{E}+04$

$9.11800 \mathrm{E}+0.3$

$5.53000 \mathrm{OE}+03$

$3.51910 \mathrm{O}+03$

$2.23945 \mathrm{E}+03$

1. $42510 \mathrm{E}+03$

$9.06898 \mathrm{~F}+02$

$3.67262 \mathrm{E}+02$

$1.48728 \mathrm{E}+02$

$7.55014 \mathrm{E}+01$

$4.80520 \mathrm{E}+01$

2.7700OE+01

1. $59680 \mathrm{E}+01$

$9.87700 \mathrm{E}+00$

$4.00000 \mathrm{E}+00$

3. $30000 \mathrm{E}+00$

$2.60000 \mathrm{E}+00$

2. $10000 \mathrm{E}+00$

$1.50000 \Omega+00$

$1.30000 \mathrm{E}+00$

1. $15000 \mathrm{E}+00$

1. $12300 \mathrm{E}+00$

1. $09700 \mathrm{O}+00$

$1.07100 \mathrm{P}+00$

$1.04500 \mathrm{E}+00$

$1.02000 \mathrm{E}+00$

9. 9600OR-OL

$9.720001 \mathrm{~B}-01$

$9.50000 \mathrm{E}-01$

$9.10000 \mathrm{E}-01$

8.50000E-01

$7.800001 \mathrm{~B}-01$

$6.25000 \mathrm{E}-01$

$5.00000 \mathrm{E}-01$

4.00000E-01
Vessel

Inner Wall

$4.65215 \mathrm{E}-02$

8. 98946E-02

2.17224E-01

$3.82395 \mathrm{E}-01$

4.73275E-01

$7.72296 \mathrm{E}-01$

6. 35858E-01

4.06194E-01

5. 06330E-01

3.9671.3E-01

2.39528E-01

3. $41624 \mathrm{E}-01$

1. $96722 \mathrm{E}-01$

1. $68901 \mathrm{E}-01$

1. $86747 \mathrm{E}-01$

1. $91052 \mathrm{E}-01$

$1.49867 \mathrm{E}-01$

1. $94168 \mathrm{E}-01$

1. $52868 \mathrm{E}-01$

1. 54899E-01

1. $67455 \mathrm{E}-01$

1. 69881E-01

1.70587E-01

1. $62448 \mathrm{E}-01$

1.64180E-01

1.61660E-01

1. 57323E-01

1. 50048E-01

1. $41298 \mathrm{E}-01$

1. $44207 \mathrm{E}-01$

1. $47148 \mathrm{E}-01$

1. $47100 \mathrm{E}-01$

1. $41328 \mathrm{E}-01$

1. $43095 \mathrm{E}-01$

1. $42581 \mathrm{E}-01$

1. $44851 \mathrm{E}-01$

1. $42359 \mathrm{E}-01$

1. $41225 \mathrm{E}-01$

1. $43276 \mathrm{E}-01$

1. $13413 \mathrm{E}-01$

1. $42644 \mathrm{~F}-\mathrm{O} 1$

1. $43547 \mathrm{E}-01$

1.38241 $\mathrm{F}-01$

1. 38617 E-0 i

1. $35848 \mathrm{i}-01$

1. $39871 \mathrm{~F}-01$

$1.46731 \mathrm{E}-01$

1. $63596 \mathrm{E}-01$
Inside Of

Shield Tank

Inner Wall

1.75511E-02

2.71099E-02

1. 05594E-01

3.07518E-01

$9.05378 \mathrm{E}-01$

2. $66636 \mathrm{E}+00$

3. $10734 \mathrm{E}+00$

1. $62186 \mathrm{E}+00$

3. $04509 \mathrm{E}+00$

$2.58278 \mathrm{E}+0 \mathrm{O}$

1. $22716 \mathrm{E}+00$

1. $81009 \mathrm{E}+00$

1. $27669 \mathrm{E}+00$

$9.39117 \mathrm{E}-01$

6. $99908 \mathrm{E}-01$

8.32586E-01

$5.21870 \mathrm{E}-01$

$7.30727 \mathrm{E}-01$

$4.71101 \mathrm{E}-01$

3. $57768 \mathrm{E}-01$

3. 83052E-01

3.67131E-01

3. $57131 \mathrm{E}-01$

3. 27238E-01

3. $12541 \mathrm{E}-01$

2. 94383E-01

2.64080E-01

2. 36349E-01

2. 12706E-01

2.0583.1E-01

2.00122E-01

1. $95696 \mathrm{E}-01$

1. 80869E-01

1. $81661 \mathrm{E}-01$

1. $80056 \mathrm{E}-01$

1.81700F-01

1. $77513 \mathrm{E}-01$

1.75147 E-01

1.76594E-01

1.75298E-01

1. 73448E-01

1.72452E-01

1. $62585 \mathrm{~F}-01$

1. $57975 \mathrm{E}-01$

1. $45488 \mathrm{E}-01$

1. $37477 \mathrm{E}-01$

1.25861E-01

1. 20588E-01
Dutside of

Shield Tank

Inner Wall

1.89874E-02

$2.80014 \mathrm{E}-02$

$1.05269 \mathrm{E}-01$

3.01003E-01

9.11236E-01

$2.53427 \mathrm{E}+\mathrm{OO}$

$2.81728 \mathrm{E}+00$

1. $54784 \mathrm{E}+0 \mathrm{O}$

$2.49673 \mathrm{E}+00$

$2.02891 \mathrm{E}+00$

1. $16997 \mathrm{E}+00$

1. $18793 \mathrm{E}+00$

$1.06437 \mathrm{E}+00$

$9.61545 \mathrm{E}-01$

$6.74191 \mathrm{E}-01$

$7.926605-01$

$6.08245 \mathrm{E}-01$

$7.97781 \mathrm{E}-01$

$6.112290-01$

5.34410E-01

$5.4601 .2 \mathrm{E}-01$

$5.31782 \mathrm{E}-01$

$5.18582 \mathrm{E}-01$

$4.98237 \mathrm{E}-01$

$4.81191 \mathrm{E}-01$

$4.63617 \mathrm{E}-01$

4.37759E-01

4. 17097E-01

4.04339E-01

$4.0444 .1 \mathrm{E}-01$

4.02054E-01

$4.01545 \mathrm{E}-01$

3.86912E-01

3.90794E-01

3.9054.1E-01

$3.94067 \mathrm{E}-01$

3.88931E-01

$3.86959 \mathrm{E}-01$

3. 92469E-01

3.90059E-01

3. $91640 \mathrm{r}-01$

3.87959E-01

3.80760E-01

$3.81120 \mathrm{E}-01$

3.75072E-01

3.75481E-01

3.67917E-01

3.65936E-01 
Table 3.1 (continued)

$\begin{array}{lllll}49 & 3.50000 \mathrm{E}-01 & 1.82506 \mathrm{E}-01 & 1.16354 \mathrm{E}-01 & 3.65021 \mathrm{E}-01 \\ 5 n & 3.20000 \mathrm{E}-01 & 2.00304 \mathrm{E}-01 & 1.1 .2817 \mathrm{E}-01 & 3.65690 \mathrm{E}-01 \\ 51 & 3.00000 \mathrm{E}-01 & 2.18631 \mathrm{E}-01 & 1.09503 \mathrm{E}-01 & 3.67133 \mathrm{E}-01 \\ 52 & 2.80000 \mathrm{E}-01 & 2.19038 \mathrm{E}-01 & 1.06947 \mathrm{E}-01 & 3.73634 \mathrm{E}-01 \\ 53 & 2.50000 \mathrm{E}-01 & 2.95958 \mathrm{E}-01 & 1.07920 \mathrm{E}-01 & 3.96272 \mathrm{E}-01 \\ 54 & 2.20000 \mathrm{E}-01 & 3.62980 \mathrm{E}-01 & 1.17515 \mathrm{E}-01 & 4.61061 \mathrm{E}-01 \\ 55 & 1.80000 \mathrm{E}-01 & 4.36144 \mathrm{E}-01 & 1.43222 \mathrm{E}-01 & 6.21388 \mathrm{E}-01 \\ 56 & 1.40000 \mathrm{E}-01 & 4.69364 \mathrm{E}-01 & 1.81122 \mathrm{E}-01 & 9.05317 \mathrm{E}-01 \\ 57 & 1.0000 \mathrm{E}-01 & 4.30881 \mathrm{E}-01 & 2.02509 \mathrm{E}-01 & 1.1481 .1 \mathrm{E}+00 \\ 58 & 8.00000 \mathrm{E}-02 & 3.69549 \mathrm{E}-01 & 2.04039 \mathrm{E}-01 & 1.25779 \mathrm{E}+00 \\ 59 & 6.70000 \mathrm{E}-02 & 3.12635 \mathrm{E}-01 & 1.94721 \mathrm{E}-01 & 1.27846 \mathrm{E}+00 \\ 60 & 5.80000 \mathrm{E}-02 & 2.60253 \mathrm{E}-01 & 1.78262 \mathrm{E}-01 & 1.24060 \mathrm{E}+00 \\ 61 & 5.00000 \mathrm{E}-02 & 2.06635 \mathrm{E}-01 & 1.54261 \mathrm{E}-01 & 1.14470 \mathrm{E}+00 \\ 62 & 4.20000 \mathrm{E}-02 & 1.55580 \mathrm{E}-01 & 1.25117 \mathrm{E}-01 & 9.97938 \mathrm{E}-01 \\ 63 & 3.50000 \mathrm{E}-02 & 1.16092 \mathrm{E}-01 & 9.85665 \mathrm{E}-02 & 8.43117 \mathrm{E}-01 \\ 64 & 3.00000 \mathrm{E}-02 & 8.50503 \mathrm{E}-02 & 7.50741 \mathrm{E}-02 & 6.89992 \mathrm{E}-01 \\ 65 & 2.50000 \mathrm{E}-02 & 5.73140 \mathrm{E}-02 & 5.20482 \mathrm{E}-02 & 5.23422 \mathrm{E}-01 \\ 66 & 2.00000 \mathrm{E}-02 & 3.40037 \mathrm{E}-02 & 3.13110 \mathrm{E}-02 & 3.54348 \mathrm{E}-01 \\ 67 & 1.50000 \mathrm{E}-02 & 1.62634 \mathrm{E}-02 & 1.47990 \mathrm{E}-02 & 1.97951 \mathrm{E}-01 \\ 68 & 1.00000 \mathrm{E}-02 & 4.97469 \mathrm{E}-03 & 4.24523 \mathrm{E}-03 & 7.35046 \mathrm{E}-02 \\ 69 & 5.00000 \mathrm{E}-03 & 1.30740 \mathrm{E}-04 & 9.00863 \mathrm{E}-05 & 2.50389 \mathrm{E}-03\end{array}$




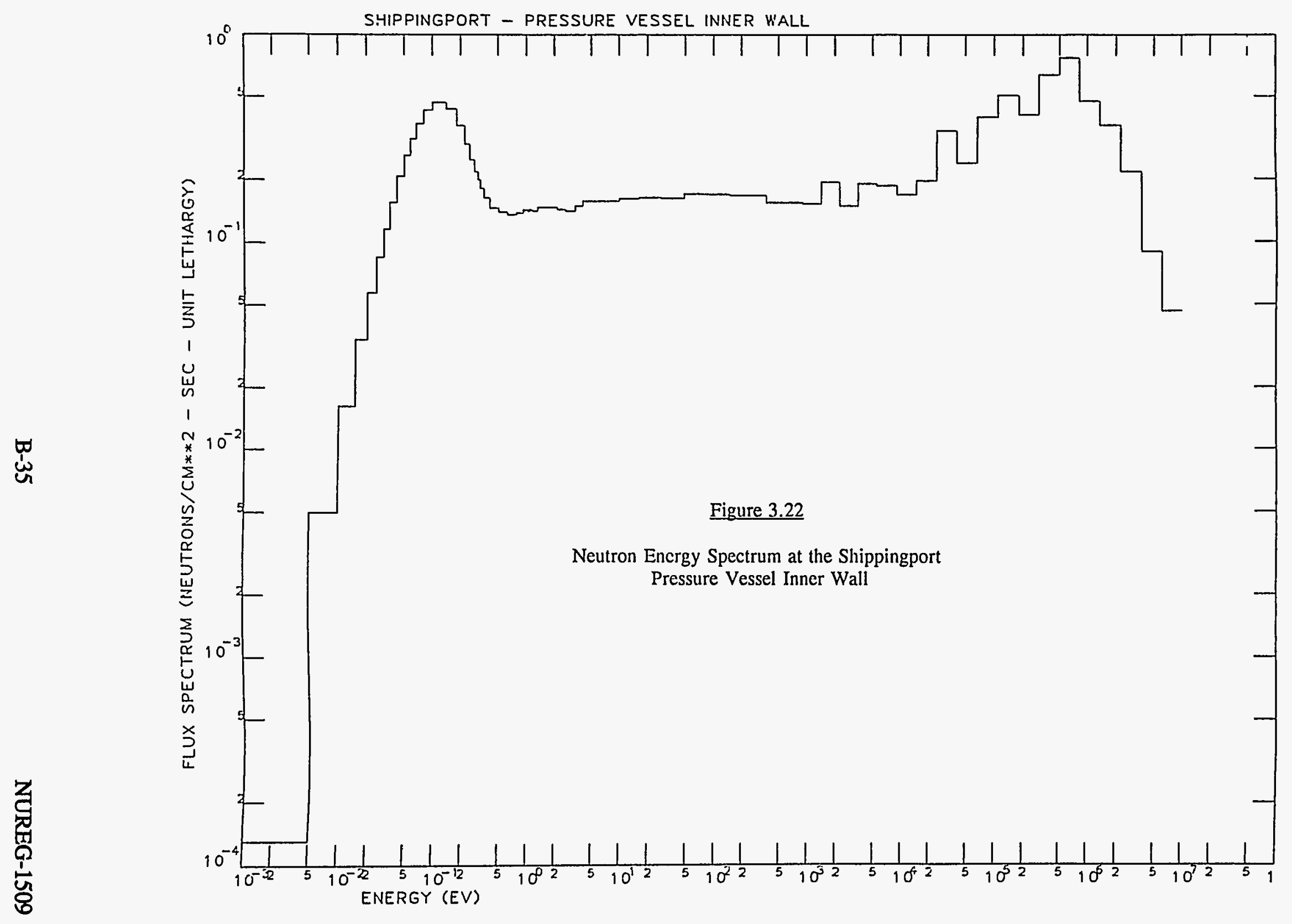




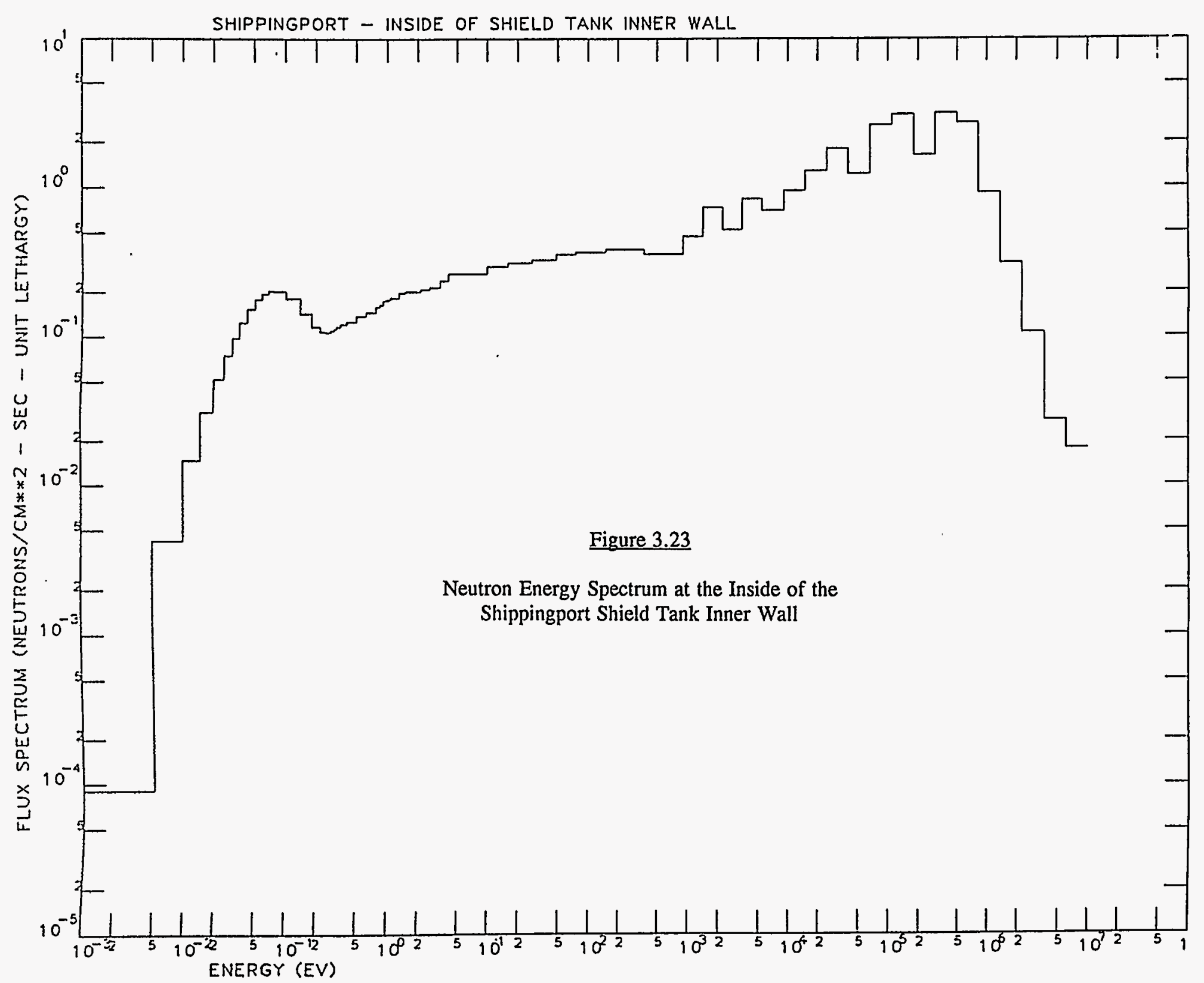




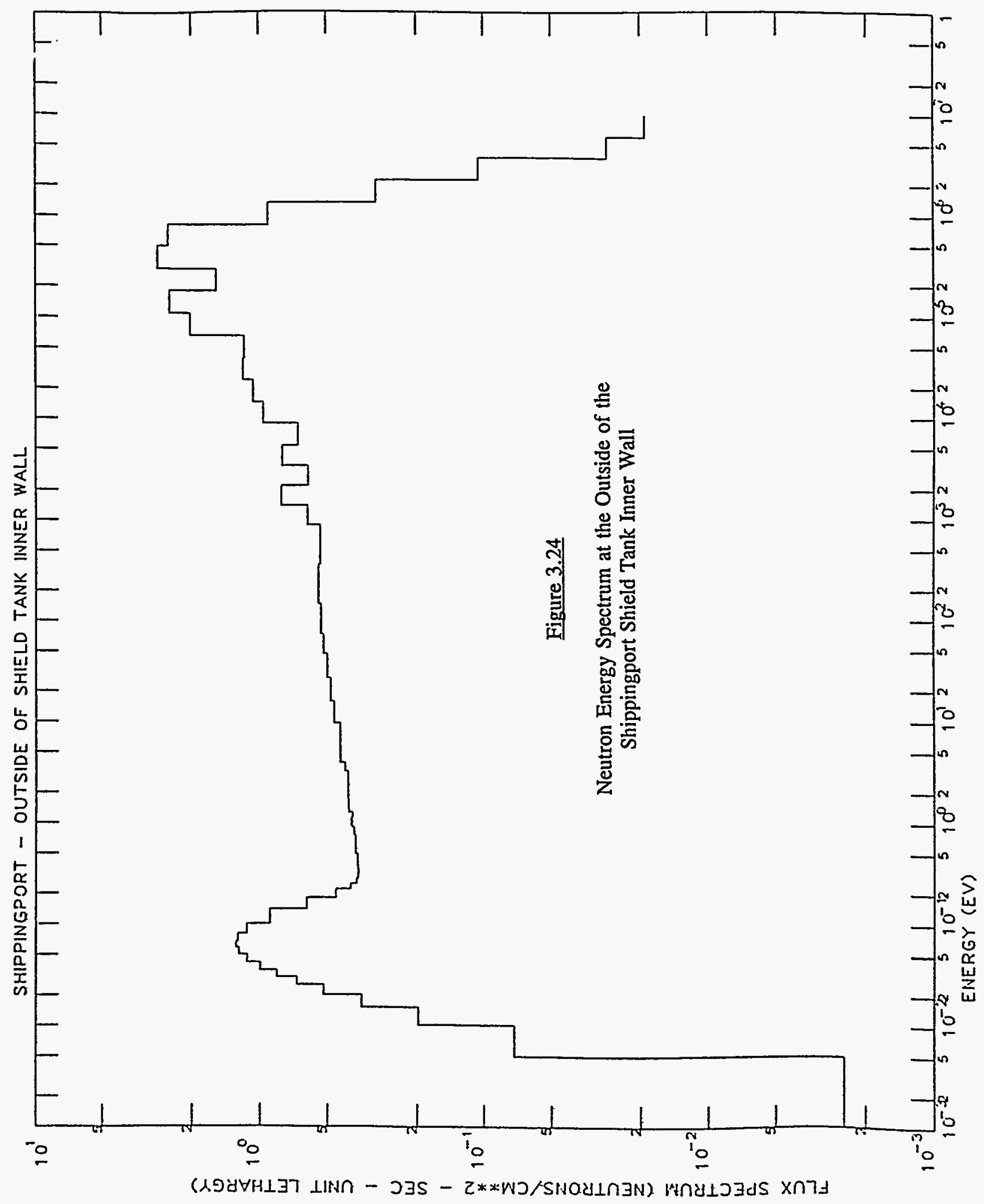


Table 3.2 Neutron Fluences for Inner Surface of Pressure Vessel

\begin{tabular}{|l|c|c|c|c|}
\hline & $\begin{array}{c}\text { Fast } \\
\text { Fluence } \\
(\mathrm{E}>1.0 \mathrm{MeV})\end{array}$ & $\begin{array}{c}\text { Fast } \\
\text { Fluence } \\
(\mathrm{E}>0.1 \mathrm{MeV})\end{array}$ & $\begin{array}{c}\text { Thermal } \\
\text { Fluence } \\
(\mathrm{E}<0.4 \mathrm{eV})\end{array}$ & $\begin{array}{c}\text { Total } \\
\text { Fluence }\end{array}$ \\
\hline
\end{tabular}

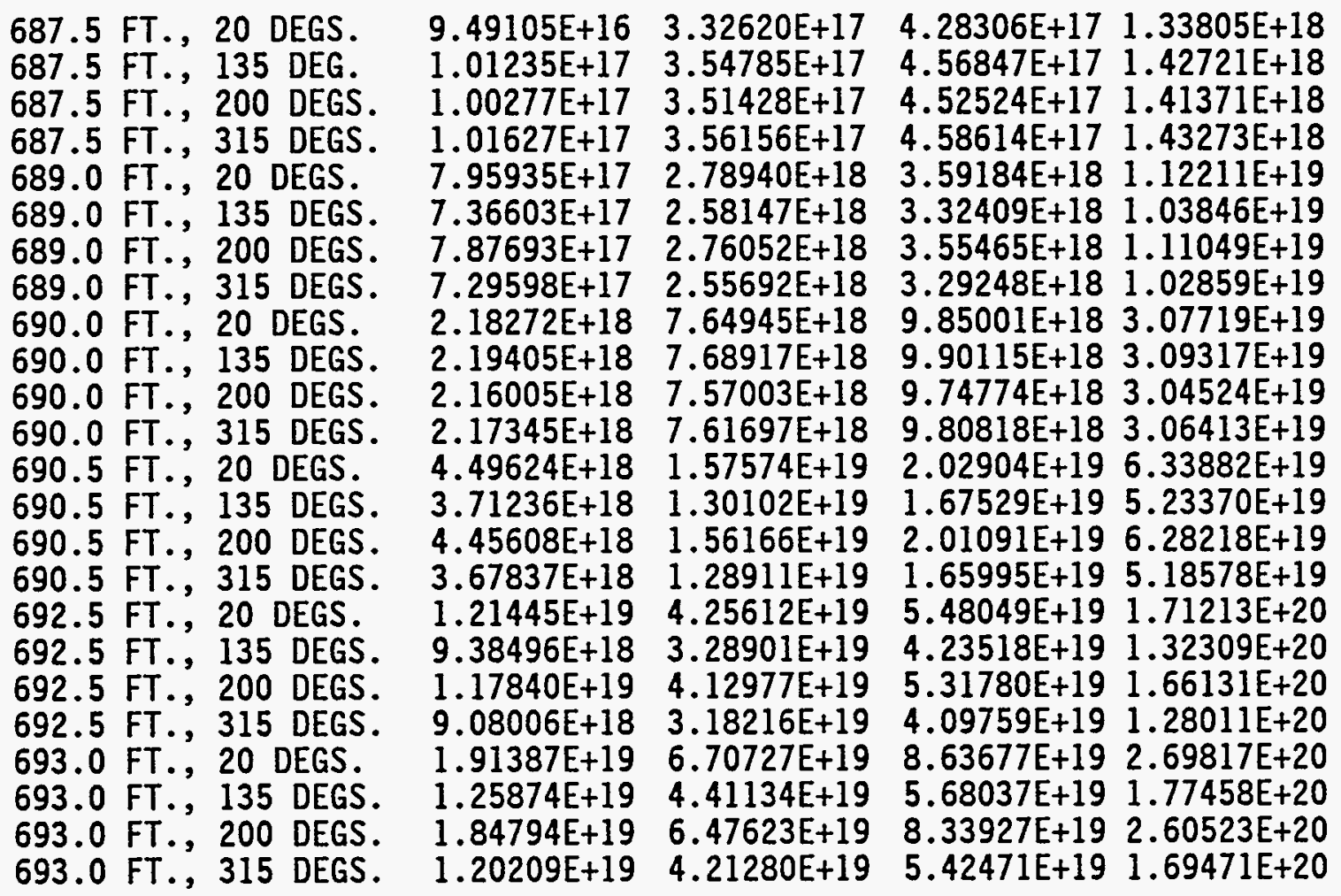


Table 3.3 Neutron Fluences for Inner Surface of Shield Tank Inner Wall

\begin{tabular}{|l|c|c|c|c|}
\hline Location & $\begin{array}{c}\text { Fast } \\
\text { Fluence } \\
(\mathrm{E}>1.0 \mathrm{MeV})\end{array}$ & $\begin{array}{c}\text { Fast } \\
\text { Fluence } \\
(\mathrm{E}>0.1 \mathrm{MeV})\end{array}$ & $\begin{array}{c}\text { Thermal } \\
\text { Fluence } \\
(\mathrm{E}<0.4 \mathrm{eV})\end{array}$ & $\begin{array}{c}\text { Total } \\
\text { Fluence }\end{array}$ \\
\hline
\end{tabular}

687.5 FT., 20 DEGS. $687.5 \mathrm{FT} ., 135$ DEGS. 687.5 FT., 200 DEGS. 687.5 FT., 315 DEGS. 689.0 FT., 20 DEGS. 689.0 FT., 135 DEGS. $689.0 \mathrm{FT} ., 200$ DEGS. $689.0 \mathrm{FT}$., 315 DEGS. 690.0 FT., 20 DEGS. $690.0 \mathrm{FT} ., 135$ DEGS. 690.0 FT., 200 DEGS. 690.0 FT., 315 DEGS. 690.5 FT., 20 DEGS. 690.5 FT., 135 DEGS. 690.5 FT., 200 DEGS. 690.5 FT., 315 DEGS. 692.5 FT., 20 DEGS. 692.5 FT., 135 DEGS. 692.5 FT., 200 DEGS. 692.5 FT., 315 DEGS. 693.0 FT., 20 DEGS. 693.0 FT., 135 DEGS. 693.0 FT., 200 DEGS. 693.0 FT., 315 DEGS.

\section{2. $25042 E+15$}

$1.82912 E+15$

$2.25042 E+15$

$1.82807 \mathrm{E}+15$

$2.25042 \mathrm{E}+16$

$1.82912 \mathrm{E}+16$

$2.25042 \mathrm{E}+16$

$1.82807 \mathrm{E}+16$

$5.62922 \mathrm{E}+16$

$4.57493 \mathrm{E}+16$

$5.62604 \mathrm{E}+16$

$4.57176 \mathrm{E}+16$

$1.29563 \mathrm{E}+17$

$1.03460 \mathrm{E}+17$

$1.29351 \mathrm{E}+17$

$1.03291 \mathrm{E}+17$

$3.34917 \mathrm{E}+17$

3.66778E+17

$3.29518 \mathrm{E}+17$

2.56374E+17

$3.73129 \mathrm{E}+17$

2. $93634 \mathrm{E}+17$

$3.61697 \mathrm{E}+17$

$2.84002 E+17$
$2.64783 E+16$

$2.15214 E+16$

$2.64783 E+16$

$2.15090 E+16$

$2.64783 \mathrm{E}+17$

$2.15214 \mathrm{E}+17$

$2.64783 \mathrm{E}+17$

2.15090E+17

$6.62331 \mathrm{E}+17$

$5.38284 \mathrm{E}+17$

$6.61957 \mathrm{E}+17$

5.37910E+17

$1.52443 \mathrm{E}+18$

$1.21730 \mathrm{E}+18$

$1.52194 \mathrm{E}+18$

$1.21531 \mathrm{E}+18$

$3.94061 \mathrm{E}+18$

4.31549E+18

$3.87709 \mathrm{E}+18$

$3.01649 \mathrm{E}+18$

$4.39022 E+18$

$3.45488 \mathrm{E}+18$

$4.25572 E+18$

$3.34155 \mathrm{E}+18$
$5.24835 E+15 \quad 6.71072 E+16$ $4.26583 \mathrm{E}+15 \quad 5.45443 \mathrm{E}+16$ $5.24835 \mathrm{E}+15 \quad 6.71072 \mathrm{E}+16$ $4.26336 \mathrm{E}+15 \quad 5.45128 \mathrm{E}+16$ $5.24835 E+16 \quad 6.71072 E+17$ $4.26583 E+16 \quad 5.45443 E+17$ $5.24835 \mathrm{E}+16 \quad 6.71072 \mathrm{E}+17$ $4.26336 \mathrm{E}+16 \quad 5.45128 \mathrm{E}+17$ $1.31283 \mathrm{E}+171.67863 \mathrm{E}+18$ $1.06695 \mathrm{E}+17 \quad 1.36424 \mathrm{E}+18$ $1.31209 \mathrm{E}+17 \quad 1.67768 \mathrm{E}+18$ $1.06621 \mathrm{E}+17 \quad 1.36329 \mathrm{E}+18$ $3.02163 E+173.86355 E+18$ $2.41286 \mathrm{E}+173.08516 \mathrm{E}+18$ $3.01669 E+173.85724 E+18$ $2.40891 E+173.08011 E+18$ $7.81081 E+179.98717 E+18$ $8.55388 \mathrm{E}+17 \quad 1.09373 \mathrm{E}+19$ $7.68491 E+179.82619 E+18$ $5.97907 E+177.64505 E+18$ $8.70199 E+171.11267 \mathrm{E}+19$ $6.84804 E+17 \quad 8.75613 E+18$ $8.43538 E+17 \quad 1.07858 E+19$ $6.62339 \mathrm{E}+17 \quad 8.46889 \mathrm{E}+18$ 
Table 3.4 Neutron Fluences for Outer Surface of Shield Tank Inner Wall

\begin{tabular}{|l|c|c|c|c|}
\hline Location & $\begin{array}{c}\text { Fast } \\
\text { Fluence } \\
(\mathrm{E}>1.0 \mathrm{MeV})\end{array}$ & $\begin{array}{c}\text { Fast } \\
\text { Fluence } \\
(\mathrm{E}>0.1 \mathrm{MeV})\end{array}$ & $\begin{array}{c}\text { Therma } \\
\text { Fluence } \\
(\mathrm{E}<0.4 \mathrm{eV})\end{array}$ & $\begin{array}{c}\text { Total } \\
\text { Fluence }\end{array}$ \\
\hline
\end{tabular}

687.5 FT., 20 DEGS.

687.5 FT., 135 DEGS.

687.5 FT., 200 DEGS.

$687.5 \mathrm{FT} ., 315$ DEGS.

689.0 FT., 20 DEGS.

$689.0 \mathrm{FT} ., 135$ DEGS.

$689.0 \mathrm{FT} ., 200$ DEGS.

689.0 FT., 315 DEGS.

690.0 FT., 20 DEGS.

690.0 FT., 135 DEGS.

690.0 FT., 200 DEGS.

690.0 FT., 315 DEGS.

690.5 FT., 20 DEGS.

690.5 FT., 135 DEGS.

690.5 FT., 200 DEGS.

690.5 FT., 315 DEGS.

692.5 FT., 20 DEGS.

692.5 FT., 135 DEGS.

692.5 FT., 200 DEGS.

692.5 FT., 315 DEGS.

693.0 FT., 20 DEGS.

693.0 FT., 135 DEGS.

693.0 FT., 200 DEGS.

693.0 FT., 315 DEGS.
$1.67888 \mathrm{E}+15$

$1.34459 E+15$

$1.67888 \mathrm{E}+15$

$1.34353 \mathrm{E}+15$

$1.67888 \mathrm{E}+16$

$1.34459 \mathrm{E}+16$

$1.67888 \mathrm{E}+16$

$1.34353 \mathrm{E}+16$

$4.19985 \mathrm{E}+16$

$3.36305 \mathrm{E}+16$

4.19773E+16

$3.35988 \mathrm{E}+16$

$9.66705 \mathrm{E}+16$

$7.60099 \mathrm{E}+16$

$9.65225 \mathrm{E}+16$

$7.58829 \mathrm{E}+16$

$2.49981 \mathrm{E}+17$

$1.91585 \mathrm{E}+17$

$2.45961 \mathrm{E}+17$

$1.88094 \mathrm{E}+17$

$2.78438 \mathrm{E}+17$

$2.15705 \mathrm{E}+17$

$2.69869 \mathrm{E}+17$

$2.08512 \mathrm{E}+17$
$1.78883 E+16$

$1.43264 \mathrm{E}+16$

$1.78883 \mathrm{E}+16$

$1.43152 \mathrm{E}+16$

$1.78883 \mathrm{E}+17$

$1.43264 \mathrm{E}+17$

$1.78883 \mathrm{E}+17$

$1.43152 \mathrm{E}+17$

$4.47490 \mathrm{E}+17$

$3.58330 \mathrm{E}+17$

$4.47265 E+17$

$3.57992 \mathrm{E}+17$

$1.03002 E+18$

$8.09878 E+17$

$1.02844 E+18$

$8.08525 E+17$

$2.66352 E+18$

$2.04132 \mathrm{E}+18$

$2.62069 E+18$

$2.00413 E+18$

$2.96674 \mathrm{E}+18$

$2.29832 E+18$

$2.87543 E+18$

$2.22167 \mathrm{E}+18$
$2.22583 E+167.37215 E+16$

$1.78263 \mathrm{E}+16 \quad 5.90422 \mathrm{E}+16$

$2.22583 E+167.37215 E+16$

$1.78122 \mathrm{E}+16 \quad 5.89958 \mathrm{E}+16$

$2.22583 \mathrm{E}+17 \quad 7.37215 \mathrm{E}+17$

$1.78263 \mathrm{E}+17 \quad 5.90422 \mathrm{E}+17$

$2.22583 \mathrm{E}+17 \quad 7.37215 \mathrm{E}+17$

$1.78122 \mathrm{E}+17 \quad 5.89958 \mathrm{E}+17$

$5.56808 \mathrm{E}+17 \quad 1.84420 \mathrm{E}+18$

$4.45867 \mathrm{E}+17 \quad 1.47675 \mathrm{E}+18$

$5.56528 E+17 \quad 1.84327 E+18$

$4.45446 \mathrm{E}+17 \quad 1.47536 \mathrm{E}+18$

$1.28164 \mathrm{E}+18 \quad 4.24491 \mathrm{E}+18$

$1.00772 E+18 \quad 3.33768 E+18$

$1.27968 \mathrm{E}+18 \quad 4.23841 \mathrm{E}+18$

$1.00604 E+183.33210 E+18$

$3.31420 \mathrm{E}+18 \quad 1.09769 \mathrm{E}+19$

$2.54000 E+18 \quad 8.41271 E+18$

$3.26091 E+18 \quad 1.08004 E+19$

$2.49372 E+18 \quad 8.25941 E+18$

$3.69148 E+181.22265 E+19$

$2.85978 E+189.47184 E+18$

$3.57788 E+181.18503 E+19$

$2.76440 \mathrm{E}+189.15596 \mathrm{E}+18$ 
Table 3.5 Neutron Fluences for Inner Surface of Shield Tank Outer Wall

\begin{tabular}{|l|c|c|c|c|}
\hline & $\begin{array}{c}\text { Fast } \\
\text { Fluence } \\
(\mathrm{E}>1.0 \mathrm{MeV})\end{array}$ & $\begin{array}{c}\text { Fast } \\
\text { Fluence } \\
(\mathrm{E}>0.1 \mathrm{MeV})\end{array}$ & $\begin{array}{c}\text { Thermal } \\
\text { Fluence } \\
(\mathrm{E}<0.4 \mathrm{eV})\end{array}$ & $\begin{array}{c}\text { Total } \\
\text { Fluence }\end{array}$ \\
\hline
\end{tabular}

687.5 FT., 20 DEGS. 687.5 FT., 135 DEGS. 687.5 FT., 200 DEGS. 687.5 FT., 315 DEGS. $689.0 \mathrm{FT} ., 20 \mathrm{DEGS}$. $689.0 \mathrm{FT} ., 135$ DEGS. 689.0 FT., 200 DEGS. $689.0 \mathrm{FT} . ; 315$ DEGS. 690.0 FT., 20 DEGS. $690.0 \mathrm{FT}$., 135 DEGS. 690.0 FT., 200 DEGS. 690.0 FT., 315 DEGS. 690.5 FT., 20 DEGS. 690.5 FT., 135 DEGS. 690.5 FT., 200 DEGS. 690.5 FT., 315 DEGS. 692.5 FT., 20 DEGS. 692.5 FT., 135 DEGS. 692.5 FT., 200 DEGS. 692.5 FT., 315 DEGS. 693.0 FT., 20 DEGS. 693.0 FT., 135 DEGS. 693.0 FT., 200 DEGS. 693.0 FT., 315 DEGS.
4.95572E+09

4.69010E+09

$4.95572 \mathrm{E}+09$

$4.69010 \mathrm{E}+09$

$4.95673 \mathrm{E}+10$

$4.69010 \mathrm{E}+10$

$4.95572 \mathrm{E}+10$

4.69010E+10

$1.23918 \mathrm{E}+11$

$1.17253 \mathrm{E}+11$

$1.23918 \mathrm{E}+11$

$1.17253 \mathrm{E}+11$

$2.83386 \mathrm{E}+11$

2.64904E+11

2.83184E+11

2. $64803 E+11$

$7.19371 \mathrm{E}+11$

$6.59383 \mathrm{E}+11$

$7.13110 \mathrm{E}+11$

$6.54231 \mathrm{E}+11$

$7.96127 E+11$

$7.33208 \mathrm{E}+11$

$7.83098 \mathrm{E}+11$

$7.22300 \mathrm{E}+11$
$6.93883 E+09$

$6.56693 \mathrm{E}+09$

$6.93883 \mathrm{E}+09$

$6.56693 \mathrm{E}+09$

$6.94025 E+10$

$6.56693 \mathrm{E}+10$

$6.93883 \mathrm{E}+10$

$6.56693 \mathrm{E}+10$

$1.73506 \mathrm{E}+11$

$1.64173 \mathrm{E}+11$

$1.73506 \mathrm{E}+11$

$1.64173 \mathrm{E}+11$

$3.96788 \mathrm{E}+11$

$3.70910 \mathrm{E}+11$

$3.96505 \mathrm{E}+11$

$3.70769 \mathrm{E}+11$

$1.00724 \mathrm{E}+12$

$9.23246 \mathrm{E}+11$

$9.98474 \mathrm{E}+11$

$9.16033 \mathrm{E}+11$

$1.11471 \mathrm{E}+12$

$1.02661 \mathrm{E}+12$

$1.09647 \mathrm{E}+12$

$1.01134 \mathrm{E}+12$
$5.76478 E+091.71711 E+10$

$5.45580 E+091.62508 E+10$

$5.76478 \mathrm{E}+091.71711 \mathrm{E}+10$

$5.45580 \mathrm{E}+091.62508 \mathrm{E}+10$

$5.76595 \mathrm{E}+10 \quad 1.71746 \mathrm{E}+11$

$5.45580 \mathrm{E}+10 \quad 1.62508 \mathrm{E}+11$

$5.76478 \mathrm{E}+10 \quad 1.71711 \mathrm{E}+11$

$5.45580 \mathrm{E}+10 \quad 1.62508 \mathrm{E}+11$

$1.44149 \mathrm{E}+11 \quad 4.29365 \mathrm{E}+11$

$1.36395 \mathrm{E}+11 \quad 4.06270 \mathrm{E}+11$

$1.44149 \mathrm{E}+11 \quad 4.29365 \mathrm{E}+11$

$1.36395 E+11 \quad 4.06270 E+11$

$3.29651 E+11 \quad 9.81907 E+11$

$3.08152 E+119.17869 E+11$

$3.29416 \mathrm{E}+119.81207 \mathrm{E}+11$

$3.08035 E+119.17520 E+11$

$8.36815 E+11 \quad 2.49256 E+12$

$7.67031 \mathrm{E}+11 \quad 2.28470 \mathrm{E}+12$

$8.29531 \mathrm{E}+112.47086 \mathrm{E}+12$

$7.61040 \mathrm{E}+11 \quad 2.26685 \mathrm{E}+12$

$9.26100 E+112.75851 E+12$

$8.52910 E+112.54050 E+12$

$9.10945 E+112.71337 E+12$

8.40221E+11 2.50271E+12 
Table 3.6 Neutron Fluences for Outer Surface of Shield Tank Outer Wall

\begin{tabular}{|l|c|c|c|c|}
\hline & $\begin{array}{c}\text { Fast } \\
\text { Fluence } \\
(\mathrm{E}>1.0 \mathrm{MeV})\end{array}$ & $\begin{array}{c}\text { Fast } \\
\text { Fluence } \\
(\mathrm{E}>0.1 \mathrm{MeV})\end{array}$ & $\begin{array}{c}\text { Thermal } \\
\text { Fluence } \\
(\mathrm{E}<0.4 \mathrm{eV})\end{array}$ & $\begin{array}{c}\text { Total } \\
\text { Fluence }\end{array}$ \\
\hline
\end{tabular}

\begin{tabular}{|c|c|c|c|}
\hline 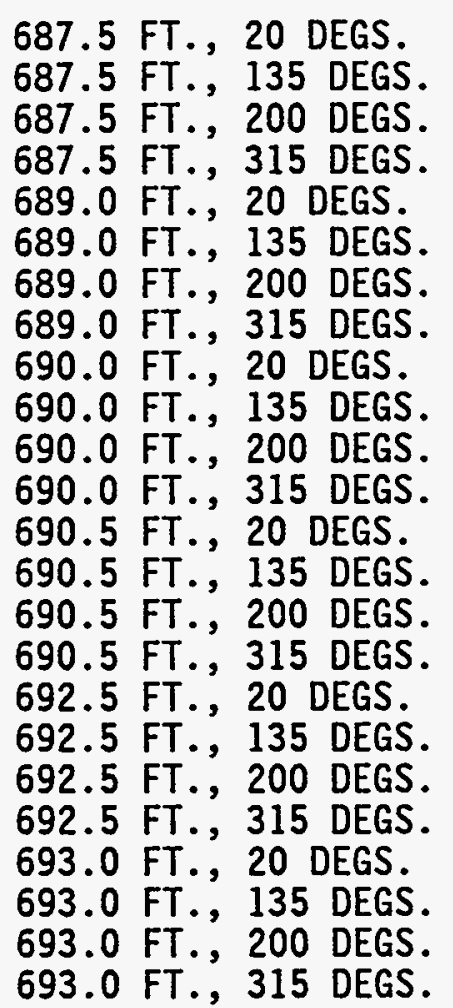 & $\begin{array}{l}3.82132 \mathrm{E}+09 \\
3.62030 \mathrm{E}+09 \\
3.82132 \mathrm{E}+09 \\
3.61929 \mathrm{E}+09 \\
3.82132 \mathrm{E}+10 \\
3.62030 \mathrm{E}+10 \\
3.82132 \mathrm{E}+10 \\
3.61929 \mathrm{E}+10 \\
9.55581 \mathrm{E}+10 \\
9.05277 \mathrm{E}+10 \\
9.55279 \mathrm{E}+10 \\
9.04974 \mathrm{E}+10 \\
2.18491 \mathrm{E}+11 \\
2.04551 \mathrm{E}+11 \\
2.18289 \mathrm{E}+11 \\
2.04349 \mathrm{E}+11 \\
5.54661 \mathrm{E}+11 \\
5.09003 \mathrm{E}+11 \\
5.49813 \mathrm{E}+11 \\
5.05064 \mathrm{E}+11 \\
6.13855 \mathrm{E}+11 \\
5.65975 \mathrm{E}+11 \\
6.03754 \mathrm{E}+11 \\
5.57591 \mathrm{E}+11\end{array}$ & $\begin{array}{l}5.18661 \mathrm{E}+09 \\
4.91377 \mathrm{E}+09 \\
5.18661 \mathrm{E}+09 \\
4.91240 \mathrm{E}+09 \\
5.18661 \mathrm{E}+10 \\
4.91376 \mathrm{E}+10 \\
5.18661 \mathrm{E}+10 \\
4.91240 \mathrm{E}+10 \\
1.29699 \mathrm{E}+11 \\
1.22872 \mathrm{E}+11 \\
1.29658 \mathrm{E}+11 \\
1.22831 \mathrm{E}+11 \\
2.96554 \mathrm{E}+11 \\
2.77633 \mathrm{E}+11 \\
2.96279 \mathrm{E}+11 \\
2.77359 \mathrm{E}+11 \\
7.52831 \mathrm{E}+11 \\
6.90861 \mathrm{E}+11 \\
7.46251 \mathrm{E}+11 \\
6.85514 \mathrm{E}+11 \\
8.33175 \mathrm{E}+11 \\
7.68188 \mathrm{E}+11 \\
8.19464 \mathrm{E}+11 \\
7.56809 \mathrm{E}+11\end{array}$ & $\begin{array}{ll}1.08905 \mathrm{E}+09 & 7.80214 \mathrm{E}+09 \\
1.03177 \mathrm{E}+09 & 7.39171 \mathrm{E}+09 \\
1.08905 \mathrm{E}+09 & 7.80214 \mathrm{E}+09 \\
1.03148 \mathrm{E}+09 & 7.38965 \mathrm{E}+09 \\
1.08905 \mathrm{E}+10 & 7.80214 \mathrm{E}+10 \\
1.03177 \mathrm{E}+10 & 7.39170 \mathrm{E}+10 \\
1.08905 \mathrm{E}+10 & 7.80214 \mathrm{E}+10 \\
1.03148 \mathrm{E}+10 & 7.38965 \mathrm{E}+10 \\
2.72336 \mathrm{E}+10 & 1.95105 \mathrm{E}+11 \\
2.57999 \mathrm{E}+10 & 1.84834 \mathrm{1}+11 \\
2.72249 \mathrm{E}+10 & 1.95043 \mathrm{E}+11 \\
2.57912 \mathrm{E}+10 & 1.84772 \mathrm{E}+11 \\
6.22686 \mathrm{1}+10 & 4.46101 \mathrm{E}+11 \\
5.82959 \mathrm{1}+10 & 4.17640 \mathrm{1}+11 \\
6.22111 \mathrm{E}+10 & 4.45688 \mathrm{E}+11 \\
5.82383 \mathrm{E}+10 & 4.17227 \mathrm{E}+11 \\
1.58075 \mathrm{E}+11 & 1.13247 \mathrm{E}+12 \\
1.45063 \mathrm{E}+11 & 1.03925 \mathrm{E}+12 \\
1.56694 \mathrm{E}+11 & 1.12257 \mathrm{E}+12 \\
1.43940 \mathrm{E}+11 & 1.03121 \mathrm{E}+12 \\
1.74945 \mathrm{E}+11 & 1.25333 \mathrm{E}+12 \\
1.61300 \mathrm{E}+11 & 1.15557 \mathrm{E}+12 \\
1.72066 \mathrm{E}+11 & 1.23271 \mathrm{E}+12 \\
1.58910 \mathrm{E}+11 & 1.13846 \mathrm{1}+12\end{array}$ \\
\hline
\end{tabular}


Appendix C 



\section{APPENDIX C}

R. E. Johnson: "Recommendations Regarding Evaluation of Cast Stainless Steel with Respect to Aging Embrittlement," based on reviews of ANL reports by P. K. Nagata and W. G. Reuter, INEL. 


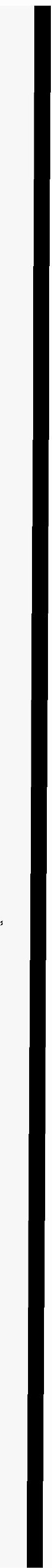




\section{RECOMMENDATIONS REGARDING EVALUATION OF CAST STAINLESS STEEL WITH RESPECT TO AGING EMBRITTLEMENT}

The results of the work done in support of the resolution of GSI-15 led to the conclusion that radiation embrittlement of RPV supports is not as serious a problem as the HFIR surveillance data first suggested. However, even the limited survey of supports in operating nuclear power plants showed that some steels of initial construction might exhibit limited resistance to brittle fracture. Therefore, as noted more fully in the text of this NUREG, there may be conditions which would lead licensees to conduct a structural reevaluation.

When work began on resolution of GSI-15, it was fully expected that some of the operating reactor RPV supports would require an engineering analysis to ensure the structural integrity. To that end, the staff and the Technical Assistance Contractor developed a method for doing such an analysis. The method can be found in Chapter 4. For those cases where insufficient data or other limitations prevent the analyst from completing the reevaluation on the basis of the fracture resistance, a structural consequence analysis is suggested. An evaluation was completed for the NRC by LLNL and those results could serve as guidance. As noted in Section 3.1, a more realistic consequence analysis would consider the potential for degradation in components which are important to the safety of the plant in the event of RPV support failure.

Failure of the RPV supports would induce additional loads on the primary coolant piping. In fact, the LLNL report specifically included the piping as the conduit for the loads otherwise carried by the RPV supports. Therefore, the integrity of the vessel supports is an important part of the consequence analysis. For plants with ferritic steel piping in the primary coolant lines, evaluation methods recommended by the ASME Boiler and Pressure Vessel Code, Section $\mathrm{XI}$, should be followed. For plants with Austenitic stainless steel primary coolant lines, the potential for degradation by the process of thermal aging must be considered. Because aging embrittlement of stainless steel may be unfamiliar to structural engineers, a brief overview of what it is, how it may play a role in the reassessment of RPV supports and how it may be analyzed is given in this Appendix.

\section{AGING EMBRITTLEMENT}

Although holding most common Austenitic stainless steels at a high temperature for a long time will induce a loss of ductility to some degree, experiments have shown that castings are more vulnerable. A rather thorough, recent, treatment dealing with the effect on tensile properties was published in Reference 1. An earlier report (Reference 2) presents a procedure and correlations for predicting Charpy impact energy, tensile flow stress, fracture resistance (in the form of J-R curves), tearing modulus (T) and the elastic-plastic toughness, $J_{\text {Icc }}$, of aged cast stainless steel (specification: ASTM A 351) from given material parameters. Cast stainless steel made to ASTM A 351 is subject to embrittlement when exposed to low temperatures in the range 400 to $842^{\circ} \mathrm{F}$. The thermal embrittlement is expressed as a decrease in the Charpy V-notch impact energy or decrease in the plane strain fracture toughness, $K_{\mathrm{Ic}}$ •

The chemical composition of cast stainless steel is adjusted to result in a duplex microstructure. That is, on solidification there will be a mixture of body-centered-cubic ferrite and facecentered-cubic Austenite. The ferrite will increase the strength and corrosion resistance and reduce the tendency toward hot cracking during solidification. Laboratory studies have led to the conclusion that the ferrite phase is responsible for the appearance of a transition behavior in 
Charpy impact data and for the aging embrittlement. Although the changes in properties resemble age-hardening phenomena, the kinetics of the aging reaction are very sluggish at pressure vessel operating temperatures (about $550^{\circ} \mathrm{F}$ ). Metallurgical experiments (Reference 3) have demonstrated that the physical change underlying the embrittlement is spinodal decomposition. Depending on the detailed chemical composition, precipitation of nickel- or silicon-rich "G" phase also may occur. Steels with relatively high volume fractions of ferrite may be more susceptible to embrittlement than run-of-the-mill steels. The microstructure of the steel is very important in determining the degree or extent of thermal embrittlement. For example, should the ferrite phase form a continuous network through the Austenite grains or should there be a continuous boundary between the two phases, there will be an easy path for crack propagation and the material will be prone to brittle fracture.

The grades of ASTM A 351 steel that are of importance to this study are CF-3, CF-8 and CF8M. The first two also can be made to a restricted chemistry, within the bounds of the parent specification, to obtain a higher relative volume of the ferrite phase which confers a higher tensile yield and ultimate (those steels are denoted: CF-3A and CF-8A). The CF-3 steels are lowcarbon and are least sensitive to thermal embrittlement; the CF-8M steels are high-carbon, contain Mo additions and are most prone to embrittlement. As noted below, evaluation of cast stainless steel as part of a consequence analysis will depend on the metallurgical details of the component.

\section{CONSEOUENCE ANALYSIS CONSIDERATIONS}

The potential for low-temperature embrittlement in cast stainless steel should be a sufficient motive to evaluate components constructed of those materials to ensure their continued ability to meet the design requirements independent of problems related to other components. The issues stemming from the use of cast stainless steels (embrittlement; limited inspectability) were addressed in a "Fitness-for-Service" format in Reference 4. The importance of cast stainless steel primary piping in a consequence evaluation was identified in Reference 5 Using load combinations classified as Service Level $D$ in accord with the ASME Boiler and Pressure Vessel Code, the analysts performed a structural evaluation of the consequences of RPV support failure. It was concluded that the primary coolant piping was capable of transferring the vessel loads to other support structures (of steam generators and main coolant pumps).

The evidence at hand, therefore, allows one to say that RPV support failure may be acceptable from the safety viewpoint of radioactive release providing that the piping does not fail. A consequence analysis done for the purpose of evaluating the risk associated with RPV support failure must include analyses of the cast stainless steel in the primary coolant lines. Because accidents, especially earthquakes, show no respect for structural conditions, the prudent approach is to evaluate the cast stainless under the worst conditions. From abundant experimental data, the behavior of embrittled cast stainless is not different in appearance from ferritic steels. That is, the shape of the curve of fracture resistance as a function of metal temperature is sigmoidal, being very low at low temperatures and rising to an upper shelf value at high temperatures. Thus many observers have noted that even after a long aging time (embrittling treatment), these alloys exhibit adequate fracture resistance at operating temperatures. Although that is essentially true, it is equally true that accidents may happen at any time. Therefore, the evaluation should be for room temperature and end-of-life conditions. 


\section{EVALUATION}

Detailed steps to be taken in evaluating the potential for low-temperature aging embrittlement of cast stainless steels can be obtained from Reference 2. For completeness, the reviewer should familiarize himself with Reference 6, an earlier report on procedures and correlations for predicting the aging embrittlement change in fracture toughness.

In Reference 2, one can find a procedure for estimating the saturation Charpy V-notch impact energy $\left(E_{C . v}\right)$ at room temperature. The $E_{c . v}$ at saturation was defined as that value found in a given alloy after a very long time at temperature. Two different approaches were given to estimate the saturation $\mathbf{E}_{\mathrm{c.v}}$ room temperature value. Both require knowledge of the steel chemistry. Either Certified Material Test Reports or chemical analysis of samples taken from the component (e.g.: prolongations, archival material, etc.) can be used.

In one approach (using the symbols given in Reference 2), the following equation is solved:

$$
\log _{10} C_{\text {set }}=\mathbf{a}+(\mathrm{b}) \exp (-\mathrm{c} \Phi) \text {, }
$$

where: $\quad \Phi$ (a material parameter)

$$
\begin{array}{llr}
=\delta_{c}(\mathrm{Cr}+\mathrm{Si})(\mathrm{C}+0.4 \mathrm{~N}) & & \text { for CF-3 an } \\
=\delta_{c}(\mathrm{Ni}+\mathrm{Si}+\mathrm{Mn})^{2}(\mathrm{C}+0.4 \mathrm{~N}) / 5 & & \text { for CF-8M; }
\end{array}
$$

and:

$$
\delta_{c}(\text { ferrite content })=100.3\left(\mathrm{Cr}_{\mathrm{eq}} / \mathrm{Ni}_{\mathrm{eq}}\right)^{2}-170.72\left(\mathrm{Cr}_{\mathrm{eq}} / \mathrm{Ni}_{\mathrm{eq}}\right)+74.22 \text {, }
$$

$$
\begin{aligned}
& \mathrm{Cr}_{\mathrm{eq}}=\mathrm{Cr}+1.21(\mathrm{Mo})+0.48(\mathrm{Si})-4.99 \\
& \mathrm{Ni}_{\mathrm{eq}}=\mathrm{Ni}+0.11(\mathrm{Mn})-0.0086(\mathrm{Mn})^{2}+18.4(\mathrm{~N})+24.5(\mathrm{C})+2.77
\end{aligned}
$$

If the nitrogen content $(\mathrm{N})$ is not known, a value of 0.04 wt.\% can be used. The values of the constants $a, b$ and $c$ were given for the several grades of steel as:

\begin{tabular}{lccc}
\hline & \multicolumn{2}{c}{ Constants in the above equation } & \\
\cline { 2 - 4 } \multicolumn{1}{c}{ Grade } & $\mathrm{a}$ & $\mathrm{b}$ & $\mathrm{c}$ \\
\hline CF-3, CF-8 & 1.15 & 1.36 & -0.035 \\
CF8M $(<10 \% \mathrm{Ni})$ & 1.10 & 2.12 & -0.041 \\
CF8M $(>10 \% \mathrm{Ni})$ & 1.10 & 2.64 & -0.064 \\
\hline
\end{tabular}

In the second approach, the room temperature impact energy at saturation is calculated directly from the chemical analysis results. The relationship depends on the grade of steel.

For CF-3 AND CF-8:

$$
\begin{gathered}
\log _{10} C_{\text {Vsat }}=5.64-0.006 \delta_{c}-0.185 \mathrm{Cr}+0.273 \mathrm{Mo}-0.204 \mathrm{Si} \\
+0.044 \mathrm{Ni}-2.12(\mathrm{C}+0.4 \mathrm{~N})
\end{gathered}
$$

and for CF-8M:

$$
\begin{aligned}
& \log _{10} \mathrm{C}_{\text {vast }}=7.28-0.011 \delta_{\mathrm{c}}-0.185 \mathrm{Cr}-0.369 \mathrm{Mo}-0.451 \mathrm{Si} \\
& +0.044 \mathrm{Ni}-4.71(\mathrm{C}+0.4 \mathrm{~N}) \text {. }
\end{aligned}
$$

It was recommended (in Reference 2) that for each evaluation, the saturation, room temperature, Charpy energy be calculated by both approaches and that the lower value be used. 
Guidance can be found in Reference 2 for the estimation of the fracture resistance of cast stainless steels in terms of $\mathrm{J}-\mathrm{R}$ curves. One approach is to base the estimation on the room temperature, saturation, impact energy value. To do so, the power-law relation for the J-R curve is used:

where:

$$
\mathbf{J}_{\mathbf{d}}=\mathbf{C} \Delta \mathbf{a}^{\mathbf{n}} \text {, }
$$

$\mathbf{J}_{\mathbf{d}}$ is the deformation-theory $\mathrm{J}$-integral.

From graphical correlations between the coefficient " $\mathrm{C}$ " and the room temperature saturation $\mathbf{E}_{\mathrm{C}-\mathrm{v}}$, lower-bound curves were drawn for four material conditions: grades CF-3 or CF-8 as static or centrifugal castings and grade CF-8M in either of the same two cast states. Thus four equations were given for the four combinations. The same thing was done using high temperature data but those results are of no concern here. The several lower-bound correlations were combined with the power-law equation as:

where:

$$
J_{\mathrm{d}}=\mathrm{a}\left[\mathrm{C}_{\mathrm{vad}}\right]^{\mathrm{b}}[\Delta \mathrm{a}]^{\mathrm{n}} \text {, }
$$

$$
\mathbf{n}=\mathbf{c}+\mathbf{d}\left[\log _{10} \mathrm{C}_{\mathrm{Vsec}}\right] \text {. }
$$

Values for the constants $a, b, c$ and $d$ in the above two equations were given in tables in Reference 2 for the three grades of ASTM A 351, as static- or centrifugally-cast at room or high temperature.

In the event that the chemical composition of the steel to be evaluated is not known, Reference 2 provided values for the coefficient (C) and exponent (n) of the power-law equation for the J-R curve based on the ferrite content of the stainless steel. Values of the parameters were tabulated for the three grades of ASTM A 351 in the static- and centrifugally-cast conditions at room and elevated temperature at three ferrite content levels: $<10,10-$ to-15 and $>15 \%$.

Enough information is available to evaluate the condition of cast stainless steel in a conservative way. After estimating a J-R curve, the methods of fracture mechanics can be employed to determine the margin for failure for any known or assumed flaw size. The less sophisticated approach is to determine the saturation Charpy V-notch energy at room temperature and decide if it is sufficient. To some extent, such an evaluation must rely on judgement. Inasmuch as the operating criterion of a minimum of $50 \mathrm{ft}-\mathrm{lb}$ has served well for ferritic reactor pressure vessels, it also should be adequate for cast stainless steel which behaves much like a ferritic steel when embrittled. 


\section{REFERENCES}

1. NUREG/CR-6142, "Tensile-Property Characterization of Thermally Aged Cast Stainless 2Steels," Argonne National Laboratory, February, 1994.

2. NUREG/CR-4744, "Long-Term Embrittlement of Cast Duplex Stainless Steels in LWR Systems," Semiannual Report for April-September 1992, Argonne National Laboratory, July, 1992.

3. T. R. Leax, S. S. Brenner and J. A. Spitznagel, "Atom Probe Examination of Thermally Aged CF8M Cast Stainless Steel," AIME Metallurgical Transactions A, Vol. 23A, October, 1992, p. 2725.

4. "Cast Austenitic Stainless Steel Sourcebook," M. E. Lapides, ed., Electric Power Research Institute, Palo Alto, California, October, 1991.

5. NUREG/CR-5644, "Consequence Evaluation of Radiation Embrittlement of Trojan Reactor Pressure Vessel Supports," Lawrence Livermore National Laboratory, October, 1990.

6. NUREG/CR-4513, "Estimation of Fracture Toughness of Cast Stainless Steels During Thermal Aging in LWR Systems," Argonne National Laboratory, June, 1991. 
Appendix D 



\title{
Potential Effects of Gamma Radiation
}

\author{
Eric H. Ottewitte
}

Idaho National Engineering Laboratory

October 1993 


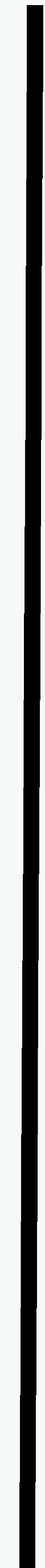




\section{ABSTRACT}

This present study investigates the role of gamma-induced radiation damage to reactor pressure vessels. It 1) evaluates the effects of gamma radiation based on a review of the literature and 2) specifically assesses the relative contribution of gamma radiation to atomic displacements in the reactor vessel wall. A review of the Sequoyah capsule data indicated that information on neutron to gamma ratios could not be obtained from the report. Consequently, a bounding calculation was performed.

Search of the literature indicates that, in addition to atomic displacement, photons can also

- $\quad$ cause changes in alloy morphology (grain structure)

- $\quad$ enhance diffusion, leading to decomposition of over-saturated austenite, and to strengthening and embrittlement of steel

- accelerate intergranular stress corrosion cracking of stainless steels and nickel-base alloys via its effects on material micro-chemistry (e.g, radiation-induced segregation), water chemistry (e.g., radiolysis), and stress (e.g., radiation induced creep and hardening).

First principal calculations suggest that $\gamma$-induced atomic displacement is $\ll 1 \%$ of that from neutrons in the pressure vessel wall of power reactors. More detailed calculations, specific to the Sequoyah Reactor, would require extensive coupled neutron/photon transport calculations plus the computer programming of algorithms for calculation of energy-dependent, photon-induced, atomic displacement cross sections. The inclusion of TLDs in the capsule would be very useful.

In summary, this study indicates that although gamma radiation contributes little to atomic displacement or gas production, it may significantly affect grain structure, atomic diffusion and stress corrosion cracking. However, the isolation of the capsule specimens from water chemistry effects precludes their testing for stress corrosion cracking. 



\section{CONTENTS}

ABSTRACT $\ldots \ldots \ldots \ldots \ldots \ldots \ldots \ldots \ldots \ldots \ldots \ldots \ldots \ldots \ldots \ldots$ iii

INTRODUCTION $\ldots \ldots \ldots \ldots \ldots \ldots \ldots \ldots \ldots \ldots \ldots \ldots \ldots \ldots \ldots \ldots$

Literature Search on Gamma-Induced Radiation Damage . . . . . . . . . . . . 1

Neutron-Induced Damage to LWR Pressure Vessels . . . . . . . . . . . . . . 1

Gamma-Induced Damage Mechanisms . . . . . . . . . . . . . . . . 2

STATE-OF-THE-ART FOR GAMMA-RAY-INDUCED RADIATION DAMAGE $\ldots \ldots \ldots$

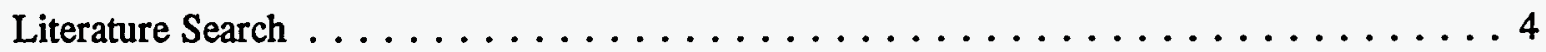

Summary of Book Sources $\ldots \ldots \ldots \ldots \ldots \ldots \ldots \ldots$

General Literature Search . . . . . . . . . . . . . . . . 4

Calculational Models for Gamma-Ray-Induced Radiation Damage $\ldots \ldots \ldots \ldots$

ANALYSIS OF GAMMA-RAY INTERACTION EFFECTS $\ldots \ldots \ldots \ldots \ldots \ldots$

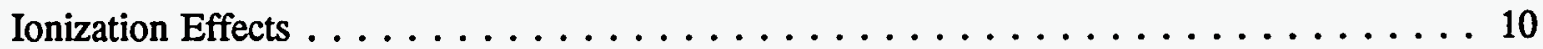

Atomic Displacements by Energized Electrons $\ldots \ldots \ldots \ldots \ldots \ldots$

Estimation of the Gamma Spectrum-Averaged Dpa Cross Section $\left\langle\sigma_{\gamma, \text { dpa }}\right\rangle$ for Iron 11 Estimation of the Neutron Dpa Cross Section $\left\langle\sigma_{\mathrm{n}, \mathrm{dpa}}\right\rangle$ for Iron . . . . . . . . 14 Estimation of the Gamma-to-Neutron Flux and Dpa Ratios . . . . . . . . . . 14

Photon Dpa Production in a Fusion Reactor Environment . . . . . . . . . . 16

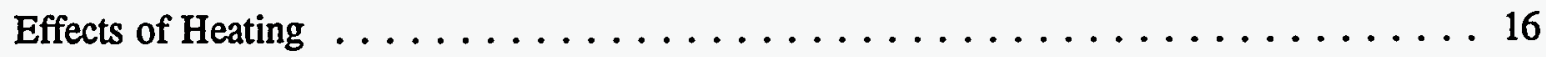

Synergistic Intergranular Stress-Assisted Corrosion Cracking $\ldots \ldots \ldots \ldots$

CONCLUSIONS AND RECOMMENDATIONS $\ldots \ldots \ldots \ldots \ldots \ldots \ldots$

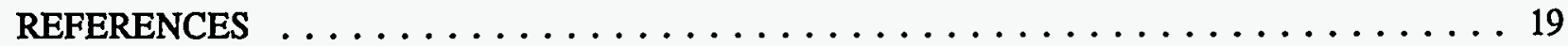

Appendix A-LLNL Communications $\ldots \ldots \ldots \ldots \ldots \ldots \ldots \ldots \ldots \ldots \ldots \ldots$

Appendix B--Mini-Treatise on Gamma Irradiation Damage $\ldots \ldots \ldots \ldots \ldots \ldots$. . . . . B-1 



\section{Potential Effects of Gamma Radiation}

\section{INTRODUCTION}

This study investigates the role of gamma-induced radiation damage. It first examines the $\gamma$ induced phenomena found in the literature. It then estimates the number of atomic displacements per atom (dpa) induced by gamma rays relative to that by neutrons. Dpa constitutes the principal damage measure of concern in the Westinghouse surveillance program. A review of the Sequoyah capsule data indicated that information on neutron to gamma ratios could not be obtained from the report. Consequently, a bounding calculation was performed.

\section{Literature Search on Gamma-Induced Radiation Damage}

The literature was searched for measured and theoretical effects of gamma radiation on the mechanical properties of vessel steels and structural materials. This was accomplished by searching the conventional literature database of titles, abstracts and key words from reports, journal articles and conference proceedings for the broad combination of "gamma" and "radiation damage." That produced some 600 titles. Examination of these resulted in the selection of ten pertinent articles. Though many of those are either not in English or not readily available, we were able to obtain a few of the reports and abstracts from most.

Numerous books on radiation damage were assessed for subsection treatments of $\gamma$-induced radiation damage. Such sources are not always covered in the literature databases. Principal book sources are the series of annual reviews published by Annual Reviews Inc. of Palo Alto, the ASTM Conference Series on Radiation Damage and various textbooks. These book sources provided the basis for our assessment of $\boldsymbol{\gamma}$-induced radiation damage by atomic displacement.

\section{Neutron-Induced Damage to LWR Pressure Vessels ${ }^{1}$}

The principal mechanisms in neutron-induced radiation damage are the number of atomic displacements and the quantity of helium and hydrogen gas produced. The helium gas lends itself as a nucleation site for accumulation of clustered vacancies and other gas atoms, leading to the formation of voids and subsequently to swelling and other macroscopic effects.

The ability of a steel pressure vessel, which contains the reactor core and its primary coolant, to resist fracture is an important factor in assessing the life and safety of nuclear power plants. The overall effects of fast neutron irradiation on the mechanical properties of low-alloy, ferritic pressure vessel steels such as SA508 Class 2 forging (base material of the Sequoyah Unit 2 reactor pressure vessel belt line) are well documented in the literature. Certain conditions of irradiation can cause low-alloy ferritic materials to increase in hardness and tensile properties, and to decrease in ductility and toughness.

Appendix G to Section III of the ASME Boiler and Pressure Vessel Code, "Protection Against Non-ductile Failure," presents a method for performing analyses to guard against fracture in reactor pressure vessels. The method uses fracture mechanics concepts and calculates the reference nil-ductility temperature $\left(\mathrm{RT}_{\mathrm{NDT}}\right)$, adjusted for the effects of radiation. 
To perform these adjustments requires knowledge of the neutron environment (energy spectrum, flux, fluence) to which the test specimens were exposed. These data are normally obtained from passive neutron flux monitors contained in each of the surveillance capsules.

To relate the changes observed in the test specimens to the present and future condition of the reactor vessel, a relationship must be established between the neutron environment at various positions within the reactor vessel and that experienced by the test specimens. The correlation of changes in measured materials properties with fast neutron fluence $(E>1.0 \mathrm{MeV})$ has traditionally been accepted for development of damage trend curves for assessing vessel condition. However, assessing the differences in neutron energy spectra at surveillance capsule locations on both sides of the pressure vessel wall should enable more accurate evaluation of damage gradients through the wall.

To obtain such an energy-dependent damage function for data correlation, ASTM Standard Practice E853, "Analysis and Interpretation of Light Water Reactor Surveillance Results," recommends reporting displacements per iron atom (dpa iron) along with fluence $(E>1.0 \mathrm{MeV})$ to provide a data base for future reference. ASTM Standard Practice E693, "Characterizing Neutron Exposures in Ferritic Steels in Terms of Displacements per Atom," specifies the energy-dependent dpa function to be used for this evaluation. Revision 2 to the Regulatory Guide 1.99, "Radiation Damage to Reactor Vessel Materials," promulgates the use of dpa to assess embrittlement gradients in the pressure vessel wall.

Ramirez et al. ${ }^{1}$ evaluated the neutron dosimetry for the test specimens contained in surveillance Capsule X. They reported fast neutron exposure parameters in terms of fast neutron fluence $(E>$ $1.0 \mathrm{MeV}$ ), fast neutron fluence $(E>0.1 \mathrm{Mev}$ ), and displacements per atom (dpa) of iron. The first two of these parameters simply represent integrals of the flux over a specific portion of the fast neutron energy spectrum. The dpa parameter provides a more sophisticated integral of the product of the energy-dependent flux and the energy-dependent cross section (probability) for neutrons to displace atoms from their present location; i.e., it incorporates the fact that the effectiveness of neutrons in displacing atoms varies with neutron energy. In addition to being more rigorous, the dpa parameter provides a basis for comparison to $\gamma$-induced atomic displacement damage which can also be expressed in terms of dpa.

\section{Gamma-Induced Damage Mechanisms}

Neutrons induce damage in structural materials principally through hadronic ${ }^{\mathrm{b}}$ interactions of neutron scattering with, and capture by, the nucleus. This results in atomic displacement and generation of hydrogen and helium gas.

Gamma rays cannot undergo such reactions: they interact by the weaker electromagnetic interaction ${ }^{c}$ and effect little momentum transfer due to their zero rest mass. They cause very little direct displacement or gas production. However, they can energize electrons which in turn have sufficient mass to induce atomic displacement, though again by electromagnetic interaction.

To compare the effects of $\gamma$-induced damage to relative neutron-induced damage, one needs to use parameters or measures common to both phenomena: neutron flux is not equivalent to gamma ray

b. Hadrons such as neutrons, protons, and alphas interact with other nucleons (particles inside the nucleus) by means of the "strong" or "hadronic" interaction involving the exchange of virtual pions and other bosons.

c. Electromagnetic interactions consist of the exchange of massless photons only. 
flux. The key neutron-induced damage parameters in structural materials are gas production rates and dpa. Gammas produce nil gas but do indirectly displace atoms. Cross sections for dpa production have been developed, allowing the direct comparison of neutrons and photons for atomic displacements.

Gamma rays are also able to directly deposit heat energy, subsequently inducing changes in the grain structure. They can also dissociate water molecules adjacent to structural materials, thereby enhancing stress-induced corrosion. 


\section{STATE-OF-THE-ART FOR GAMMA-RAY-INDUCED RADIATION DAMAGE}

One principal objective of this study was to survey the current state-of-the-art for the effects of $\gamma$-irradiation on structural materials. Effects of $\gamma$-radiation upon molecular bonds (such as in glasses, bonding agents, and organic and inorganic compounds) were excluded. To do this survey a literature search was performed and discussions were held regarding radiation damage data with scientists at the National Nuclear Data Center at Brookhaven National Laboratory, Radiation Shielding Information Center at Oak Ridge National Laboratory and Nuclear Data Center at the Lawrence Livermore National Laboratory.

\section{Literature Search}

The literature search covered gamma-induced radiation damage in published books as well as in the general databases of reports, journal articles and conference proceedings. From past experience in radiation damage, principal book sources have been the series of annual reviews published by Annual Reviews Inc. of Palo Alto and the work of Kelly. ${ }^{1}$ The following sections address these book and general literature sources in turn.

\section{Summary of Book Sources}

Table 1 contains the assessment of four major review articles on radiation damage. The 1953 review by Dienes ${ }^{2}$ and the 1979 review by Stiegler and Mansur ${ }^{3}$ do not specifically deal with $\gamma$ radiation. A 1956 review by Brooks ${ }^{4}$ mentions that the germanium atom displacement efficiency per photon is about $10^{-3}$ that of fast neutrons. The 1962 review by Goland ${ }^{5}$ presents an empirical formulation for calculating $\gamma$-induced dpa. Kelly ${ }^{2}$ further developed that work in 1966, discussed later in this report.

\section{General Literature Search}

Table 2 compiles the relevant articles found in some 600 titles obtained from a general literature search on gamma-induced radiation damage. Key results are the following:

- $\quad$ Fiore $^{6}$ concluded that $\gamma$-irradiation must affect the structure in some alloys since it causes property changes such as a decrease in toughness. In alloys which display a damping minimum in internal friction measurements, the precipitate morphology changes during irradiation, with coarsening and/or de-coarsening and re-nucleation being observed.

Weidinger et al. ${ }^{7}$ investigated irradiated molybdenum by the perturbed angular correlation technique using ${ }^{111}$ In as the radioactive source. Their results show that defects become trapped at the probe atom in an annealing stage around $500 \mathrm{~K}$. Three different defect configurations were identified.

- Kuribayashi et al.$^{8}$ found that $\gamma$-radiation increased intergranular stress corrosion cracking (IGSCC) susceptibility of sensitized type 304 stainless steel in boiling $\mathrm{NaCl}$ solution. 
Table 1. Summary of review articles on radiation damage in the Annual Reviews of Materials Science (M) and Annual Reviews of Nuclear Science $(\mathrm{N})$

\begin{tabular}{|c|c|c|c|c|}
\hline Volume & Year & \begin{tabular}{|c|} 
First \\
Author
\end{tabular} & Article Title & Substance of Article Pertinent to $\gamma$-Induced Damage in Structural Materials \\
\hline M9 & 1979 & Stiegler & $\begin{array}{l}\text { Radiation Effects in } \\
\text { Structural Materials }\end{array}$ & $\begin{array}{l}\text { Examines the microscopic mechanisms of radiation damage induced by energetic particles. Does not deal with specific } \\
\text { effects of gammas. }\end{array}$ \\
\hline N12 & 1962 & Goland $^{6}$ & \begin{tabular}{|l|} 
Atomic \\
Displacements in \\
Solids by Nuclear \\
Radiation
\end{tabular} & $\begin{array}{l}\text { Gamma rays are capable of producing displacements through a number of interactions. The three most prominent ones are } \\
\text { the photoelectric effect, the Compton effect, and pair production. For the low gamma-ray energies found in fission reactors, } \\
\text { the first and second effects are the most important ones to consider. In a solid both effects can produce secondary electrons } \\
\text { having sufficient energy to displace atoms. Calculation of the atomic displacement eross section for gamma rays is difficult } \\
\text { because it involves a triple integration over: (a) the differential cross section for energy transfer to electrons by the Comptor } \\
\text { or photo-electric process; (b) the range of the electrons, and (c) the differential displacement cross section for electrons, } \\
\text { mentioned earlier. Dienes \& Vineyard discussed the problem and gave a few results for an assumed displacement threshold } \\
\text { of } 25 \mathrm{ev.} \mathrm{Galavanov}{ }^{10} \text { treated it more thoroughly: he compared atomic-displacement cross sections for elastic seattering of } \\
\text { gamma rays, for nuclear recoil during photoemission, and for elastic scattering of photoelectrons and Compton electrons. } \\
\text { More recently Oen \& Holmes }{ }^{11} \text { carried out extensive calculations for various values of gamma-ray energy, threshold } \\
\text { energy, and atomic number. Their results have not yet been adequately correlated with experiments. In view of the } \\
\text { accuracy of the computations, such comparisons should be of importance in relating property changes to the number of } \\
\text { displaced atoms in a solid. }\end{array}$ \\
\hline N6 & 1956 & Brooks ${ }^{3}$ & $\begin{array}{l}\text { Nuclear Radiation } \\
\text { Effects in Solids }\end{array}$ & Mentions that displacement efficiency per photon is about $10^{-3}$ that of fast neutrons in the case of $\mathrm{Ge}$ \\
\hline N2 & 1953 & Dienes $^{3}$ & $\begin{array}{l}\text { Radiation Effects in } \\
\text { Solids }\end{array}$ & Focusses on fast massive particles. \\
\hline
\end{tabular}


Table 2. Synopsis of general near-term literature search on $\gamma$-induced radiation effects in reactor structural materials

\begin{tabular}{|c|c|c|c|}
\hline Reference & Year & Article Title & Substance of Article Pertinent to $\gamma$-Induced Damage in Structural Materials \\
\hline Fiore $^{7}$ & 1974 & $\begin{array}{l}\text { Gamma-Irradiation Damage in } \\
\text { Age Hardening Al Alloys }\end{array}$ & $\begin{array}{l}\text { This report describes an experimental program directed toward an understanding of the mechanisms of } \\
\gamma \text {-irradiation damage in precipitation-hardenable Al alloys. Pure } \mathrm{Al} \text { and a series of age-hardenable } \mathrm{Al} \text { alloys were } \\
\gamma \text {-irradiated with a } \mathrm{Co}^{60} \text { source at a dose of } 6 \times 10^{3} \mathrm{rads} / \mathrm{min} \text {. Internal friction measurements were made at } 80 \mathrm{Khz} \\
\text { by means of the Marx technique on samples in situ during irradiation. The results showed that toughness noticeably } \\
\text { decreased with } \gamma \text {-irradiation. The authors concluded that } \gamma \text {-irradiation must influence structure since it influences } \\
\text { properties. } \\
\text { In Al and } \mathrm{Al}-3 \mathrm{w} / \mathrm{O} \mathrm{Cu} \text {, the damping decreased monotonically with irradiation as expected. The decrease is } \\
\text { attributed to the immobilization of dislocations by the radiation-induced point defect pinners. In } 2024-\mathrm{T} 6,2017-\mathrm{T} 6 \\
\text { and Al-9.5 } \mathrm{Mg} \text {, the damping passes through a minimum and begins an anomalous increase after } 4 \text { to } 7 \text { hours of } \\
\text { irradiation. Electron micrographs show that in } \mathrm{Al} \text { and } \mathrm{Al}-3 \mathrm{w} / \mathrm{O} \mathrm{Cu} \text {, irradiation does not influence structure. In the } \\
\text { alloys which display the damping minimum however, precipitate morphology changes during irradiation, with } \\
\text { coarsening and/or de-coarsening and re-nucleation being observed. The effect appears to depend upon the presence } \\
\text { of Mg. Theory predicts that } \gamma \text {-irradiation can change the morphology by either Rutherford collision or Coulombic } \\
\text { repulsion. }\end{array}$ \\
\hline Weidinger 8 & 1979 & $\begin{array}{l}\text { Defect Configurations in } \\
\text { Irradiated Molybdenum }\end{array}$ & $\begin{array}{l}\text { Irradiated molybdenum was investigated by the perturbed angular correlation technique using }{ }^{11 /} \text { In as the } \\
\text { radioactive source. Results showed that defects become trapped at the probe atom in annealing stage III around } 500 \\
\text { K. By quadrupole interaction three different defect configurations were identified. }\end{array}$ \\
\hline $\bar{K}_{\text {Kuribayashi9 }}$ & 1983 & $\begin{array}{l}\text { Influence of Gamma Radiation } \\
\text { on Intergranular Stress } \\
\text { Corrosion Cracking of } \\
\text { Austenitic Stainless Steel }\end{array}$ & $\begin{array}{l}\text { In order to examine the environmental influence of gamma radiation on intergranular stress corrosion cracking } \\
\text { (IGSCC) of sensitized austenitic stainless steel, tests were conducted with and without gamma radiation in boiling } \\
12 \% \mathrm{NaCl} \text { solution, } \mathrm{pH} \text { adjusted to } 3 \text { with } \mathrm{HCl} \text {, and in high temperature oxygenated pure water }\left(230^{\circ} \mathrm{C} \text { ). Results }\right. \\
\text { are as follows: 1) } \gamma \text { radiation increased IGSCC susceptibility of sensitized type } 304 \text { stainless steel in boiling } 12 \% \\
\text { Nacl solution, Ph adjusted to } 3 \text { with Hel. The ferric ions }\left(\mathrm{Fe}^{3+}\right) \text { are radiolytically formed by } \gamma \text { radiation from the } \\
\left.\text { ferrous ions ( } \mathrm{Fe}^{2+}\right) \text { in acid solution, and this phenomenon is the widely known principal of Frick's Dosimeter. The } \\
\text { ferric ions may act as strong oxidizing agent and may increase the susceptibility to IGSCC in the acid boiling } \\
\text { chloride solution. 2) } \gamma \text {-radiation increased IGSCC susceptibility of sensitized type } 304 \text { stainless steel also in high } \\
\text { temperature oxygenated pure water. The amount of total Fe in aqueous solution after SCC testing, increases by } \gamma \\
\text { radiation, so the oxidization of metals is advanced by } \gamma \text { radiation in high temperature pure water. }\end{array}$ \\
\hline Mural ${ }^{10}$ & $\overline{1984}$ & $\begin{array}{l}\text { Gamma-Radiation Aging of } \\
\text { Deformed Austenite }\end{array}$ & $\begin{array}{l}\text { Effect of gamma-radiation treatment with an integral dose of } 3.5 \times 10^{9} \text { roentgen at normal temperature on aging of } \\
\text { deformed austenite in the } 10 \mathrm{Kh} 18 \mathrm{~N} 13 \mathrm{AM} 3 \text { type steel has been studied. Stress-strain diagrams obtained for the } \\
\text { specimens point to the fact that gamma-radiation treatment has analogy with aging at } 200^{\circ} \mathrm{C} \text {. It has been noted that } \\
\text { decomposition of over-saturated austenite, strengthening, and embrittlement of steel are conditioned by } \\
\text { radiation-enhanced diffusion but not by radiation defects. }\end{array}$ \\
\hline Marsh $^{13}$ & 1986 & $\begin{array}{l}\text { Influence of Radiation on the } \\
\text { Corrosion of Stainless Steel }\end{array}$ & $\begin{array}{l}\text { The effect of gamma radiation on the electrode corrosion of type } 304 \mathrm{~L} \text { steel in } 300 \mathrm{ppm} \mathrm{Cl} \text { has been studied. In } \\
\text { open systems with argon or Ar-20\% oxygen gas blankets irradiation at a dose rate of } 2000 \mathrm{~Sv} / \mathrm{h} \text { causes the steady } \\
\text { rest potential of the metal to increase by } 200-300 \mathrm{mV} \text {. This increase is partly due to cathodic depolarization by } \\
\text { oxidizing radical and molecular radiolysis products, but may also involve adsorption of these species onto the metal } \\
\text { surface. Radiolysis products also inhibit the initiation of pitting corrosion at low electrode potentials, but have no } \\
\text { effect on the repassivation of established pits. }\end{array}$ \\
\hline
\end{tabular}


Table 2. Synopsis of general near-term literature search on $\gamma$-induced radiation effects in reactor structural materials (Continued)

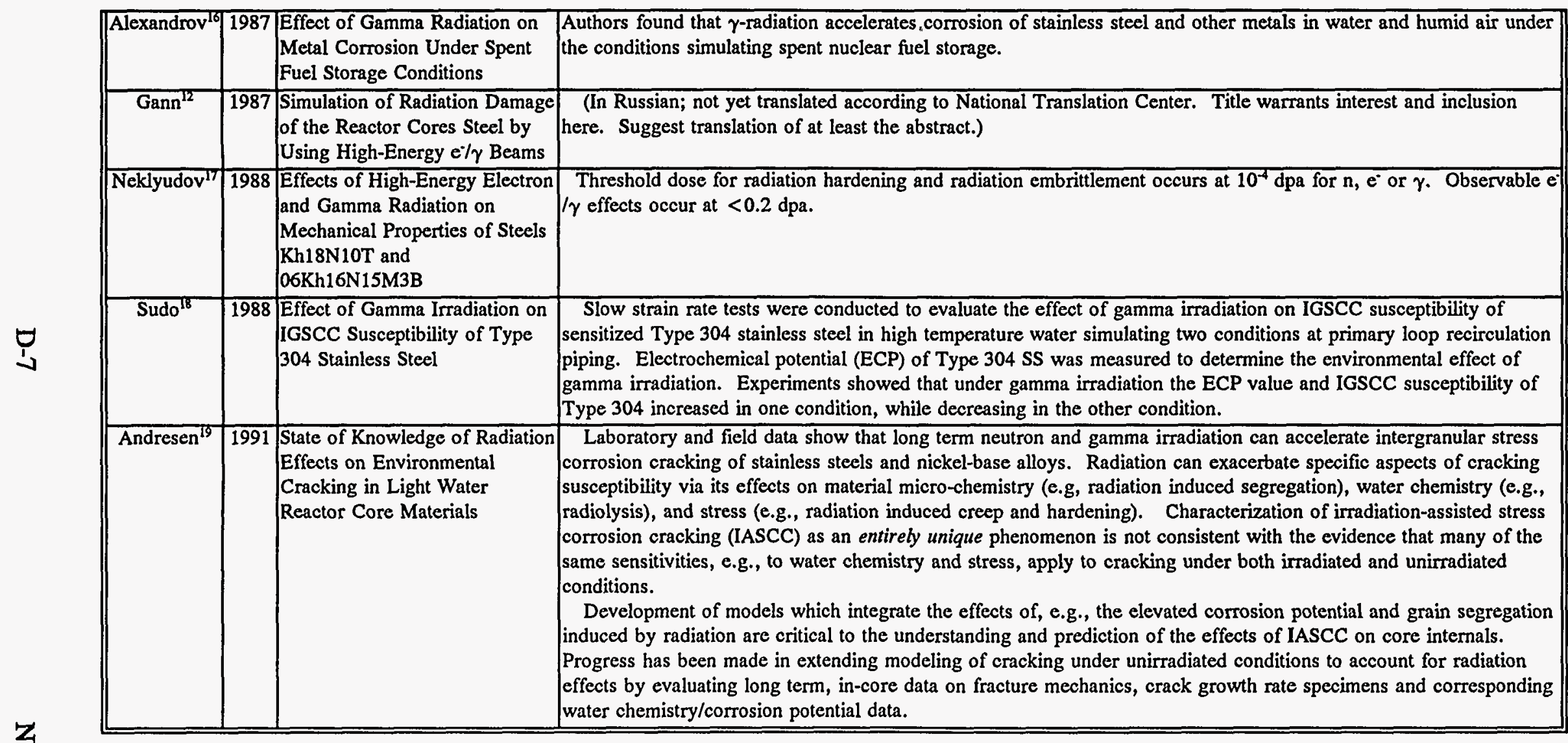


- Mural' and Shcherbedinskij ${ }^{13}$ observed gamma-radiation effects analogous to those from aging at $200{ }^{\circ} \mathrm{C}$. They noted that decomposition of over-saturated austenite, strengthening, and embrittlement of steel are conditioned by radiation-enhanced diffusion but not by radiation defects.

- Marsh et al..$^{14}$ observed that, in open systems with argon or Ar-20\% oxygen gas blankets, irradiation causes the steady rest potential of the metal to increase. This increase is partly due to cathodic depolarization by oxidizing radical and molecular radiolysis products, but may also involve adsorption of these species onto the metal surface. Radiolysis products also inhibit the initiation of pitting corrosion at low electrode potentials, but have no effect on the repassivation of established pits.

- Alexandrov et al.$^{15}$ found that $\gamma$-radiation accelerates corrosion of stainless steel and other metals in water and humid air under the conditions simulating spent nuclear fuel storage.

- Neklyudov et al. ${ }^{16}$ found that the threshold dose for radiation hardening and radiation embrittlement occurs at $10^{-4} \mathrm{dpa}$ for $\mathrm{n}, \mathrm{e}^{-}$or $\gamma$. Observable $\mathrm{e}^{-} / \gamma$ effects occur at $<0.2$ dpa.

- $\quad$ Sudo et al. ${ }^{17}$ concluded from slow strain rate tests that $\gamma$-radiation affects the electrochemical potential and IGSCC susceptibility of Type 304 in high temperature water. The direction of the changes depended upon the water chemistry.

- Laboratory and field data from Andresen et al..$^{18}$ show that long term neutron and gamma irradiation can accelerate intergranular stress corrosion cracking of stainless steels and nickel-base alloys. Radiation can exacerbate specific aspects of cracking susceptibility via its effects on material micro-chemistry (e.g, radiation induced segregation), water chemistry (e.g., radiolysis), and stress (e.g., radiation induced creep and hardening). Characterization of irradiation-assisted stress corrosion cracking (IASCC) as an entirely unique phenomenon is not consistent with the evidence that many of the same sensitivities, e.g., to water chemistry and stress, apply to cracking under both irradiated and unirradiated conditions.

These articles reveal a number of mechanisms, alternative to atomic displacement, whereby gamma radiation may affect the behavior of the pressure vessel wall. To quantify these phenomena for the Sequoyah pressure vessel and/or the surveillance capsule would be a major undertaking, far beyond the scope of the present study. The absence of articles on $\gamma$-induced atomic displacements in the general literature tends to confirm past and present experience that it plays a minor role relative to neutron-induced atomic displacement in a fission reactor environment.

\section{Calculational Models for Gamma-Ray-Induced Radiation Damage}

In $1982 \gamma$-induced radiation damage to fusion first-walls was assessed at the Idaho National Engineering Laboratory (INEL). That work included the development of a formalism to calculate $\gamma$ induced dpa cross sections based on the work of Kelly. ${ }^{2}$ Such data might be incorporated into the existing neutron/photon structure of the MACKLIB ${ }^{19}$ radiation damage data base. This would then take advantage of, as well as enhance, existing coupled neutron/photon transport and damage analysis capability. ${ }^{20}$ 
An extensive library of neutron-induced dpa cross sections already exists. Consequently I contacted the sponsoring nuclear data community, namely the Cross Section Evaluation Working Group, coordinated through the National Nuclear Data Center (NNDC) to see if any work on $\gamma$ induced dpa had occurred since 1982. V. McLane ${ }^{21}$ of NNDC directed me to Steven Warshaw at LLNL who is attempting to develop a fairly complete data base for $\gamma$-induced radiation damage, extending up to $40 \mathrm{MeV}$ (Appendix A). That work, which is just begun, appears to center on photonuclear $(\gamma, n)$ reactions, mostly at energies above those occurring in a fission reactor.

Photonuclear cross sections contribute relatively little to radiation damage in a fission reactor: the cross sections are very low and the threshold gamma energy is generally $>7 \mathrm{MeV}$.

I also checked with the Radiation Shielding Information Center at ORNL regarding the availability of codes and data. The only help there was that the codes TECALC ${ }^{22}$ and HEITLER, ${ }^{23}$ identified in 1982 for potential use as subroutines in writing a code, were still available. 


\section{ANALYSIS OF GAMMA-RAY INTERACTION EFFECTS}

Gamma rays cause damage by three mechanisms: ionization, energized electrons and heating. ${ }^{2}$ This section systematically evaluates how these mechanisms might individually and collectively affect the Sequoyah pressure vessel and its surveillance capsule. It uses the results of the literature search in the previous section and adds an evaluation of $\gamma$-induced atomic displacement damage. The role of the latter relative to neutron-induced damage is evaluated quantitatively. The other phenomena are only qualitatively analyzed.

\section{Ionization Effects}

The principal ionization effect will likely be in water radiolysis which in turn affects intergranular stress-assisted corrosion cracking, discussed in a later section. Neutrons can also contribute to radiolysis through atomic displacement reactions (via neutron scattering or capture). However, photons should dominate the breaking of atomic and molecular bonds by means of electromagnetic interactions with the atomic electrons: neutrons are incapable of such electromagnetic interactions. We note that the test specimens in the surveillance capsule will not experience the water chemistry effects that the vessel wall will.

\section{Atomic Displacement by Energized Electrons}

As discussed above, photons interact by electromagnetic interaction and are generally incapable of directly displacing atoms or generating helium and hydrogen gases. However, photons can set free energetic electrons which can transfer the $25-40 \mathrm{eV}$ needed to displace atoms. We seek here to compare atomic displacements by photons to those by neutrons. Should the former be relatively insignificant from first principles, the extensive effort to calculate them specifically for the Sequoyah reactor pressure vessel would not be required.

The principal measure addressed here is one that is common to both neutrons and photons: the number of displacements per atom (dpa). Dpa is a product of the projectile flux and the projectile's cross section for producing displacements. The atomic displacement rate by either neutrons or photons can be calculated as follows:

$$
(\text { Dpa rate })_{i}=\int_{E_{d}}^{\infty} \sigma_{i, d p a}\left(E_{i}\right) \cdot \phi_{i}\left(E_{i}\right) d E_{i}
$$

where

$$
\begin{aligned}
& \mathrm{i} \quad=\text { neutron or photon } \\
& \sigma_{\mathrm{i}, \mathrm{dpa}}=\text { dpa cross section for particle } \mathrm{i} \\
& \phi_{\mathrm{i}}=\text { flux of particle } \mathrm{i} \\
& \mathrm{E}_{\mathrm{i}}=\text { energy of particle } \mathrm{i}
\end{aligned}
$$

The ratio of $\gamma$-induced dpa to neutron-induced dpa will be the product of the photon to neutron ratio for the dpa cross section with the same ratio for the flux at the position of interest: 


$$
\frac{(\text { Dpa rate })_{\gamma}}{(\text { Dpa rate })_{n}}=\frac{\int_{E_{d}}^{\infty} \sigma_{\gamma, d p a}\left(E_{\gamma}\right) \cdot \phi_{\gamma}\left(E_{\gamma}\right) d E_{\gamma}}{\int_{E_{d}}^{\infty} \sigma_{n, d p a}\left(E_{n}\right) \cdot \phi_{n}\left(E_{n}\right) d E_{n}}=\frac{\left\langle\sigma_{\gamma, d p a}\right\rangle}{\left\langle\sigma_{n, d p a}\right\rangle} \cdot \frac{\int_{E_{d}}^{\infty} \phi_{\gamma}\left(E_{\gamma}\right) d E_{\gamma}}{\int_{E_{d}}^{\infty} \phi_{n}\left(E_{n}\right) d E_{n}}
$$

where

$$
\left\langle\sigma_{i, d p a}\right\rangle=\frac{\int_{E_{d}}^{\infty} \sigma_{i, d p a}\left(E_{i}\right) \cdot \phi_{i}\left(E_{i}\right) d E_{i}}{\int_{E_{d}}^{\infty} \phi_{i}\left(E_{i}\right) d E_{i}}
$$

\section{Estimation of the Gamma Spectrum-Averaged Dpa Cross Section $<\sigma_{\gamma_{1} d p a}>$ for Iron}

Kelly ${ }^{2}$ shows in Appendix B that the dpa cross section $\sigma_{\gamma, \text { dpa }}$ is primarily due to Compton scattering. Figure 1 shows the variation of that cross section $\sigma_{\gamma, \text { ppe }}^{c}$ with gamma ray energy $E_{\gamma}$ for select atomic numbers $Z$. Note that the cross sections vary smoothly with $Z$ as well as with $E_{\gamma}$. That is because the electromagnetic interaction depends on $\mathrm{Z}$ and not on nuclear quantum numbers as the hadronic interactions do. Consistent with the ASTM standard and the report by Ramirez et al., we desire to evaluate the $\gamma$-induced dpa for iron $(Z=26)$. However, for simplicity and because of the smooth behavior with $Z$, and considering that other uncertainties are much larger, we use the $Z=29$ curve in Figure 1 rather than interpolate or implement a computer program.

The reactor gamma flux spectrum $\phi_{\gamma}\left(E_{\gamma}\right)$, needed to evaluate $\left\langle\sigma_{\gamma, \phi p a}\right\rangle$ in Equation (3), comprises four components: prompt fission gammas, delayed gammas from fission products, prompt gammas from neutron capture $(n, \gamma)$ reactions, and delayed gammas from the decay of activation products other than fission products. The contribution of the latter component is generally negligible except perhaps locally to its source. The energy release per fission from the first three components totals approximately $20 \mathrm{MeV}^{24,25,26}$

Unruh and Tomlinson ${ }^{27}$ (see also Soodak ${ }^{28}$ ) fit the reactor total gamma (prompt plus delayed) spectrum by the following expression:

$$
\phi_{\gamma}\left(E_{\gamma}\right) \sim \exp \left(-1,11 E_{\gamma}\right)
$$

where

$$
\begin{aligned}
& \phi_{\gamma}=\text { gamma ray flux } \\
& \mathrm{E}_{\gamma}=\text { total energy of the gamma ray. }
\end{aligned}
$$

The average gamma energy from the spectrum in Equation (4) is $1 / 1.11 \approx 0.9 \mathrm{MeV}$. (The average energy of prompt gamma rays is $\sim 1 \mathrm{MeV} .{ }^{29}$ The energy of delayed and capture gamma rays should be lower because the total energy release is much lower in those reactions.) 
Cross section for atomic displacement by Compton scattering, $\sigma_{\gamma, \mathrm{dpa}}^{\mathrm{c}}(\mathrm{b} \cdot \mathrm{dpa})$

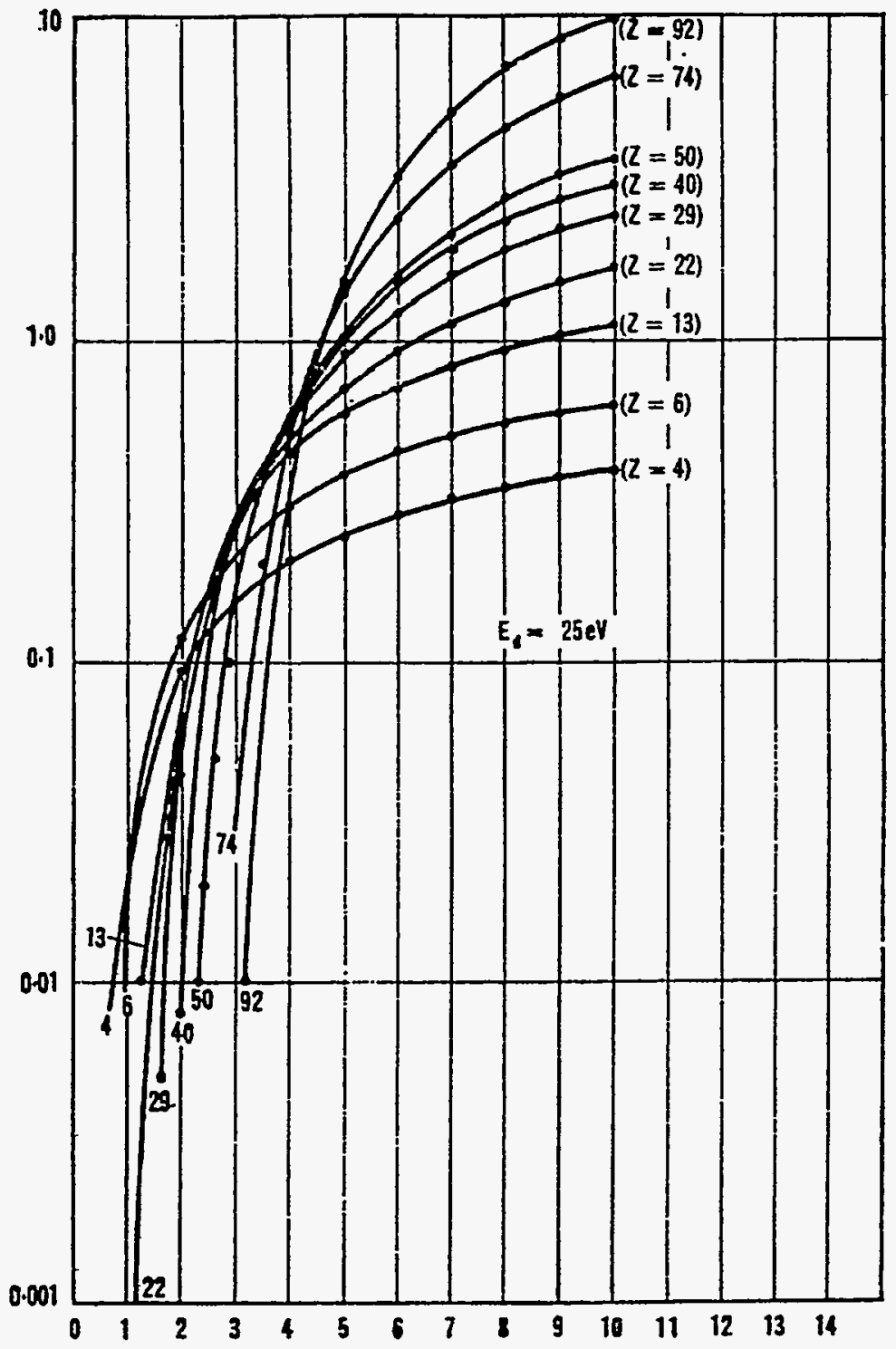

Gamma-ray energy (units of $m_{e} c^{2}=0.511 \mathrm{MeV}$ )

Figure 1. Cross sections for atomic displacement by Compton scattering ${ }^{2}$

Table 3 presents the spreadsheet evaluation of the gamma-spectrum-averaged cross section of Equation (3), using the cross sections from Figure 1 and the flux from Equation (4), and approximating the integrals by finite summations:

$$
\left\langle\sigma_{\gamma, d p a}\right\rangle=\frac{\int_{E_{d}}^{\infty} \sigma_{\gamma, d p a}\left(E_{\gamma}\right) \cdot \phi_{\gamma}\left(E_{\gamma}\right) d E_{\gamma}}{\int_{E_{d}}^{\infty} \phi_{\gamma}\left(E_{\gamma}\right) d E_{\gamma}} \approx \frac{\sum_{g} \sigma_{g} \cdot \phi_{g} \cdot \Delta E_{g}}{\sum_{g} \phi_{g} \cdot \Delta E_{g}} \approx 31 \mathrm{mb}
$$


Table 3. Calculation of the spectrum-averaged cross section for gamma-induced dpa

\begin{tabular}{|c|c|c|c|c|c|c|c|}
\hline $\begin{array}{l}\text { Group } \\
\text { No. }\end{array}$ & $\begin{array}{l}\mathrm{E}_{\gamma, \text { lower }} \\
(\mathrm{MeV})\end{array}$ & $\begin{array}{c}E_{\text {tvg }} \\
(\mathrm{MeV})\end{array}$ & $\begin{array}{c}\Delta \mathrm{E} \\
(\mathrm{MeV})\end{array}$ & $\begin{array}{c}\text { Flux, } \phi_{\gamma} \\
(\mathrm{MeV})\end{array}$ & $\phi_{\gamma} \cdot \Delta \mathrm{E}$ & $\begin{array}{c}\sigma_{\gamma, \mathrm{dpp}}\left(\mathrm{E}_{\text {avv }}\right) \\
\text { (bams) }\end{array}$ & $\sigma_{\gamma, \mathrm{dp} \mathrm{e}} \cdot \phi_{\gamma} \cdot \Delta \mathrm{E}$ \\
\hline 1 & 0 & 0.125 & 0.25 & $\overline{8.70 \mathrm{E}-01}$ & $2.18 \mathrm{E}-01$ & & \\
\hline 2 & 0.25 & 0.375 & 0.25 & $6.60 \mathrm{E}-01$ & $1.65 \mathrm{E}-01$ & & \\
\hline 3 & 0.5 & 0.625 & 0.25 & $5.00 \mathrm{E}-01$ & $1.25 \mathrm{E}-01$ & & \\
\hline 4 & 0.75 & 0.875 & 0.25 & $3.79 \mathrm{E}-01$ & $9.47 \mathrm{E}-02$ & & \\
\hline 5 & 1 & 1.125 & 0.25 & $2.87 \mathrm{E}-01$ & $7.17 \mathrm{E}-02$ & 0 & 0.00 \\
\hline 6 & 1.25 & 1.375 & 0.25 & $2.17 \mathrm{E}-01$ & $5.43 \mathrm{E}-02$ & 0.004 & 2.17E-04 \\
\hline 7 & 1.5 & 1.625 & 0.25 & $1.65 \mathrm{E}-01$ & $4.12 \mathrm{E}-02$ & 0.02 & $8.23 \mathrm{E}-04$ \\
\hline 8 & 1.75 & 1.875 & 0.25 & $1.25 \mathrm{E}-01$ & $3.12 \mathrm{E}-02$ & 0.043 & $1.34 \mathrm{E}-03$ \\
\hline 9 & 2 & 2.125 & 0.25 & $9.45 \mathrm{E}-02$ & $2.36 \mathrm{E}-02$ & 0.08 & $1.89 \mathrm{E}-03$ \\
\hline 10 & 2.25 & 2.375 & 0.25 & $7.16 \mathrm{E}-02$ & $1.79 E-02$ & 0.13 & $2.33 \mathrm{E}-03$ \\
\hline 11 & 2.5 & 2.625 & 0.25 & $5.43 \mathrm{E}-02$ & $1.36 \mathrm{E}-02$ & 0.2 & $2.71 \mathrm{E}-03$ \\
\hline 12 & 2.75 & 2.875 & 0.25 & $4.11 \mathrm{E}-02$ & $1.03 E-02$ & 0.245 & $2.52 \mathrm{E}-03$ \\
\hline 13 & 3 & 3.125 & 0.25 & $3.12 \mathrm{E}-02$ & $7.79 \mathrm{E}-03$ & 0.3 & $2.34 \mathrm{E}-03$ \\
\hline 14 & 3.25 & 3.375 & 0.25 & $2.36 \mathrm{E}-02$ & $5.90 \mathrm{E}-03$ & 0.37 & $2.18 \mathrm{E}-03$ \\
\hline 15 & 3.5 & 3.625 & 0.25 & $1.79 \mathrm{E}-02$ & $4.47 \mathrm{E}-03$ & 0.45 & $2.01 \mathrm{E}-03$ \\
\hline$\overline{16}$ & 3.75 & 3.875 & 0.25 & $1.36 \mathrm{E}-02$ & $3.39 \mathrm{E}-03$ & 0.52 & $1.76 \mathrm{E}-03$ \\
\hline 17 & 4 & 4.125 & 0.25 & $1.03 \mathrm{E}-02$ & $2.57 \mathrm{E}-03$ & 0.6 & $1.54 \mathrm{E}-03$ \\
\hline 18 & 4.25 & 4.375 & 0.25 & $7.78 \mathrm{E}-03$ & $1.94 \mathrm{E}-03$ & 0.7 & $1.36 \mathrm{E}-03$ \\
\hline 19 & 4.5 & 4.625 & 0.25 & $5.89 \mathrm{E}-03$ & $1.47 \mathrm{E}-03$ & 0.75 & $1.11 \mathrm{E}-03$ \\
\hline 20 & 4.75 & 4.875 & 0.25 & 4.47E-03 & $1.12 \mathrm{E}-03$ & 0.85 & $9.49 \mathrm{E}-04$ \\
\hline 21 & 5 & 5.125 & $\overline{0.25}$ & $3.38 \mathrm{E}-03$ & $8.46 \mathrm{E}-04$ & 0.92 & $7.78 \mathrm{E}-04$ \\
\hline 22 & 5.25 & 5.375 & $\overline{0.25}$ & $2.56 \mathrm{E}-03$ & $6.41 \mathrm{E}-04$ & 1.05 & $6.73 \mathrm{E}-04$ \\
\hline 23 & 5.5 & 5.625 & 0.25 & $1.94 \mathrm{E}-03$ & $4.86 \mathrm{E}-04$ & 1.1 & $5.34 \mathrm{E}-04$ \\
\hline 24 & 5.75 & 5.875 & 0.25 & $1.47 \mathrm{E}-03$ & $3.68 \mathrm{E}-04$ & 1.2 & $4.42 \mathrm{E}-04$ \\
\hline 25 & 6 & 6.125 & 0.25 & $1.12 E-03$ & $2.79 \mathrm{E}-04$ & 1.25 & $3.48 \mathrm{E}-04$ \\
\hline 26 & 6.25 & 6.375 & 0.25 & $8.45 E-04$ & $2.11 \mathrm{E}-04$ & 1.3 & $2.75 \mathrm{E}-04$ \\
\hline 27 & 6.5 & 6.625 & 0.25 & $6.40 \mathrm{E}-04$ & $1.60 \mathrm{E}-04$ & 1.4 & $2.24 \mathrm{E}-04$ \\
\hline 28 & 6.75 & 6.875 & 0.25 & $4.85 \mathrm{E}-04$ & $1.21 \mathrm{E}-04$ & 1.45 & $1.76 \mathrm{E}-04$ \\
\hline 29 & 7 & 7.125 & 0.25 & $3.68 \mathrm{E}-04$ & $9.19 \mathrm{E}-05$ & 1.6 & $1.47 \mathrm{E}-04$ \\
\hline 30 & 7.25 & 7.375 & 0.25 & $2.78 \mathrm{E}-04$ & $6.96 \mathrm{E}-05$ & 1.7 & $1.18 \mathrm{E}-04$ \\
\hline 31 & 7.5 & 7.625 & 0.25 & $2.11 \mathrm{E}-04$ & $5.27 \mathrm{E}-05$ & 1.75 & $9.23 \mathrm{E}-05$ \\
\hline 32 & 7.75 & 7.875 & $\overline{0.25}$ & $1.60 \mathrm{E}-04$ & $4.00 \mathrm{E}-05$ & 1.8 & $7.19 \mathrm{E}-05$ \\
\hline 33 & 8 & 8.125 & 0.25 & $1.21 \mathrm{E}-04$ & $3.03 \mathrm{E}-05$ & 1.95 & $5.90 \mathrm{E}-05$ \\
\hline 34 & 8.25 & 8.375 & 0.25 & $9.18 \mathrm{E}-05$ & $2.29 \mathrm{E}-05$ & 2 & $4.59 \mathrm{E}-05$ \\
\hline 35 & 8.5 & 8.625 & 0.25 & $6.95 \mathrm{E}-05$ & $1.74 \mathrm{E}-05$ & 2.05 & $3.56 \mathrm{E}-05$ \\
\hline 36 & 8.75 & 8.875 & 0.25 & $5.27 \mathrm{E}-05$ & $1.32 \mathrm{E}-05$ & 2.1 & $2.77 \mathrm{E}-05$ \\
\hline 37 & 9 & 9.125 & 0.25 & $3.99 \mathrm{E}-05$ & $229.298 \mathrm{E}-06$ & 2.15 & $2.15 \mathrm{E}-05$ \\
\hline 38 & 9.25 & 9.375 & 0.25 & $3.02 E-05$ & $7.56 \mathrm{E}-06$ & 2.2 & $1.66 \mathrm{E}-05$ \\
\hline 39 & 9.5 & 9.625 & 0.25 & $2.29 \mathrm{E}-05$ & $5.73 \mathrm{E}-06$ & 2.3 & $1.32 \mathrm{E}-05$ \\
\hline 40 & 9.75 & 9.875 & 0.25 & $1.74 \mathrm{E}-05$ & $4.34 \mathrm{E}-06$ & 2.35 & $1.02 \mathrm{E}-05$ \\
\hline & 10 & & & & & & \\
\hline \multicolumn{5}{|c|}{ SUM } & $8.97 \mathrm{E}-01$ & & $2.75 \mathrm{E}-02$ \\
\hline \multicolumn{6}{|c|}{$0-10 \mathrm{MeV}$ Average } & 0.030673 & \\
\hline
\end{tabular}




\section{Estimation of the Neutron Dpa Cross Section $\left\langle\sigma_{n, \phi s}\right\rangle$ for Iron}

Ramirez et al. ${ }^{1}$ calculated the neutron-induced dpa production rate $(\mathrm{dpa} / \mathrm{s})$ for iron in the Sequoyah pressure vessel. Dividing their reported dpa rates by their reported integral $>0.1 \mathrm{MeV}$ neutron flux one has

$$
\left\langle\sigma_{n, d p a}\right\rangle=\frac{\int_{0.1 \mathrm{MeV}}^{\infty} \sigma_{n, d p a}\left(E_{n}\right) \cdot \phi\left(E_{n}\right) d E_{n}}{\int_{0.1 \mathrm{MeV}}^{\infty} \phi\left(E_{n}\right) d E_{n}} \approx 500-600 \text { barns }
$$

The choice of $0.1 \mathrm{MeV}$ for the lower integral limit here is arbitrary but acceptable in as much as few displacements occur at lower neutron energies. It remains, however, to use the same limit in the flux ratio below. Flux monitors in the Sequoyah capsule indicate ${ }^{1}$ the thermal flux to be about $1 / 4$ of the total. On this basis, overall we expect an uncertainty less than a factor of 2 in $\left\langle\sigma_{\gamma, \text { dpa }}\right\rangle$.

We calculate that the ratio of the efficiency (cross section) for displacing iron atoms by photons relative to that for fast neutrons is thus $31 \times 10^{-3} / 500=\sim 0.06 \times 10^{-3}$. This is considerably less than the $10^{-3}$ mentioned for germanium atoms by Brooks ${ }^{5}$ in 1956 , but not necessarily inconsistent for the following reasons:

1. atomic displacement by neutrons occurs predominantly at fast neutron energies. There different threshold nuclear reactions are opening up with increasing energy. Only for nuclei common to fission reactors have these cross sections been measured and/or evaluated with any significant accuracy. We expect a poor state of knowledge for fast neutron germanium cross sections in 1956 relative to the same for iron atoms presently.

2. neutron cross sections are totally dependent upon nuclear quantum numbers. Consequently cross sections fluctuate widely from nucleus to nucleus; proximity in atomic number $\mathrm{Z}$ will have little significance upon neutron cross sections.

\section{Estimation of the Gamma-to-Neutron Flux and Dpa Ratios}

Based on the release of $20 \mathrm{MeV}$ gamma energy per fission and a mean gamma energy of 0.9 $\mathrm{MeV}$ as discussed above, we approximate the gamma population as $220.9-\mathrm{MeV}$ gammas per fission. The mean number of fission neutrons per fission is -2.5 for ${ }^{235} \mathrm{U} .{ }^{30}$ Thus we estimate that the gamma-to-neutron flux ratio in the core is of the order of $10^{1}$.

Because gammas are more prone to absorption than neutrons and because reactors are designed to reflect neutrons back into the core, this ratio should decrease as one approaches and passes through the reactor vessel wall. Figures 2 and 3 confirm this trend: they show the calculated neutron flux and gamma dose distribution through a series of radial water and steel layers in a small (70 MW) pressurized water reactor. We then have from Equation (2): 

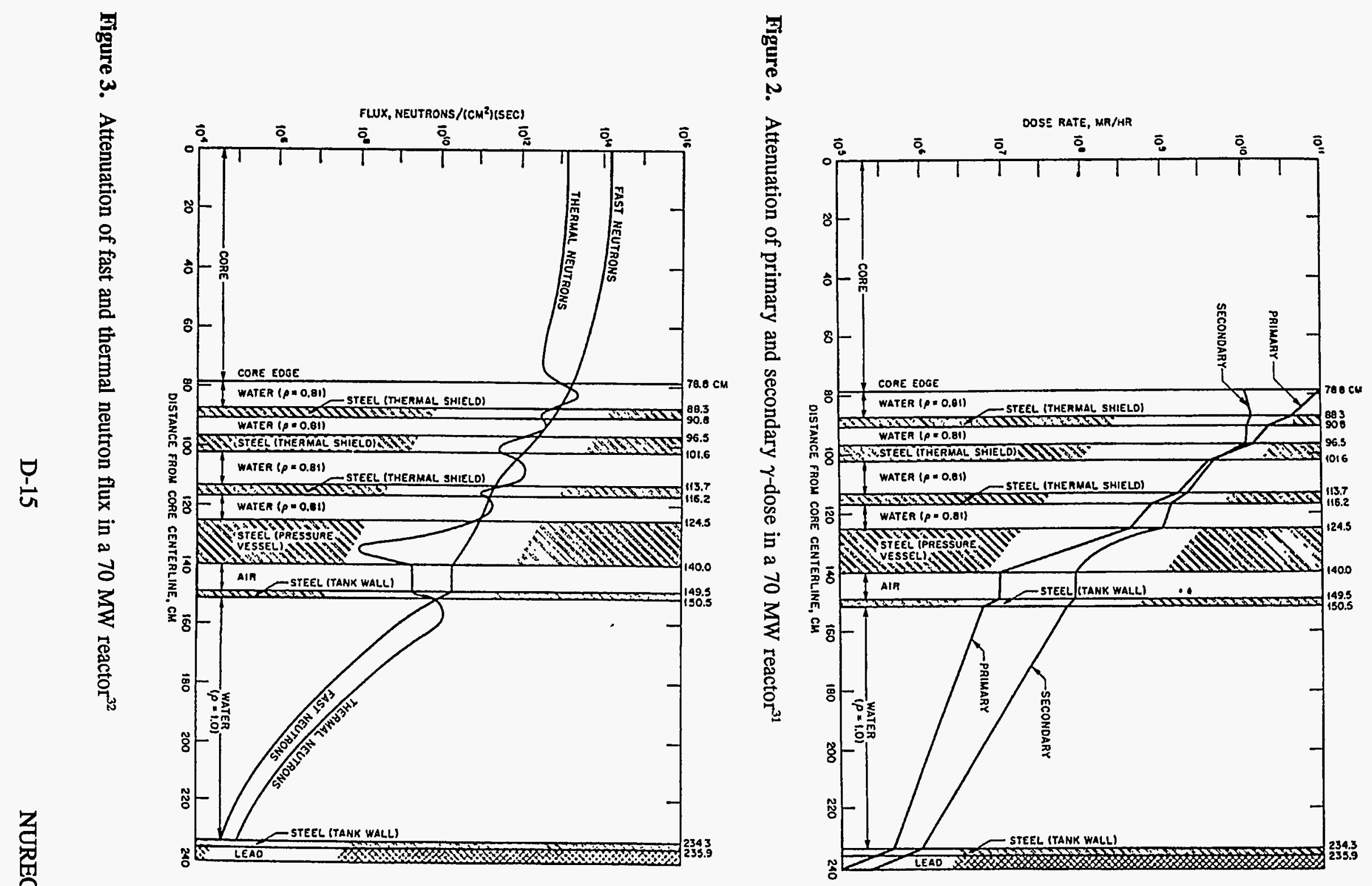


$$
\frac{(\text { Dpa rate })_{\gamma}}{(\text { Dpa rate })_{n}}=\frac{\left\langle\sigma_{\gamma, d p a}\right\rangle}{\left\langle\sigma_{n, d p a}\right\rangle} \cdot\left\{\frac{\int_{E_{d}}^{\infty} \phi_{\gamma}\left(E_{\gamma}\right) d E_{\gamma}}{\int_{E_{d}}^{\infty} \phi_{n}\left(E_{n}\right) d E_{n}}\right\} \leq \frac{31 \times 10^{-3}}{500} \cdot 10=6 \times 10^{-4}
$$

Ramirez et al. ${ }^{1}$ calculated that the neutron-induced dpa rate falls off by about a factor of 10 over the width of the Sequoyah pressure vessel wall. That reflects the decreasing fast neutron flux and the sharp decrease in the neutron-induced dpa cross section with neutron energy. However, from Figures 1-3 one expects the gamma flux and the gamma-induced dpa cross section to decrease even more sharply. As a result the gamma-to-neutron dpa ratio should further decrease through the pressure vessel wall by 1-2 orders of magnitude. However, we will conservatively not use that fact in our comparison: this further emphasizes our result to be an upper bound.

Together these arguments indicate that $\gamma$-induced atomic displacement is $\ll 1 \%$ of that from neutrons in the pressure vessel wall of all fission power reactors including Sequoyah's. Note that the value of $1 \%$ allows for a factor of 16 uncertainty on our calculated estimate, not including the 1-2 orders of magnitude mentioned above.

\section{Photon Dpa Production in a Fusion Reactor Environment}

A 1982 unpublished INEL study concluded that the photon flux would have to be about 1000 times greater to equal the neutron induced atom displacement damage. Thus, even though the gamma flux was a factor of two higher it contributed only $0.2 \%$ of the neutron damage. That result supports the present work, being roughly at the same order of magnitude.

\section{Effects of Heating}

Photons also induce heating, leading to changes in alloy morphology (grain structure) and chemical diffusion. The importance of these phenomena was not addressed in this study. For the Sequoyah reactor, the effects of heating in the surveillance capsule specimens should represent the effects of heating in the actual pressure vessel wall.

Gamma heating likely exceeds neutron heating in the vessel wall and the surveillance capsule. This could be quantified by calculating photon and neutron heating rates ("kerma") once coupled neutron/photon fluxes were calculated. Neutron heating could be derived from the existing dosimetry measurements. Gamma heating could be deduced by adding thermoluminescent dosimeters (TLDs) into the surveillance capsule. For consistency and to minimize correction factors, neutron-sensitive TLDs could be added as well.

\section{Synergistic Intergranular Stress-Assisted Corrosion Cracking}

Intergranular stress-assisted corrosion cracking of stainless steels and nickel-base alloys occurs even under unirradiated conditions due to water chemistry and stress. Gamma-irradiation synergistically exacerbates cracking susceptibility via its combined effects on material micro-chemistry (e.g, radiation-induced segregation), water chemistry (e.g., radiolysis), and stress (e.g., radiationinduced creep and hardening). ${ }^{16}$ We note that the test specimens in the Sequoyah surveillance capsule will not experience the water chemistry effects that the vessel wall will. Temperatures and 
temperature gradients may also differ due to cooling differences. Thus the surveillance capsule may be non-representative for this synergistic phenomenon. 


\section{CONCLUSIONS AND RECOMMENDATIONS}

1. Cursory evaluation indicates that $\gamma$-induced atomic displacement in the neighborhood of the Sequoyah Reactor pressure vessel wall is $\ll 1 \%$ of that from neutrons. The surveillance capsule contained no detection devices capable of measuring the gamma fluence or energy deposition (such as TLDs). The atomic displacement damage encountered by the specimens in the surveillance capsule should be representative of that encountered in the pressure vessel wall.

2. Photons induce heating, leading to changes in alloy morphology (grain structure). They also enhance diffusion leading to decomposition of oversaturated austenite and to strengthening and embrittlement of steel. No specific analysis of these effects for Sequoyah was attempted. The impact of $\gamma$-heating upon the results from the surveillance capsule should be representative of those in the neighborhood of the pressure vessel wall.

3. Gamma-irradiation can accelerate intergranular stress corrosion cracking of stainless steels and nickel-base alloys. It exacerbates cracking susceptibility via its effects on material micro-chemistry (e.g, radiation-induced segregation), water chemistry (e.g., radiolysis), and stress (e.g., radiation induced creep and hardening). Many of these sensitivities, e.g., to water chemistry and stress, apply to cracking under unirradiated conditions as well. No specific analysis of these effects for Sequoyah was attempted. The results from the test specimens in the surveillance capsule may be non-representative of what the Sequoyah pressure vessel wall experiences in this regard due to their isolation from water chemistry effects.

A potential more-detailed evaluation of atomic displacement would include the following:

1. a coupled neutron/photon calculation of the Sequoyah Reactor, at least in one (radial) dimension, out through the pressure vessel. This would greatly increase the accuracy of both the total neutron to total photon flux ratio as well as provide the correct neutron and photon energy spectra for use in determining the dpa cross sections and reaction rates.

2. writing a Fortran program which will calculate the gamma-induced Dpa production cross section. EG\&G Idaho Report RE-P-81-095 outlines the formalism. This report was authored in December 1981 and must first be brought up to date. We have checked and found that no one else has developed such a capability since 1981 .

Conclusions 2 and 3 above are based on a qualitative assessment of the literature. A multidiscipline effort might further investigate these phenomena including an effort at quantification. 


\section{REFERENCES}

1. B. T. Kelly, Irradiation Damage to Solids, Pergamon Press, 1966.

2. G. J. Dienes, "Radiation Effects in Solids," Annual Reviews of Nuclear Science, 1953, 2, pp.187ff.

3. J. O. Stiegler and L. K. Mansur, "Radiation Effects in Structural Materials," Annual Reviews of Materials Science, 1979, 9, pp.405-454.

4. H. Brooks, "Nuclear Radiation Effects in Solids," Annual Reviews of Nuclear Science, 1956, 6, pp. $215 f f$.

5. A. N. Goland, "Radiation Effects in Structural Materials," Annual Reviews of Nuclear Science, 1962, 12 , pp.243 ff.

6. Nicholas P. Fiore, Gamma-Irradiation Damage in Age Hardening Al Alloys, No. 167, AD-786578, July 1974.

7. A. Weidinger et al., "Defect Configurations in Irradiated Molybdenum," Physics Letters, Volume 72A, No. 4, 5, 23 July 1979, p. 369 .

8. Munetaka Kuribayashi et al., "Influence of $\gamma$-Radiation on Intergranular stress Corrosion cracking of Austenitic stainless Steel," Ishikawajima-Harima Giho (Japan) 23, 6, November 1983, p. $521-526$.

9. G. J. Dienes and G. H. Vineyard, Pad?ation Effects in Solid's, New York: Interscienoe Publishers, 1957.

10. V. V. Galavanov, Soviet Physics solid state 1, 390 (1959)

11. O. S. Oen and D. K. Holmes, J. Appl. Phys. 30, No. 8, 1289 (1959).

12. V. V. Gan, et al., "Simulation of Padiation Danege of the Reactor cares Steel by Using High-Energy e/ $/ \gamma$ Beams," Physics of Radiation Defects and Radiation Materials Science. Scientific-Technical Collection, INIS-SU-80, 1987, p. 70-72.

13. V. V. Mural' and G. V. Shcherbedinskij, "Gamma-Radiation Aging of Deformed Austenite," Metalloved. Term. Obrab. Met. (USSR), v6, 1984, p. 47-48.

14. G. P. Marsh et al., "Influence of Radiation on the Corrosion of Stainless Steel," Corros. Sci. (United Kingdom) 26, 11, 1986, p. 971-982.

15. A. B. Alexandrov et al., "Effect of Gamma Radiation on Metal Corrosion Under Spent Fuel storage Conditions," Long Term Wet Spent Nuclear Fuel storage. Proceedings of a Technical Committee Meeting on Behaviour of Used Fuel Assemblies and Storage Equipment at Long Term Wet storage Conditions held in Leningrad, USSR, 26-30 May, 1986, IAEA-TECDOC-418, CONF-8608147, April 1987, p. 181-190. 
16. I. M. Neklyudov, et al., Effects of High-Energy Electron and Gamma Radiation on Mechanical Properties of Steels KhI8N1OT and 06Kh16N15M3B, KFTI-88-53, 1988

17. A. Sudo et al., "Effect of Gamma Irradiation on IGSCC Susceptibility of Type 304 stainless steel," Proceedings of 1988 JAIF International Conference on Water Chemistry in Nuclear Power Plants. Operational Experience and New Technologies for Management, Tokyo, Japan, 13 April 1988, CONF-8804174, 1988, v.2.

18. P. I. Andersen et al., "State of Knowledge of Radiation Effects on Environmental Cracking in Light Water Reactor Core Materials," 1989 Workshop on LWR Radiation Water Chemistry and its Influence on In-core structural Materials, Palo Alto, CA, 14-15 Nov 1989, EPRI-NP-7033, Mar 1991, p.5.29-5.66.

19. Y. Gohar and M. A. Abdou, MACKLIB-IV, a Library of Nuclear Response Functions Generated with the MACK-IV Computer Program from ENDF/B-IV, ANL/FPP/TM-106.

20. E. H. Ottewitte, $F Y$ 79-82 Overview of Radiation Effects Capability Development (CurrentIy G3411812A), RE-P-81-019, February 1981.

21. V. McLane, National Nuclear Data Center, Brookhaven National Laboratory, private communication, 28 April 1993

23. P. S. Stansbury, TECALC - A Program to Calculate Compton, Coherent, and Photoelectric Mass Attenuation Coefficients for Photons with Energies Less than $1 \mathrm{MeV}$ and to Assist in the Evaluation and Formulation of Photon-Equivalent Materials, ORNL-TM4451, January 1974; RSIC Computer Code Collection, "Interactive Calculation of Compton Coherent and Photoelectric Mass Attenuation Coefficients for Photons $(E<1 \mathrm{MeV})$, and the Mass Absorption coefficient for Known Materials." ORNL-PSR-74.

23. A. Foderaro, Subroutine HEITLER, AERE-M, 1956, (September 1967); RSIC Peripheral Shielding Routine Collection, "HEITLER Cross section Generator," ORNL-PSR-4.

24. Harold Etherington (ed.), Nuclear Engineering Handbook, New York: McGraw-Hill Book Company, Inc., 1958.

25. Samuel Glasstone and Alexander Sesonske, Nuclear Reactor Engineering, Princeton, New Jersey: D. Van Nostrand Company, Inc., 1963 .

26. Joel Weisman (ed.), Elements of Nuclear Reactor Design, New York: Elsevier Scientific Publishing Company, 1977.

27. W. G. Unruh and M. Tomlinson, "Mean Gamma-ray Energy Absorption Coefficients," Nucl. Applications 3, 1967, p. 548 .

28. H. Soodak (ed.), Reactor Handbook, Second Edition, New York: Interscience Publishers, 1962, p.15-16. 
29. Samuel Glasstone and Alexander Sesonske, Nuclear Reactor Engineering, Princeton, New Jersey: D. Van Nostrand Company, Inc., 1963 , p. 93 .

30. H. Soodak (ed.), op.cit., p.9.

31. S. Glasstone and A. Sesonske, op.cit., p.603

32. Ibid, p. 602 

2. TITLE AND SUBTITLE

Radiation Effects on Reactor Pressure Vessel Supports
5. AUTHOH(S)
R.E. Johnson, NRC
R.E. Lipinski, INEL

\begin{tabular}{c|c}
\hline \multicolumn{2}{|c}{ DATE REPORT PUBLISHED } \\
\hline MONTH & YEAR \\
MaY & 1996 \\
\hline
\end{tabular}

4. FIN OR GRANT NUMBER

6. TYPE OF REPORT

7. PERIOD COVERED (Inchusive Oates)

8. PERFORMING ORGANIZATION - NAME AND ADDRESS IIf NAC, provide Divizion, Office or Region, U.S. Nucker Resulatary Commistion, end mailing modress; il contractor, provide

Division of Engineèring Technology

Office of Nuclear Regulatory Research

U.S. Nuclear Regutatory Commission

Idaho National Engineering Laboratory

Washington, DC 20555-0001

11426 Rockville Pike

Rockville, MD 20852

9. SPONSORING ORGANIZATION - NAME AND ADDRESS IIf NAC, type "Same as above"; if contractor, provide NRC Division, Office or Region, U.S. Nuclear Regulatory Commission. end molling poddress.)

Division of Engineering Technology

Office of Nuclear Regulatory Research

U.S. Nuclear Regulatory Commission

Washington, DC 20555-0001

10. SUPPLEMENTARY NOTES

11. ABSTRACT (200wonds or kas)

The NRC Generic Safety Issue No. 15, (GSI-15), "Radiation Effects on Reactor Pressure Vessel Supports," was established to evaluate the concern that low-temperature, low-flux-level neutron irradiation might embrittle reactor pressure vessel supports to a significant degree and compromise plant safety. Evaluation of the surveillance samples from the High Flux Isotope Reactor (HFIR) at the Oak Ridge National Laboratory (ORNL) led to the conclusion that the embrittlement rates of some materials used for pressurized water reactor pressure vessel (RPV) supports could be higher than expected. This disclosure raised a concern that a brittle fracture of the RPV supports could occur during the anticipated 1 ife-span of the plant. A later study by the ORNL demonstrated that gamma radiation contributed a significant amount of the embrittlement in the HFIR surveillance. specimens. However, the shielding provided by the thick steel shell of the RPV ensures that degradation of RPV supports from gamma irradiation is improbable or minimal. This report (1) describes the technical findings resulting from the work done in accord with the GSI-15 Task Action Plan and (2) was used, in part, as the basis for technical resolution of the issue.

12. KEY WORDS/DESCR!PTORS (List wonds or phrases that will assist researthers in locating the report.)

nuclear reactor pressure vessel, structural supports, irradiation, integrity evaluation, consequence analysis, gamma radiation

\begin{tabular}{l} 
13. AVAILABILITY STATEMENT \\
unl imited \\
14. SECURITY CLASSIFICATION \\
\hline (This Poos) \\
unclas sified \\
(This Repon) \\
uncl as s ified \\
15. NUMBER Of PAGES \\
16. PRICE
\end{tabular}




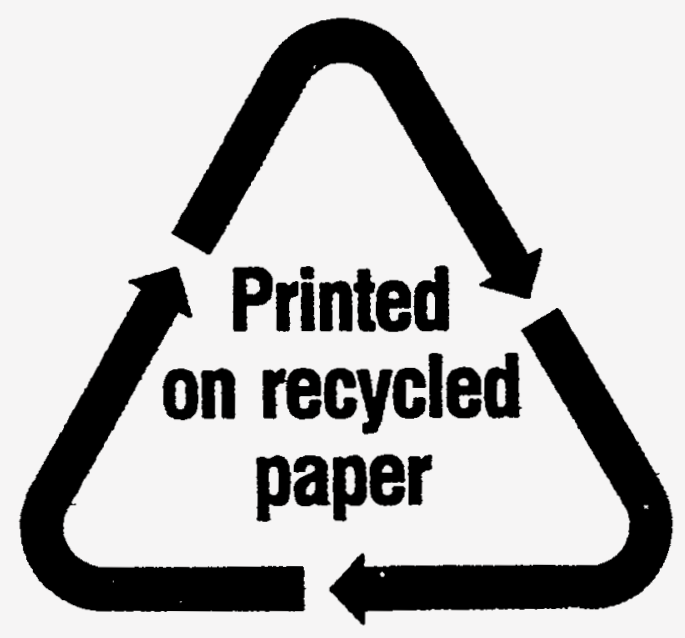

Federal Recycling Program 